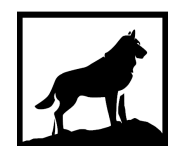

Michigan

Technological

18.5 University
Michigan Technological University

Digital Commons @ Michigan Tech

EXPERIMENTAL AND MODELING STUDY OF PARTICULATE

MATTER OXIDATION UNDER LOADING CONDITIONS FOR A SCR CATALYST ON A DIESEL PARTICULATE FILTER

Abhishek Jadav

Michigan Technological University, akjadav@mtu.edu

Copyright 2018 Abhishek Jadav

Recommended Citation

Jadav, Abhishek, "EXPERIMENTAL AND MODELING STUDY OF PARTICULATE MATTER OXIDATION UNDER LOADING CONDITIONS FOR A SCR CATALYST ON A DIESEL PARTICULATE FILTER", Open AccesS Master's Thesis, Michigan Technological University, 2018.

https://doi.org/10.37099/mtu.dc.etdr/733

Follow this and additional works at: https://digitalcommons.mtu.edu/etdr

Part of the Energy Systems Commons 


\title{
EXPERIMENTAL AND MODELING STUDY OF PARTICULATE MATTER OXIDATION UNDER LOADING CONDITIONS FOR A SCR CATALYST ON A DIESEL PARTICULATE FILTER
}

\author{
By \\ Abhishek Jadav \\ A THESIS \\ Submitted in partial fulfillment of the requirements for the degree of \\ MASTER OF SCIENCE \\ In Mechanical Engineering \\ MICHIGAN TECHNOLOGICAL UNIVERSITY \\ 2018 \\ (C) 2018 Abhishek Jadav
}


This thesis has been approved in partial fulfillment of the requirements for the Degree of MASTER OF SCIENCE in Mechanical Engineering.

Department of Mechanical Engineering - Engineering Mechanics

\author{
Thesis Co-Advisor: Dr. Jeffrey Naber \\ Thesis Co-Advisor: Dr. John Johnson \\ Committee Member: $\quad$ Dr. Mahdi Shahbakhti \\ Department Chair: Dr. William Predebon
}




\section{Table of Contents}

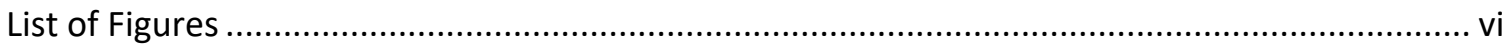

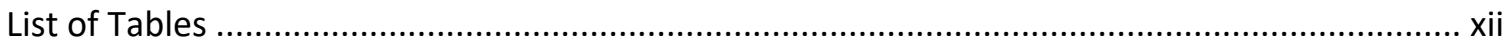

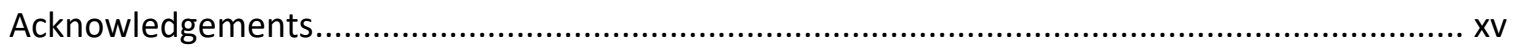

List of Abbreviations, Notations and Symbols ...........................................................................

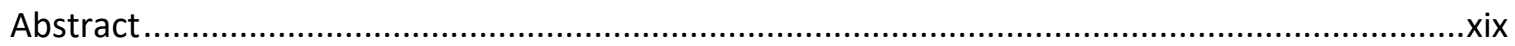

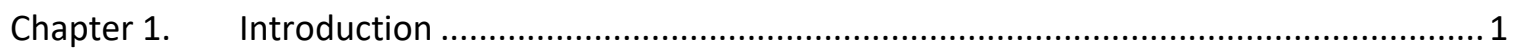

1.1 Diesel Engine Aftertreatment System Research ........................................................

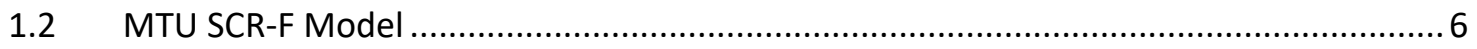

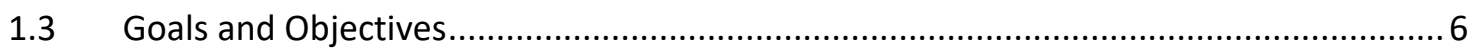

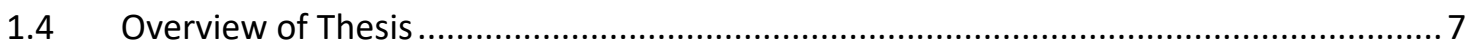

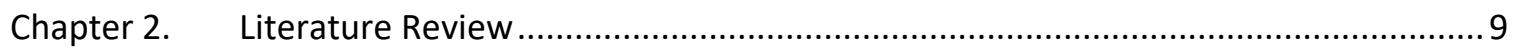

2.1 Oxidation of PM With and Without Urea Injection ............................................... 9

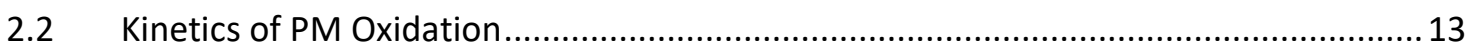

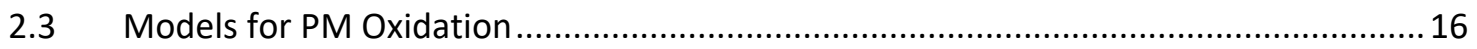

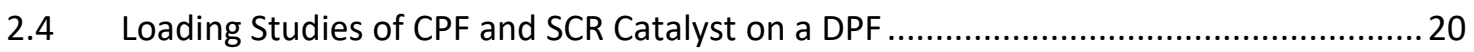

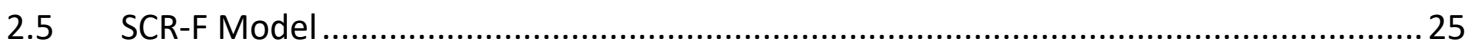

Chapter 3. Experimental Setup, Instrumentation and Test Procedures ................................ 30

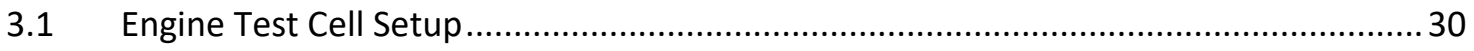

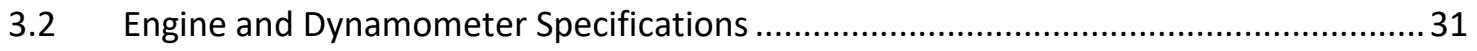

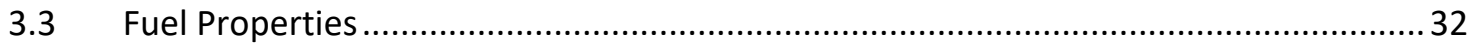

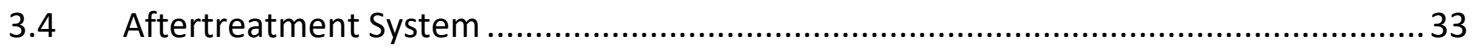

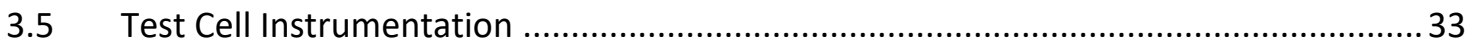

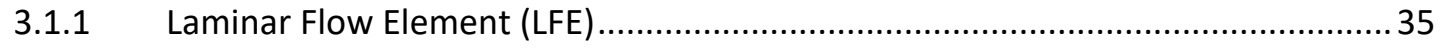

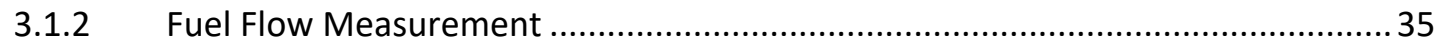




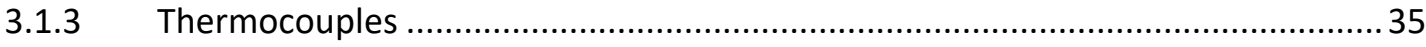

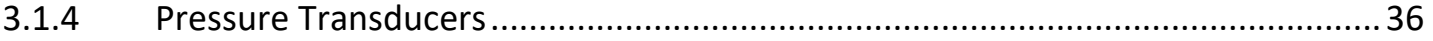

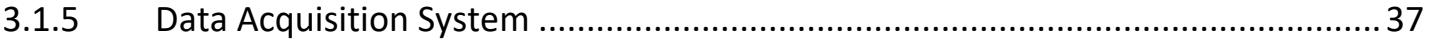

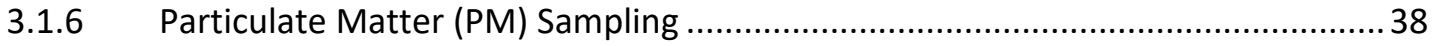

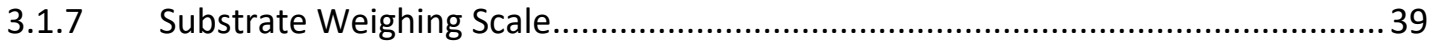

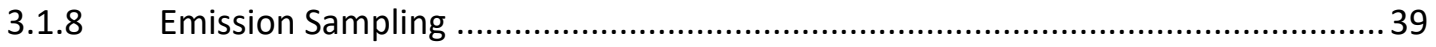

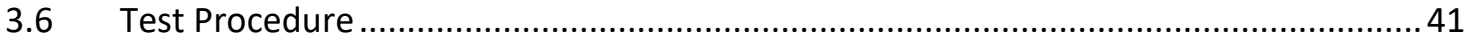

3.7 Test Matrix for Loading Tests w/o Urea …............................................................. 45

3.8 Test Matrix for Loading Tests w/ Urea.................................................................. 47

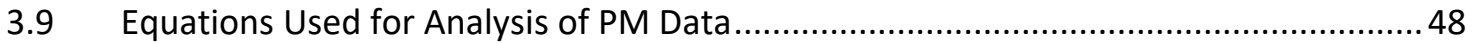

3.10 Equations Used for Calculation of Experimental Reaction Rate ................................50

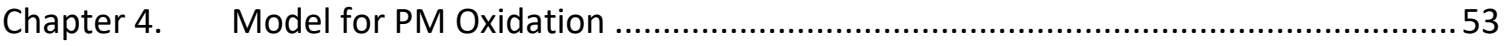

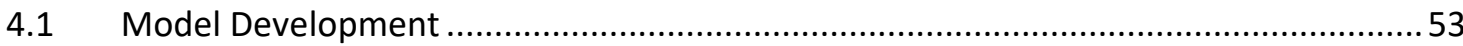

4.2 Application of the PM Oxidation Model's Reaction Rate Results in the SCR-F Model .. 59

4.3 Calibration of the SCR-F Model With Loading Tests w/o Urea Data ............................60

4.4 Calibration of the PM Oxidation Model With Passive Oxidation w/o Urea Data ..........63

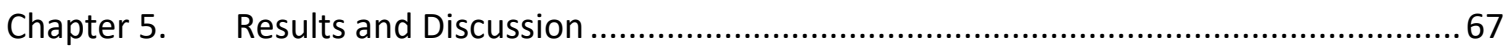

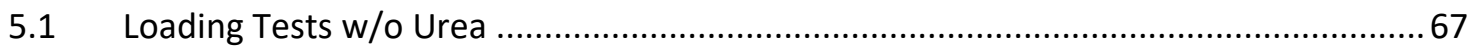

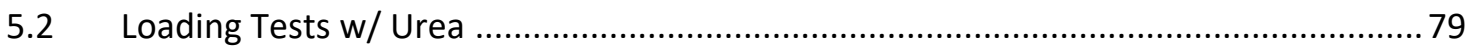

5.3 Comparison of Results for Loading Tests w/o and w/ Urea ..................................... 87

5.4 Calibration of SCR-F Model With Reaction Rate Data From the PM Oxidation Model for

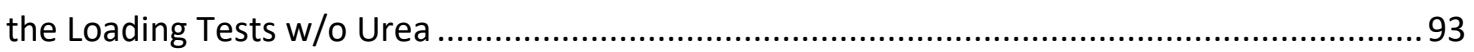

5.5 Calibration of the PM Oxidation Model with Passive Oxidation w/o Urea Data ......... 101

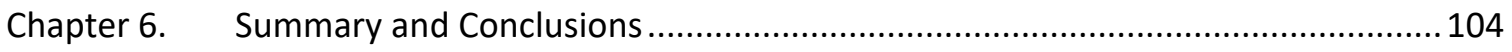

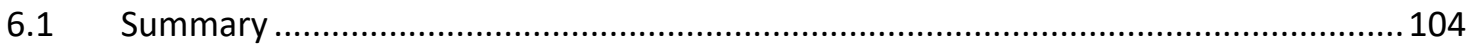




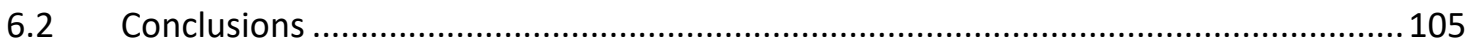

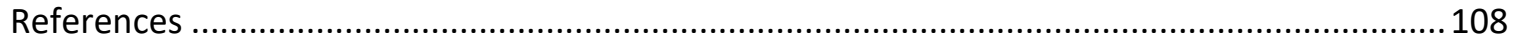

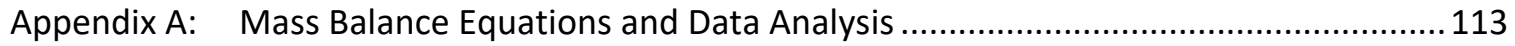

Appendix B: Validation Test for NO Conversion across DOC ….......................................... 119

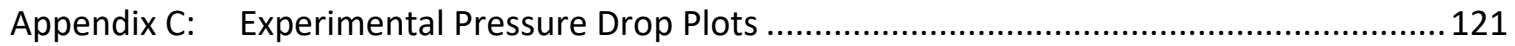

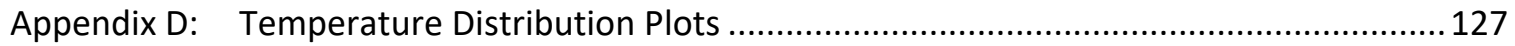

Appendix E: $\quad$ Model PM Mass Retained Plots for Loading Tests w/o Urea Data ....................... 138

Appendix F: $\quad$ Model Pressure Drop Plots for Loading Tests w/o Urea Data ............................. 142

Appendix G: $\quad$ Model PM Mass Retained Plots for Passive Oxidation w/o Urea Data [8] .......... 146

Appendix H: Permissions to Use Copyrighted Materials...................................................... 150 


\section{List of Figures}

Figure 1.1: EPA Emission Standards for Light Duty Vehicles [2] ............................................. 1

Figure 1.2: Schematic of the Cummins ISB 2013 Production Aftertreatment System [4] .............. 2

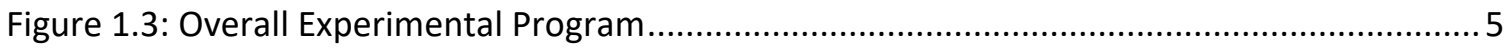

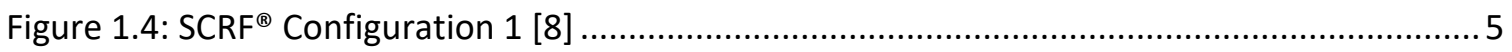

Figure 2.1: Competition Between PM Oxidation and SCR Reactions [14] ................................. 11

Figure 2.2: Passive Regeneration Capability of the SCR catalyst on a DPF With and Without Urea

Figure 2.3: Predicted Soot Oxidation Reaction Rates for Passive Regeneration Experiments With and Without $\mathrm{NH}_{3}$ Injection at $350^{\circ} \mathrm{C}$ and $450^{\circ} \mathrm{C}$ for a SCR catalyst on a DPF [14]

Figure 2.4: Dependence of the Pseudo First Order Rate Coefficient on Carbon Mass Conversion

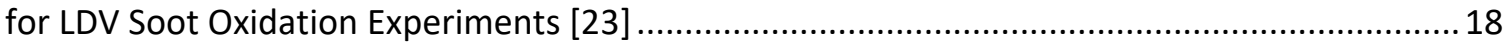

Figure 2.5: Soot Oxidation Rate on Catalyst Coated Filters at Different Temperatures [31] ........ 19

Figure 2.6: Pressure Drop Components After 5 Hours of Loading for $20 \%$ and $75 \%$ Load Test

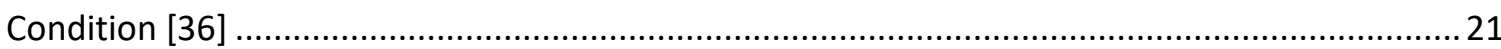

Figure 2.7: Total PM Oxidized After 5 Hours of Loading by Type and Physical Location [36] ....... 21

Figure 2.8: Distribution of PM Mass Oxidized by Location at 2200 RPM [38] ............................. 22

Figure 2.9: Comparison of Kinetics of PM Oxidation During Passive Oxidation and Loading Conditions in CPF [7]

Figure 2.10: Comparison of Kinetics of PM Oxidation During Passive Oxidation and Loading

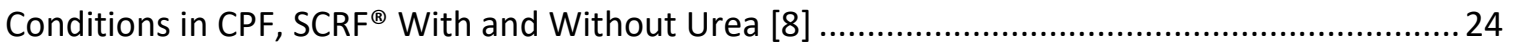

Figure 2.11: Schematic for the Channel Geometry in a Zone in the SCR-F Model ....................... 25

Figure 2.12: Schematic Showing Filtration of PM in the Cake and the Wall [21] ........................26

Figure 2.13: Schematic of Temperature Solver Mesh for SCR-F Model [21] ..............................28 
Figure 3.1: Schematic Layout of the Engine Test Cell Setup [4] ............................................... 30

Figure 3.2: Schematic of the Instrumentation in the Test Cell [8] .............................................. 34

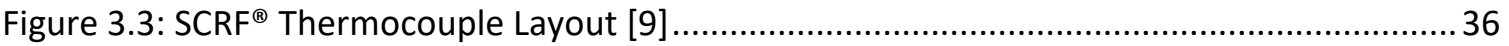

Figure 3.4: Manual Sampling Train, Sampling Probe and Dry Gas Meter [8] ............................ 38

Figure 3.5: Production $\mathrm{NO}_{\mathrm{x}}$ Sensor $\quad$ Figure 3.6: Delphi $\mathrm{NH}_{3}$ Sensor ......................................... 41

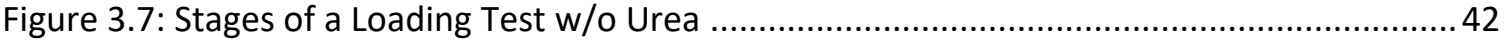

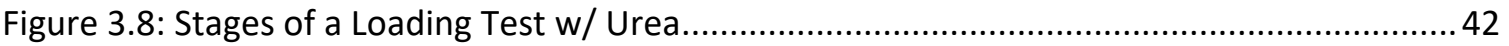

Figure 3.9: $\mathrm{SCRF}^{\circledR}$ Pressure Drop vs Time for a Typical Loading Test (Warmup and SCRF ${ }^{\circledR}$ Cleanout Stage Omitted) 43

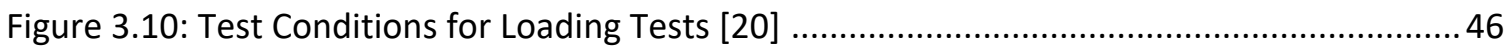

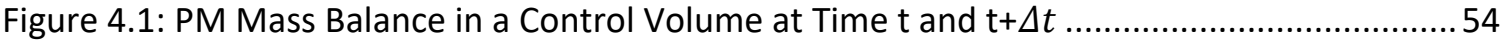

Figure 4.2: Schematic Representation of the Variation of Mass Retained in the SCRF ${ }^{\circledR}$ With Time 56

Figure 4.3: Variation of the Oxidation Factor (k) With Percentage of PM Oxidized $(\xi)[23] \ldots \ldots . .57$

Figure 4.4: Schematic of the Model Developed for PM Oxidation .............................................58

Figure 4.5: Flow Chart for the Calibration of SCR-F Model with Loading Tests w/o Urea Data ....62

Figure 4.6: Pressure Drop vs Time for a Passive Oxidation Test PO-C [8] ...................................63

Figure 4.7: Comparison of Calibrated Oxidation Factor (k) w.r.t Percentage of PM Oxidized With That Used Initially From Reference [23] 65

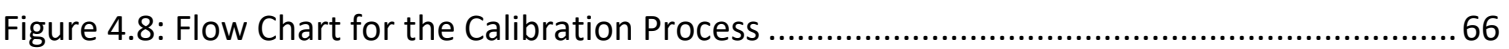

Figure 5.1: NO Conversion Across DOC vs DOC Inlet Temperature for Loading Tests w/o Urea .. 70 Figure 5.2: Comparison of $\mathrm{NO}_{\mathrm{x}}$ Data From Calterm and Mass Spectrometer at UDOC ................ 72

Figure 5.3: Comparison of $\mathrm{NO}_{\mathrm{x}}$ Data From Calterm and Mass Spectrometer at USCRF ${ }^{\circledR} \ldots \ldots . . . . . . . .72$

Figure 5.4: Comparison of $\mathrm{NO}_{\mathrm{x}}$ Data From Calterm and Mass Spectrometer at DSCRF ${ }^{\circledR} \ldots \ldots . . . . . . . .73$

Figure 5.5: PM Mass Balance as Percentage of PM In (Expt.) for Loading Tests w/o Urea ........... 75 
Figure 5.6: PM Mass Balance (Expt.) for Loading Tests w/o Urea

Figure 5.7: Comparison of PM Oxidation Kinetics for Passive Oxidation [8] and Loading Conditions w/o Urea in $\mathrm{SCRF}^{\circledR}$ 78

Figure 5.8: NO Conversion Across DOC vs DOC Inlet Temperature for Loading Tests w/ Urea .... 80

Figure 5.9: Comparison of $\mathrm{NO}_{x}$ Data From Calterm and Mass Spectrometer at UDOC 81

Figure 5.10: Comparison of $\mathrm{NO}_{x}$ Data From Calterm and Mass Spectrometer at USCRF ${ }^{\circledR}$ 82

Figure 5.11: Comparison of $\mathrm{NO}_{\mathrm{x}}$ Data From Calterm and Mass Spectrometer at $\mathrm{DSCRF}^{\circledR}$ .82

Figure 5.12: PM Mass Balance (Expt.) as \% of PM In for Loading Tests w/ Urea .84

Figure 5.13: PM Mass Balance (Expt.) for Loading Tests w/ Urea .85

Figure 5.14: Comparison of SCRF ${ }^{\circledR}$ PM Oxidation Kinetics for Passive Oxidation [8] and Loading Conditions With Urea...... .86

Figure 5.15: Reaction Rate Comparison for Loading Tests w/o and w/ Urea. 88

Figure 5.16: Comparison of Cumulative PM Retained and PM Oxidized as Percentage of PM In for Loading Tests w/o and w/ Urea .89

Figure 5.17: Comparison of Cumulative PM Retained and PM Oxidized for Loading Tests w/o and w/ Urea .89

Figure 5.18: Comparison of PM Oxidation Kinetics for Passive Oxidation [8] and Loading Conditions With and Without Urea in $\mathrm{SCRF}^{\circledR}$ 90

Figure 5.19: Comparison of Pressure Drop Across SCRF ${ }^{\circledR}$ vs Time Plots for $L 3$ Reduced w/o and w/ Urea

Figure 5.20: Comparison of Pressure Drop Across SCRF ${ }^{\circledR}$ vs Time plots for $\mathrm{L}_{3}$ Nominal w/o and w/ Urea. 92

Figure 5.21: Expt. Pressure Drop Normalized by Exhaust Flow Rate vs Expt. PM Retained for Loading Tests w/o Urea .....

Figure 5.22: Model Pressure Drop Normalized by Exhaust Flow Rate vs Model PM Retained for Loading Tests w/o Urea 96 
Figure 5.23: Cake Pressure Drop Normalized by Exhaust Flow Rate vs Cake PM Retained for Loading Tests w/o Urea

Figure 5.24: Wall Pressure Drop Normalized by Exhaust Flow Rate vs Wall PM Retained for Loading Tests w/o Urea

Figure 5.25: PM Mass Balance(Model) as \% of PM In for Loading Tests w/o Urea 98

Figure 5.26: PM Retained in the Cake and the Wall ..... 99

Figure 5.27: PM Retained in the Cake and the Wall as \% of Total PM Retained..... 99

Figure 5.28: PM Oxidized in the Cake and the Wall. 100

Figure 5.29: PM Oxidized in the Cake and the Wall as \% of Total PM Oxidized 100

Figure B.1: NO Conversion Across DOC vs DOC Inlet Temperature. 120

Figure C.1: SCRF ${ }^{\oplus}$ Pressure Drop vs Time for L1 Nominal 121

Figure C.2: SCRF ${ }^{\circledR}$ Pressure Drop vs Time for L1 Reduced [11]. 121

Figure C.3: SCRF ${ }^{\circledR}$ Pressure Drop vs Time for L2 Nominal 122

Figure C.4: SCRF ${ }^{\circledR}$ Pressure Drop vs Time for L2 Reduced 122

Figure C.5: SCRF ${ }^{\circledR}$ Pressure Drop vs Time for L3 Nominal 123

Figure C.6: SCRF ${ }^{\circledR}$ Pressure Drop vs Time for L3 Reduced . 123

Figure C.7: SCRF ${ }^{\oplus}$ Pressure Drop vs Time for L4 Nominal 124

Figure C.8: SCRF ${ }^{\circledast}$ Pressure Drop vs Time for L4 Reduced . 124

Figure C.9: SCRF ${ }^{\circledR}$ Pressure Drop Comparison for L1 Nominal w/o and w/ Urea 125

Figure C.10: SCRF ${ }^{\circledR}$ Pressure Drop Comparison for L1 Reduced w/o and w/ Urea 125

Figure C.11: SCRF ${ }^{\oplus}$ Pressure Drop Comparison for L3 Nominal w/o and w/ Urea. 126

Figure C.12: SCRF ${ }^{\circledR}$ Pressure Drop Comparison for L3 Reduced w/o and w/ Urea 126

Figure D.1: SCRF ${ }^{\circledR}$ Model Temperature Distribution for L1 Nominal (155 minutes into S2) ....... 128

Figure D.2: SCRF ${ }^{\circledR}$ Experimental Temperature Distribution for L1 Reduced (134 minutes into S2) 
Figure D.3: SCRF ${ }^{\circledR}$ Model Temperature Distribution for L1 Reduced (134 minutes into S2)....... 129

Figure D.4: SCRF ${ }^{\circledR}$ Experimental Temperature Distribution for L2 Nominal (180 minutes into S2)

Figure D.5: SCRF ${ }^{\circledR}$ Model Temperature Distribution for L2 Nominal (180 minutes into S2) ....... 130

Figure D.6: SCRF ${ }^{\circledR}$ Experimental Temperature Distribution for L2 Reduced (73 minutes into S2)

Figure D.7: SCRF ${ }^{\circledR}$ Model Temperature Distribution for L2 Reduced (73 minutes into S2)......... 131

Figure D.8: SCRF ${ }^{\circledR}$ Experimental Temperature Distribution for L3 Nominal (136 minutes into S2)

Figure D.9: SCRF ${ }^{\circledR}$ Model Temperature Distribution for L3 Nominal (136 minutes into S2) ....... 132

Figure D.10: SCRF ${ }^{\circledR}$ Experimental Temperature Distribution for L3 Reduced (152 minutes into S2)

Figure D.11: SCRF ${ }^{\circledR}$ Model Temperature Distribution for L3 Reduced (152 minutes into S2)..... 133

Figure D.12: SCRF ${ }^{\circledR}$ Experimental Temperature Distribution for L4 Nominal (190 minutes into S2)

Figure D.13: SCRF ${ }^{\circledR}$ Model Temperature Distribution for L4 Nominal (190 minutes into S2) ..... 134

Figure D.14: SCRF ${ }^{\circledR}$ Experimental Temperature Distribution for L4 Reduced (154 minutes into S2)

Figure D.15: SCRF ${ }^{\circledR}$ Model Temperature Distribution for L4 Reduced (154 minutes into S2)..... 135

Figure D.16: SCRF ${ }^{\circledR}$ Experimental Temperature Distribution for L1 Nominal with Urea (151

minutes into S2)

Figure D.17: SCRF ${ }^{\oplus}$ Experimental Temperature Distribution for L1 Reduced with Urea (148 minutes into S2)

Figure D.18: SCRF ${ }^{\oplus}$ Experimental Temperature Distribution for L3 Nominal with Urea (90 minutes into S2)

Figure E.1: PM Mass Retained vs Time for L1 Nominal 138 
Figure E.2: PM Mass Retained vs Time for L1 Reduced 138

Figure E.3: PM Mass Retained vs Time for L2 Nominal 139

Figure E.4: PM Mass Retained vs Time for L2 Reduced 139

Figure E.5: PM Mass Retained vs Time for L3 Nominal 140

Figure E.6: PM Mass Retained vs Time for L3 Reduced 140

Figure E.7: PM Mass Retained vs Time for L4 Nominal 141

Figure E.8: PM Mass Retained vs Time for L4 Reduced 141

Figure F.1: Pressure Drop vs Time for L1 Nominal.. 142

Figure F.2: Pressure Drop vs Time for L1 Reduced ... 142

Figure F.3: Pressure Drop vs Time for L2 Nominal 143

Figure F.4: Pressure Drop vs Time for L2 Reduced..... 143

Figure F.5: Pressure Drop vs Time for L3 Nominal 144

Figure F.6: Pressure Drop vs Time for L3 Reduced ..... 144

Figure F.7: Pressure Drop vs Time for L4 Nominal. 145

Figure F.8: Pressure Drop vs Time for L4 Reduced 145

Figure G.1: PM Mass Retained vs Time for PO-A 146

Figure G.2 PM Mass Retained vs Time for PO-C 146

Figure G.3 PM Mass Retained vs Time for PO-E 147

Figure G.4 PM Mass Retained vs Time for PO-B 147

Figure G.5 PM Mass Retained vs Time for PO-B Rpt. 148

Figure G.6 PM Mass Retained vs Time for PO-D. 148

Figure G.7 PM Mass Retained vs Time for PO-D Rpt. 149 


\section{List of Tables}

Table 1.1: US EPA Emission Standards for Heavy Duty Diesel Engines [1] ................................. 1

Table 2.1: Kinetics of $\mathrm{NO}_{2}$ Assisted Oxidation From Various References .................................... 15

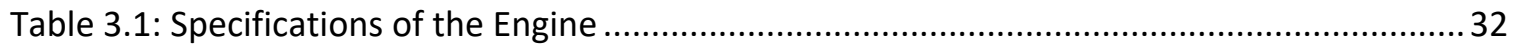

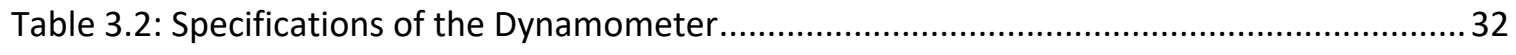

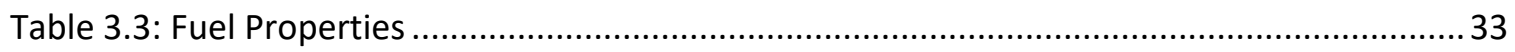

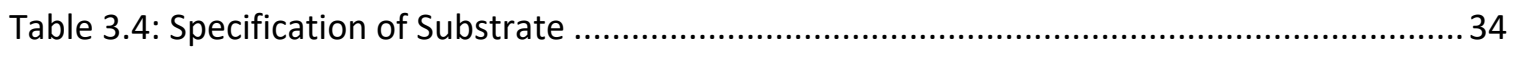

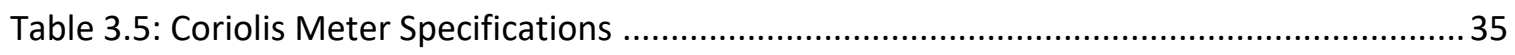

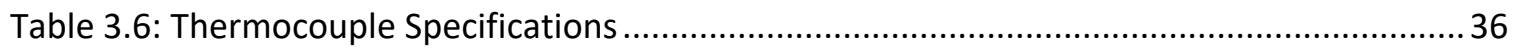

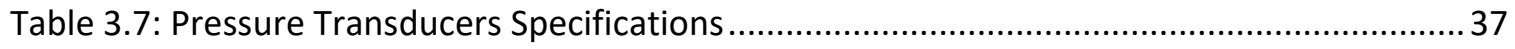

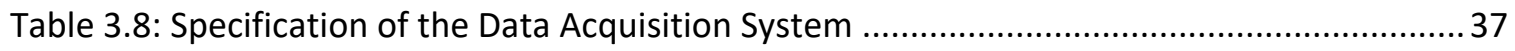

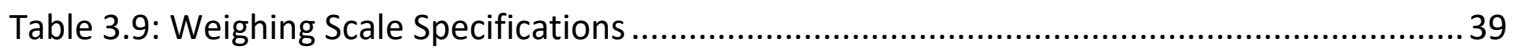

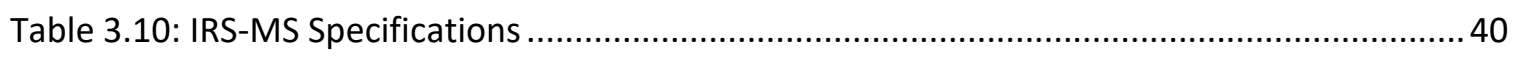

Table 3.11: Pierburg Emission Bench Specifications [8] ...................................................... 40

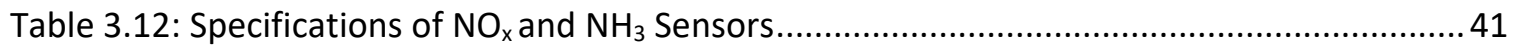

Table 3.13: Warmup Stage Engine Conditions ….................................................................... 43

Table 3.14: Test Matrix for Loading Tests w/o Urea............................................................... 47

Table 3.15: Emission Data for Loading Tests w/o Urea Obtained by Point Validation Test .......... 47

Table 3.16: Test Matrix for Loading Tests w/ Urea ................................................................ 48

Table 3.17: Emission Data for Loading Tests w/ Urea Obtained by Point Validation Test ............ 48

Table 5.1: Engine and Exhaust Conditions for Stage 2 in Loading Tests w/o Urea....................... 68

Table 5.2: Emission Data Across DOC for Loading Tests w/o Urea.............................................69

Table 5.3: Emission Data Across SCRF ${ }^{\oplus}$ for Loading Tests w/o Urea .......................................... 71

Table 5.4: PM Balance for Stage 1 for Loading Tests w/o Urea................................................ 74 
Table 5.5: PM Balance for Stage 2 for Loading Tests w/o Urea

Table 5.6: Variables to Compare Kinetics of $\mathrm{NO}_{2}$ Assisted PM Oxidation Without Urea .............. 76

Table 5.7: Engine and Exhaust Conditions for Stage 2 in Loading Tests w/ Urea .......................... 79

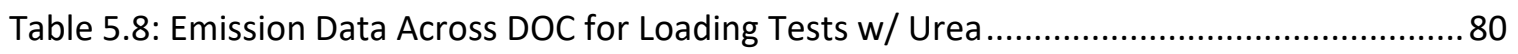

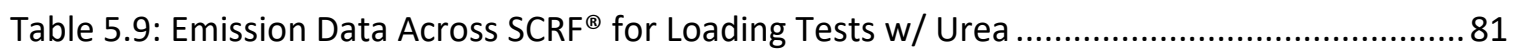

Table 5.10: $\mathrm{NO}_{\mathrm{x}}$ Reduction Performance of $\mathrm{SCRF}^{\circledR}$ at ANR 1.0 During Stage 2 for Loading Tests w/

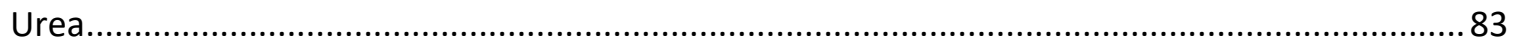

Table 5.11: PM Balance for Stage 1 for Loading Tests w/ Urea................................................ 83

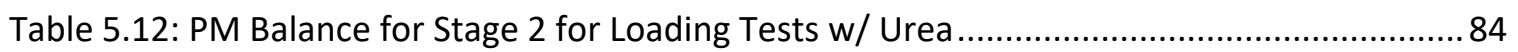

Table 5.13: Variables to Compare Kinetics of $\mathrm{NO}_{2}$ Assisted PM Oxidation With Urea.................. 85

Table 5.14: Variables to Compare $\mathrm{NO}_{2}$ Assisted PM Oxidation With and Without Urea Injection87 Table 5.15: Variables Important for Comparing Pressure Drop Across SCRF ${ }^{\circledR}$ for L3 Reduced w/o

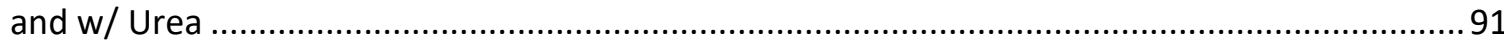

Table 5.16: Variables Important for Comparing Pressure Drop Across SCRF ${ }^{\circledR}$ for L3 Nominal w/o

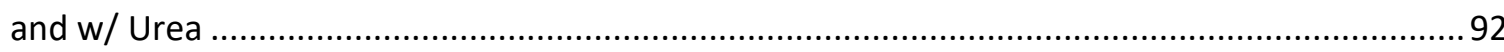

Table 5.17: Cake and Wall PM Oxidation Kinetics From Calibration of Loading Test w/o Urea Data 93

Table 5.18: SCR-F Model Pressure Drop Parameters From Calibration of Loading Test w/o Urea Data

Table 5.19: Comparison of Experimental and Model PM Retained at the End of Stage 1 and Stage 2 94

Table 5.20: Comparison of Experimental and Model Pressure Drop at the End of Stage 2 2.........95

Table 5.21: Loading Conditions for Stage 2 in Configuration 1 Tests w/o Urea [8] ..................... 101

Table 5.22: Passive Oxidation Conditions for Configuration 1 Tests w/o Urea [8]...................... 102

Table 5.23: Calibrated $\mathrm{NO}_{2}$ Assisted PM Oxidation Kinetics From the PM Oxidation Model...... 102 
Table 5.24: Comparison of Experimental and Model PM Retained at the End of Stage 1, Stage 2

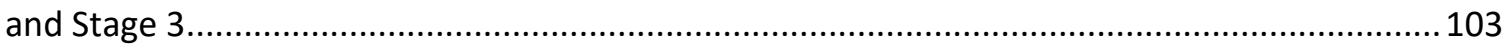

Table A.1: Estimation of Stage 1 Filtration Efficiency and Ratio of PM Oxidized and PM Entering

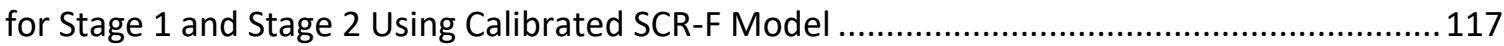

Table A.2: SCRF ${ }^{\circledR}$ Weights and PM Retained in Stage 1 and Stage 2 .....................................118

Table B.1: NO Conversion Across DOC - Validation Test............................................................ 119 


\section{Acknowledgements}

I would like to thank several people for providing me the opportunity and helping me throughout the course of this research and completing my thesis.

Foremost, I would like to express my gratitude and appreciation to my advisors, Dr. John Johnson and Dr. Jeffrey Naber for providing me the opportunity to be a part of this Consortium project and for their constant support and guidance during the course of this research. Dr. John Johnson helped me in understanding the experimental data to ensure data integrity, and the modeling work related to the study. His continuous guidance and feedback has helped me in writing this thesis. Dr. Jeffrey Naber has been instrumental in analyzing the experimental data as well troubleshooting technical difficulties in the test cell. Additionally, I would like to thank Dr. Mahdi Shahbakhti for being a part of my thesis committee.

I would like to thank my colleagues and fellow students at Michigan Tech, Sagar Sharma, Prince Lakhani and Andrew Pochettino for their assistance during the experimental testing. Additionally, I would like to thank Venkata Rajesh Chundru for his continuous support in the modeling work. I would also like to thank Paul Dice, Christopher Pinnow and Steve Lehmann for their assistance in troubleshooting hardware and software issues in the test cell. Also, I would like to extend thanks to Walter Woodland at V\&F Instruments Inc. and Andreas Fredrich at AVL for their continuous support in fixing problems with the emission analyzers.

I would like to thank the members of MTU Diesel Engine Aftertreatment Research Consortium from Cummins and Isuzu for providing me the financial support throughout the duration of this research. The research would not have been possible without the ISB 2013 engine and the production aftertreatment system provided by Cummins and the $\mathrm{SCRF}^{\circledR}$ provided by Johnson Matthey and Corning, which were vital in this research.

Last but not the least, I would like to thank my family members and friends for their constant support and encouragement during the course of this research and my education at Michigan Tech. 


\section{List of Abbreviations, Notations and Symbols}

A

ANR

API

CLD

$\mathrm{CO}$

$\mathrm{CO}_{2}$

CPF

DDOC

DEF

delP

DOC

DPF

$\mathrm{DSCRF}^{\circledR}$

$E_{a}$

ECM

EPA

FID

FS

$\mathrm{HC}$

$\mathrm{H} / \mathrm{C}$

HD

HHV

$\mathrm{H}_{2} \mathrm{O}$

IRD

IRS-MS

k

$\mathrm{k}_{\text {avg }}$

$k_{\text {mod }}$
Pre-Exponential Factor

Ammonia to $\mathrm{NO}_{x}$ Ratio

American Petroleum Institute

Chemiluminescence Detector

Carbon Monoxide

Carbon Dioxide

Catalyzed Particulate Filter

Downstream of the DOC

Diesel Exhaust Fluid

Pressure Drop across SCRF ${ }^{\circledR}$

Diesel Oxidation Catalyst

Diesel Particulate Filter

Downstream of the $\mathrm{SCRF}^{\circledR}$

Activation Energy

Engine Control Module

Environmental Protection Agency

Flame Ionization Detector

Full Scale

Hydrocarbons

Hydrogen to Carbon Ratio

Heavy Duty

Higher Heating Value

Water

Infrared Detector

Infrared Spectrometry Mass Spectrometer

Oxidation Factor

Average Oxidation Factor

Modified Rate Constant 


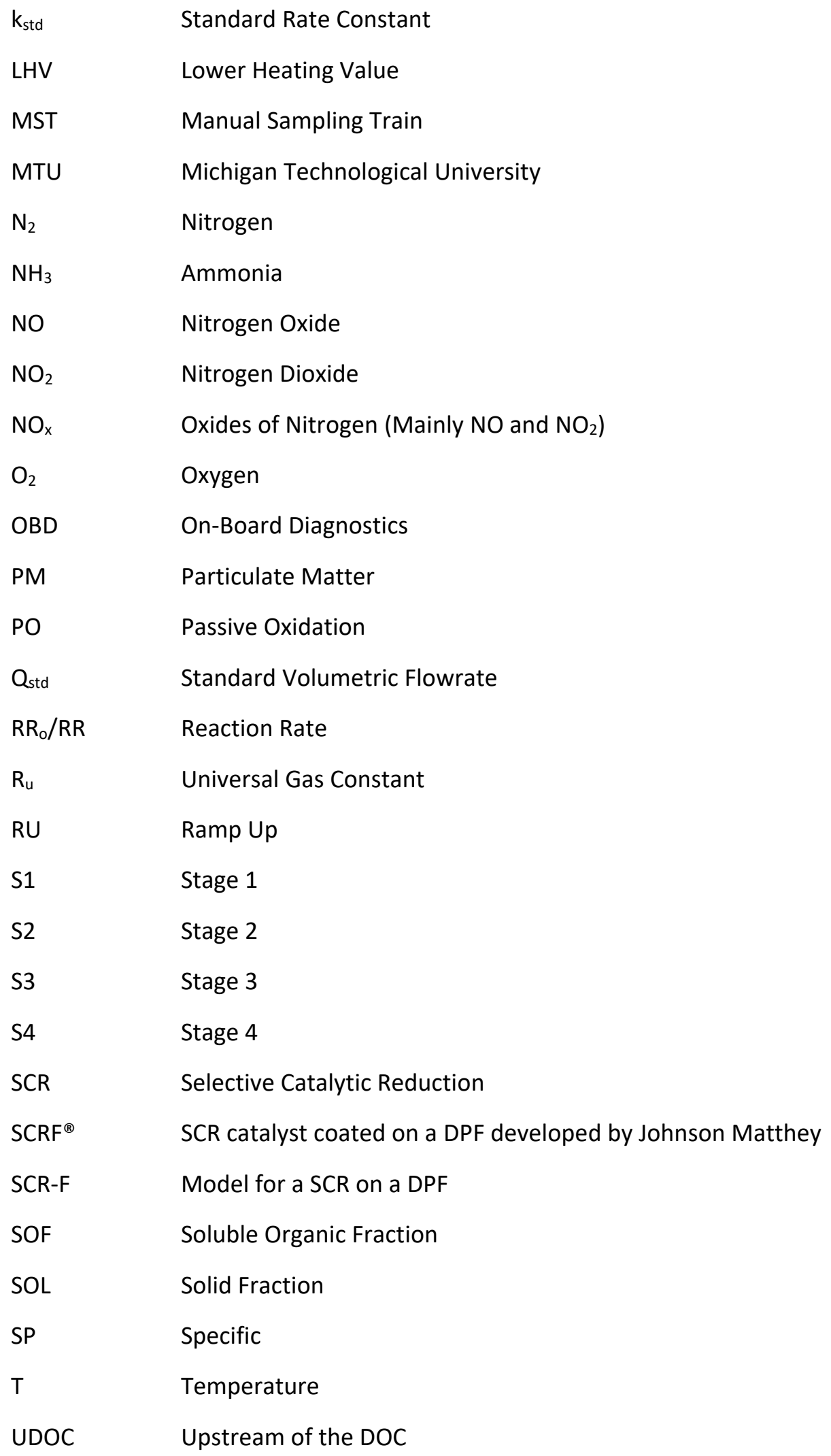




$\begin{array}{ll}\text { USCRF }^{\circledR} & \text { Upstream of the SCRF } \\ \text { Y } & \text { Mass Fraction } \\ \text { W } & \text { Molecular Weight } \\ \text { w/o } & \text { Without } \\ \text { w/ } & \text { With }\end{array}$




\section{Abstract}

The heavy-duty diesel engines use a Diesel Oxidation Catalyst (DOC), a Catalyzed Particulate Filter (CPF), a Selective Catalytic Reduction (SCR) with urea injection and a Ammonia Oxidation Catalyst (AMOX), to meet the US EPA 2010/2013 particulate matter (PM) and $\mathrm{NO}_{\mathrm{x}}$ emission standards. However, it is not possible to achieve the 2015 California low $\mathrm{NO}_{x}$ standards with this arrangement. Hence, there is a need to improve the existing aftertreatment system. This can be achieved by coating the SCR catalyst on a diesel particulate filter (DPF), thus combining the PM filtration and $\mathrm{NO}_{\mathrm{x}}$ reduction functionality into a single device. This reduces the overall volume/weight of the system and provides opportunity for packaging flexibility and improved thermal management along with the possibility of higher $\mathrm{NO}_{x}$ reduction with a downstream SCR system.

The SCR catalyst on a DPF used in this study is known as a SCRF ${ }^{\circledR}$ which was supplied by Johnson Matthey and Corning. Previous research on the CPF and $\mathrm{SCRF}^{\circledR}$ at MTU highlighted that the reactivity of $\mathrm{PM}$ retained in the $\mathrm{CPF}$ and $\mathrm{SCRF}^{\circledR}$ is higher during loading conditions compared to passive oxidation conditions i.e. when the flow rate of PM entering the CPF or SCRF ${ }^{\circledR}$ is higher in loading conditions compared to the low flow rate and higher PM reaction rate during passive oxidation conditions. A 2013 Cummins ISB engine with a DOC-SCRF ${ }^{\circledR}$ arrangement was used to perform twelve tests (eight tests without urea injection and four tests with urea injection) in order to determine the $\mathrm{NO}_{2}$ assisted passive oxidation performance of the $\mathrm{SCRF}^{\circledR}$ under loading conditions with and without urea injection. The primary focus of this study was to carry out Loading Tests with and without Urea injection and measure species concentrations, PM mass retained, exhaust flowrates, substrate temperature distributions, pressure drop across the filter, and to determine the kinetics of $\mathrm{NO}_{2}$ assisted $\mathrm{PM}$ oxidation under loading conditions and compare it with kinetics under passive oxidation conditions.

The $\mathrm{NO}_{2}$ assisted passive oxidation performance of the $\mathrm{SCRF}^{\circledR}$ was experimentally studied by running the engine at 2400 RPM and four different loads at nominal and reduced rail pressure for 5.5 hours in two stages of loading. These conditions were intended to span the SCRF ${ }^{\circledR}$ inlet temperatures in the range of $264-364^{\circ} \mathrm{C}$ and inlet $\mathrm{NO}_{2}$ concentrations in the range of $52-120 \mathrm{ppm}$. Four conditions out of these eight conditions were repeated with the injection of urea in the form of diesel exhaust fluid at a target ammonia to $\mathrm{NO}_{x}$ ratio of 1.0 to investigate both the $\mathrm{NO}_{\mathrm{x}}$ 
reduction performance, as well as the effect of urea on the $\mathrm{NO}_{2}$ assisted passive oxidation performance.

From the conclusions of the study based on the experimental data, it was found that the cumulative percentage of $\mathrm{PM}$ oxidized in the $\mathrm{SCRF}^{\circledR}$ increases with the increase in engine load due to higher $\mathrm{SCRF}^{\circledR}$ temperatures and $\mathrm{NO}_{2}$ concentrations. On average, the reactions rates with urea injection during loading conditions in the $\mathrm{SCRF}^{\circledast}$ are $25 \%$ lower compared to the reaction rates without urea injection. The reactivity of PM under loading conditions with and without urea injection is higher compared to the reactivity of PM under passive oxidation with and without urea injection. For a lumped PM oxidation model, a higher pre-exponential for $\mathrm{NO}_{2}$ assisted oxidation is needed for loading as compared to passive oxidation conditions. It was not possible to determine the kinetics of $\mathrm{NO}_{2}$ assisted oxidation of PM under loading conditions from the experimental data using a standard Arrhenius model which lead to the development of a different model for PM oxidation.

A PM oxidation model was developed based on the shrinking core model which keeps the identity of the incoming PM masses in the SCRF ${ }^{\circledR}$ as compared to SCR-F model being developed at MTU which is lumped model for PM oxidation. The PM oxidation model was calibrated to simulate PM oxidation in the $\mathrm{SCRF}^{\circledR}$ with a single set of kinetics under wide range of conditions including loading and passive oxidation conditions. The reaction rate results from the PM oxidation model were then applied to the SCR-F model to simulate the pressure drop across SCRF ${ }^{\circledR}$ and the PM retained in the $\mathrm{SCRF}^{\circledR}$ for the loading conditions used in this study. The SCR-F model was calibrated using experimental data from Loading Tests w/o Urea to simulate the PM retained within $\pm 2 \mathrm{~g}$ and pressure drop across $\mathrm{SCRF}^{\oplus}$ within $\pm 0.5 \mathrm{kPa}$ of the experimental data at the end of the test. The calibrated SCR-F model was also used to estimate the cake, wall and channel pressure drop and the PM retained in the cake and wall for the Loading Tests w/o Urea to check the integrity of experimental data and the consistency of the model.

The $\mathrm{NO}_{2}$ assisted kinetics for $\mathrm{PM}$ oxidation in the $\mathrm{SCRF}^{\circledR}$ without urea injection using the SCR-F model resulted in an activation energy of $96 \mathrm{~kJ} / \mathrm{gmol}$ and pre-exponential factor of $2.6 \mathrm{~m} / \mathrm{K}-\mathrm{s}$ for the cake and $1.8 \mathrm{~m} / \mathrm{K}$-s for the wall. An analysis of the results from the SCR-F model suggests that for all the conditions, $84-92 \%$ of the total PM retained was in the PM cake layer and the oxidation in the PM cake layer accounted for $72-84 \%$ of the total PM mass oxidized during loading.

$\mathrm{XX}$ 


\section{Chapter 1. Introduction}

Diesel engine emissions are being regulated by various organizations around the world. The Environmental Protection Agency (EPA) in the U.S. sets standards for engine tail pipe emissions which are becoming more stringent for heavy duty diesel engines every few years as seen in Table 1.1. Figure 1.1 shows emission standards for light duty vehicles on the FTP-75 cycle. As a result, engine manufacturers are continuously coming up with solutions and developing new technologies to meet the emission standards by controlling the oxides of nitrogen ( $\mathrm{NO}, \mathrm{NO}_{2}$ and $\mathrm{N}_{2} \mathrm{O}$ ) and particulate matter (PM) which are the major emissions of concern from diesel engines.

Table 1.1: US EPA Emission Standards for Heavy Duty Diesel Engines [1]

\begin{tabular}{|c|c|c|c|c|}
\hline \multirow{2}{*}{ Emission Gases } & \multicolumn{5}{|c|}{ EPA Standard - Implementation Year } \\
\cline { 2 - 5 } & $\mathbf{2 0 0 4}$ & $\mathbf{2 0 0 7 - 0 9}$ & $\mathbf{2 0 1 0}$ & $\mathbf{2 0 1 5}$ \\
\cline { 2 - 5 } & \multicolumn{4}{|c|}{$\mathrm{g} / \mathrm{bhp}-\mathrm{hr}$} \\
\hline NO $_{\mathbf{x}}$ & $\mathbf{2 . 0 0 ^ { * }}$ & 1.2 & 0.2 & $0.02^{\#}$ \\
\hline NMHC & $0.5^{*}$ & 0.14 & 0.14 & 0.14 \\
\hline CO & 15.5 & 15.5 & 15.5 & 15.5 \\
\hline PM & 0.1 & 0.01 & 0.01 & 0.01 \\
\hline
\end{tabular}

*Alternative standard: $\mathrm{NMHC}+\mathrm{NO}_{\mathrm{x}}=2.5 \mathrm{~g} / \mathrm{bhp}-\mathrm{hr}$

\#Manufacturers may choose California Optional Low NO $\mathrm{N}_{\mathrm{x}}$ Standard

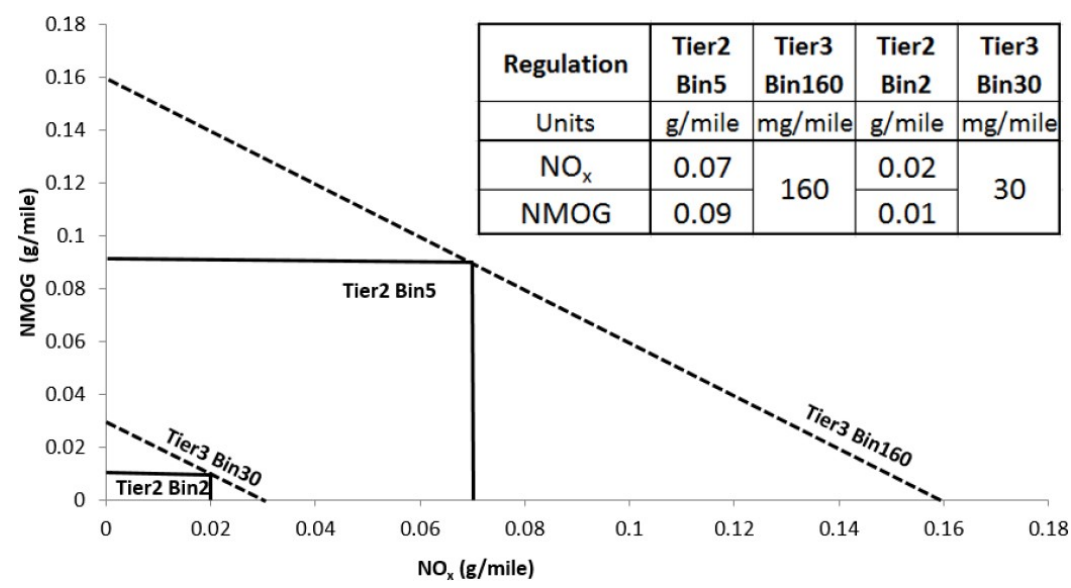

Figure 1.1: EPA Emission Standards for Light Duty Vehicles [2]

Many technologies are being implemented on diesel engine to control emissions which include exhaust gas recirculation (EGR), advanced fuel injection strategies etc. Particularly for heavy duty 
diesel engines, a typical aftertreatment system consisting of a Diesel Oxidation Catalyst (DOC), a Catalyzed Particulate Filter (CPF), a Selective Catalytic Reduction (SCR) with urea injection assembly and an Ammonia Oxidation Catalyst (AMOX) is currently being used by manufacturers to meet the EPA standards for year 2010/2013 shown in Table 1.1 [3].

\subsection{Diesel Engine Aftertreatment System Research}

A typical aftertreatment system for a heavy duty diesel engine is shown in Figure 1.2. The engine exhaust flows through the DOC, CPF, decomposition tube and the SCR system. SCR-B catalyst shown in Figure 1.2 is a substrate with SCR catalyst coated in the front and AMOX catalyst at the back of the substrate.

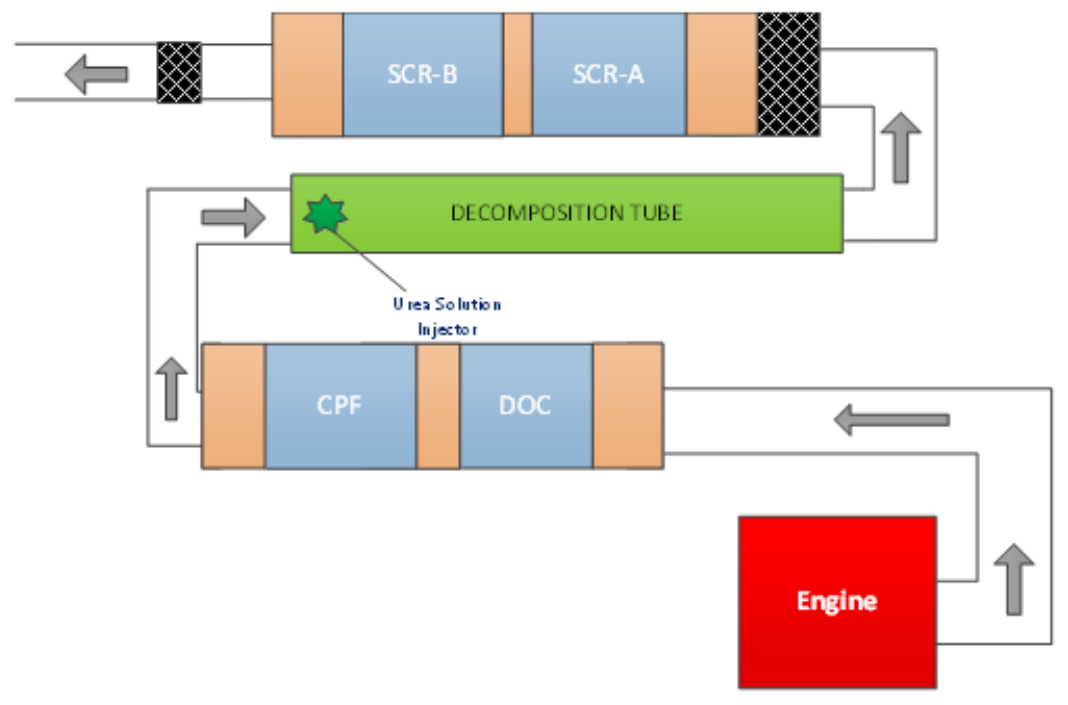

Figure 1.2: Schematic of the Cummins ISB 2013 Production Aftertreatment System [4]

The DOC is a flow through catalyst that oxidizes the nitrogen oxide (NO), carbon monoxide (CO) and hydrocarbon $(\mathrm{HC})$ in the exhaust stream to nitrogen dioxide $\left(\mathrm{NO}_{2}\right)$, carbon dioxide $\left(\mathrm{CO}_{2}\right)$ and water $\left(\mathrm{H}_{2} \mathrm{O}\right)$. The DOC is placed upstream of the filter to increase the proportion of $\mathrm{NO}_{2}$ by oxidizing the $\mathrm{NO}$ in the exhaust as the proportion of $\mathrm{NO}_{2}$ in the diesel exhaust is relatively low (5$15 \%$ of total $\mathrm{NO}_{\mathrm{x}}$ ) [5]. This promotes the $\mathrm{NO}_{2}$ assisted oxidation of PM in the CPF. The $\mathrm{NO}$ to $\mathrm{NO}_{2}$ conversion in the DOC is a function of exhaust space velocity, DOC inlet temperature, inlet NO concentration and is maximum for DOC inlet temperatures in the range of $300-350^{\circ} \mathrm{C}$ after which 
it starts decreasing [6]. The DOC is also used to oxidize the hydrocarbons in the diesel fuel dosed late into the combustion cycle during active regeneration. The $\mathrm{HC}$ conversion increases with the increase in DOC inlet temperature [6].

The CPF is a wall flow device which filters the PM in the exhaust and oxidizes the PM retained in the wall and the cake layer by $\mathrm{NO}_{2}$ assisted oxidation and thermal oxidation with $\mathrm{O}_{2}$. Both the mechanisms occur simultaneously although one may be the dominant mechanism at certain conditions. The $\mathrm{NO}_{2}$ assisted oxidation is dominant in the temperature range $250-400^{\circ} \mathrm{C}$ [5] whereas the thermal oxidation is dominant in temperatures above $400^{\circ} \mathrm{C}$ [7].

The SCR is a flow through device with a honeycomb structure. Catalysts such as oxides of copper $(\mathrm{Cu})$, iron $(\mathrm{Fe})$ or vanadium $(\mathrm{V})$ are coated on the channels of the substrate. The SCR is used to reduce the $\mathrm{NO}_{\mathrm{x}}$ in the exhaust to nitrogen $\left(\mathrm{N}_{2}\right)$ and water $\left(\mathrm{H}_{2} \mathrm{O}\right)$. This is done by injecting a urea solution (32.5\% conc. by weight) also known as Diesel Exhaust Fluid (DEF) into the exhaust stream. The urea decomposes into ammonia $\left(\mathrm{NH}_{3}\right)$, carbon dioxide $\left(\mathrm{CO}_{2}\right)$ and water $\left(\mathrm{H}_{2} \mathrm{O}\right)$. The ammonia produced by decomposition of urea is adsorbed and stored on the surface of the catalyst which reacts with $\mathrm{NO}$ and $\mathrm{NO}_{2}$ and reduces the $\mathrm{NO}_{x}$.

The AMOX is placed downstream of the SCR substrate and oxidizes the ammonia that slips out of the SCR to nitrogen $\left(\mathrm{N}_{2}\right)$ and water $\left(\mathrm{H}_{2} \mathrm{O}\right)$. The ammonia slip out of SCR occurs due to over injection of urea solution or low exhaust temperatures where the $\mathrm{NH}_{3}$ doesn't react with the $\mathrm{NO}$ and $\mathrm{NO}_{2}$. Although these systems are effective in achieving the 2010/2013 EPA standards, it is not possible to achieve the 2015 California low $\mathrm{NO}_{x}$ standards with this arrangement. Hence, there is a need to improve the existing aftertreatment system by increasing the SCR catalyst volume. But this will increase the cost of the system due to the precious metal involved and also increase the weight and volume of the overall system which might cause packaging issues as well.

To solve this, the SCR catalyst can be combined with a diesel particulate filter (DPF) into a single device which is known as SCR catalyst on a DPF or SCR-on-DPF or SDPF. The SCR catalyst is coated on the DPF substrate wall thus combining both the $\mathrm{NO}_{x}$ reduction and PM oxidation functionality into a single device which reduces the overall volume and weight of the system and provides the opportunity for packaging flexibility and improved thermal management [3]. The SCR catalyst on 
a DPF used in this study is known as $\mathrm{SCRF}^{\circledR}$ and was supplied by Johnson Matthey and Corning. The $\mathrm{SCRF}^{\circledR}$ is a wall flow device with a Cu-zeolite based SCR catalyst coated on the substrate walls. The engine and aftertreatment research done at MTU is a part of the Consortium effort with Cummins and Isuzu as partners. Figure 1.3 shows the overall experimental program with different phases of testing. A Cummins ISB 20136.7 L engine was used for the experimental testing in order to collect data and characterize the performance of the CPF, SCR and SCRF ${ }^{\circledR}$. The production or the baseline system at MTU consists of a DOC, CPF decomposition tube and SCR system as shown in Figure 1.2. In Configuration 1, the CPF is replaced with a spacer and the SCR system is replaced with the $\mathrm{SCRF}^{\circledR}$ as shown in Figure 1.4. In Configuration 2, the SCR is replaced with the $\mathrm{SCRF}^{\circledR}$ and the CPF is used in this system to remove the PM in order to determine the SCR kinetics of the $\mathrm{SCRF}^{\circledR}$. In Configuration 3, the CPF is replaced with the $\mathrm{SCRF}^{\circledR}$ and the SCR is placed downstream of the $\mathrm{SCRF}^{\oplus}$. Details about these three $\mathrm{SCRF}^{\circledR}$ Configurations and the experimental work performed on all the three Configurations at MTU is given in references $[8,9,10]$.

Based on the previous research at MTU on the production system and Configuration 1, it was observed that the reactivity of $\mathrm{PM}$ retained in the $\mathrm{CPF}$ and $\mathrm{SCRF}^{\circledR}$ is higher during loading conditions compared to passive oxidation conditions i.e. when the flow rate of PM entering the CPF or $\mathrm{SCRF}^{\circledR}$ is higher in loading conditions compared to the low flow rate and higher PM reaction rate during passive oxidation conditions $[4,8]$. Hence, to further understand and characterize the difference in reactivity of PM during loading conditions and passive oxidation conditions, loading tests at different engine conditions at different temperatures and $\mathrm{PM}$ and $\mathrm{NO}_{2}$ concentrations were carried out with and without urea injection. 


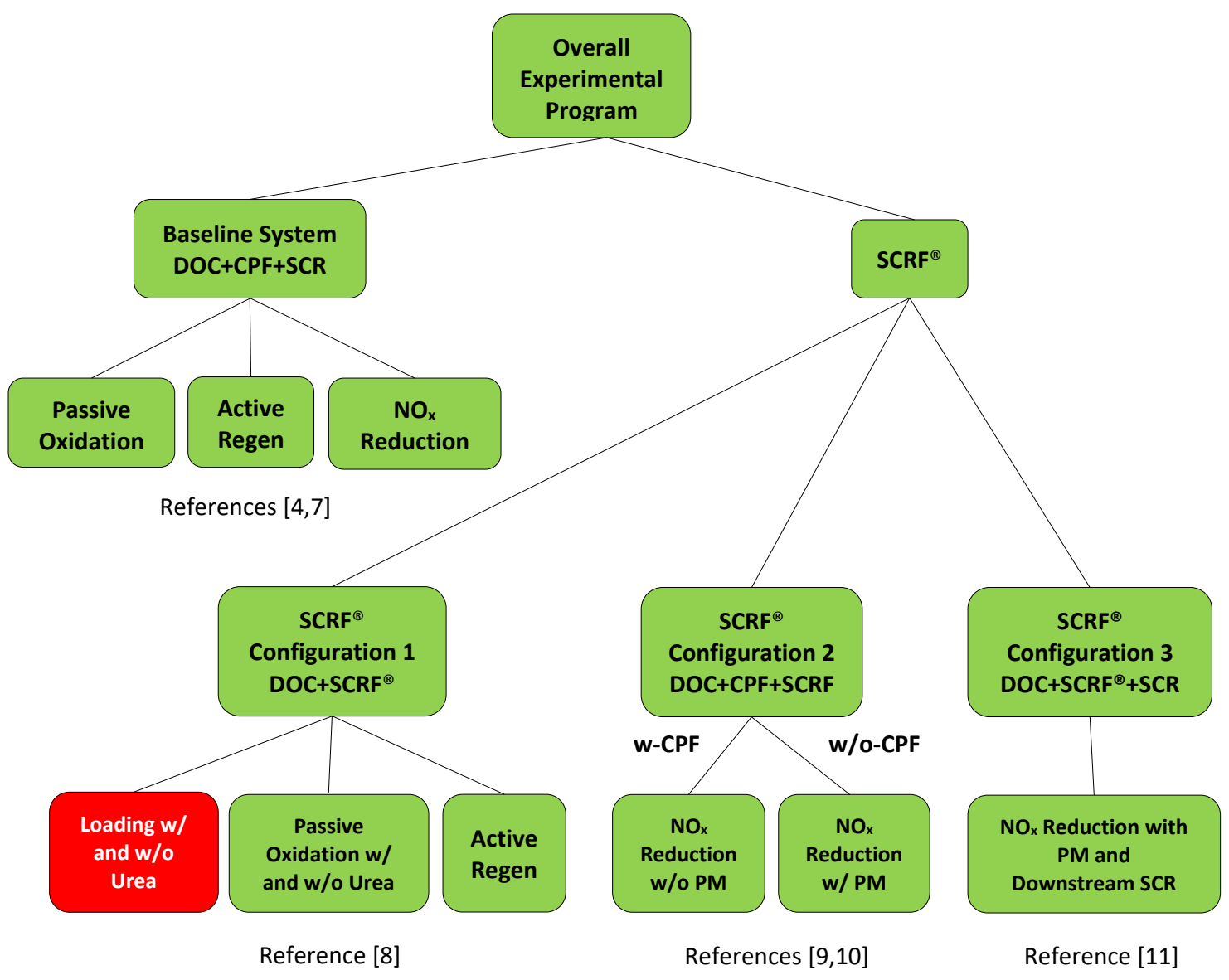

Figure 1.3: Overall Experimental Program

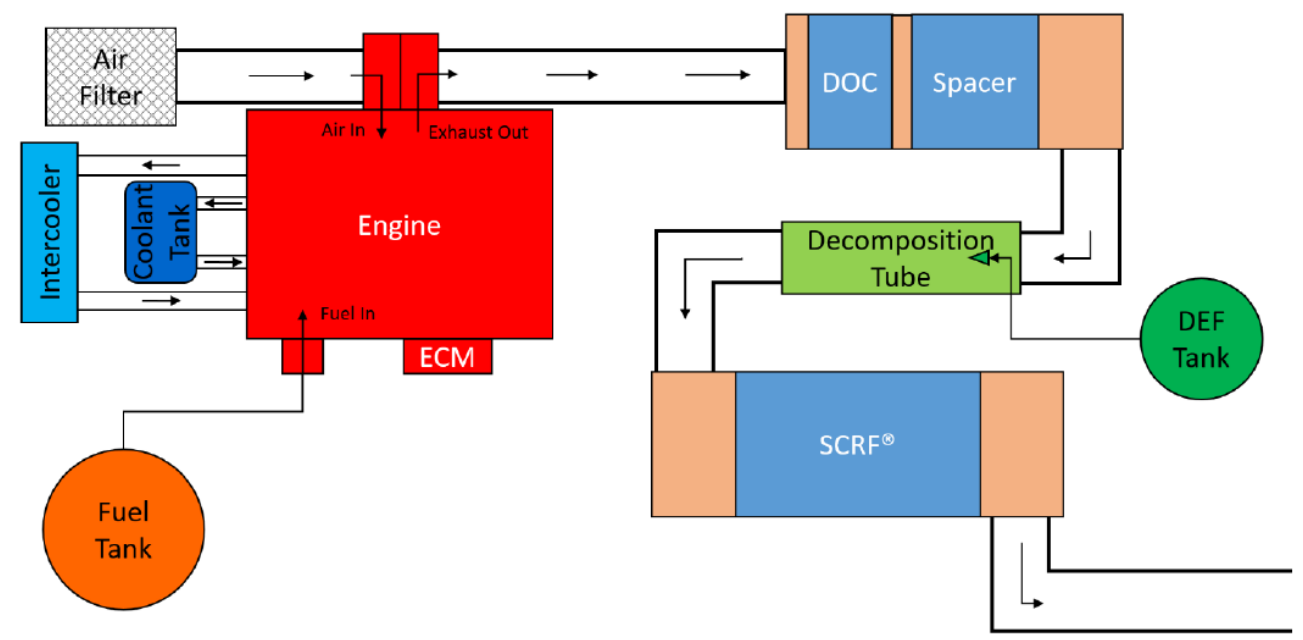

Figure 1.4: $\mathrm{SCRF}^{\circledR}$ Configuration 1 [8] 


\subsection{MTU SCR-F Model}

The SCR-F model is being developed at MTU [12] to simulate the performance of the SCRF ${ }^{\circledR}$ under different engine conditions. The model is capable of simulating the PM loading and oxidation via $\mathrm{NO}_{2}$ assisted and thermal oxidation mechanisms, and the filtration of the PM in the cake and the substrate wall. It can simulate the total pressure drop across the $\mathrm{SCRF}^{\circledR}$ and estimate the individual contribution of the PM cake, wall and the channel to the total pressure drop. It has the ability to simulate the reaction of chemical species - $\mathrm{NO}, \mathrm{NO}_{2}, \mathrm{CO}, \mathrm{CO}_{2}, \mathrm{O}_{2}$ and $\mathrm{HC}$ across the $\mathrm{SCRF}^{\circledR}$. The model is also capable of predicting the temperature and PM distribution in both the radial and axial direction in the $\mathrm{SCRF}^{\circledR}$. The development of the model will be briefly discussed in Section 2.5.

The model has been calibrated using experimental data from the Configuration 1 passive oxidation without urea and active regeneration tests [8], and Configuration 2 without PM [9]. Currently, it is being calibrated using experimental data for passive oxidation with urea in Configuration 1 [8] and experimental data for $\mathrm{NO}_{x}$ reduction with PM in Configuration 2 [9]. The procedure for the calibration and the results are being developed. The SCR-F model has been used to simulate the $\mathrm{PM}$ retained in the $\mathrm{SCRF}^{\circledR}$, the total pressure drop across $\mathrm{SCRF}^{\circledR}$ and the temperature distribution in $\mathrm{SCRF}^{\circledR}$ for the tests performed in this study. Also, the model values have been compared to the experimental data to help in determining the integrity of the experimental data as the model is expected to be consistent.

\subsection{Goals and Objectives}

The primary focus of this study is to experimentally determine the PM oxidation performance of the $\mathrm{SCRF}^{\oplus}$ under loading conditions with and without urea injection and to characterize the differences in the PM oxidation kinetics for loading and passive oxidation conditions with and without urea injection. The data from this study will be used to develop and calibrate a PM oxidation model. The results of this model will be applied to the SCR-F model to simulate the oxidation characteristics of PM under loading conditions. 
Objectives:

- Conduct experimental studies in order to determine the oxidation characteristics of the $\mathrm{PM}$ in the $\mathrm{SCRF}^{\circledast}$ during loading with and without urea injection for various engine conditions with different temperature and $\mathrm{NO}_{2}$ concentrations.

- Study the effects of different space velocities, inlet temperatures, $\mathrm{NO}_{2}$ concentration and fuel rail pressure on the $\mathrm{SCRF}^{\circledR}$ pressure drop and the $\mathrm{PM}$ mass retained under loading conditions with and without urea injection.

- Determine the kinetics of $\mathrm{NO}_{2}$ assisted $\mathrm{PM}$ oxidation in the $\mathrm{SCRF}^{\circledR}$ under loading conditions with and without urea injection. Characterize the difference in the PM oxidation kinetics for loading and passive oxidation conditions with and without urea injection.

- Study the effect of urea on PM oxidation in the $\mathrm{SCRF}^{\oplus}$ under loading conditions.

- Develop a model based on the microstructure of PM particles that keeps track of incoming $\mathrm{PM}$ mass samples into the $\mathrm{SCRF}^{\circledR}$ to simulate the $\mathrm{PM}$ retained in the $\mathrm{SCRF}^{\circledast}$ for a single set of kinetics for PM oxidation under loading and passive oxidation conditions.

- Calibrate the SCR-F model using experimental data as input to simulate the PM retained in the $\mathrm{SCRF}^{\circledR}$ and pressure drop across the $\mathrm{SCRF}^{\circledR}$ under loading conditions with and without urea. Validate the performance of the model by comparing the simulation results and the experimental data.

\subsection{Overview of Thesis}

As discussed in Section 1.2, the focus of this thesis is on the PM oxidation performance of the $\mathrm{SCRF}^{\circledR}$ under loading conditions with and without urea injection. This chapter presented a brief introduction on the diesel engine aftertreatment system research followed by the goals and objectives of this study.

Chapter 2 discusses the published literature related to the oxidation of PM in a SCR catalyst on a DPF with and without urea injection. There is also a discussion on the comparison of $\mathrm{NO}_{2}$ assisted PM oxidation kinetics from various experimental and modeling studies along with different 
models used for PM oxidation in the literature. It also provides a background and motivation for the research conducted.

Chapter 3 discusses the experimental setup and procedures used for collecting data. There is a brief introduction on the test cell setup and different instruments used followed by discussion on the test procedure and test matrix for the experiments.

Chapter 4 focuses on the development of the PM oxidation model and calibration process. It discusses the integration of the PM oxidation model into the SCR-F model followed by the process used for calibrating the SCR-F model with experimental data from the tests conducted. There is brief discussion on the process followed for calibrating the PM oxidation model using experimental data from the passive oxidation tests in reference [8].

Chapter 5 presents the data and results from the experimental tests conducted followed by the comparison of results for loading and passive oxidation conditions with and without urea injection. The performance of the calibrated SCR-F model and the PM oxidation model is discussed by comparing the simulated data with the experimental data.

Chapter 6 summarizes the results from the experimental and modeling studies and draws conclusions of the research.

This is followed by Appendices A through $\mathrm{G}$ which provide additional data and information that supports the various chapters. 


\section{Chapter 2. Literature Review}

The focus of this chapter is to discuss published literature related to the objectives of this study and providing a background for the research conducted. The first section discusses the mechanisms of PM oxidation in a SCR catalyst on a DPF followed by a review of the literature to understand the effect of SCR reactions on the PM oxidation in the filter. The next section provides a brief description on the kinetics of PM oxidation followed by a discussion of the different models for PM oxidation to determine the kinetics of PM oxidation. This is followed by a section pertaining to loading studies of CPFs and SCR catalysts on DPFs. The last section discusses the development of the SCR-F model.

\subsection{Oxidation of PM With and Without Urea Injection}

The SCR catalyst on a DPF has dual functionality of filtering the PM as well as reducing the $\mathrm{NO}_{\mathrm{x}}$ in the diesel exhaust. As the PM gets loaded in the filter, the pressure drop across the filter increases which increases the backpressure on the engine. This deteriorates engine performance and increases fuel consumption and PM, CO and HC emissions [1]. To solve this problem, the PM in the filter has to be periodically oxidized by a process commonly known as 'active regeneration'. There are two gases in the diesel exhaust $-\mathrm{O}_{2}$ and $\mathrm{NO}_{2}$ which play an important role in the oxidation of PM. There are two mechanisms for PM oxidation, the $\mathrm{NO}_{2}$ assisted and the thermal oxidation which is $\mathrm{O}_{2}$ assisted. Both the mechanisms occur simultaneously although one may be the dominant mechanism at certain temperature conditions. The $\mathrm{NO}_{2}$ assisted oxidation is dominant in the temperature range $250-400^{\circ} \mathrm{C}$ [5] whereas the thermal oxidation is dominant in temperatures above $400^{\circ} \mathrm{C}$ [7]. The temperatures in all the experimental tests performed in this study are below $400^{\circ} \mathrm{C}$ and therefore it is assumed that $\mathrm{NO}_{2}$ assisted oxidation is the dominant mechanism for PM oxidation. The literature pertaining to $\mathrm{NO}_{2}$ assisted oxidation is discussed further in this Chapter. The literature pertaining to thermal oxidation can be found in references $[4,8]$.

\section{$\mathrm{NO}_{2}$ Assisted Oxidation}

In this mechanism, the PM retained in the filter is oxidized as a result of the reaction of $\mathrm{NO}_{2}$ with the PM. In a typical diesel aftertreatment system, an oxidation catalyst (DOC) is placed upstream of the filter to increase the proportion of $\mathrm{NO}_{2}$ by oxidizing the $\mathrm{NO}$ in the exhaust as the proportion 
of $\mathrm{NO}_{2}$ in the diesel exhaust is relatively low (5-15\% of total $\mathrm{NO}_{\mathrm{x}}$ ) [5]. This promotes the oxidation of $\mathrm{PM}$ in the filter by increasing the amount of $\mathrm{NO}_{2}$ into the filter. Equation 1 describes the oxidation of $\mathrm{NO}$ to $\mathrm{NO}_{2}$ in the DOC. As discussed earlier, the $\mathrm{NO}$ to $\mathrm{NO}_{2}$ conversion efficiency of the DOC depends on factors such as space velocity, inlet temperatures and NO concentrations [6]. The DOC conversion efficiency peaks at temperatures in the range of $300-350^{\circ} \mathrm{C}[6]$.

$$
\mathrm{NO}+\frac{1}{2} \mathrm{O}_{2} \stackrel{\text { yields }}{\Longleftrightarrow} \mathrm{NO}_{2}
$$

Equations 2 and 3 describes the $\mathrm{NO}_{2}$ assisted oxidation of $\mathrm{PM}$ in the filter. The increased proportion of $\mathrm{NO}_{2}$ in the exhaust due to $\mathrm{NO}$ to $\mathrm{NO}_{2}$ conversion in the DOC increases the PM oxidation rate [5].

$$
\begin{aligned}
& \mathrm{C}+\mathrm{NO}_{2} \stackrel{\text { yields }}{\longrightarrow} \mathrm{NO}+\mathrm{CO} \\
& \mathrm{C}+2 \mathrm{NO}_{2} \stackrel{\text { yields }}{\longrightarrow} 2 \mathrm{NO}+\mathrm{CO}_{2}
\end{aligned}
$$

As explained earlier, the SCR catalyst on a DPF can reduce $\mathrm{NO}_{\mathrm{x}}$ in the exhaust with the ammonia SCR reactions. Equations 4 and 5 describes the standard and fast SCR reactions respectively which are two important reactions [13].

$$
\begin{aligned}
& 4 \mathrm{NH}_{3}+4 \mathrm{NO}+\mathrm{O}_{2} \stackrel{\text { yields }}{\longrightarrow} 4 \mathrm{~N}_{2}+6 \mathrm{H}_{2} \mathrm{O} \\
& 4 \mathrm{NH}_{3}+2 \mathrm{NO}+2 \mathrm{NO}_{2} \stackrel{\text { yields }}{\longrightarrow} 4 \mathrm{~N}_{2}+6 \mathrm{H}_{2} \mathrm{O}
\end{aligned}
$$

In the SCR catalyst on a DPF, there is a competition between the SCR and PM oxidation reactions for consumption of $\mathrm{NO}_{2}$. This is schematically shown in Figure 2.1. A summary of published research about the effect of SCR reactions on PM oxidation is described in the following paragraphs. 


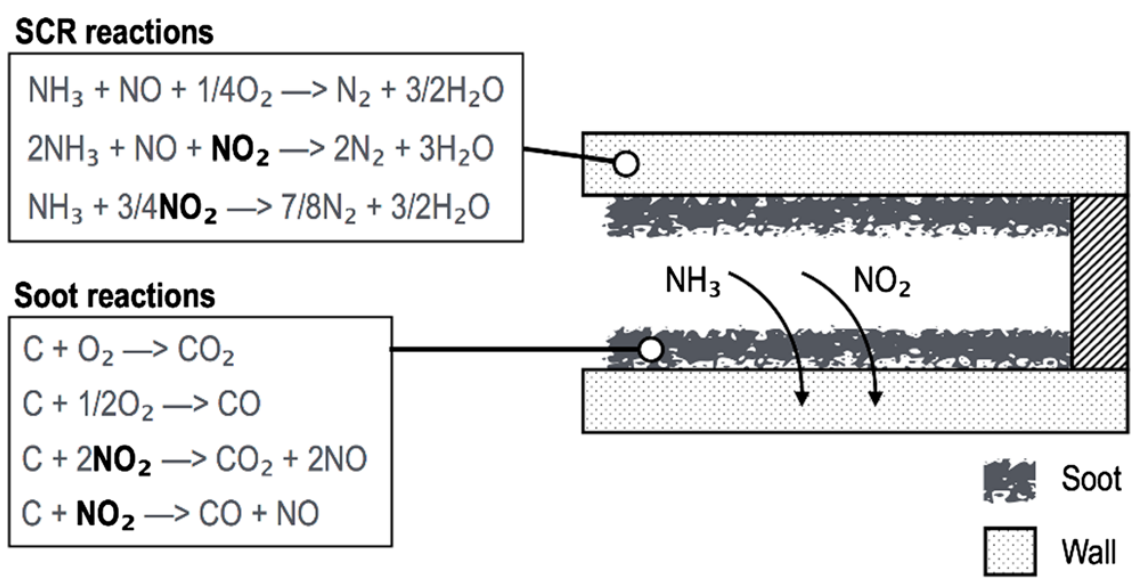

Figure 2.1: Competition Between PM Oxidation and SCR Reactions [14]

Czerwinkski et al. [15] studied the passive oxidation performance of a SCR catalyst on a DPF with and without urea injection. The filter was loaded to $3 \mathrm{~g} / \mathrm{L}$ (around $20 \mathrm{~g}$ for 5 repeated tests) with urea dosing of $36 \mathrm{~g} / \mathrm{h}$ using a HD $3.0 \mathrm{~L}$ Iveco engine. The soot loading in the filter decreased by $81 \%$ without urea compared to $41 \%$ decrease with urea injection at ANR 1.0. This is because urea dosing hinders $\mathrm{NO}_{2}$ assisted oxidation [15].

Naseri et al. [16] studied the passive regeneration capability of a Cu-zeolite SCR catalyst on a DPF with and without urea injection after the loading it up to $3 \mathrm{~g} / \mathrm{L}$. A $2007 \mathrm{MY}$ heavy-duty diesel engine was used to conduct passive oxidation experiments for 30 minutes with Engine Out $\mathrm{NO}_{\mathrm{x}}$ $4.5 \mathrm{~g} / \mathrm{hp}-\mathrm{hr}$ and DOC inlet temperature of $300^{\circ} \mathrm{C}$ (DOC Out NO2/NOx $=0.26$ ) and $400^{\circ} \mathrm{C}$ (DOC Out $\mathrm{NO}_{2} / \mathrm{NO}_{\mathrm{x}}=0.30$ ). At $300^{\circ} \mathrm{C}$, there was a net soot gain of $5 \%$ without urea as compared to net soot gain of $20 \%$ with urea injection at ANR 1.2 as shown in Figure 2.2. However, at $400^{\circ} \mathrm{C}$, there was a $25 \%$ net soot oxidation without urea compared to $19 \%$ net soot oxidation with urea injection at ANR 1.2 as shown in Figure 2.2. The lower soot oxidation with urea injection at $400^{\circ} \mathrm{C}$ is attributed to $\mathrm{NO}_{2}$ conversion via SCR reaction in the SCR catalyst on a DPF [16]. 


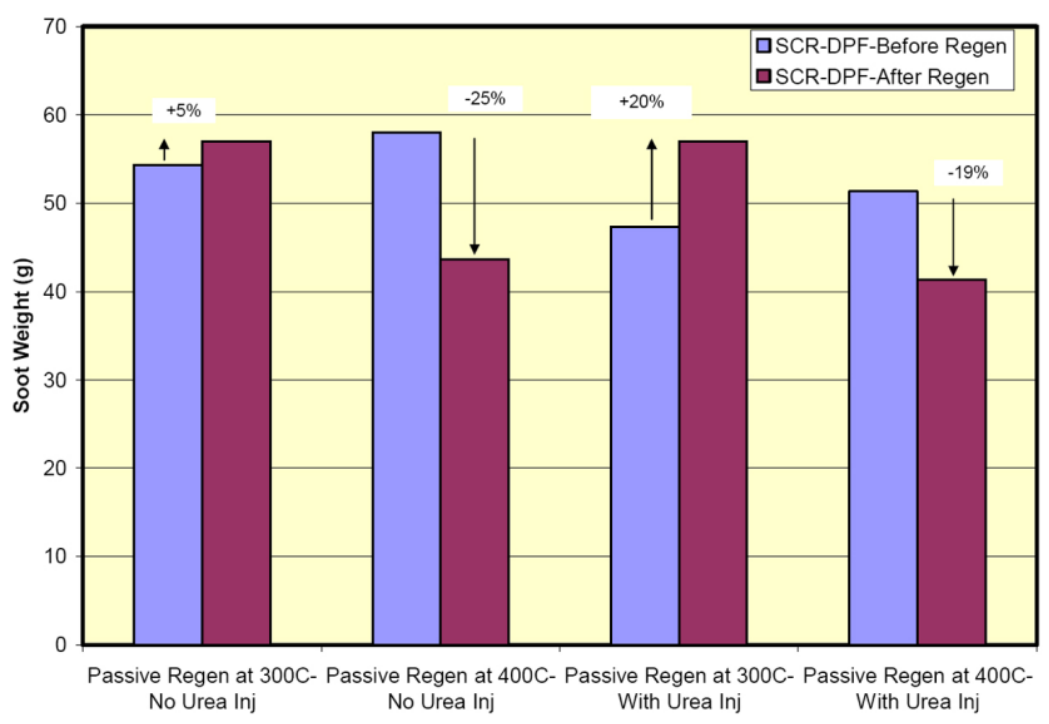

Figure 2.2: Passive Regeneration Capability of the SCR catalyst on a DPF With and Without Urea [16]

Troconi et al. [14] performed modeling and experimental studies to investigate the effect of SCR activity on passive regeneration characteristics of a Cu-zeolite SCR catalyst on a DPF. A 2.2 L Euro 4 Daimler $\mathrm{OM} 646$ engine was used to perform two passive oxidation tests at $350^{\circ} \mathrm{C}$ and $450^{\circ} \mathrm{C}$ with and without $\mathrm{NH}_{3}$ injection. At $350^{\circ} \mathrm{C}$, the net oxidized soot mass at the end of the experiments was $6.2 \mathrm{~g}$ without $\mathrm{NH}_{3}$ compared to $5.1 \mathrm{~g}$ with $\mathrm{NH}_{3}$ injection. At $450^{\circ} \mathrm{C}$, the net oxidized soot mass was $9.4 \mathrm{~g}$ without $\mathrm{NH}_{3}$ compared to $8.6 \mathrm{~g}$ with $\mathrm{NH}_{3}$ injection. It is evident that there is a negative effect of $\mathrm{SCR}$ reactions on the $\mathrm{NO}_{2}$ assisted oxidation as the measured oxidized soot mass is lower for the cases when $\mathrm{NH}_{3}$ is injected [14]. The contribution of $\mathrm{NO}_{2}$ and $\mathrm{O}_{2}$ to the total reaction rate for soot oxidation for each of these tests is shown in Figure 2.3. It is clearly observed that the $\mathrm{NH}_{3}$ injection lowers the contribution of $\mathrm{NO}_{2}$ to the soot oxidation at both the temperatures as a part of $\mathrm{NO}_{2}$ is reduced by $\mathrm{NH}_{3}$ before it reacts with soot resulting in lower soot oxidation rates. However, the effect of $\mathrm{NH}_{3}$ on the contribution of $\mathrm{O}_{2}$ to the soot oxidation is negligible. 


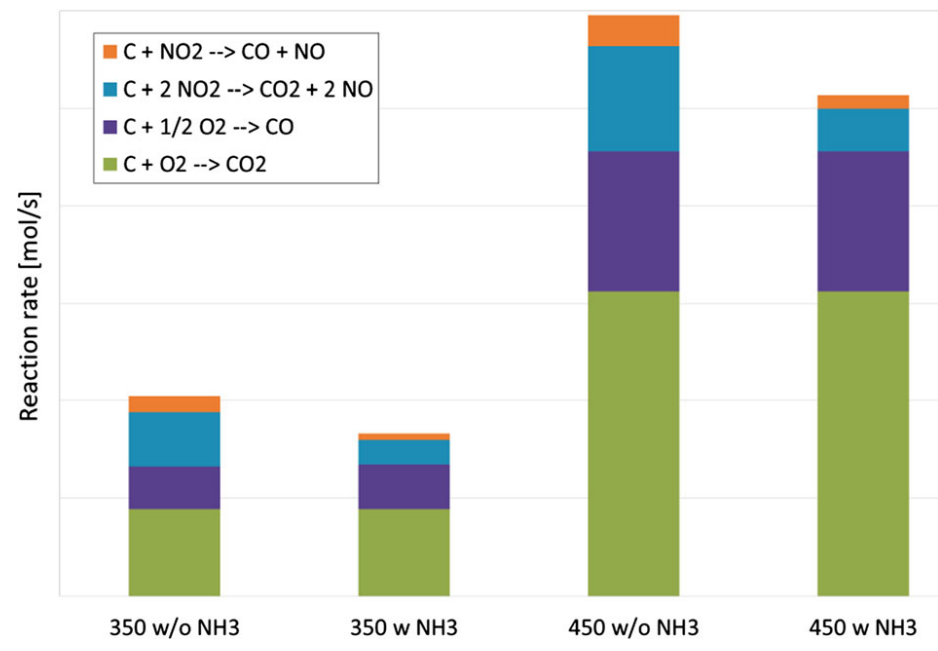

Figure 2.3: Predicted Soot Oxidation Reaction Rates for Passive Regeneration Experiments With and Without $\mathrm{NH}_{3}$ Injection at $350^{\circ} \mathrm{C}$ and $450^{\circ} \mathrm{C}$ for a SCR catalyst on a DPF [14]

\subsection{Kinetics of PM Oxidation}

In this study, experimental tests were designed to determine the kinetics of $\mathrm{NO}_{2}$ assisted oxidation of the $\mathrm{PM}$ retained in the $\mathrm{SCRF}^{\circledast}$ for different loading conditions. The kinetics or the reaction rate of the PM oxidation is a function of temperature at which the reaction takes place, and the oxidant $\left(\mathrm{NO}_{2}\right.$ or $\left.\mathrm{O}_{2}\right)$ concentrations. Generally, the models used to understand the kinetics of PM oxidation are the standard Arrhenius model and the modified Arrhenius model. The equation for the standard Arrhenius model is given in Equation 6.

$$
k_{s t d}=A * e^{-\frac{E a}{R u^{* T}}}
$$

where,

$\mathrm{k}_{\mathrm{std}}$ is the rate constant for the reaction $[1 / \mathrm{s}]$,

$A$ is the frequency factor or pre-exponential factor $[1 / s]$,

$E_{a}$ is the activation energy of the reaction $[\mathrm{kJ} / \mathrm{gmol}]$,

$R_{u}$ is the universal gas constant $=8314[\mathrm{~kJ} / \mathrm{gmol}-\mathrm{K}]$,

$\mathrm{T}$ is temperature of the reaction $[\mathrm{K}]$.

The equation for the modified Arrhenius model is similar to the standard Arrhenius model. However, the rate constant has a temperature dependent term. The equation of the modified Arrhenius model is given in Equation 7. 


$$
k_{\text {mod }}=B * T^{n} * e^{-\frac{E_{a}}{R_{u} * T}}
$$

where,

$\mathrm{k}_{\text {mod }}$ is the rate constant for the modified Arrhenius model [1/s],

$B$ is the frequency factor or per-exponential factor $\left[1 / s-K^{n}\right]$,

$T^{n}$ is the temperature of the reaction to the power $n$, where $n$ is the order of the reaction $\left[K^{n}\right]$.

Over the years, many researchers have conducted tests which includes reactor based studies or experiments on an engine with DOC-CPF (or DPF or SCR catalyst on a DPF) arrangement along with modeling efforts to determine the kinetics of $\mathrm{NO}_{2}$ assisted and $\mathrm{O}_{2}$ assisted oxidation. The kinetics of $\mathrm{NO}_{2}$ assisted oxidation from the literature are given in Table 2.1. A range of activation energies are reported in the literature from $40-122 \mathrm{~kJ} / \mathrm{gmol}$ for $\mathrm{NO}_{2}$ assisted oxidation. Similarly, activation energies from various sources for $\mathrm{NO}_{2}$ assisted and thermal oxidation has been summarized in references $[4,8]$. Many sources have reported that activation energy for $\mathrm{NO}_{2}$ or $\mathrm{O}_{2}$ assisted oxidation depend on the PM composition [17], the temperature [17, 18], catalytic coating of the CPF [19] and many other factors. Hence, when comparing the activation energies from these sources, all the dependencies and testing conditions have to be taken into account. Also, it is important to note that the units for pre-exponential factor from different sources are different depending on the model and the relations used with respect to oxidant concentration. Reference [20] and reference [21] have used mole fractions and mass fractions respectively for the $\mathrm{NO}_{2}$ concentrations whereas references $[4,8]$ have used mole concentrations in ppm respectively to determine the $\mathrm{NO}_{2}$ assisted kinetics of PM oxidation.

The order of the reaction (n) used in Equation 7 is generally considered to be one (pseudo-first order) as reported by references $[4,8,18,19,20,22,23,24]$. However, some authors have determined or referenced order of reaction for $\mathrm{NO}_{2}$ or $\mathrm{O}_{2}$ other than one. Reference [25] reports order of 0.76 to 0.94 for $\mathrm{O}_{2}$ whereas reference [26] reports order of 0.39 for $\mathrm{O}_{2}$ in thermal oxidation of Printex-U. Zero order for $\mathrm{NO}_{2}$ has been reported by reference [27] in $\mathrm{NO}_{2}$ assisted oxidation at around $300^{\circ} \mathrm{C}$ and an increasing dependence on $\mathrm{NO}_{2}$ with temperature. In this study, a pseudo-first order reaction i.e. order one has been assumed for $\mathrm{NO}_{2}$ assisted oxidation of PM. 
Table 2.1: Kinetics of $\mathrm{NO}_{2}$ Assisted Oxidation From Various References

\begin{tabular}{|c|c|c|c|c|c|c|c|c|}
\hline Ref. \# & $\begin{array}{l}\text { Reference } \\
\text { Name }\end{array}$ & $\begin{array}{c}\text { Kinetics } \\
\text { Model }\end{array}$ & $\begin{array}{l}\text { Activation } \\
\text { Energy }\end{array}$ & $\begin{array}{c}\text { Pre-Exponential } \\
\text { Factor }\end{array}$ & $\begin{array}{c}\text { Temperature } \\
\text { Range }\end{array}$ & $\begin{array}{c}\mathrm{NO}_{2} \\
\text { Range }\end{array}$ & Test Type & Notes \\
\hline$[-]$ & {$[-]$} & {$[-]$} & [kJ/gmol] & {$[-]$} & {$\left[{ }^{\circ} \mathrm{C}\right]$} & [ppm] & {$[-]$} & {$[-]$} \\
\hline [28] & $\begin{array}{l}\text { Dabhoiwala } \\
\text { et. al. }\end{array}$ & $\begin{array}{l}\text { Modified } \\
\text { Arrhenius }\end{array}$ & 73 & $0.5-3[\mathrm{~m} / \mathrm{K} / \mathrm{s}]$ & $273-461$ & $13-169$ & $\begin{array}{l}\text { PM produced by a Heavy-Duty Diesel Engine } \\
\text { (2002 Cummins ISM-330) and oxidized in CPFs } \\
\text { with different catalyst loadings }\end{array}$ & - \\
\hline [27] & $\begin{array}{l}\text { Triana et. } \\
\text { al. }\end{array}$ & $\begin{array}{l}\text { Modified } \\
\text { Arrhenius }\end{array}$ & 122 & $100[\mathrm{~m} / \mathrm{K} / \mathrm{s}]$ & $286-429$ & $60-128$ & $\begin{array}{l}\text { Modeling study of a DOC-CPF using PM produced } \\
\text { by a John Deere } 8.1 \mathrm{~L} 175 \mathrm{~kW} @ 1200 \mathrm{rpm}, 1060 \\
\mathrm{~N}-\mathrm{m} \text { turbo and aftercooled HP and common rail } \\
\text { injection engine, trapped and oxidized in a CPF }\end{array}$ & - \\
\hline [23] & $\begin{array}{l}\text { Messerer } \\
\text { et. al. }\end{array}$ & $\begin{array}{l}\text { Standard } \\
\text { Arrhenius }\end{array}$ & 115 & $1.17\left[10^{6} / \mathrm{s}\right]$ & $275-450$ & $0-800$ & $\begin{array}{c}\text { Oxidation of FBR with Pt washcoat collected PM } \\
\text { using reactor feed gas, produced by a LDV diesel } \\
\text { engine }\end{array}$ & - \\
\hline [23] & $\begin{array}{l}\text { Messerer } \\
\text { et. al. }\end{array}$ & $\begin{array}{l}\text { Standard } \\
\text { Arrhenius }\end{array}$ & 98 & $7.36\left[10^{4} / \mathrm{s}\right]$ & $275-450$ & $0-710$ & $\begin{array}{c}\text { Oxidation of FBR with Pt washcoat collected PM } \\
\text { using reactor feed gas, produced by a HDV diesel } \\
\text { engine }\end{array}$ & - \\
\hline [24] & $\begin{array}{l}\text { Kandylas } \\
\text { et. al. }\end{array}$ & $\begin{array}{l}\text { Modified } \\
\text { Arrhenius }\end{array}$ & 40 & $\begin{array}{c}0.5 \\
{\left[\mathrm{gmol}-\mathrm{K} / \mathrm{m}^{2} / \mathrm{s}^{2}\right]} \\
\end{array}$ & $165-416$ & $200-400$ & $\begin{array}{l}\text { PM produced by a } 1.9 \mathrm{~L}, 66 \mathrm{~kW} @ 4 \mathrm{k} \mathrm{rpm}, \\
\text { turbocharged, } \mathrm{DI} \text { and EGR and oxidized in a DPF }\end{array}$ & - \\
\hline [20] & $\begin{array}{l}\text { Premchand } \\
\text { et. al. }\end{array}$ & $\begin{array}{l}\text { Standard } \\
\text { Arrhenius }\end{array}$ & 74 & $\begin{array}{l}0.1[\mathrm{~m} / \mathrm{s}] \text { for cake } \\
\text { and } 0.35[\mathrm{~m} / \mathrm{s}] \\
\text { for wall }\end{array}$ & $253-408$ & $61-112$ & \multirow{2}{*}{$\begin{array}{l}\text { PM produced by a } 2007 \text { Cummins ISL } 272 \mathrm{~kW} \\
\text { engine and oxidized in a production CPF }\end{array}$} & $\begin{array}{l}\text { Activation Energy based on } \\
\text { experimental data [22] and } \\
\text { frequency factors estimated } \\
\text { using a computational I-D } \\
\text { CPF model developed at MTU }\end{array}$ \\
\hline [21] & $\begin{array}{l}\text { Mahadevan } \\
\text { et. al. }\end{array}$ & $\begin{array}{l}\text { Standard } \\
\text { Arrhenius }\end{array}$ & 60.8 & $\begin{array}{l}0.007[\mathrm{~m} / \mathrm{K} / \mathrm{s}] \text { for } \\
\text { cake and } 0.007 \\
{[\mathrm{~m} / \mathrm{K} / \mathrm{s}] \text { for wall }}\end{array}$ & $253-408$ & $61-112$ & & $\begin{array}{c}\text { Activation Energy and } \\
\text { frequency factors estimated } \\
\text { using a 2-D CPF/SCR-F high } \\
\text { fidelity model developed at } \\
\text { MTU }\end{array}$ \\
\hline [7] & $\begin{array}{l}\text { Raghavan } \\
\text { et. al. }\end{array}$ & $\begin{array}{l}\text { Standard } \\
\text { Arrhenius }\end{array}$ & 87.5 & $8.15\left[10^{6} / \mathrm{s}\right]$ & $302-389$ & $330-1013$ & \multirow{2}{*}{$\begin{array}{l}\text { PM produced by a } 2013 \text { Cummins ISB } 2013280 \\
\text { hp engine and oxidized in a production CPF }\end{array}$} & $\begin{array}{c}\text { Aftreatment Configuration: } \\
\text { DOC-CPF-SCR }\end{array}$ \\
\hline [4] & $\begin{array}{l}\text { Raghavan } \\
\text { et. al. }\end{array}$ & $\begin{array}{l}\text { Modified } \\
\text { Arrhenius }\end{array}$ & 89 & $\begin{array}{c}15.2 * 10^{-3} \\
{[1 / \mathrm{K} / \mathrm{ppm} / \mathrm{s}]}\end{array}$ & $302-389$ & $330-1013$ & & $\begin{array}{l}\text { Aftreatment Configuration: } \\
\text { DOC-CPF-SCR }\end{array}$ \\
\hline [8] & $\begin{array}{l}\text { Gustafson } \\
\text { et. al. }\end{array}$ & $\begin{array}{l}\text { Standard } \\
\text { Arrhenius }\end{array}$ & 99.2 & $113.7[1 / \mathrm{ppm} / \mathrm{s}]$ & $273-377$ & $117-792$ & \multirow{2}{*}{$\begin{array}{c}\text { PM produced by a } 2013 \text { Cummins ISB } 2013280 \\
\text { hp engine and oxidized in the SCRF }\end{array}$} & $\begin{array}{l}\text { Aftreatment Configuration: } \\
\text { DOC-SCRF }^{\circledR} \text { w/o urea }\end{array}$ \\
\hline [8] & $\begin{array}{l}\text { Gustafson } \\
\text { et. al. }\end{array}$ & $\begin{array}{l}\text { Standard } \\
\text { Arrhenius }\end{array}$ & 96 & $23.1[1 / \mathrm{ppm} / \mathrm{s}]$ & $273-373$ & $171-821$ & & $\begin{array}{l}\text { Aftreatment Configuration: } \\
\text { DOC-SCRF }{ }^{\circledR} \mathrm{w} / \text { urea }\end{array}$ \\
\hline
\end{tabular}




\subsection{Models for PM Oxidation}

The rate of oxidation of carbonaceous materials or soot can be described using the general kinetic model equation described by Equation 8 [25].

$$
R R_{O}=N_{t} * k(T) * f\left(p_{O_{2}}, p_{N_{2}}, p_{\mathrm{H}_{2} \mathrm{O}}, \ldots \ldots\right)
$$

where,

$\mathrm{RR}_{\mathrm{o}}$ is the reaction rate,

$\mathrm{N}_{\mathrm{t}}$ is the total number of active carbon sites,

$k(T)$ is the temperature dependent reaction rate constant (Equation 6 and 7 in section 2.2),

$f\left(p_{\mathrm{O}_{2}}, p_{\mathrm{NO}_{2}}, p_{\mathrm{H}_{2} \mathrm{O}}, \ldots \ldots\right)$ is a function which describes the dependency of reaction rate on partial pressure of various gas components which is generally linear as reported by references $[18,29]$.

Several different approaches have been followed to determine the total number of active sites $\left(N_{t}\right)$. References $[25,30]$ reports relating $N_{t}$ to an active site concentration and to soot surface as described by Equation 9 [25].

$$
N_{t}=\lambda * S_{a}
$$

where,

$\lambda$ is the surface concentration of active sites,

$\mathrm{S}_{\mathrm{a}}$ is the specific surface area.

The specific surface area $\left(\mathrm{S}_{\mathrm{a}}\right)$ can be expressed as a function of the fraction of the soot oxidized as described by Equation 10 [25].

$$
S_{a}=S_{a, o} *\left(1-\xi_{m}\right)^{n}
$$

Where,

$\mathrm{S}_{\mathrm{a}, \mathrm{o}}$ is the initial specific surface area,

$\xi_{m}$ is the fraction of soot oxidized,

$\mathrm{n}$ is the reaction order in carbon. 
The reactivity of soot with respect to its oxidation has been investigated by many researchers over the years and it has been found that microstructure of the soot particles plays an important role in its oxidation behavior [31]. Many models have been proposed based on the microstructure of soot particles, one of which is the Bhatia and Perlmutter model [32] described by Equation 11. This model is based on growth of pores with random pore size distribution [33]. For low values of $\xi_{m}$ the surface to volume ratio or specific surface area increases with $\xi_{m}$ while at high value of $\xi_{m}$ it decreases. $\psi$ is a structural factor that determines the value of $\xi_{m}$ at which this reversal of trend occurs.

$$
S_{a}=S_{a, o} *\left(1-\xi_{m}\right) * \sqrt{1-\psi * \ln \left(1-\xi_{m}\right)}
$$

Another model known as the shrinking core model [33] assumes soot particles to be dense ideal spheres which implies that surface area shrinks more slowly than the mass of the soot [17]. As the soot particle oxidizes, the specific surface area increases and hence the reaction rate increases. There are contrasting reasons proposed for the increase in surface area with oxidation. Reference [34] reports the reason to be the change in density of the soot particle whereas reference [35] proposes the reason to be the increase in porosity of the soot particle. The shrinking core model is described in Equation 12 and is similar to Equation 11 with $n=-1 / 3$.

$$
S_{a}=S_{a, o} *\left(1-\xi_{m}\right)^{-\frac{1}{3}}
$$

In the shrinking core model, the surface area of soot particle is not proportional to the mass of the particle. Hence, the fresh soot particle has less exposed surface area per unit mass than a particle already reduced by oxidation. For example, overall reactivity of $1 \mathrm{~g}$ of fresh soot is lower than the overall reactivity of same mass of partially oxidized soot. Hence for modeling, the age of different soot populations needs to be tracked along with the mass of the soot remaining, in order to correlate mass of the soot to the reactive surface area. A model based on the shrinking core model that can track each of incoming soot particles in the filter has been developed in this study 
which is discussed in detail in section 4.1. A summary of the published research reporting varying reaction kinetics during PM oxidation in reactor studies is described in the following paragraphs.

Yezerets et al. [17] performed serial temperature programmed oxidation experiments on soot samples in a reactor with $10 \% \mathrm{O}_{2} / \mathrm{He}$ feed gas. They reported a lower activation energy for oxidizing the initial $10-25 \%$ of the soot samples. It was proposed that the increased initial reactivity of soot samples was not because of hydrocarbons adsorbed on the soot particles but due to changes in the properties of particulate matter or due to formation of highly reactive species on the surface of carbon in the soot samples.

Messerer et al. [23] carried out reactor based oxidation experiments at different temperatures on LDV and HDV diesel soot samples with feed gas (150 ppm NO $\mathrm{N}_{2}, 45 \mathrm{ppm} \mathrm{NO}, 10 \% \mathrm{O}_{2}$, and 3\% $\mathrm{H}_{2} \mathrm{O}$ in $\mathrm{N}_{2}$ ). The variation of the reaction rates with the amount of soot oxidized in these experiments is shown in Figure 2.4. They attributed the initial high reactivity and the initial decrease of the rate of soot oxidation to the consumption of the most reactive soot components (adsorbed hydrocarbons, SFG) which account for almost $25 \%$ of the initial soot carbon mass. The linear increase in the reactivity for the region between $25 \%$ to $75 \%$ mass oxidized and non-linear increase in the reactivity for the region approaching $100 \%$ oxidation of the soot samples were explained with increasing surface-to-volume ratio and reactant accessibility using a shrinking core model expression, indicating fairly uniform reactivity and homogeneous chemical structures of the bulk material and the core of soot investigated [23].

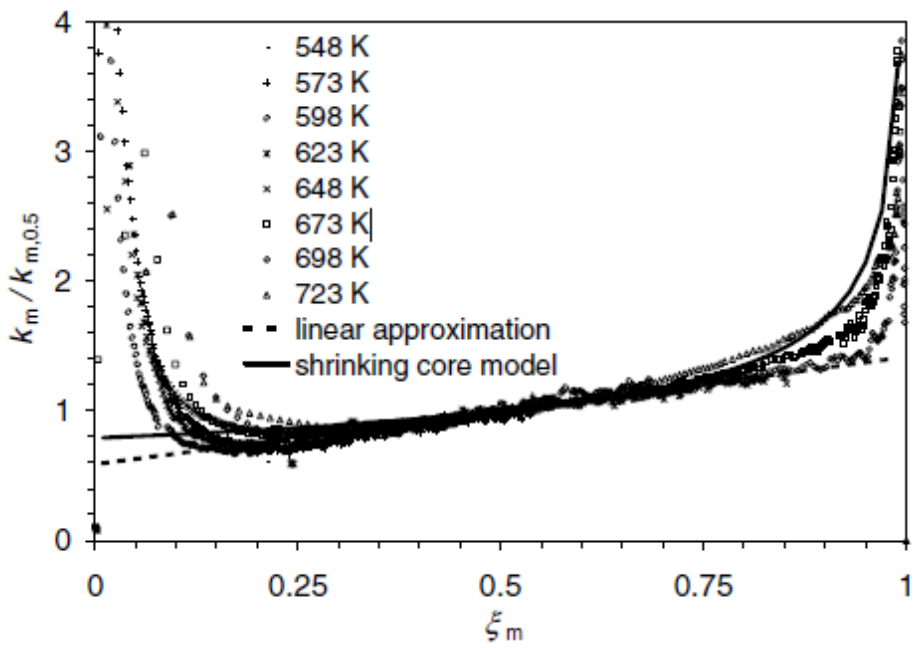

Figure 2.4: Dependence of the Pseudo First Order Rate Coefficient on Carbon Mass Conversion for LDV Soot Oxidation Experiments [23] 
Konstandopoulos et al. [31] performed temperature programmed oxidation experiments by loading the soot samples generated from a common rail $1.9 \mathrm{~L}$ diesel engine, on a catalyst coated filter placed in a reactor. The filter samples were exposed to synthetic exhaust $\left(10 \% \mathrm{O}_{2}\right.$ in $\left.\mathrm{N}_{2}\right)$ at a constant volume flow rate and the temperature was increased from $250^{\circ} \mathrm{C}$ to $700^{\circ} \mathrm{C}$ at a rate of $3^{\circ} \mathrm{C} / \mathrm{min}$. A population model for different classes of soot particles in different states of contact with the catalyst was developed and applied to the experimental data. They reported three activation energies, lower activation energy $(80 \mathrm{~kJ} / \mathrm{gmol}$ ) attributed to adsorbed organics (SOF, SFG) on the soot particles and relatively high activation energy of $120 \mathrm{~kJ} / \mathrm{gmol}$ and $180 \mathrm{~kJ} / \mathrm{gmol}$ corresponding to the shell and core respectively of the soot particles that are assumed to have a core-shell structure [35]. Konstandopoulos et al. [31] also performed isothermal experiments for soot oxidation on a catalyst coated filter. The variation of reactivity of soot particles with fraction of soot oxidized for these experiments is shown in Figure 2.5. The trend observed and its proposed explanation was similar to that reported by reference [23].

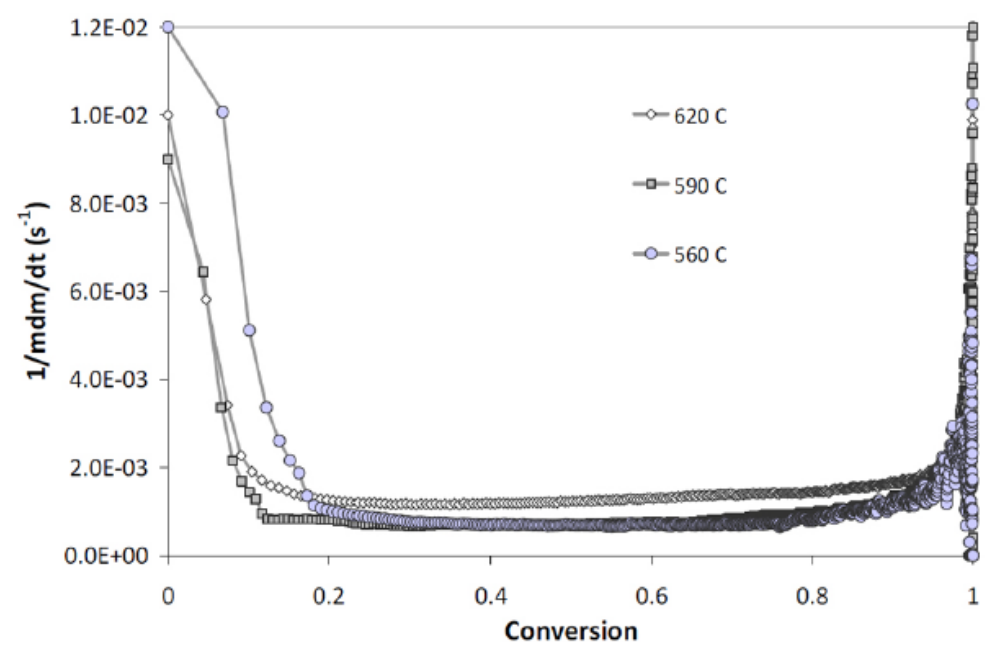

Figure 2.5: Soot Oxidation Rate on Catalyst Coated Filters at Different Temperatures [31] 


\subsection{Loading Studies of CPF and SCR Catalyst on a DPF}

This section discusses the experiments performed by researchers on engine-dyno system with a CPF or SCR catalyst on a DPF to understand the characteristics of PM oxidation at different engine conditions leading to different exhaust flow rates or space velocities, $\mathrm{NO}_{2}$ concentrations and inlet temperatures. A summary of the published research on this is described in the following paragraphs.

Hasan et al. [36] performed experiments on a Cummins ISM 2002 engine at rated speed (2100 RPM) and 20, 40, 60 and 75\% of full load (1120 Nm) with and without a DOC upstream of the CPF to understand the effect of temperature and $\mathrm{NO}_{2}$ concentrations on the PM oxidation in the catalyzed continuously regenerating trap $\left(C C R T^{\circledR}\right)$. The MTU 1-D 2-layer CPF model was improved and calibrated using the experimental data to simulate and compare the evolution of pressure drop across the CPF, PM retained in the CPF and filtration efficiency with time to the experimental data. The model was also used to predict the evolution of cake, wall and channel pressure drop with time as well as the evolution of oxidation rate and PM retained in layer 1, layer 2 and wall in the CPF with time. The contribution of different components to the total pressure drop across the CPF after 5 hours of loading for $20 \%$ and $75 \%$ load test conditions is shown in Figure 2.6. Similarly, the PM oxidized in layer 1, layer 2 and wall in the CPF after 5 hours of loading along with the mechanism for PM oxidation for all the test conditions is shown in Figure 2.7. The percentage of PM oxidized increases with the increase in engine load due to higher temperatures and $\mathrm{NO}_{2}$ concentrations. Also, for higher load (75\%), pressure drop across CPF is lower compared to $20 \%$ load because of higher oxidation rate of PM in the wall as seen in Figure 2.6 and 2.7. Kinetics for PM oxidation in the wall were different from the kinetics for cake layers and did not change with temperature, exhaust flow rate or $\mathrm{NO}_{2}$ concentrations. The same experiments and similar modeling work was performed by Dabhoiwala et al. [37] using the same engine with a different DOC and CPF. The trends in the percentage of PM oxidized and pressure drops was similar to that reported by reference [36]. 


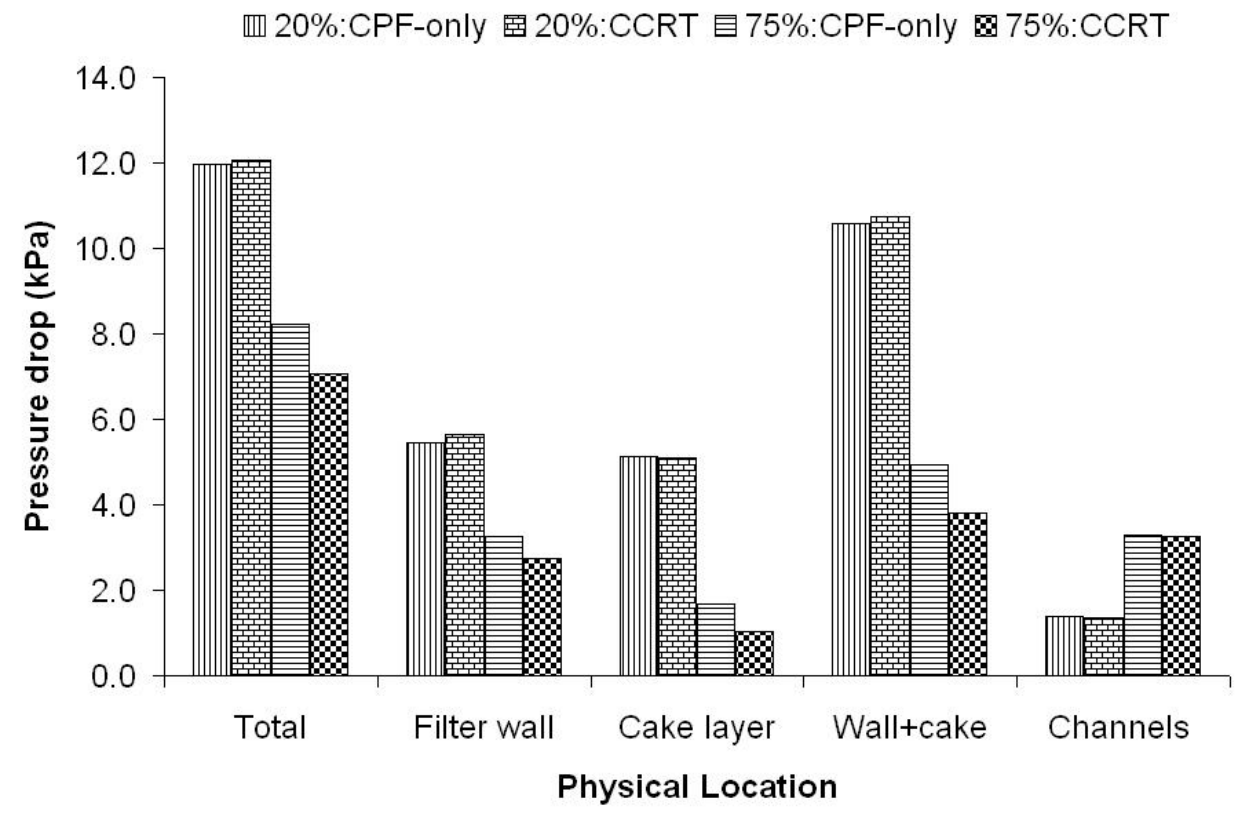

Figure 2.6: Pressure Drop Components After 5 Hours of Loading for 20\% and 75\% Load Test Condition [36]

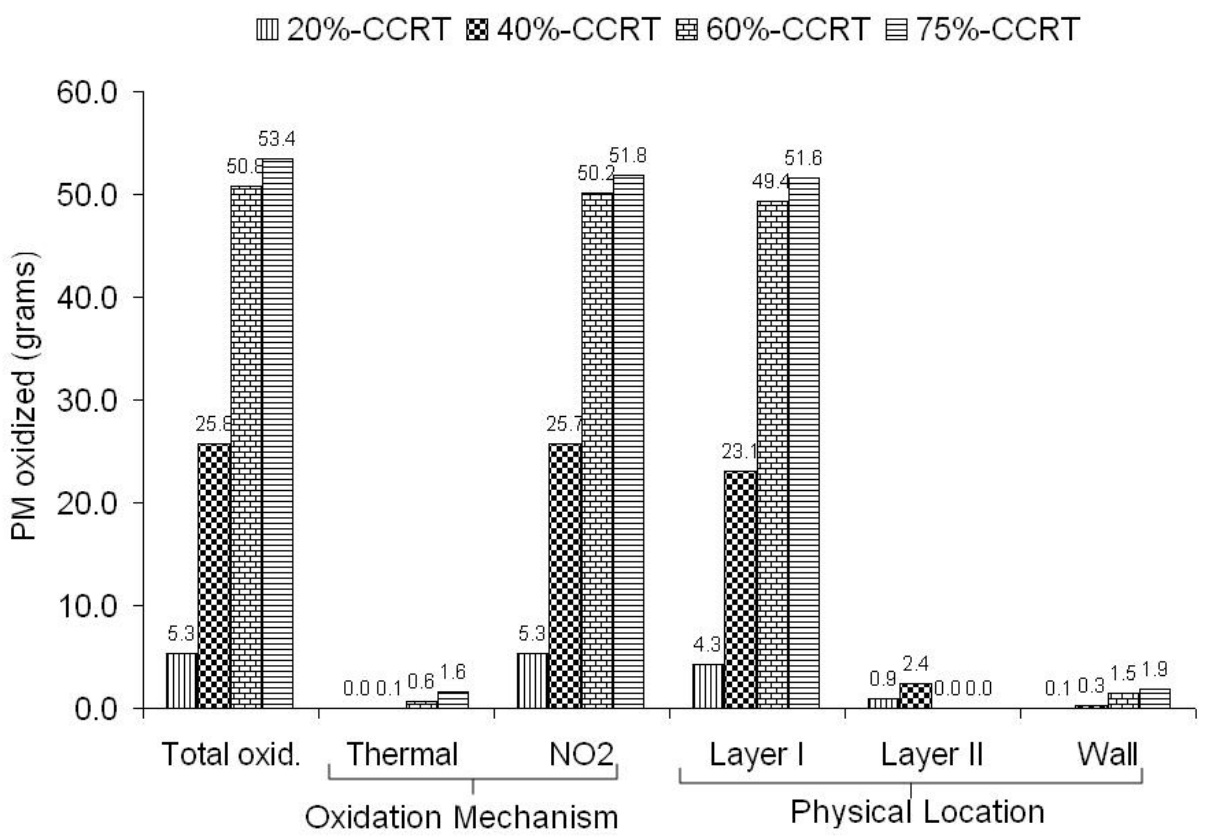

Figure 2.7: Total PM Oxidized After 5 Hours of Loading by Type and Physical Location [36] 
Similar to the experiments performed by Hasan et al. [36] and Dabhoiwala et al. [37], Premchand et al. [38] performed a series of experiments on a 2004 John Deere $6.8 \mathrm{~L}$ engine at two engine speeds ( 2200 RPM and 1650 RPM) at four engine load ranging from $25 \%$ to $100 \%$ of rated torque at the respective engine speeds. The improved MTU 1-D 2-layer CPF model from reference [36] was calibrated using the experimental data for 2200 RPM tests and was used to predict the evolution of cake, wall and channel pressure drop with time as well as the evolution of oxidation rate and PM retained in layer 1, layer 2 and wall in the CPF with time. The PM oxidized in layer 1, layer 2 and wall in the CPF after 8 hours of loading for the $25 \%$ and $100 \%$ CPF and CCRT ${ }^{\circledR}$ test conditions predicted by the model is shown in Figure 2.8. It was observed that the percentage of PM oxidized by the CPF is higher at higher engine loads due to higher temperatures and $\mathrm{NO}_{2}$ concentrations. The PM cake layer is the primary filter in the CPF after it is formed with filtration efficiency higher than $99 \%$. Also, wall filtration efficiency decreases with increasing wall oxidation.

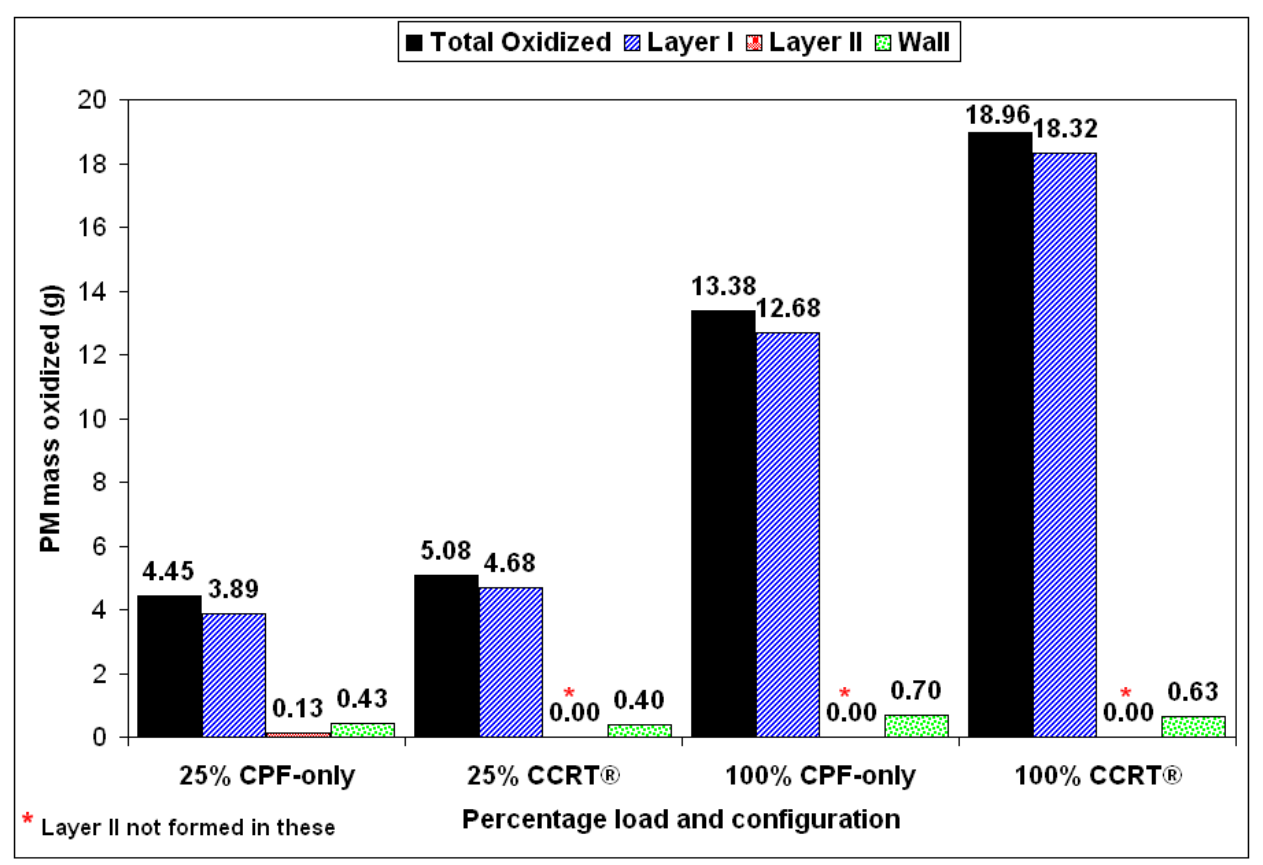

Figure 2.8: Distribution of PM Mass Oxidized by Location at 2200 RPM [38]

Raghavan et al. [4, 7] performed passive oxidation experiments to determine the kinetics of PM oxidation. The experiments consisted of first loading the CPF to a pre-determined amount of PM loading and then oxidizing the PM under selected exhaust conditions, followed by a post oxidation loading stage. A 2013 Cummins ISB 6.7 L engine was used to load $30 \mathrm{~g}$ of PM in the CPF at engine 
condition $2400 \mathrm{RPM}$ and $200 \mathrm{Nm}$ and 30\% reduced fuel rail pressure for 5.5 hours. The passive oxidation conditions had $\mathrm{NO}_{2}$ concentrations ranging from 137 to $1013 \mathrm{ppm}$ and temperatures ranging from 299 to $388^{\circ} \mathrm{C}$. An Arrhenius plot of PM oxidation during the passive oxidation and loading stages is shown in Figure 2.9. As seen from Figure 2.9, the reaction rates during loading (S2) are higher compared to the passive oxidation stage (PO). The authors reported that the higher reaction rates during S2 are due to the oxidation of loosely packed topmost layers of PM cake which is thought to be more readily oxidized under relatively low $\mathrm{NO}_{2}$ concentrations and temperature conditions observed during S2. Also, it was proposed that higher reactivity for S2 could be due to the nature of PM being oxidized being similar to the initially oxidized PM in reference [17] or the order of PM oxidation w.r.t $\mathrm{NO}_{2}$ might be higher during loading conditions as suggested in reference [39].

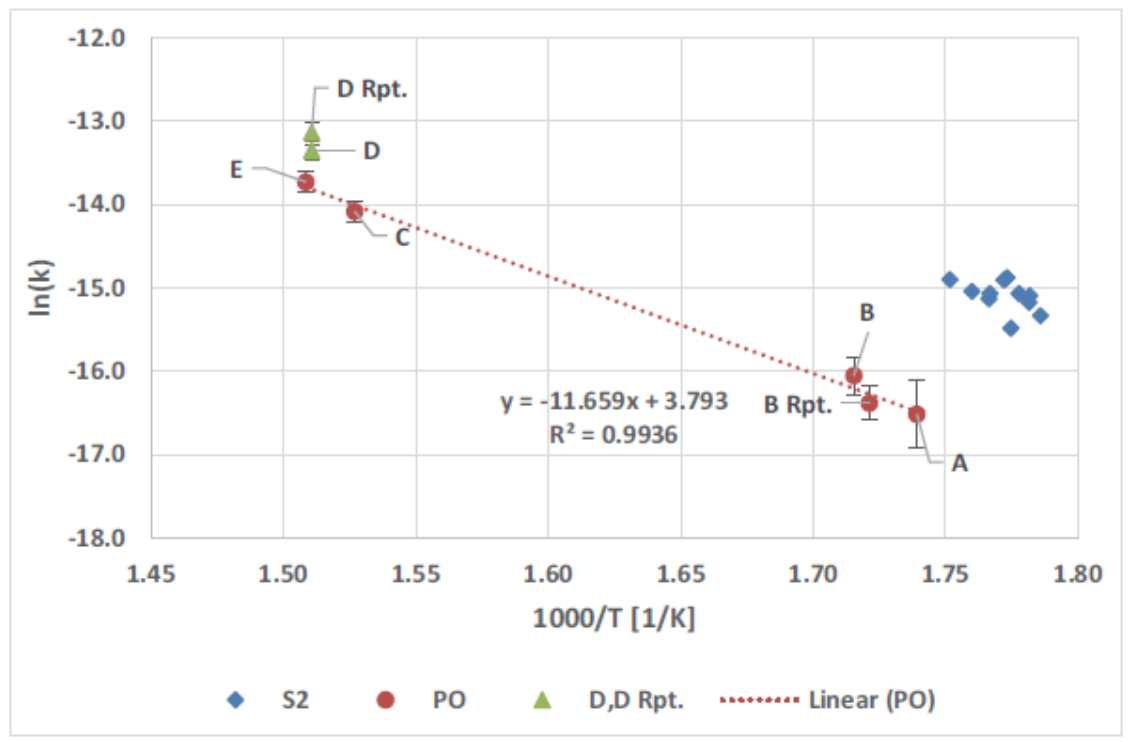

Figure 2.9: Comparison of Kinetics of PM Oxidation During Passive Oxidation and Loading Conditions in CPF [7]

Gustafson et al. [8] performed passive oxidation experiments on a $\mathrm{SCRF}^{\circledR}$ with and without urea injection. The engine, loading condition, passive oxidation conditions and the test procedure were the same as used by reference [4]. An Arrhenius plot showing the comparison of PM oxidation during the passive oxidation and loading stages in $\mathrm{CPF}$ and $\mathrm{SCRF}^{\circledR} \mathrm{w} /$ and $\mathrm{w} / \mathrm{o}$ urea is shown in Figure 2.10. As seen from Figure 2.10, the reaction rates during loading (S2) are higher compared to the passive oxidation stage (PO) for the $\mathrm{SCRF}^{\circledR} \mathrm{w} /$ and $\mathrm{w} / \mathrm{o}$ urea. It was proposed that the lower 
fuel rail pressure used in the loading stages compared to the nominal fuel rail used in the passive oxidation stage might have an influence on the oxidation rates. A similar trend was also observed by reference [4] for the CPF. Also, the reaction rate constant is reported to be $60 \%$ lower with urea injection with the $\mathrm{SCRF}^{\circledR}$.

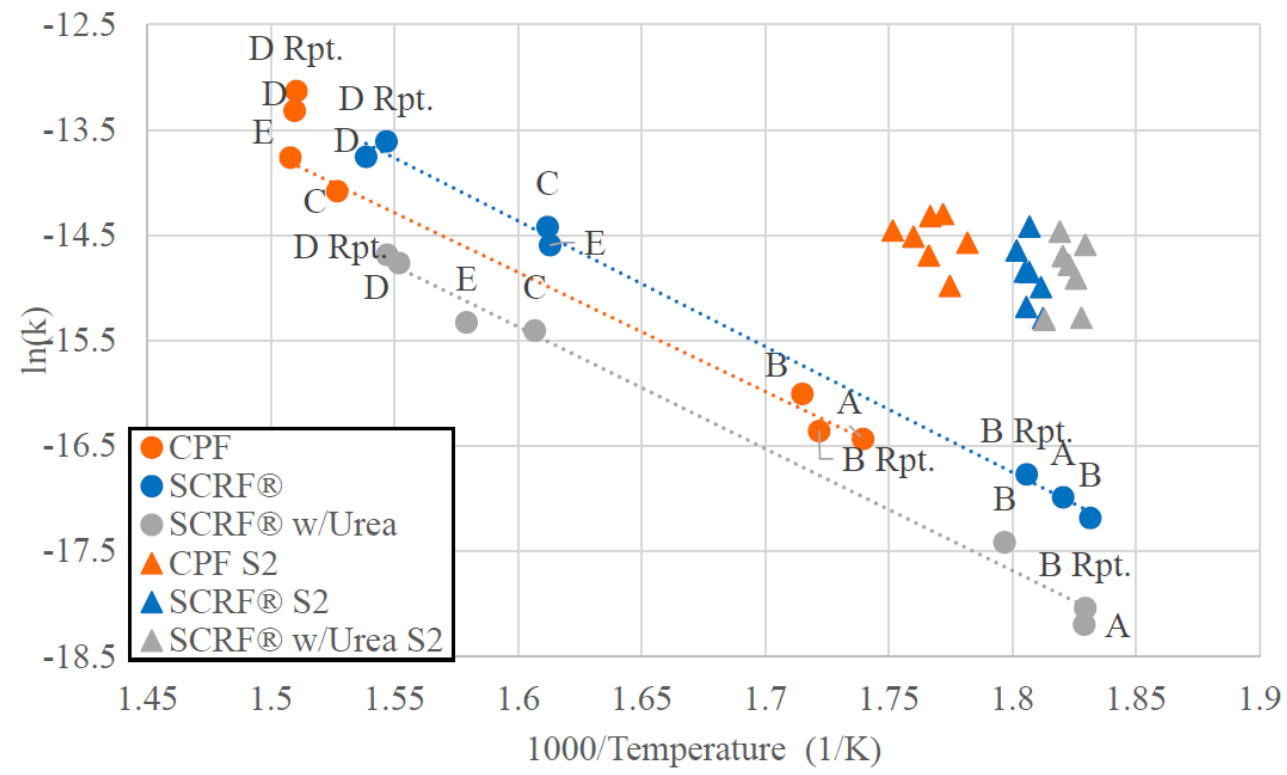

Figure 2.10: Comparison of Kinetics of PM Oxidation During Passive Oxidation and Loading Conditions in CPF, SCRF ${ }^{\circledR}$ With and Without Urea [8]

Based on the modeling work performed by references $[37,38]$ using the 1-D 2 layer CPF model, a decreasing trend of pre-exponential for $\mathrm{NO}_{2}$ assisted $\mathrm{PM}$ oxidation in the cake and wall was observed for a particular value of activation energy, with increasing engine load. Similarly, references $[4,8]$ reported a different set of kinetics for $\mathrm{NO}_{2}$ assisted $\mathrm{PM}$ oxidation during loading and passive oxidation in the $\mathrm{CPF}$ and $\mathrm{SCRF}^{\circledR}$ based on the experimental data. The calibration of the SCR-F model with passive oxidation data without urea for $\mathrm{SCRF}^{\circledR}$ from reference [8] also resulted in a different set of kinetics for PM oxidation during the loading conditions and passive oxidation conditions [40]. This served as a motivation to perform the loading tests on the SCRF ${ }^{\circledR}$ similar to that performed on the CPF by references [36, 37, 38], to understand and characterize the difference in the kinetics for $\mathrm{NO}_{2}$ assisted $\mathrm{PM}$ oxidation during loading and passive oxidation conditions. The experimental data for these loading tests will be used to calibrate and develop a model for PM oxidation based on the shrinking core model, which is capable of simulating the PM 
oxidation during loading and passive oxidation conditions for a single set of kinetics to overcome the limitations of the SCR-F model as it is a lumped model for PM oxidation as explained in the next section.

\subsection{SCR-F Model}

The focus of this section is to understand the development of the SCR-F model for PM filtration and oxidation, pressure drop and the temperature [12]. This provides a better understanding of the parameters to be calibrated in the SCR-F model to simulate the PM oxidation performance in the $\mathrm{SCRF}^{\circledR}$ under loading conditions using the experimental data.

In the SCR-F model, the full volume of $\mathrm{SCRF}^{\circledR}$ is divided into user configurable number of axial and radial zones wherein each zone consists of multiple inlet and outlet channels [21]. The channel geometry for each zone is illustrated by the schematic in Figure 2.11. Each zone consists of the substrate wall, PM cake and empty volume for inlet and outlet channels.

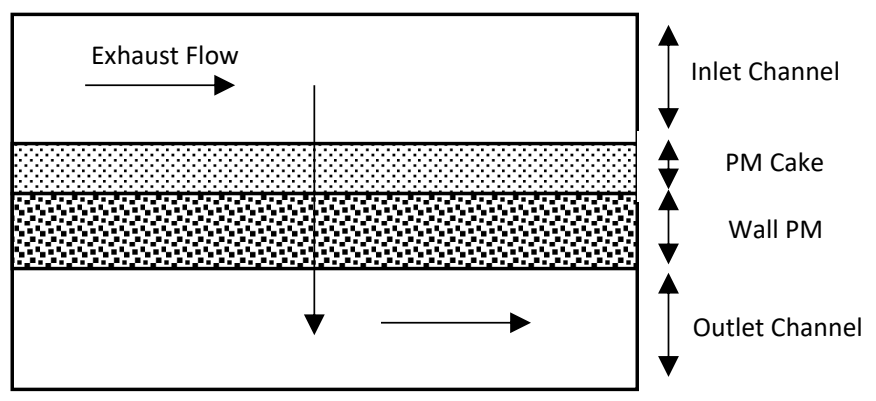

Figure 2.11: Schematic for the Channel Geometry in a Zone in the SCR-F Model

\section{PM Filtration and Oxidation Model}

The SCR-F model takes into account the PM filtration within the substrate wall and cake separately. In each zone, the substrate wall is discretized into four slabs as shown in Figure 2.12 and the PM filtration takes place in a sequence starting from the cake through the four slabs in the wall. 


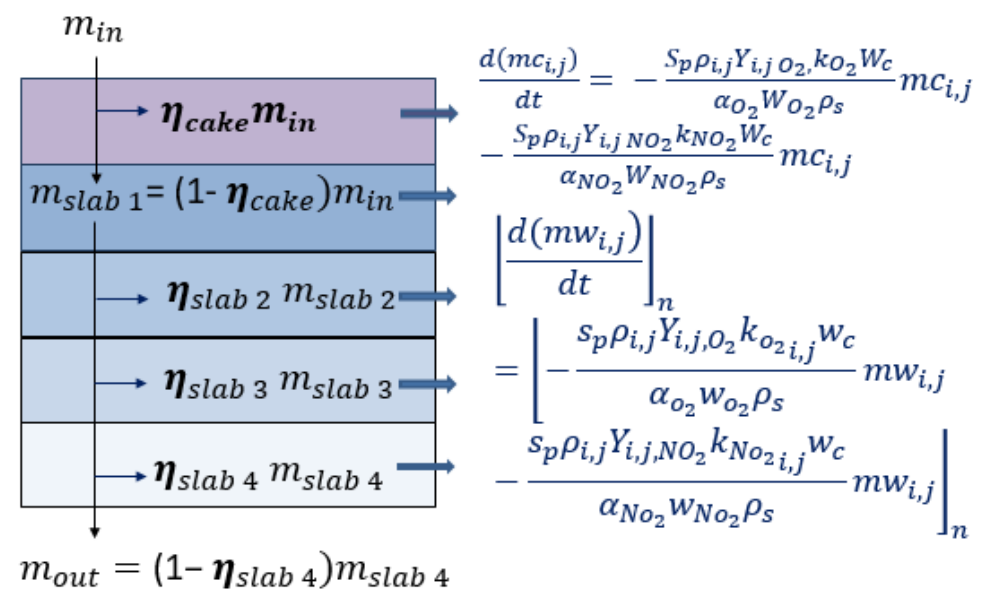

Figure 2.12: Schematic Showing Filtration of PM in the Cake and the Wall [21]

The overall filtration efficiency is calculated using Equation 13 [21].

$$
\eta_{\text {total }, i, j}=1-\left[\left(1-\eta_{\text {cake }, i, j}\right) \prod_{n=1}^{n=4}\left(1-\eta_{\text {wall }, i, j \text { slab } n}\right)\right]
$$

where, $\eta_{c a k e, i, j}$ is the PM cake layer filtration efficiency and $\eta_{\text {wall }, i, j \text { slab } n}$ is the filtration efficiency of each slab in the substrate wall. Details about development of Equation 13 can be found in reference [20].

The PM retained in the cake layer and substrate wall is oxidized by $\mathrm{NO}_{2}$ assisted and thermal oxidation reactions. Equations 14 and 15, used in the SCR-F model, describe the reaction rate for the $\mathrm{NO}_{2}$ assisted oxidation of PM in the cake layer and substrate wall respectively within each zone. Similar equations have been used for the thermal oxidation in the model with a different set of kinetics given in reference [21].

$$
\begin{aligned}
& R R_{N O_{2, \text { cake }}}=\frac{s_{p} * \rho_{i, j} * Y_{i, j, N O_{2}} * A_{\text {cake }} * T_{i, j} * e^{\left(-\frac{E a, N O_{2}}{R_{u} * T_{i, j}}\right)} * W_{C}}{\alpha_{N O_{2}} W_{N O_{2}} \rho_{s}} \\
& R R_{N O_{2, w a l l}}=\frac{s_{p} * \rho_{i, j} * Y_{i, j, N O_{2}} * A_{w a l l} * T_{i, j} * e^{\left(-\frac{E_{a, N O_{2}}}{R_{u} * T_{i, j}}\right)} * W_{C}}{\alpha_{\mathrm{NO}_{2}} W_{N O_{2}} \rho_{s}}
\end{aligned}
$$


where, $\mathrm{s}_{\mathrm{P}}$ is the specific surface area of PM $[1 / \mathrm{m}], \rho_{i, j}$ is the density of gas in each zone $\left[\mathrm{kg} / \mathrm{m}^{3}\right]$, $Y_{i, j, \mathrm{NO}_{2}}$ is the mass fraction of inlet $\mathrm{NO}_{2}$ in each zone, $\mathrm{A}_{\text {cake }}$ is the pre-exponential for PM cake $[\mathrm{m} / \mathrm{K}-\mathrm{s}], \mathrm{A}_{\text {wall }}$ is the pre-exponential for PM in the substrate wall $[\mathrm{m} / \mathrm{K}-\mathrm{s}], T_{i, j}$ is temperature of the filter in each zone $[\mathrm{K}], E_{a, \mathrm{NO}_{2}}$ is the activation energy for $\mathrm{NO}_{2}$ assisted PM oxidation [kJ/gmol], $\mathrm{R}_{\mathrm{u}}$ is the universal gas constant [8.314 J/gmol- $\mathrm{K}], \mathrm{W}_{\mathrm{C}}$ is the molecular weight of carbon $[\mathrm{kg} / \mathrm{kmol}]$, $\alpha_{\mathrm{NO}_{2}}$ is the $\mathrm{NO}_{2}$ oxidation partial factor, $\mathrm{W}_{\mathrm{NO2}}$ is the molecular weight of $\mathrm{NO}_{2}[\mathrm{~kg} / \mathrm{kmol}]$ and $\rho_{\mathrm{S}}$ is the PM density $\left[\mathrm{kg} / \mathrm{m}^{3}\right]$.

\section{Pressure Drop Model}

The pressure drop across the PM cake and wall in each zone has been modeled using Darcy's flow equation. Equations 16 and 17 from reference [21] show the calculation of pressure drop due to PM cake and wall respectively in the SCR-F model.

$$
\begin{aligned}
& \Delta P_{\text {cake }, i, j}=\mu_{i, j} v_{s, i, j} \frac{w_{p, i, j}}{k_{\text {cake }, i, j}} \\
& \Delta P_{\text {wall }, i, j}=\mu_{i, j} v_{w, i, j} \frac{w_{s}}{k_{w a l l, i, j}}
\end{aligned}
$$

where, $\Delta P_{\text {cake }, i, j}$ is the pressure drop due to PM cake at each zone, $\Delta P_{\text {wall,i,j }}$ is the pressure drop due to the substrate wall at each zone, $\mu_{i, j}$ is the dynamic viscosity of the exhaust gas at each zone, $v_{w, i, j}$ is the velocity of gas through the substrate wall at each zone, $v_{s, i, j}$ is the velocity of gas through the PM cake layer at each zone, $w_{s}$ is the substrate wall thickness, $w_{p, i, j}$ is the PM cake layer thickness at each zone, $k_{w a l l, i, j}$ is the wall permeability at each zone and $k_{c a k e, i, j}$ is the PM cake layer permeability at each zone. The detailed formulation of the terms used in Equations 16 and 17 and the formulae used for the channel pressure drop is given in reference [21].

\section{Temperature Model}

The temperature model has been developed based on the resistance node terminology in reference [41]. The model takes into account the energy stored in the filter due to heat conduction along the length of the filter $\left(\dot{Q}_{\text {cond,axial }}\right)$, heat conduction in the radial direction of the 
filter $\left(\dot{Q}_{\text {cond,radial }}\right)$, convection between the filter and the inlet and outlet channel gas $\left(\dot{Q}_{\text {conv } 1}\right.$ and $\left.\dot{Q}_{\text {conv } 2}\right)$, energy released during the oxidation of the PM cake $\left(\dot{Q}_{\text {reac,PM }}\right)$, energy released during oxidation of the $\mathrm{HC}$ in the inlet channel gas $\left(\dot{Q}_{\text {reac }, H C}\right)$, enthalpy transfer by the wall-flow gas $\left(\dot{Q}_{\text {wall-flow }}\right)$ and heat transfer due to radiation exchange between channel surfaces $\left(\dot{Q}_{\text {rad }}\right)$.

Figure 2.13 shows the schematic of the mesh used for the temperature model. The model discretizes each zone into separate control volumes for inlet channels, filter and outlet channels. The energy balance equations are applied for control volume of the inlet and outlet channels and are explained in detail in reference [21].

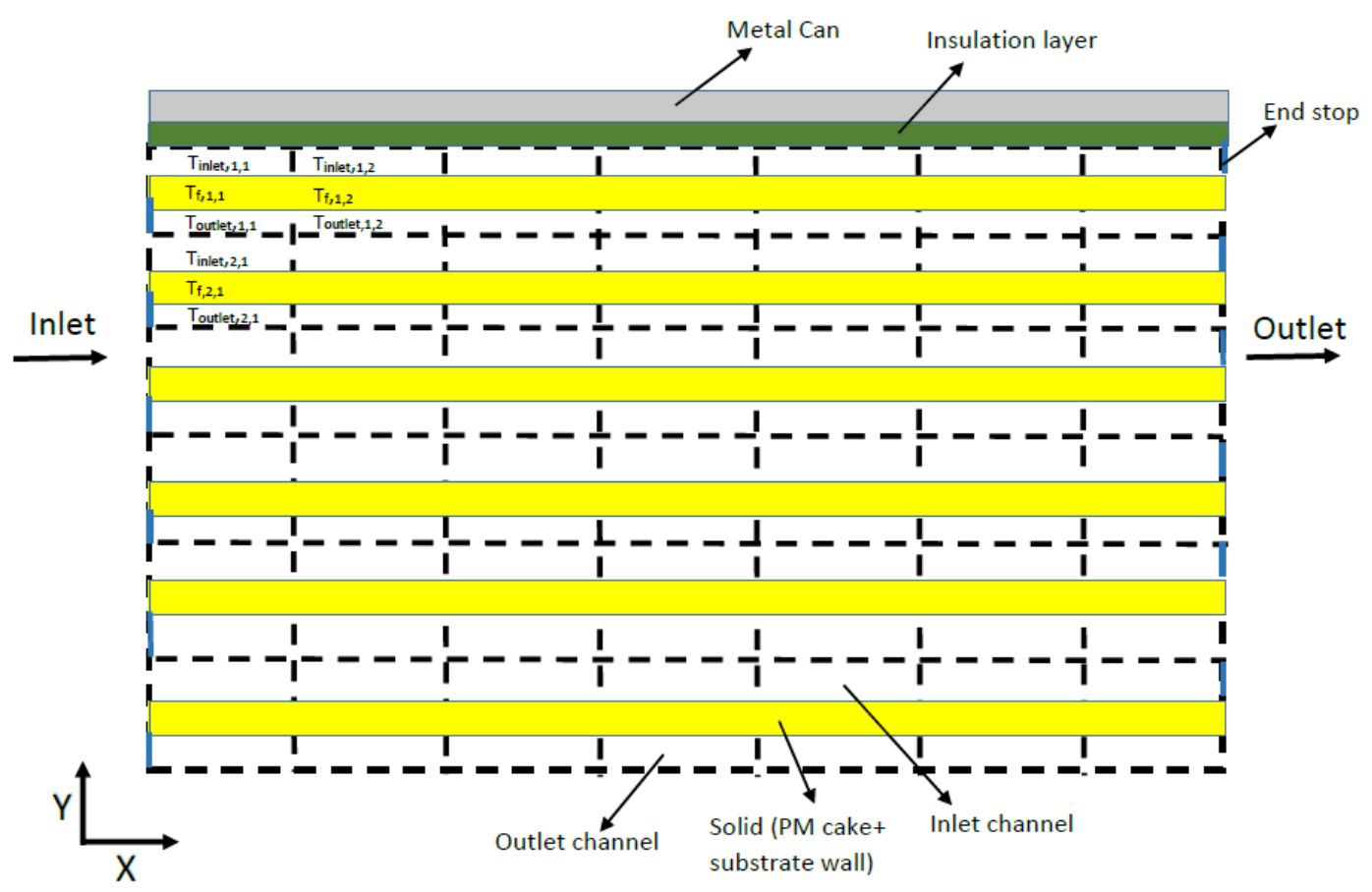

Figure 2.13: Schematic of Temperature Solver Mesh for SCR-F Model [21]

The energy equation for the control volume of filter in each zone is given by Equation 18 which is used to calculated to calculate the temperature of the filter in each zone.

$$
\begin{aligned}
\left(\rho_{s} c_{s} V s_{i, j}+\rho_{f} c_{f} V f_{i, j}\right) \frac{d T_{f, i, j}}{d t}= & \dot{Q}_{c o n d, a x i a l}+\dot{Q}_{c o n d, \text { radial }}+\dot{Q}_{c o n v 1}+\dot{Q}_{c o n v 2}+\dot{Q}_{r e a c, P M}+ \\
& \dot{Q}_{r e a c, H C}+\dot{Q}_{\text {wall-flow }}+\dot{Q}_{\text {rad }}
\end{aligned}
$$


where, $T_{f}$ is the temperature of the filter. Again, the detailed formulae for terms in Equation 18 can be found in reference [21].

The SCR-F model, developed as discussed in the above paragraphs, has been calibrated using experimental data from passive oxidation $\mathrm{w} / \mathrm{o}$ urea and active regeneration tests from reference [8]. The calibrated SCR-F model along with the PM oxidation model (Section 4.1) was used to model the PM retained, pressure drop and temperature distribution in the $\mathrm{SCRF}^{\circledR}$ for loading conditions in this study and compared to the experimental data which is discussed in detail in Section 5.4. 


\section{Chapter 3. Experimental Setup, Instrumentation and Test Procedures}

This chapter focuses on the overall layout of the test cell, specifications of the aftertreatment components and instruments used for testing. It also provides a detailed description of the test procedures and the test matrix used for the experimental tests. A brief description of the test cell layout along with the sensors and components used is given in the next section. A detailed description of the engine, dynamometer and aftertreatment components is given in the subsequent sections. The chapter ends with a discussion of the test procedures and the test matrix for the Loading Tests along with the terms and equations used for the analysis of the data obtained from these tests.

\subsection{Engine Test Cell Setup}

This section discusses the layout of the engine, aftertreatment system (DOC and $\mathrm{SCRF}^{\circledR}$ ), instrumented sensors and the sampling locations within the test setup. The schematic layout of engine test cell is shown in Figure 3.1.

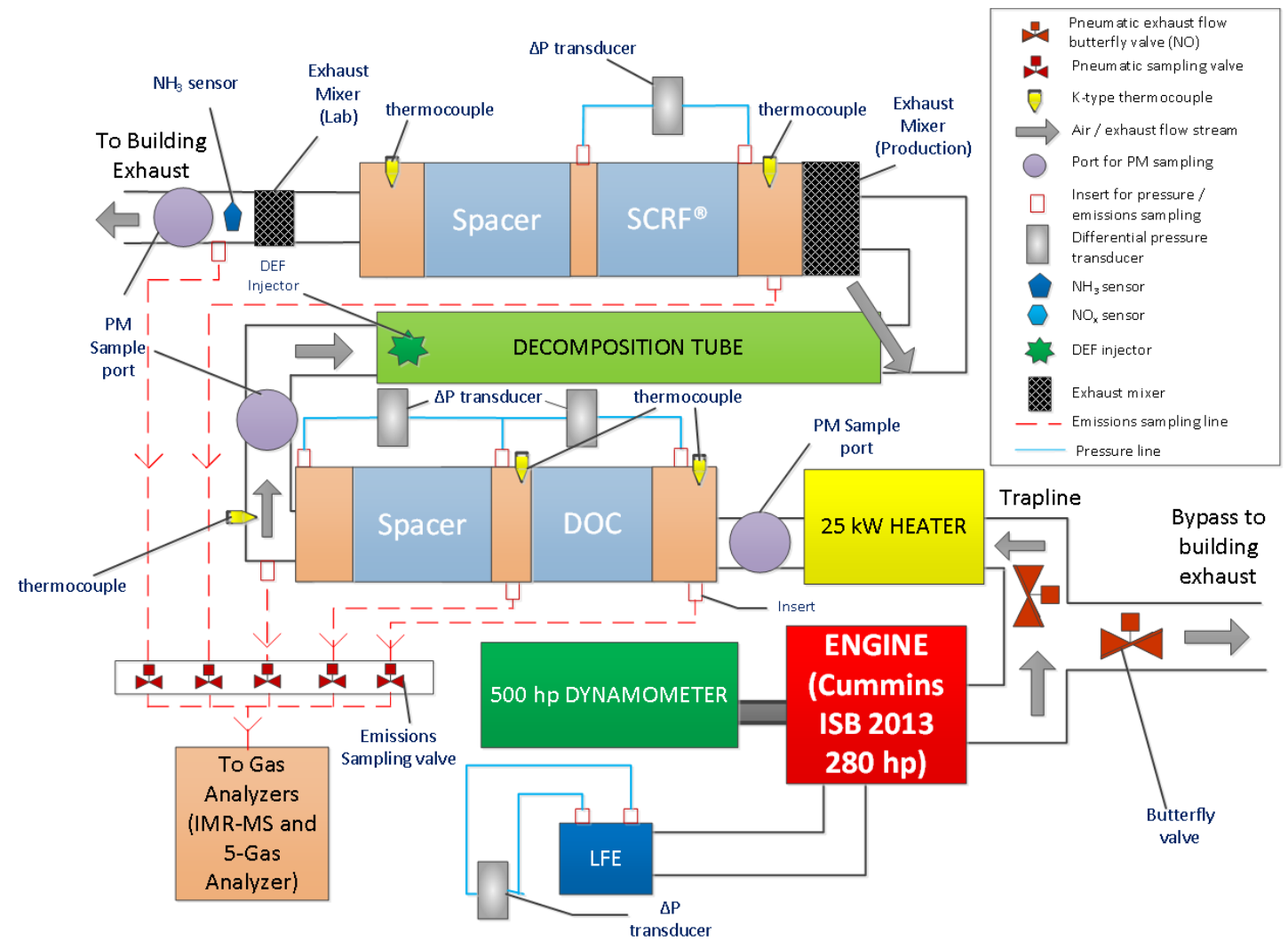

Figure 3.1: Schematic Layout of the Engine Test Cell Setup [4] 
Fuel used in the engine is pumped from the fuel shed into the smaller day tank which periodically gets filled as fuel is consumed. The fuel then flows through a Coriolis flow meter which measures the rate of fuel flow. After passing through the Coriolis flow meter, it is cooled by the building water supply in a tube heat exchanger. It is then supplied to the engine after passing it through a four-micron filter and fuel water separator. The ventilation system for the test cell provides fresh air to the engine air filter which then flows through the Laminar Flow Element (LFE). The pressure drop across the LFE has been calibrated for the mass flow rate of air entering the engine using mathematical relations supplied by the manufacturer.

The exhaust from the engine flows downstream through a 4-inch diameter exhaust pipe, from where it can be directed either into the trap line, which leads through the aftertreatment system before exiting to the building exhaust, or directly through the bypass line to the building exhaust. Opening or closing the pneumatic butterfly valve corresponding to the trap line or bypass line allows us to switch the path of the exhaust flow. In the trap line, the exhaust gas flows through a $25 \mathrm{~kW}$ production heater which can be used to raise the temperature of the gas entering the aftertreatment system in a controlled manner without changing the engine conditions. After passing through the heater, the exhaust flows through the $\mathrm{DOC}$ which oxidizes $\mathrm{NO}$ into $\mathrm{NO}_{2}, \mathrm{CO}$ into $\mathrm{CO}_{2}$ and $\mathrm{HC}$ into $\mathrm{CO}_{2}$ and $\mathrm{H}_{2} \mathrm{O}$. The exhaust then flows through the decomposition tube where the DEF solution, consisting of deionized water and urea, can be injected into the decomposition tube. After this, the exhaust gas flows through a mixer to allow the DEF decomposition products/droplets and the exhaust gas to form a homogeneous mixture. The exhaust gas then flows through the $\mathrm{SCRF}^{\circledR}$ which is a wall flow device that has dual functionality of filtering the PM as well as reducing $\mathrm{NO}_{\mathrm{x}}$. After the exhaust flows through the $\mathrm{SCRF}^{\oplus}$, it goes through a mixer before exiting to the building exhaust.

\subsection{Engine and Dynamometer Specifications}

A Cummins ISB 2013 heavy duty diesel engine was used for this study. A proprietary ECM software called Calterm III was supplied by Cummins along with the engine to monitor and log data from various sensors mounted on the engine and aftertreatment system. This software was also used to control important engine and aftertreatment parameters like enabling manual control of urea injection and deciding the flow rate of urea injection, or manually controlling the fuel rail injection pressure etc. The specifications of the engine are listed in Table 3.1. 
Table 3.1: Specifications of the Engine

\begin{tabular}{|l|l|}
\hline Model & Cummins ISB Heavy Duty \\
\hline Year of Manufacture & 2013 \\
\hline Cylinders & 6, Inline \\
\hline Bore x Stroke & $107 \times 124 \mathrm{~mm}$ \\
\hline Displacement & $6.7 \mathrm{~L}\left(409 \mathrm{in}^{3}\right)$ \\
\hline Rated Speed and Power & $2400 \mathrm{RPM}$ and $208 \mathrm{~kW}$ \\
\hline Peak Torque & $895 \mathrm{Nm} @ 1600 \mathrm{RPM}$ \\
\hline Fuel System & Direct Injection (Common Rail) \\
\hline Aspiration & Variable Geometry Turbocharger (VGT) \\
\hline EGR System & Electronically Controlled and Cooled \\
\hline
\end{tabular}

An eddy current dynamometer was used to control the speed and the load on the engine. The dynamometer was controlled by a Digalog Model 1022A controller with two modes of operation - Constant Speed and Constant Load. The Constant Speed mode was used for all the tests while using the throttle to control the load on the engine. The specifications for the dynamometer are listed in Table 3.2.

Table 3.2: Specifications of the Dynamometer

\begin{tabular}{|l|l|}
\hline Manufacturer & Dynamatic \\
\hline Model & DM8121HS \\
\hline Type & Eddy Current \\
\hline Construction & Wet Gap \\
\hline Controller & Digalog Model 1022A \\
\hline Load Cell & BLH Electronics U3G1C \\
\hline Oiling & Constant Oiling Leveler \\
\hline Maximum Torque & 1501 ft-lbs at 1750 RPM \\
\hline Constant Power & 500 hp from 1750-7000 RPM \\
\hline
\end{tabular}

\subsection{Fuel Properties}

The properties for the ultra-low sulfur diesel (USLD) used in the experimental tests for this study are listed in Table 3.3. The same blend of fuel was used throughout testing as it was stored and consumed from a local fuel storage facility. 
Table 3.3: Fuel Properties

\begin{tabular}{|c|c|}
\hline Fuel Type & ULSD-2 \\
\hline API. Gravity at $15.6{ }^{\circ} \mathrm{C}$ & 35.4 \\
\hline SP. Gravity at $15.6{ }^{\circ} \mathrm{C}$ & 0.848 \\
\hline Viscosity at $40^{\circ} \mathrm{C}$ & 2.999 \\
\hline Total Sulfur (ppm) & 7 \\
\hline Initial Boiling Point $\left({ }^{\circ} \mathrm{C}\right)$ & 184 \\
\hline Final Boiling Point $\left({ }^{\circ} \mathrm{C}\right)$ & 363 \\
\hline Cetane Index & 48.7 \\
\hline Water Content (ppm) & 34 \\
\hline Higher Heating Value $^{1}(\mathrm{MJ} / \mathrm{kg})$ & 45.68 \\
\hline Lower Heating Value ${ }^{1}(\mathrm{MJ} / \mathrm{kg})$ & 42.89 \\
\hline $\mathrm{H} / \mathrm{C}^{2}$ & 1.833 \\
\hline
\end{tabular}

\subsection{Aftertreatment System}

The aftertreatment system used in this study consists of a Diesel Oxidation Catalyst (DOC) and $\mathrm{SCRF}^{\circledast}$ (SCR catalyst on a DPF) from Cummins, Johnson Matthey and Corning. The DOC is a flow through device capable of oxidizing $\mathrm{CO}, \mathrm{NO}$ and $\mathrm{HC}$ in the engine exhaust. The $\mathrm{SCRF}^{\circledR}$ is a wall flow device that has dual functionality of filtering the $\mathrm{PM}$ as well as reducing $\mathrm{NO}_{\mathrm{x}}$. The specifications of these components are listed in Table 3.4.

\subsection{Test Cell Instrumentation}

There were several production sensors, non-production sensors and measurement devices that were used for collecting data during the experimental tests. A schematic of these instruments along with the engine and dynamometer is shown in the Figure 3.2. 
Table 3.4: Specification of Substrate

\begin{tabular}{|c|c|c|}
\hline Component & DOC & $\mathrm{SCRF}^{\circledR}$ \\
\hline Material & Cordierite & Cordierite \\
\hline Catalyst & $\mathrm{Pt}$ & Cu-zeolite \\
\hline Diameter (in) & 9 & 10.5 \\
\hline Diameter of Substrate (mm) & 228.6 & 266.7 \\
\hline Length (in) & 4 & 12 \\
\hline Length (mm) & 101.6 & 304.8 \\
\hline Cell Geometry & Square & Square \\
\hline Total Volume (L) & 4.17 & 17.04 \\
\hline Open Volume (L) & 3.5 & 10.2 \\
\hline Cell Density (/in²) & 400 & 200 \\
\hline Cell Width (mil) & 46 & 55 \\
\hline Cell Width $(\mathrm{mm})$ & 1.16 & 1.39 \\
\hline Filtration Area $\left(\mathrm{in}^{2}\right)$ & $\mathrm{N} / \mathrm{A}$ & 11370 \\
\hline Open Frontal Area $\left(\mathrm{in}^{2}\right)$ & 26.92 & 25.9 \\
\hline Channel Wall Thickness (mil) & 4 & 16 \\
\hline Wall Density $\left(\mathrm{g} / \mathrm{cm}^{3}\right)$ & 0.91 & N/A \\
\hline Porosity (\%) & 35 & 50 \\
\hline Mean Pore Size $(\mu \mathrm{m})$ & N/A & 16 \\
\hline Number of Inlet Cells & 25447 & 8659 \\
\hline Actual Open Surface Area $\left(\mathrm{m}^{2}\right)$ & 4.22 & 7.37 \\
\hline Surface Area of Cells $\left(\mathrm{m}^{2}\right)$ & 12.08 & 14.74 \\
\hline Perimeter of Cell (mm) & 4.67 & 5.58 \\
\hline
\end{tabular}

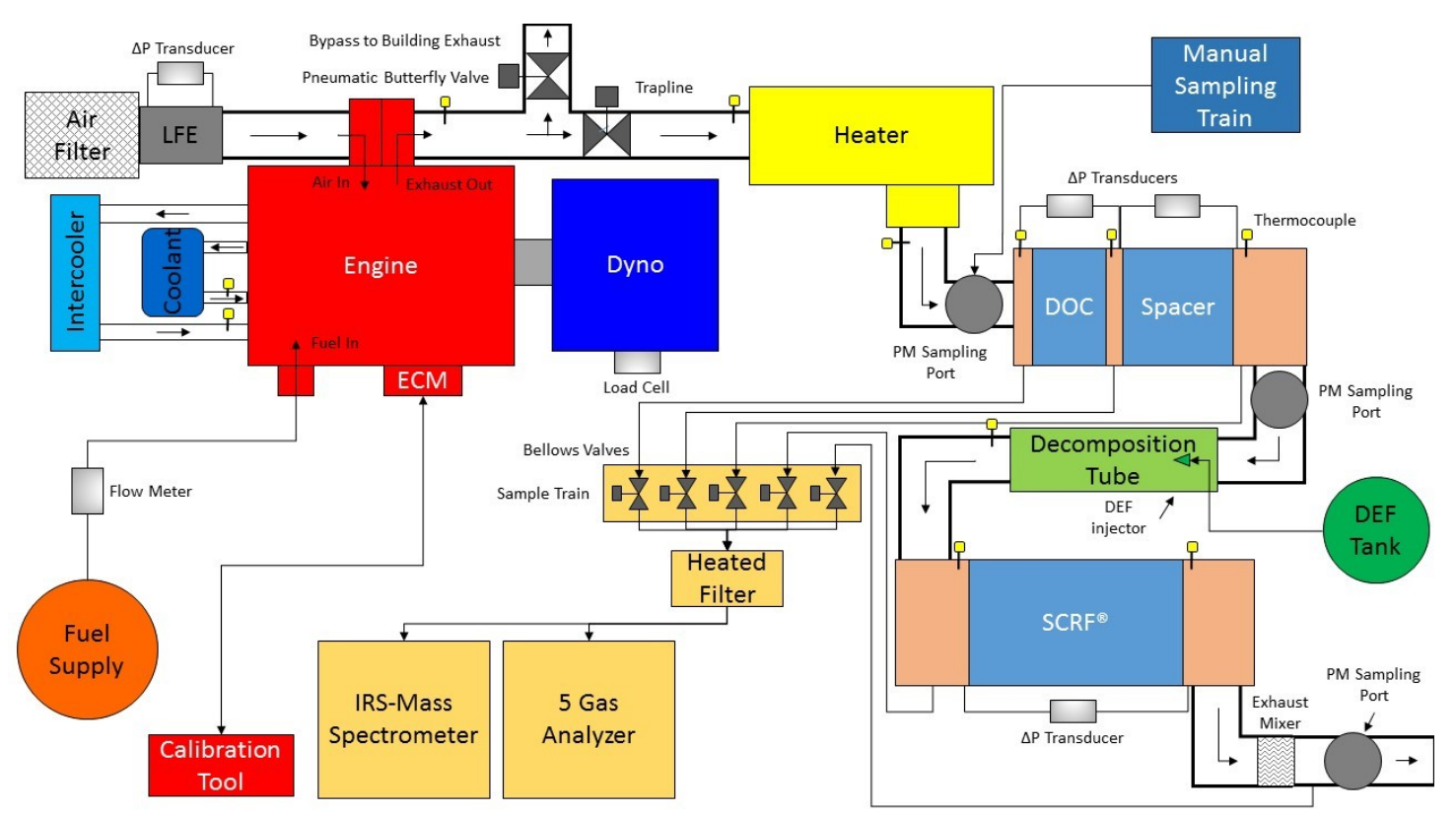

Figure 3.2: Schematic of the Instrumentation in the Test Cell [8] 
The detailed specifications for each of the instruments and devices in the test cell are described in the following paragraphs.

\subsubsection{Laminar Flow Element (LFE)}

A Laminar Flow Element model 50MC2-06F from Meriam Instruments was used to determine the mass flow rate of air entering the intake manifold. This was done by measuring the pressure difference across the orifice using a differential pressure transducer and determining the volumetric air flow rate from the calibrated flow curve provided by the manufacturer which gives the relation between the flow rate in standard cubic feet per minute and differential pressure. The volumetric flow rate was then converted to mass flow rate using the density of air at the standard conditions $\left(25^{\circ} \mathrm{C}\right.$ and $1 \mathrm{~atm}$ pressure).

\subsubsection{Fuel Flow Measurement}

A model CMFS015M319N2BAECZZ Micro Motion Coriolis Meter was used to measure the mass flow rate of fuel as well as the fuel density and temperature. The specifications of this instrument are listed in Table 3.5 .

Table 3.5: Coriolis Meter Specifications

\begin{tabular}{|c|c|c|c|}
\hline Manufacturer & \multicolumn{3}{|c|}{ Micro Motion } \\
\hline Model & \multicolumn{3}{|c|}{ CMFS015M319N2BAECZZ } \\
\hline Measurement & Flowrate & Density & Temperature \\
\hline Accuracy & $\pm 0.10 \%$ & $\pm 0.5 \mathrm{~kg} / \mathrm{m}^{3}$ & $\pm 1^{0} \mathrm{C}$ \\
\hline Repeatability & $\pm 0.05 \%$ & $\pm 0.2 \mathrm{~kg} / \mathrm{m}^{3}$ & $\pm 0.2^{\circ} \mathrm{C}$ \\
\hline
\end{tabular}

\subsubsection{Thermocouples}

K-type thermocouples were used to measure temperatures of the exhaust gas at locations upstream and downstream of the $25 \mathrm{~kW}$ heater, DOC, Spacer, Decomposition Tube, $\mathrm{SCRF}^{\circledR}$ as well as the temperature of the coolant and air intake. Twenty thermocouples, namely S1-S20 were instrumented in the $\mathrm{SCRF}^{\circledR}$ at different axial and radial locations - S1-S10 into the inlet channels and S11-S20 into the outlet channels. The layout of the thermocouples instrumented in the SCRF ${ }^{\circledR}$ is shown in Figure 3.3. The specifications of the thermocouples used are listed in Table 3.6. 
Table 3.6: Thermocouple Specifications

\begin{tabular}{|c|c|c|c|c|}
\hline Manufacturer & \multicolumn{4}{|c|}{ Omega } \\
\hline Part Number & KMQSS-125U-6 & KMQSS-032U-12 & KMQSS-020U-12 & KMQSS-020U-16 \\
\hline Type & $\mathrm{K}$ & $\mathrm{K}$ & $\mathrm{K}$ & $\mathrm{K}$ \\
\hline Length & $6^{\prime \prime}$ & $12^{\prime \prime}$ & $12^{\prime \prime}$ & $0.020^{\prime \prime}$ \\
\hline Diameter & $0.125^{\prime \prime}$ & $0.032^{\prime \prime}$ & $0.020^{\prime \prime}$ & $\pm 2.2^{\circ} \mathrm{C}$ \\
\hline Accuracy & $\pm 2.2^{\circ} \mathrm{C}$ & $\pm 2.2^{\circ} \mathrm{C}$ & $\pm 2.2^{\circ} \mathrm{C}$ & 4 \\
\hline Count & 13 & 3 & 16 & SCRF $^{\circledR} \mathrm{Channel}^{2}$ \\
\hline Location & $\begin{array}{c}\text { Exhaust, Air } \\
\text { Intake, Coolant }\end{array}$ & $\begin{array}{c}\text { Heated Sample } \\
\text { Lines }\end{array}$ & SCRF $^{\circledR} \mathrm{Channel}^{\prime}$ & \\
\hline
\end{tabular}
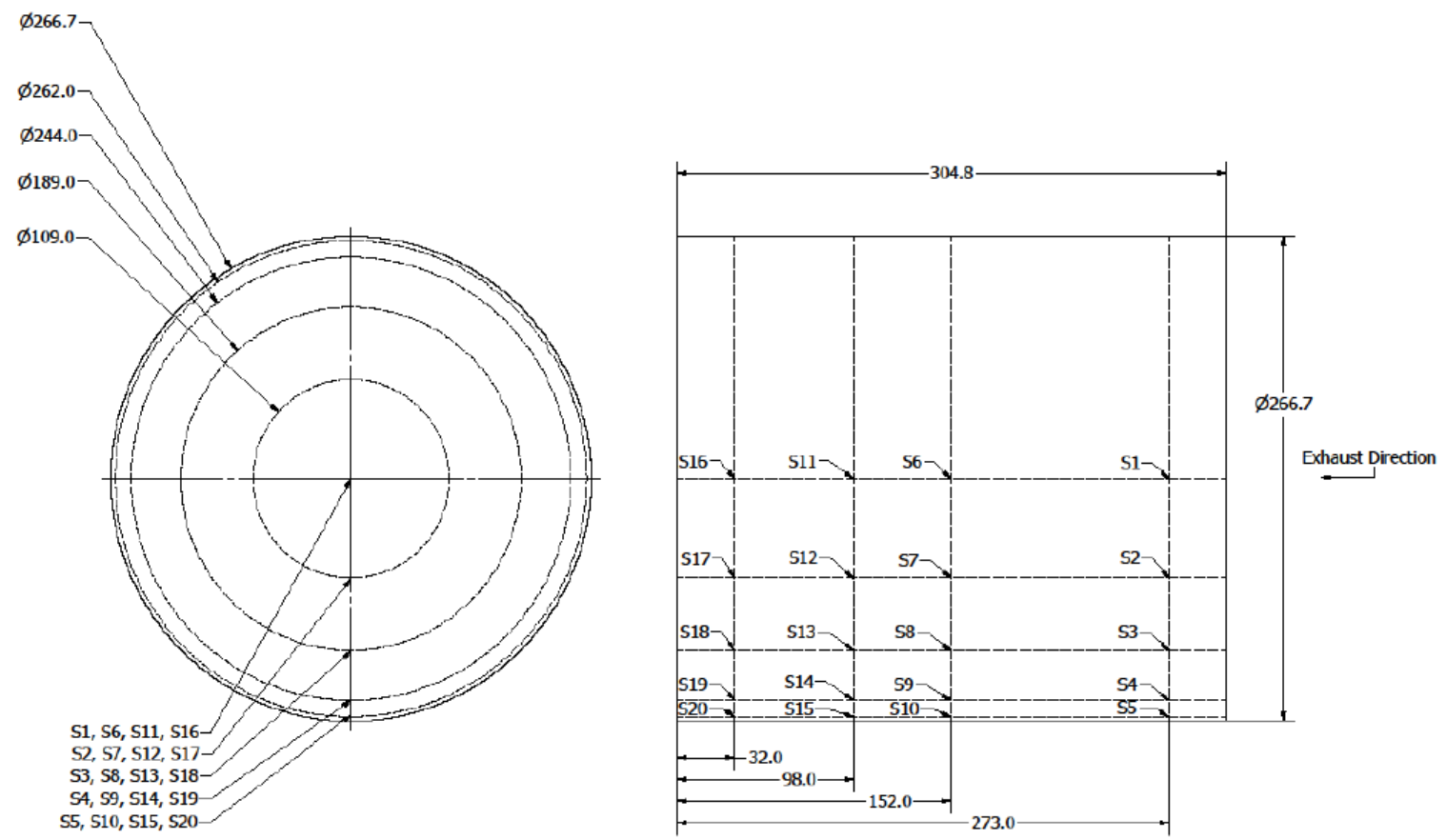

Figure 3.3: $S C R F^{\circledR}$ Thermocouple Layout [9]

\subsubsection{Pressure Transducers}

Pressure Transducers were used to measure pressure drop across the LFE, DOC and SCRF ${ }^{\circledR}$. The specifications of the pressure transducers used are listed in Table 3.7. An OMEGA HX94V Temperature and Pressure Transmitter was also used to take measurements for test cell conditions during the experimental tests. 
Table 3.7: Pressure Transducers Specifications

\begin{tabular}{|c|c|c|c|c|}
\hline Manufacturer & \multicolumn{4}{|c|}{ Omega } \\
\hline Model & PX419-26B5V & $\begin{array}{c}\text { PX429- } \\
\text { 10WDWU10V }\end{array}$ & $\begin{array}{c}\text { PX409- } \\
2.5 \text { DWU5V }\end{array}$ & $\begin{array}{c}\text { PX429- } \\
\text { 5DWU10V }\end{array}$ \\
\hline Type & Absolute & Differential & Differential & Differential \\
\hline Range & $26-32$ in $\mathrm{Hg}$ & $0-10$ in $\mathrm{H}_{2} \mathrm{O}$ & 0-2.5 PSID & 0-5 PSID \\
\hline $\begin{array}{c}\text { Accuracy, Linearity, } \\
\text { Hysteresis, } \\
\text { Repeatability }\end{array}$ & $\pm 0.08 \%$ FS & $\pm 0.08 \% \mathrm{FS}$ & $\pm 0.08 \% \mathrm{FS}$ & $\pm 0.08 \% \mathrm{FS}$ \\
\hline Output Voltage & $0-5$ VDC & $0-10$ VDC & $0-5$ VDC & $0-10$ VDC \\
\hline Measurement & $\begin{array}{c}\text { Barometric } \\
\text { Pressure }\end{array}$ & $\Delta \mathrm{P}$ LFE & $\triangle \mathrm{P} D O C$ & $\triangle \mathrm{P} \mathrm{SCRF}^{\circledR}$ \\
\hline
\end{tabular}

\subsubsection{Data Acquisition System}

Two NI cDAQ-9178 chassis from National Instruments (NI) with different modules were used to collect engine speed, load, pressure, temperature data from different locations in the test cell and control the electro-pneumatic valves in the valvetrain to allow emission sampling at different locations in the aftertreatment system. A NI LabVIEW interface was developed to log and monitor the data from these modules on the desktop computer. The specifications for the different $\mathrm{NI}$ modules are listed in Table 3.8.

A PCAN service tool was used to obtain the data from the engine ECM using CAN communication (J1939 protocol) by connecting it to the desktop computer via USB. Calterm III, the proprietary software from Cummins, was used to log and monitor the engine ECM data and manually control performance parameters like fuel rail pressure, post-combustion fuel dosing, urea dosing, throttle position etc.

Table 3.8: Specification of the Data Acquisition System

\begin{tabular}{|c|c|c|c|c|c|}
\hline Manufacturer & \multicolumn{5}{|c|}{ National Instruments } \\
\hline Module & NI 9205 & NI 9213 & NI 9263 & NI 9239 & NI 9472 \\
\hline Signal Type & Analog Input & Analog Input & $\begin{array}{c}\text { Analog } \\
\text { Output }\end{array}$ & Analog Input & $\begin{array}{c}\text { Digital } \\
\text { Output }\end{array}$ \\
\hline Signal Count & 16 Differential & 16 Differential & 4 & 4 Differential & 8 \\
\hline Quantity & 1 & 4 & 1 & 2 & 1 \\
\hline Rate & $250 \mathrm{kS} / \mathrm{s}$ & $75 \mathrm{~S} / \mathrm{s}$ & $100 \mathrm{kS} / \mathrm{s}$ & $50 \mathrm{kS} / \mathrm{s}$ & $100 \mu \mathrm{s}$ \\
\hline $\begin{array}{c}\text { Maximum } \\
\text { Range }\end{array}$ & $\pm 10 \mathrm{~V}$ & $\pm 78.125 \mathrm{mV}$ & $\pm 10 \mathrm{~V}$ & $\pm 10 \mathrm{~V}-30 \mathrm{~V}$ \\
\hline Accuracy & $6220 \mu \mathrm{V}$ & $38 \mu \mathrm{V}$ & $0.11 \mathrm{~V}$ & 0.019 V & - \\
\hline $\begin{array}{c}\text { Measurement } \\
\text { Pressure }\end{array}$ & $\begin{array}{c}\text { Temperature } \\
\text { (Thermocouple) }\end{array}$ & $\begin{array}{c}\text { Speed } \\
\text { and Load }\end{array}$ & $\begin{array}{c}\text { Speed and Load } \\
\text { Control for } \\
\text { Transients }\end{array}$ & $\begin{array}{c}\text { Valvetrain } \\
\text { Control }\end{array}$ \\
\hline
\end{tabular}




\subsubsection{Particulate Matter (PM) Sampling}

A manual sampling train manufactured by Anderson Instruments Inc. and a dry gas meter were used to measure the concentration of PM in the engine exhaust by hot sampling. Figure 3.4 shows the picture of the manual sampling train and the sampling probe. A/E type glass fiber filters with $47 \mathrm{~mm}$ diameter were used to collect the PM samples by putting the filters in the sampling probe and inserting the sampling probe into the exhaust flow through one of the three sampling ports in the aftertreatment system (Figure 3.1). The manual sampling train is used to draw the sample and measure the duration, temperature, vacuum pressure and the dry gas meter measures the volumetric flow of the exhaust gas sample. The PM concentration is then calculated using these values and the pre and post sampling weights of the glass fiber filter. The detailed information about weighing the glass fiber filter before and after the tests is given in reference [4].

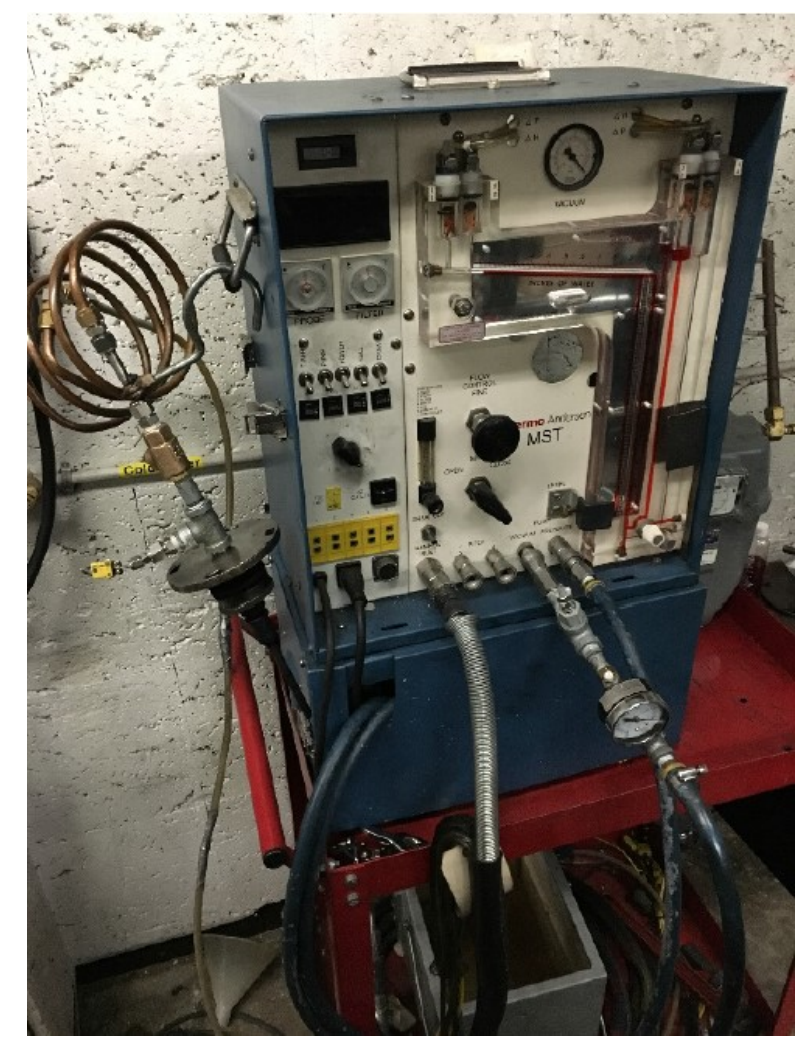

Figure 3.4: Manual Sampling Train, Sampling Probe and Dry Gas Meter [8] 


\subsubsection{Substrate Weighing Scale}

A model Ranger RD35LM weighing scale manufactured by Ohaus was used to weigh the $\mathrm{SCRF}^{\circledR}$ inbetween the stages during the test which is discussed in detail in section 3.6. The specifications of the weighing scale are listed in Table 3.9. The detailed procedure to weigh the $\mathrm{SCRF}^{\circledR}$ is discussed in detail in reference [4]. The PM mass retained during each stage of the test is calculated from the weight of the $\mathrm{SCRF}^{\circledR}$ at the end of each stage which is discussed in detail in section 3.9 .

Table 3.9: Weighing Scale Specifications

\begin{tabular}{|c|c|}
\hline Manufacturer & Ohaus \\
\hline Model & RD35LM \\
\hline Capacity & $35000 \mathrm{~g}$ \\
\hline Certified Readability & $\pm 1.0 \mathrm{~g}$ \\
\hline Readability & $\pm 0.1 \mathrm{~g}$ \\
\hline Linearity & $\pm 0.3 \mathrm{~g}$ \\
\hline
\end{tabular}

\subsubsection{Emission Sampling}

Emission samples were collected and measured at three locations in the aftertreatment system, namely, namely upstream DOC (UDOC), upstream $\mathrm{SCRF}^{\circledR}\left(\mathrm{USCRF}^{\circledR}\right)$ and downstream $\mathrm{SCRF}^{\circledR}$ $\left(\mathrm{DSCRF}^{\circledR}\right)$. The exhaust gas from these locations was allowed to flow through stainless steel sampling lines and a heated filter before being sampled by two different instruments. One of the instruments was an Airsense Ion Molecule Reaction Mass Spectrometer (IMR-MS) from V\&F Instruments Inc. and the other was the AVL AMA-4000 Pierburg Emission Bench. The temperature of the sampling lines and the heated filter was maintained at $190{ }^{\circ} \mathrm{C}$ throughout the test to avoid condensation of water vapor and to minimize adsorption of gaseous emissions on the sampling lines [44].

The Mass Spectrometer was used to measure $\mathrm{NO}, \mathrm{NO}_{2}, \mathrm{NH}_{3}$ and $\mathrm{O}_{2}$ species concentrations in the exhaust at $\mathrm{UDOC}, \mathrm{USCRF}^{\circledR}$ and $\mathrm{DSCRF}^{\circledR}$. The specifications of the Mass Spectrometer are listed in Table 3.10. The detailed procedure to operate and calibrate the Mass Spectrometer is discussed in reference [9]. 
Table 3.10: IRS-MS Specifications

\begin{tabular}{|c|c|}
\hline Manufacturer & V\&F \\
\hline Model & Airsense \\
\hline Accuracy & $< \pm 2 \%$ \\
\hline Mass Range & $0-500 \mathrm{amu}$ \\
\hline Resolution & $<1 \mathrm{amu}$ \\
\hline \multirow{2}{*}{ Lower Detection Limit } & $<1 \mathrm{ppb}$ (benzene in air) \\
\cline { 2 - 2 } & $<10 \mathrm{ppm}$ (benzene in exhaust gas) \\
\hline Drift Concentration & $< \pm 5 \%$ over 12 hours \\
\hline Reproducibility & $< \pm 3 \%$ \\
\hline Max Humidity & $80 \%$ \\
\hline Measurement Type & Wet \\
\hline Analysis Time & $10-6500 \mathrm{msec} / \mathrm{amu}$ \\
\hline Response Time & T90<50 msec \\
\hline
\end{tabular}

The Pierburg emission bench was used to measure concentrations of $\mathrm{NO} / \mathrm{NO}_{x}, \mathrm{THC}, \mathrm{O}_{2}, \mathrm{CO}$ and $\mathrm{CO}_{2}$ in the exhaust. The $\mathrm{NO} / \mathrm{NO}_{\mathrm{x}}$ analyzer was capable of measuring only one species at a time. The $\mathrm{NO}_{2}$ concentrations were estimated by subtracting $\mathrm{NO}$ from the $\mathrm{NO}_{\mathrm{x}}$ concentrations. The specifications of the Pierburg emission bench are listed in Table 3.11. The Pierburg emission bench was not used for some of the initial tests due to issues with its software and touch interface which were resolved later.

Table 3.11: Pierburg Emission Bench Specifications [8]

\begin{tabular}{|c|c|c|c|c|c|}
\hline Manufacturer & \multicolumn{5}{|c|}{ Pierburg } \\
\hline Model & \multicolumn{5}{|c|}{ AMA4000 } \\
\hline Measurement & $\mathrm{O}_{2}$ & $\mathrm{CO}$ & $\mathrm{CO}_{2}$ & $\mathrm{NO}_{\mathrm{x}} / \mathrm{NO}$ & $\mathrm{THC}$ \\
\hline Range & $0-25 \%$ & $0-5000 \mathrm{ppm}$ & $0-20 \%$ & $0-10000 \mathrm{ppm}$ & $0-20000 \mathrm{ppm}$ \\
\hline Detection Limit & $15 \mathrm{ppm}$ & $125 \mathrm{ppb}$ & $15 \mathrm{ppm}$ & $35 \mathrm{ppb}$ & $30 \mathrm{ppb} \mathrm{C_{3 }}$ \\
\hline Accuracy & N/A & N/A & N/A & $\mathrm{N} / \mathrm{A}$ & N/A \\
\hline Repeatability & $\begin{array}{c}\leq 0.5 \% \text { of the } \\
\text { measured } \\
\text { value }+2 x \text { the } \\
\text { detection limit }\end{array}$ & $\begin{array}{c}\leq 0.5 \% \text { of the } \\
\text { measured } \\
\text { value }+2 x \text { the } \\
\text { detection limit }\end{array}$ & $\begin{array}{c}\leq 0.5 \% \text { of the } \\
\text { measured } \\
\text { value }+2 x \text { the } \\
\text { detection limit }\end{array}$ & $\begin{array}{c}\leq 0.3 \% \text { of the } \\
\text { measured } \\
\text { value }+2 x \text { the } \\
\text { detection limit }\end{array}$ & $\begin{array}{c}\leq 0.5 \% \text { of the } \\
\text { measured } \\
\text { value }+2 x \text { the } \\
\text { detection limit }\end{array}$ \\
\hline Noise & $\begin{array}{c}\leq 1.0 \% \text { of the } \\
\text { measured } \\
\text { value }+2 x \text { the } \\
\text { detection limit }\end{array}$ & $\begin{array}{c}\leq 1.0 \% \text { of the } \\
\text { measured } \\
\text { value }+2 x \text { the } \\
\text { detection limit }\end{array}$ & $\begin{array}{c}\leq 1.0 \% \text { of the } \\
\text { measured } \\
\text { value }+2 x \text { the } \\
\text { detection limit }\end{array}$ & $\begin{array}{c}\leq 1.0 \% \text { of the } \\
\text { measured } \\
\text { value }+2 x \text { the } \\
\text { detection limit }\end{array}$ & $\begin{array}{c}\leq 1.0 \% \text { of the } \\
\text { measured } \\
\text { value }+2 x \text { the } \\
\text { detection limit }\end{array}$ \\
\hline Analyzer Type & Paramagnetic & IRD & IRD & CLD & FID \\
\hline $\begin{array}{c}\text { Measurement } \\
\text { Type }\end{array}$ & Dry & Dry & Dry & Wet & Wet \\
\hline
\end{tabular}


The production aftertreatment system had two UniNO ${ }_{x}$ sensors installed, one each at the engine outlet and the $\mathrm{SCR} / \mathrm{SCRF}^{\circledR}$ outlet. The sensor measured $\mathrm{NO}_{x}$ concentrations in the exhaust and displayed and logged the data through Calterm via CAN communication. Each sensor consists of a zirconia based multilayer sensing element by NGK Insulators and a control unit by Continental. A NH${ }_{3}$ sensor from Delphi was also installed at the $\mathrm{SCRF}^{\circledR}$ outlet to measure $\mathrm{NH}_{3}$ slip (Figure 3.1). Data from the $\mathrm{NH}_{3}$ sensor was monitored and logged through LabVIEW interface via CAN communication. The specifications of the sensors are listed in Table 3.12. A picture of the $\mathrm{NO}_{x}$ and $\mathrm{NH}_{3}$ sensor is shown in Figure 3.5 and 3.6 respectively.

Table 3.12: Specifications of $\mathrm{NO}_{x}$ and $\mathrm{NH}_{3}$ Sensors

\begin{tabular}{|c|c|c|c|c|c|}
\hline Component & Range & Resolution & Accuracy & Voltage Range & $\begin{array}{c}\text { Operating } \\
\text { Temperature }\end{array}$ \\
\hline $\mathrm{NO}_{\mathrm{x}}$ Sensor & $0-1500 \mathrm{ppm}$ & $0.1 \mathrm{ppm}$ & $\pm 10 \%$ & $12-32 \mathrm{~V}$ & $100-800^{\circ} \mathrm{C}$ \\
\hline $\mathrm{NH}_{3}$ Sensor & $0-1500 \mathrm{ppm}$ & $0.1 \mathrm{ppm}$ & $\pm 10 \%$ & $13.5-32 \mathrm{~V}$ & $200-500^{\circ} \mathrm{C}$ \\
\hline $\begin{array}{c}\lambda \text { Sensor, } \mathrm{O}_{2} \\
\text { (linear) }\end{array}$ & $12-21 \%$ & $0.10 \%$ & $\pm 0.3- \pm 1.4 \%$ & $24 \mathrm{~V}$ & $100-800^{\circ} \mathrm{C}$ \\
\hline
\end{tabular}

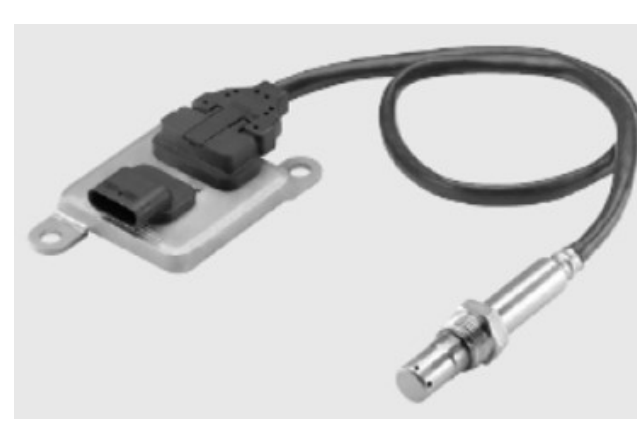

Figure 3.5: Production $\mathrm{NO}_{x}$ Sensor

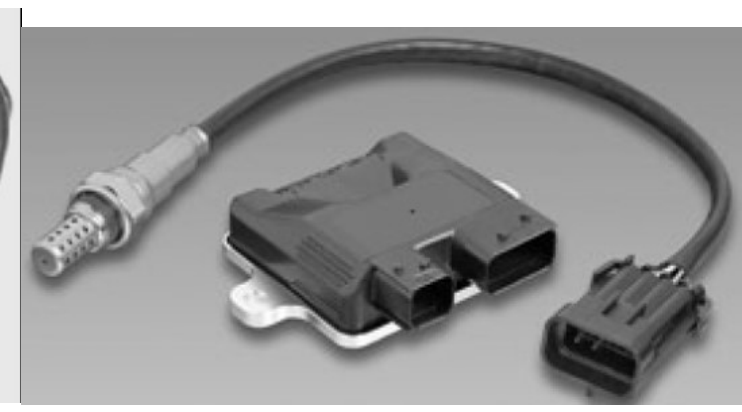

Figure 3.6: Delphi $\mathrm{NH}_{3}$ Sensor

\subsection{Test Procedure}

Primarily, the Loading Tests were designed to determine the $\mathrm{NO}_{2}$ assisted oxidation kinetics for $\mathrm{PM}$ retained in the $\mathrm{SCRF}^{\circledR}$ for different loading conditions with and without urea injection and to characterize the differences in the reaction kinetics in loading and passive oxidation conditions and also to collect data for modeling the $\mathrm{SCRF}^{\circledR}$ pressure drop and $\mathrm{PM}$ mass retained during loading conditions. The test procedures for the Loading Tests were developed by modifying the procedures used in reference [8]. Figure 3.7 shows the schematic of the test procedure followed 
for Loading Tests w/o Urea. Each Loading Test consists of a warmup, cleanout and two loading stages as shown in Figure 3.7. The detailed explanation for each of the stages is given in later paragraphs in this chapter.

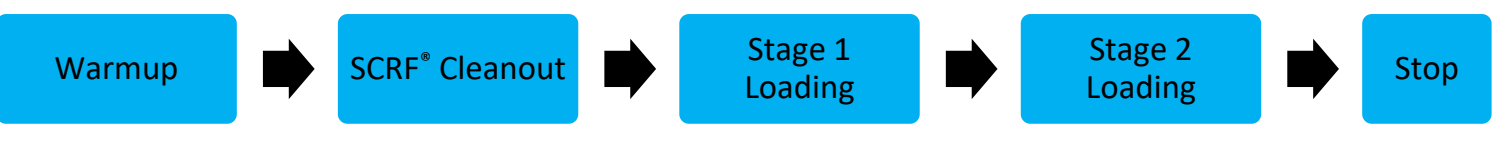

Figure 3.7: Stages of a Loading Test w/o Urea

The test procedure followed for the Loading Test $\mathrm{w} /$ Urea is similar to the procedure followed for the Loading Tests w/o Urea. The only difference between the tests is the injection of DEF at ANR 1.0 during the two loading stages as shown in Figure 3.8. This is done to understand the interaction of $\mathrm{PM}$ oxidation and $\mathrm{NO}_{\mathrm{x}}$ reduction performance in loading conditions with urea injection.

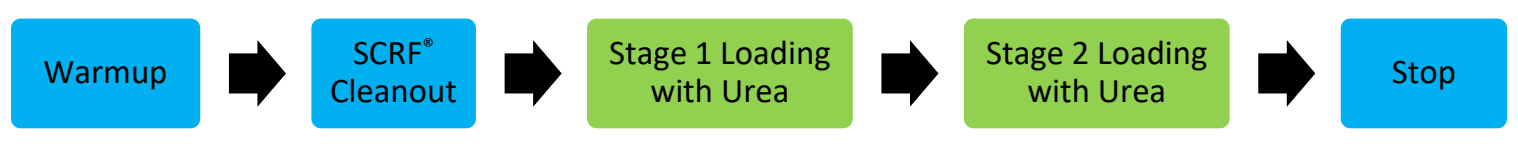

Figure 3.8: Stages of a Loading Test w/ Urea

A plot of pressure drop across $\mathrm{SCRF}^{\circledR}$ is shown in Figure 3.9 and give a graphical representation of the loading profile of a complete Loading Test. When comparing one Loading Test to another, the variable changed are engine speed, engine load and fuel rail pressure which eventually changes the $\mathrm{SCRF}^{\oplus}$ inlet temperature and $\mathrm{PM}$ and $\mathrm{NO}_{2}$ concentrations. 


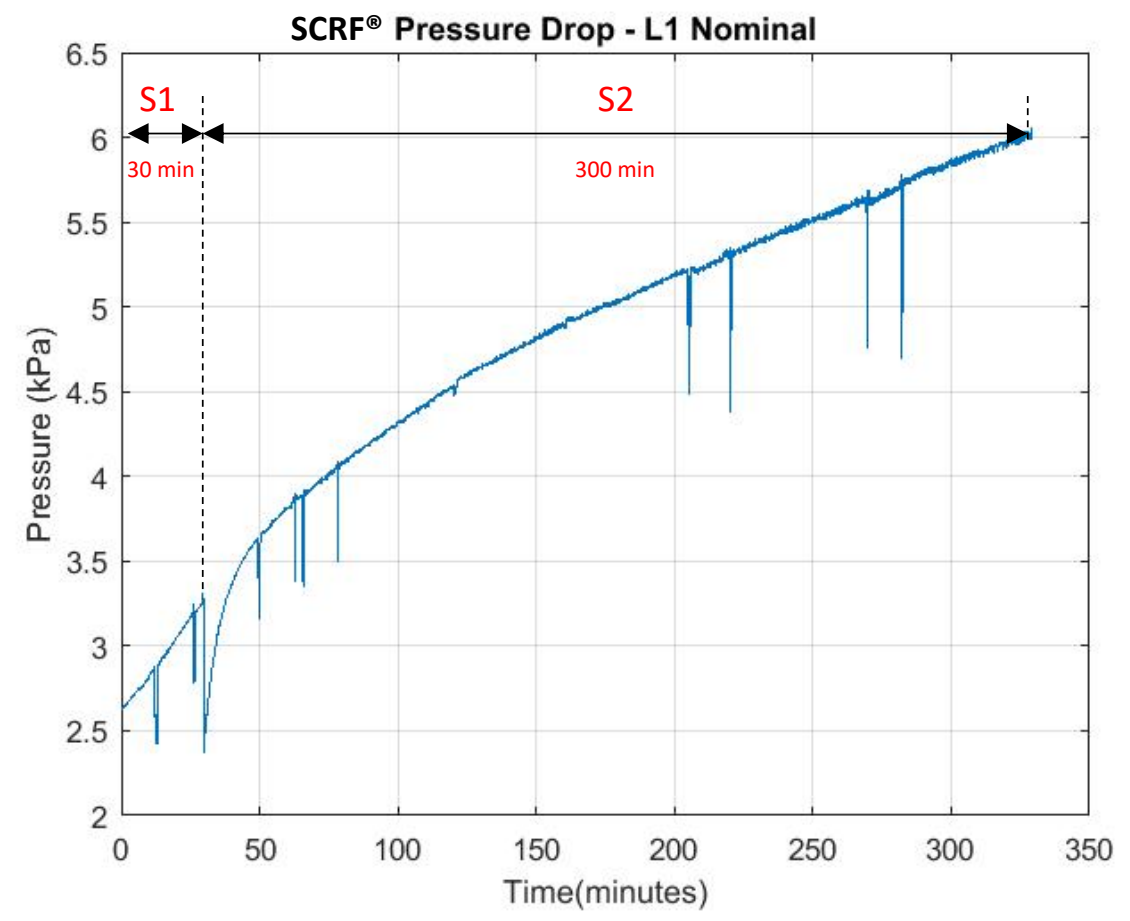

Figure 3.9: SCRF ${ }^{\circledR}$ Pressure Drop vs Time for a Typical Loading Test (Warmup and SCRF ${ }^{\circledR}$ Cleanout Stage Omitted)

\section{Warmup}

In this stage, the engine is run at specific speeds and loads for predetermined time durations as shown in Table 3.13 to allow the oil, coolant and substrate temperature to stabilize at steady state conditions. The Mass Spectrometer is calibrated and other instruments are checked in this stage so that if there are some issues, they can be addressed before starting the next stage. At the end of this stage, the exhaust flow is switched from the bypass line to the trap line to begin the SCRF ${ }^{\circledast}$ Cleanout stage.

Table 3.13: Warmup Stage Engine Conditions

\begin{tabular}{|c|c|c|c|}
\hline Engine Speed & Engine Load & Duration & Condition \\
\hline$[$ RPM] & {$[\mathrm{Nm}]$} & {$[\mathrm{min}]$} & {$[-]$} \\
\hline 750 & 20 & 3 & Idle \\
\hline 1200 & 200 & 5 & Warmup \\
\hline 1660 & 475 & 5 & Baseline \\
\hline
\end{tabular}




\section{$\mathrm{SCRF}^{\circledR}$ Cleanout}

In this stage, the $\mathrm{SCRF}^{\circledR}$ is cleaned out to remove the $\mathrm{PM}$ remaining in the $\mathrm{SCRF}^{\circledR}$ from the previous tests to ensure that we start the Stage 1 Loading with nearly zero PM loading in the SCRF ${ }^{\circledR}$. This is done by running the engine at the baseline condition shown in Table 3.13 and dosing roughly 35$38 \mathrm{mg} / \mathrm{stroke}$ of fuel late in the combustion cycle. The unburnt hydrocarbons from this dosed fuel get oxidized in the DOC which results in an exothermic reaction. As a result, the temperature of the exhaust gas increases to a temperature of around $600{ }^{\circ} \mathrm{C}$. The PM retained in the SCRF ${ }^{\circledR}$ oxidizes completely because of active regeneration at around $600{ }^{\circ} \mathrm{C}$ in $30-45$ minutes depending on the amount of PM retained from the previous tests. The pressure drop across the $\mathrm{SCRF}^{\circledast}$ is observed until it approaches a balance point or where the slope of pressure drop curve becomes zero to ensure that nearly all the $\mathrm{PM}$ loaded in the $\mathrm{SCRF}^{\circledR}$ has been oxidized during this stage. $\mathrm{A}$ balance point is defined as the point at which the rate of PM oxidation is same as the rate of PM loading in the $\mathrm{SCRF}^{\circledR}$. Once the balance point is reached, the fuel dosing is stopped and the exhaust gas temperature is allowed to stabilize for 10-15 minutes before going to the next step.

\section{Stage 1 Loading}

In this stage, the PM produced by the engine is loaded into the $\mathrm{SCRF}^{\circledR}$ by running the engine at the loading condition chosen for that specific test. The details of the engine speed, load, fuel rail

pressure and exhaust flowrate for each of the Loading Tests are given in Section 3.7. In Loading Tests w/ Urea, DEF is injected at target ANR 1.0 during the Stage 1 Loading. The loading conditions corresponding to the specific test is run for 30 minutes. During these 30 minutes, gaseous emission samples are collected and measured by the Mass Spectrometer for 10 minutes each at UDOC, $\mathrm{USCRF}^{\circledR}$ and $\mathrm{DSCRF}^{\circledR}$. A PM sample is also collected at UDOC for 10 minutes using the MST and Gas Flow Meter as described earlier in Section 3.1.6.

At the end of Stage 1, the path of the exhaust flow is switched from the trap line to the bypass line to prevent further loading of $\mathrm{PM}$ in the $\mathrm{SCRF}^{\oplus}$. The engine is then returned to idle conditions for a few minutes before shut down. Once the engine is shut down, the $\mathrm{SCRF}^{\circledR}$ is removed from the aftertreatment system and the temperatures for the thermocouples instrumented inside the $\mathrm{SCRF}^{\oplus}$ are measured manually to ensure that the average of the readings is $235 \pm 30^{\circ} \mathrm{C}$. The $\mathrm{SCRF}^{\circledast}$ 
is then weighed at the same condition without allowing it to cool down further because there is an increase in weight of the $\mathrm{SCRF}^{\circledR}$ as it cools down as observed in reference [45].

\section{Stage 2 Loading}

After weighing the $\mathrm{SCRF}^{\circledast}$ at the end of Stage 1 , the $\mathrm{SCRF}^{\circledast}$ is installed back into the aftertreatment system and the engine is brought back up to the loading condition corresponding to the specific test. The temperatures in the aftertreatment system are allowed to stabilize before switching back the path of the exhaust flow from bypass line to the trap line for the Stage 2 Loading to begin. This warmup procedure takes 5-10 minutes as the aftertreatment components are still at relatively higher temperatures. In Loading Tests w/ Urea, DEF is injected at a target ANR of 1.0 for the entire duration of Stage 2 Loading.

The Stage 2 Loading is run for 300 minutes ( 5 hours) during which gaseous emission samples are collected and measured by the Mass Spectrometer at UDOC, USCRF ${ }^{\oplus}$ and $\mathrm{DSCRF}^{\circledast}$ for 100 minutes each. In some of the tests, 60 minute measurements were made at these locations with the Mass Spectrometer and 40 minutes with the Pierburg emission bench. Five PM samples are taken during Stage 2, out of which four PM samples are taken at UDOC for 10 minutes each and one PM sample is taken at $\mathrm{DSCRF}^{\circledR}$ for 60 minutes. The $\mathrm{PM}$ sample at $\mathrm{DSCRF}^{\circledR}$ is taken following the first two samples at UDOC to equally space out the samples across the duration of Stage 2 . This is done to check if the PM concentrations in the exhaust flow vary as the $\mathrm{SCRF}^{\circledR}$ loads. After 300 minutes, the path of the exhaust flow is switched from the trap line to the bypass line to prevent further loading of $\mathrm{PM}$ in the $\mathrm{SCRF}^{\circledR}$ and the engine is returned to idle before being shut down. The weighing procedure is repeated as followed at the end of Stage 1 Loading.

\subsection{Test Matrix for Loading Tests w/o Urea}

Primarily, the Loading Tests were designed to determine the $\mathrm{NO}_{2}$ assisted oxidation kinetics for $\mathrm{PM}$ retained in the $\mathrm{SCRF}^{\circledast}$ for different loading conditions with and without urea injection and to characterize the differences in the reaction kinetics in loading and passive oxidation conditions. So, while selecting the test points for the Loading Tests, it was important to select engine conditions where more than $90 \%$ of the PM oxidation was $\mathrm{NO}_{2}$ assisted with relatively low $\mathrm{SCRF}^{\circledR}$ inlet temperatures and $\mathrm{NO}_{2}$ concentrations to have a sufficient mass of $\mathrm{SCRF}^{\circledR} \mathrm{PM}$ loading. Figure 
3.10 shows the map of $\mathrm{SCRF}^{\circledR}$ inlet temperatures and $\mathrm{NO}_{2}$ concentrations for the 2007 Cummins ISL engine and aftertreatment system from reference [20]. The blue lines represent lines of constant reaction rates and the ratios on the lines represent the contribution of $\mathrm{NO}_{2}$ to the oxidation of PM. Figure 3.10 also shows the test conditions selected (marked in red) for the Loading Tests keeping the points mentioned above in consideration.

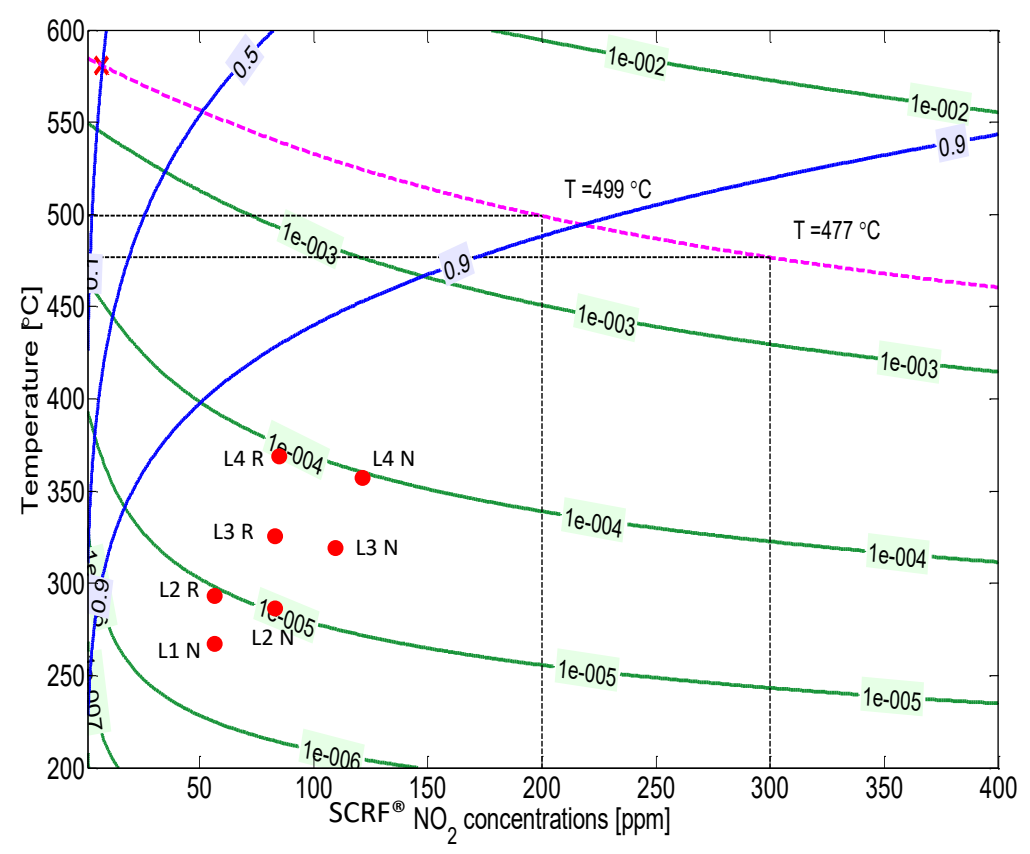

Figure 3.10: Test Conditions for Loading Tests [20]

The test matrix for the Loading Tests w/o Urea is shown in Table 3.14. Table 3.15 shows the emission data for this test matrix obtained by running point validation tests to ensure that the test conditions lie in the region in which $90 \%$ of the $\mathrm{PM}$ oxidation is $\mathrm{NO}_{2}$ assisted as shown in Figure 3.10 and that there is a variation in the PM reaction rate. 
Table 3.14: Test Matrix for Loading Tests w/o Urea

\begin{tabular}{|c|c|c|c|c|c|c|c|}
\hline Test & FRP & Speed & Load & $\begin{array}{c}\text { Exhaust } \\
\text { Flow Rate }\end{array}$ & $\begin{array}{c}\text { Std. Space } \\
\text { Velocity }\end{array}$ & $\begin{array}{c}\text { DOC Inlet } \\
\text { Temp. }\end{array}$ & $\begin{array}{c}\text { SCRF }{ }^{\circledR} \text { Inlet } \\
\text { Temp. }\end{array}$ \\
\hline$[-]$ & {$[$ Bar] } & {$[$ RPM] } & {$[\mathrm{Nm}]$} & {$[\mathrm{kg} / \mathrm{min}]$} & {$[\mathrm{k} / \mathrm{hr}]$} & {$\left[{ }^{\circ} \mathrm{C}\right]$} & {$\left[{ }^{\circ} \mathrm{C}\right]$} \\
\hline L1-Nom & 1500 & 2400 & 203 & 10.9 & 33 & 273 & 270 \\
\hline L1-Red $^{\#}$ & 1050 & 2400 & 200 & 11.2 & 33 & 276 & 273 \\
\hline L2-Nom & 1560 & 2400 & 271 & 11.4 & 34 & 293 & 293 \\
\hline L2-Red & 1092 & 2400 & 271 & 11.5 & 34 & 302 & 297 \\
\hline L3-Nom & 1575 & 2400 & 339 & 11.9 & 36 & 325 & 325 \\
\hline L3-Red & 1103 & 2400 & 339 & 12.0 & 36 & 338 & 332 \\
\hline L4-Nom & 1610 & 2400 & 406 & 12.5 & 37 & 355 & 355 \\
\hline L4-Red & 1127 & 2400 & 406 & 12.5 & 37 & 371 & 364 \\
\hline
\end{tabular}

"Data obtained from Test PO-C in reference [11]

Table 3.15: Emission Data for Loading Tests w/o Urea Obtained by Point Validation Test

\begin{tabular}{|c|c|c|c|c|c|}
\hline Test & $\mathrm{NO}_{2}$ into $\mathrm{DOC}$ & NO into DOC & $\mathrm{NO}_{2}$ into SCRF ${ }^{\circledR}$ & NO into SCRF ${ }^{\circledR}$ & PM Conc. \\
\hline$[-]$ & [ppm] & [ppm] & [ppm] & [ppm] & {$[\mathrm{mg} / \mathrm{scm}]$} \\
\hline L1-Nom & 28 & 200 & 62 & 163 & 7.2 \\
\hline L1-Red" & 22 & 161 & 58 & 128 & 11.5 \\
\hline L2-Nom & 30 & 265 & 86 & 202 & 6.5 \\
\hline L2-Red & 26 & 192 & 64 & 154 & 10.0 \\
\hline L3-Nom & 25 & 305 & 108 & 208 & 5.8 \\
\hline L3-Red & 22 & 226 & 80 & 160 & 9.0 \\
\hline L4-Nom & 15 & 355 & 118 & 240 & 5.3 \\
\hline L4-Red & 13 & 250 & 87 & 172 & 9.8 \\
\hline
\end{tabular}

\#Data obtained from Test PO-C in reference [11]

\subsection{Test Matrix for Loading Tests w/ Urea}

The test matrix for the Loading Tests $w /$ Urea is shown in Table 3.16. Four test conditions from the Loading Tests w/o Urea are being used with urea dosing at ANR 1.0. This is done to determine the effect of urea on $\mathrm{NO}_{2}$ assisted PM oxidation kinetics as well as to understand the interaction of PM oxidation and $\mathrm{NO}_{x}$ reduction with urea injection for the loading conditions. Table 3.17 shows the emission data for this test matrix obtained by running point validation tests. 
Table 3.16: Test Matrix for Loading Tests w/ Urea

\begin{tabular}{|c|c|c|c|c|c|c|c|}
\hline Test & FRP & Speed & Load & $\begin{array}{c}\text { Exhaust } \\
\text { Flow Rate }\end{array}$ & $\begin{array}{c}\text { Std. Space } \\
\text { Velocity }\end{array}$ & $\begin{array}{c}\text { DOC Inlet } \\
\text { Temp }\end{array}$ & $\begin{array}{c}\text { SCRF }^{\circledR} \text { Inlet } \\
\text { Temp. }\end{array}$ \\
\hline$[-]$ & {$[$ Bar] } & {$[$ RPM] } & {$[\mathrm{Nm}]$} & {$[\mathrm{kg} / \mathrm{min}]$} & {$[\mathrm{k} / \mathrm{hr}]$} & {$\left[{ }^{\circ} \mathrm{C}\right]$} & {$\left[{ }^{\circ} \mathrm{C}\right]$} \\
\hline L1-Nom w/ Urea & 1500 & 2400 & 203 & 10.9 & 33 & 273 & 270 \\
\hline L1-Red w/ Urea\# & 1050 & 2400 & 203 & 11.2 & 33 & 276 & 273 \\
\hline L3-Nom w/ Urea & 1575 & 2400 & 339 & 11.9 & 36 & 325 & 325 \\
\hline L3-Red w/ Urea & 1103 & 2400 & 339 & 12.0 & 36 & 338 & 332 \\
\hline
\end{tabular}

"Data obtained from Test PO-C in reference [11]

Table 3.17: Emission Data for Loading Tests w/ Urea Obtained by Point Validation Test

\begin{tabular}{|c|c|c|c|c|c|c|}
\hline Test & ANR & $\mathrm{NO}_{2}$ into $\mathrm{DOC}$ & NO into DOC & $\mathrm{NO}_{2}$ into $\mathrm{SCRF}^{\circledR}$ & NO into SCRF ${ }^{\circledR}$ & PM Conc. \\
\hline$[-]$ & {$[-]$} & [ppm] & [ppm] & [ppm] & [ppm] & [mg/scm] \\
\hline L1-Nom w/ Urea & 1.0 & 28 & 200 & 62 & 163 & 7.2 \\
\hline L1-Red w/ Urea" & 1.0 & 22 & 161 & 58 & 128 & 11.5 \\
\hline L3-Nom w/ Urea & 1.0 & 25 & 305 & 108 & 208 & 5.8 \\
\hline L3-Red w/ Urea & 1.0 & 22 & 226 & 40 & 160 & 9.0 \\
\hline
\end{tabular}

"Data obtained from Test PO-C in reference [11]

\subsection{Equations Used for Analysis of PM Data}

The terms and equations used for the analysis of the experimental data are described in the following paragraphs.

The mass of the PM produced by the engine and entering the $\mathrm{SCRF}^{\circledR}$ is calculated using Equation 19.

$$
m_{\text {in }}=c_{\text {in }} * \frac{\dot{m}_{\text {exhaust }}}{\rho_{\text {Std }}} * \frac{t_{\text {stage }}}{1000}
$$

where, $c_{i n}$ is the average PM concentration in the exhaust at engine out location $[\mathrm{mg} / \mathrm{scm}]$, $\dot{m}_{\text {exhaust }}$ is the mass flow rate of exhaust $[\mathrm{kg} / \mathrm{min}]$ calculated as the sum of the mass air flow rate and fuel flow rate from the laminar flow element and the Coriolis meter respectively and $t_{\text {stage }}$ is the duration of the stage [min].

The mass of the PM filtered out of the $\mathrm{SCRF}^{\circledR}$ is calculated using Equation 20. This includes the PM that was filtered but not oxidized.

$$
m_{\text {out }}=\left(1-\eta_{f}\right) * m_{\text {in }}
$$


where, $\eta_{f}$ is the filtration efficiency of the $\mathrm{SCRF}^{\circledR}$ calculated using Equation 21.

$$
\eta_{f}=\frac{c_{\text {in }}-c_{o u t}}{c_{\text {in }}}
$$

Only one downstream concentration is taken during the test in stage 2 , so an assumption is made that the filtration efficiency remains roughly constant after the cake layer forms. The estimation of Stage 1 filtration efficiency using the calibrated SCR-F model is discussed in Appendix A.

The mass of $\mathrm{PM}$ retained in the $\mathrm{SCRF}^{\circledR}$ at the end of the stage is calculated using Equation 22. PM retained is a cumulative value, meaning the mass of PM at the end of the Stage 2 includes the mass of PM loaded from Stage 1.

$$
m_{\text {retained }}=M_{S}-M_{\text {clean }}
$$

where, $M_{S}$ is the weight measurement of the $\mathrm{SCRF}^{\circledR}$ taken at the end of the stage [g] and $M_{\text {clean }}$ is the clean weight of the $\mathrm{SCRF}^{\circledR}$ at the start of the Stage 1 [g]. The calculation of the clean weight of the $\mathrm{SCRF}^{\circledR}$ is discussed in detail in Appendix A.

The mass of the PM oxidized [g] during the stage is calculated from the overall PM mass balance using Equation 23.

$$
m_{\text {ox }}=m_{\text {start }}+m_{\text {in }}-m_{\text {out }}-m_{\text {retained }}
$$

where, $m_{\text {start }}$ is the mass of the PM in the $\mathrm{SCRF}^{\circledast}$ at the beginning of the stage [g]. The value of $m_{\text {start }}$ for the Stage 1 is zero and for Stage 2 is equal to the $m_{\text {retained }}$ at the end of Stage 1.

The percentage of PM oxidized [\%] during the stage is calculated using Equation 24.

$$
\% m_{o x}=\frac{m_{o x}}{m_{\text {start }}+m_{\text {in }}} * 100
$$


The exhaust flow rate through the $\mathrm{SCRF}^{\oplus}$ can also be expressed in terms of the standard space velocity $[1 / \mathrm{hr}]$ or the reactor volumes per unit time flowed through the $\mathrm{SCRF}^{\circledR}$ as described by Equation 25. A higher space velocity indicates less time spent in the substrate.

$$
S V_{\text {Std }}\left[\frac{1}{\mathrm{hr}}\right]=\frac{\dot{m}_{\text {exhaust }}\left[\frac{\mathrm{kg}}{\mathrm{min}}\right]}{\rho_{\text {Std }}\left[\frac{\mathrm{kg}}{\mathrm{m}^{3}}\right] * V_{\text {Substrate }}\left[\mathrm{m}^{3}\right]} * 60\left[\frac{\mathrm{min}}{\mathrm{hr}}\right]
$$

where, $V_{\text {Substrate }}$ is the total volume of the $\mathrm{SCRF}^{\circledR}$ shown in Table $3.4\left[\mathrm{~m}^{3}\right]$.

\subsection{Equations Used for Calculation of Experimental Reaction Rate}

The procedure followed to calculate the reaction rate for PM oxidation based on the experimental data is discussed in this section. The procedure followed is similar to the procedure used by references $[4,7,8]$.

The mass balance equation or the rate of change of the mass retained in a control volume $\left(\mathrm{SCRF}^{\circledR}\right)$ as shown in Equation 26 is obtained by differentiating Equation 23 and substituting the mass oxidized $\left(\dot{\mathrm{m}}_{o x}\right)$ as the product of reaction rate $\left(\mathrm{RR}_{\mathrm{o}}\right)$ and the mass retained, and the flow rate of mass entering $\left(\dot{\mathrm{m}}_{\mathrm{in}}\right)$ as shown in Equation 27.

$$
\begin{aligned}
& \frac{\mathrm{dm}_{\text {retained }}}{\mathrm{dt}}=\dot{\mathrm{m}}_{\text {in }}-\dot{\mathrm{m}}_{\text {out }}-\mathrm{m}_{\text {retained }} * \mathrm{RR}_{O} \\
& \text { where, } \dot{m}_{\text {in }}=\frac{\dot{m}_{\text {exhaust }}}{\rho_{\text {std }}} * c_{\text {in }}
\end{aligned}
$$

Substituting Equations 20 and 27 into Equation 26 and rearranging the terms results in a first order linear differential as shown in Equation 28.

$$
\frac{\mathrm{dm}_{\text {retained }}}{\mathrm{dt}}+\mathrm{m}_{\text {retained }} * \mathrm{RR}_{o}=\eta_{\mathrm{f}} * \frac{\dot{m}_{\text {exhaust }}}{\rho_{\text {std }}} * c_{\text {in }}
$$


The solution of the linear differential equation (Equation 28) is shown in Equation 29 which is solved iteratively over the duration of interest using MATLAB to calculate the average reaction rate $\left(R R_{o}\right)$.

$$
m_{2}=\eta_{f} * c_{i n} * \frac{Q_{S t d}}{R R_{o} * 1000} *\left(1-e^{-R R_{o} * \mathrm{t}}\right)+m_{1} * e^{-R R_{o} * \mathrm{t}}
$$

where, $m_{2}$ is the mass of PM retained in the $\mathrm{SCRF}^{\circledR}$ at the end of the time step $\left[\mathrm{g}\right.$ ], and $m_{1}$ is the mass of $\mathrm{PM}$ retained in the $\mathrm{SCRF}^{\circledR}$ at the beginning of the time step $[\mathrm{g}], t$ is the duration of time step [s] and $Q_{S t d}$ is the average standard volumetric flowrate of exhaust during the stage calculated using Equation 30.

$$
Q_{S t d}\left[\frac{\mathrm{scm}}{\mathrm{s}}\right]=\frac{\dot{m}_{\text {exhaust }}\left[\frac{\mathrm{kg}}{\mathrm{min}}\right]}{\rho_{\text {Std }}\left[\frac{\mathrm{kg}}{\mathrm{m}^{3}}\right]} * \frac{1}{60\left[\frac{\mathrm{s}}{\mathrm{min}}\right]}
$$

For the calculation of average reaction rate for Stage 2 for the Loading Tests, the PM retained at the end of Stage $1\left(m_{\text {retained,S1 }}\right)$ and Stage $2\left(m_{\text {retained,S } 2}\right)$ is calculated as explained in Appendix A. The mass of the PM in the SCRF ${ }^{\circledR}$ at the beginning of the Stage $2\left(m_{\text {start,S2 }}\right)$ is equal to the PM retained at the end of Stage $1\left(m_{\text {retained,S1 }}\right)$. Based on the $m_{\text {start }, S 2}$ and $m_{\text {retained,s2 }}$ values, the reaction rate for Stage 2 is calculated following the iterative process explained below. The reaction rate results for Stage 2 for the Loading Tests $w / o$ and $w /$ Urea are discussed in detail in Section 5.1 and Section 5.2 respectively.

For the first iteration, the value of $m_{1}$ is set equal to $m_{\text {start }}$ for the stage, $R R_{o}$ is assumed zero or a value close to zero (as infinity cannot be handled by MATLAB) and the value of $m_{2}$ is calculated for the time step. For the next time step, the value of $m_{1}$ is set equal to $m_{2}$ from the previous time step and the value of $m_{2}$ is calculated for the next time step. This is continued till the final time step and the value of $m_{2}$ at the final time step is compared to the experimental $m_{\text {retained }}$ value \pm $0.05 \mathrm{~g}$. If the value of $m_{2}$ at the final time step is less than the experimental $m_{\text {retained }}-0.05 \mathrm{~g}$, the value of $R R_{o}$ is increased by $10^{-7} \mathrm{~s}^{-1}$. If the value of $m_{2}$ at the final step is more than the experimental $m_{\text {retained }}+0.05 \mathrm{~g}$, the value of $R R_{o}$ is decreased by $10^{-7} \mathrm{~s}^{-1}$. 
For the next iteration, the value of $R R_{o}$ from the previous iteration is used. The same procedure is followed for further iterations till the value of $m_{2}$ is within the tolerance limit of $m_{\text {retained }} \pm$ $0.05 \mathrm{~g}$. The value of $R R_{o}$ in the final iteration is taken as the average reaction rate during the duration of interest.

Once the value of the average reaction rate is estimated for a test condition, the value of reaction rate constant $(k)$ is calculated by normalizing the reaction rate by the $\mathrm{NO}_{2}$ concentration at the $\mathrm{SCRF}^{\circledast}$ inlet for that test condition. The natural logarithm of the reaction rate constant can be plotted versus the inverse of $\mathrm{SCRF}^{\circledR}$ inlet temperature for all test conditions to determine the kinetics of the PM oxidation using a standard Arrhenius model as seen in Figures 2.9 and 2.10. 


\section{Chapter 4. Model for PM Oxidation}

References $[4,7,8]$ reported higher reactivity of PM retained in the $\mathrm{CPF}$ and $\mathrm{SCRF}^{\circledR}$ during loading conditions compared to passive oxidation conditions as discussed in Section 2.4. The calibration of the SCR-F model with passive oxidation data from reference [8] also resulted in a different set of kinetics for PM oxidation during the loading conditions and passive oxidation conditions [40]. Hence, to model the oxidation of PM using a single set of kinetics for a wide range of conditions including loading and passive oxidation conditions, there was a need to develop a model which takes into account the microstructure of PM particles as compared to the SCR-F model which is a lumped model for PM oxidation. Motivated by this concept, a model for PM oxidation was developed using the shrinking core model [33] which takes into account the changes in the reactivity of PM particle at the microstructure level as it oxidizes and it also keeps track of each of the incoming PM masses in the oxidation process.

The focus of this chapter is on the development of the PM oxidation model which is discussed in detailed in Section 4.1. The application of the results of the PM oxidation model to the SCR-F model in order to simulate the $\mathrm{PM}$ retained in the $\mathrm{SCRF}^{\circledast}$ and the pressure drop across the $\mathrm{SCRF}^{\circledR}$ is discussed in Section 4.2. Section 4.3 describes in detail the calibration process for the SCR-F model with the loading test data. Further, the PM oxidation model was calibrated using passive oxidation data [8] to check if the model can simulate the PM oxidation using a single set of kinetics under loading and passive oxidation conditions which is discussed in Section 4.4.

\subsection{Model Development}

The model for PM oxidation has been developed from the fundamental equation of conservation of mass and a shrinking core model for PM oxidation [23, 33]. Figure 4.1 shows a control volume (depicting a $\mathrm{SCRF}^{\circledR}$ ) at time $\mathrm{t}$ with some amount of mass loaded (discretized into four lumped masses with different colors) termed as $m_{\text {retained }}(t)$. At time $t$, assume that an exhaust stream containing a lumped mass $\left(m_{\text {in }}\right)$ enters the control volume as shown in Figure 4.1. At time $t+\Delta t$, a portion of the lumped mass entering $\left(m_{i n}\right)$ is retained in the control volume while a portion of the lumped mass entering $\left(m_{\text {in }}\right)$ exits the control volume $\left(m_{\text {out }}\right)$ as the filtering efficiency is less than $100 \%$. Also, a portion of the $\mathrm{m}_{\text {retained }}(\mathrm{t})$ gets oxidized by reacting with the $\mathrm{NO}_{2}$ in the exhaust stream. The remaining portion of $m_{\text {retained }}(t)$ plus the portion of the incoming lumped mass $\left(m_{i n}\right)$ retained in the control volume is collectively termed as $\mathrm{m}_{\text {retained }}(\mathrm{t}+\Delta t)$ as shown in Figure 4.1. 


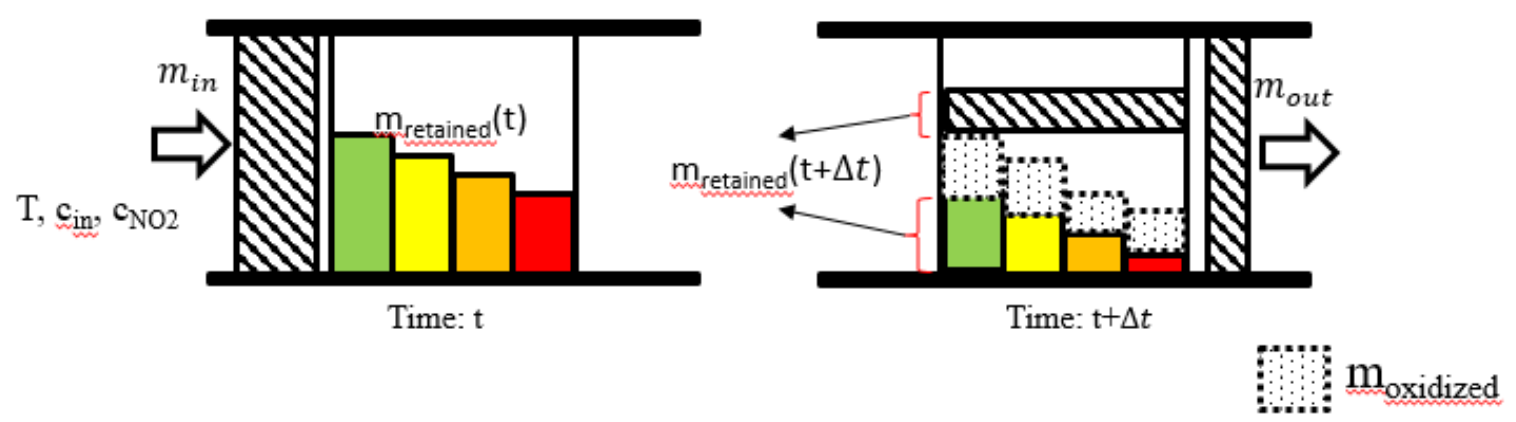

Figure 4.1: PM Mass Balance in a Control Volume at Time $t$ and $t+\Delta t$

The assumptions made in the development of this model are listed below.

- The exhaust flow rate $\left(\dot{m}_{\text {in }}\right), \mathrm{PM}$ in $\left(\mathrm{c}_{\text {in }}\right)$ and $\mathrm{NO}_{2}$ concentration $\left(\mathrm{c}_{\mathrm{NO} 2}\right)$ are assumed constant with time for a particular lumped mass entering the control volume at time $t$.

- The temperature for $\mathrm{PM}$ oxidation is assumed to be equal to the $\mathrm{SCRF}^{\circledR}$ inlet temperature and is assumed constant with time for a particular lumped mass entering the control volume at time $\mathrm{t}$.

- There is no oxidation of the lumped mass entering the control volume during time $\Delta t$ [46]. Only the PM retained in the control volume gets oxidized.

- An important point to note is that the oxidation of the different masses retained in the control volume at time t has not been uniform which is depicted by different sizes of the colored lumped masses at time $\mathrm{t}+\Delta t$ in Figure 4.1.

The mass balance equation and the inlet mass flow rate for a lumped mass entering the control volume (the $\mathrm{SCRF}^{\oplus}$ ) at during $\Delta t$ and exiting during time $\Delta t$ is described by Equations 31 and 32 .

$$
\begin{aligned}
& \frac{d m_{\text {retained }}}{d t}=\dot{m}_{\text {in }}-\dot{m}_{\text {out }}-m_{\text {retained }} * R R \\
& \text { where, } \dot{m}_{\text {in }}=\frac{\dot{m}_{\text {exhaust }}}{\rho_{\text {std }}} * c_{\text {in }}
\end{aligned}
$$

Here, $m_{\text {retained }}$ is the PM retained in the $\mathrm{SCRF}^{\circledR}[\mathrm{g}], \dot{m}_{\text {in }}$ is the flow rate of $\mathrm{PM}$ entering the $\mathrm{SCRF}^{\circledR}$ $[\mathrm{g} / \mathrm{s}], \dot{m}_{\text {out }}$ is the flow rate of PM exiting the $\mathrm{SCRF}^{\circledR}[\mathrm{g} / \mathrm{s}], \mathrm{RR}$ is the reaction rate of oxidation of PM retained $[1 / \mathrm{s}], \dot{m}_{\text {exhaust }}$ is the flow rate of exhaust $[\mathrm{g} / \mathrm{s}], \rho_{s t d}$ is the standard exhaust density - 1.18 $\mathrm{kg} / \mathrm{m}^{3}\left(25^{\circ} \mathrm{C}\right.$ and $\left.101.3 \mathrm{kPa}\right)$ and $c_{\text {in }}$ is the PM concentration in the exhaust $[\mathrm{g} / \mathrm{scm}]$. 
The $\mathrm{SCRF}^{\circledast}$ is a wall flow device and the exhaust stream entering the inlet channel passes through the porous substrate wall and exits through the outlet channel. A portion of the PM in the exhaust stream entering the inlet channels is retained in the $\mathrm{SCRF}^{\circledR}$ due to filtration in the substrate wall and the cake [21] and the remaining portion of PM exits through the outlet channels. The filtration efficiency $\left(\eta_{\mathrm{f}}\right)$ of the $\mathrm{SCRF}^{\circledR}$ as a fraction is described by Equation 33.

$$
\eta_{f}=1-\frac{\dot{m}_{\text {out }}}{\dot{m}_{\text {in }}}
$$

Equation 33 can be modified as $\dot{m}_{\text {in }}-\dot{m}_{\text {out }}=\eta_{f} \dot{m}_{\text {in }}$ which when substituted in Equation 31 results in the equation 34 for PM mass balance.

$$
\frac{d m_{\text {retained }}}{d t}=\eta_{f} \dot{m}_{\text {in }}-m_{\text {retained }} * R R
$$

For the model development, assume that there is some mass retained in the $\mathrm{SCRF}^{\circledR}$ denoted by $m_{\text {retained }}^{i}\left(t_{j}\right)$ at time $t_{j}$ due to filtration of a lumped mass (i) in the $\mathrm{SCRF}^{\circledast}$. At time $t_{j+1}$, the reduced value of the mass retained $m_{\text {retained }}^{i}\left(t_{j+1}\right)$ due to oxidation is calculated using Equation 35 which is obtained by discretizing Equation 34 for the for the lumped mass (i) with $\Delta t=t_{j+1}-t_{j}$.

$$
\frac{m_{\text {retained }}^{i}\left(t_{j+1}\right)-m_{\text {retained }}^{i}\left(t_{j}\right)}{t_{j+1}-t_{j}}=\eta_{f} \dot{m}_{\text {in }}^{i}-\frac{m_{\text {retained }}^{i}\left(t_{j+1}\right)+m_{\text {retained }}^{i}\left(t_{j}\right)}{2} * R R^{i}\left(t_{j}\right)
$$

Figure 4.2 shows the variation of mass retained with time for the different lumped masses $(i, i+1$, $i+2 \ldots$.$) entering the \mathrm{SCRF}^{\circledast}$ at time $\left(t_{j}, t_{j+1}, t_{j+2} \ldots.\right)$ respectively i.e. after every assumed time step of 1 minute. The value of the mass retained decreases or increases with time as it gets oxidized as seen in Figure 4.2. 


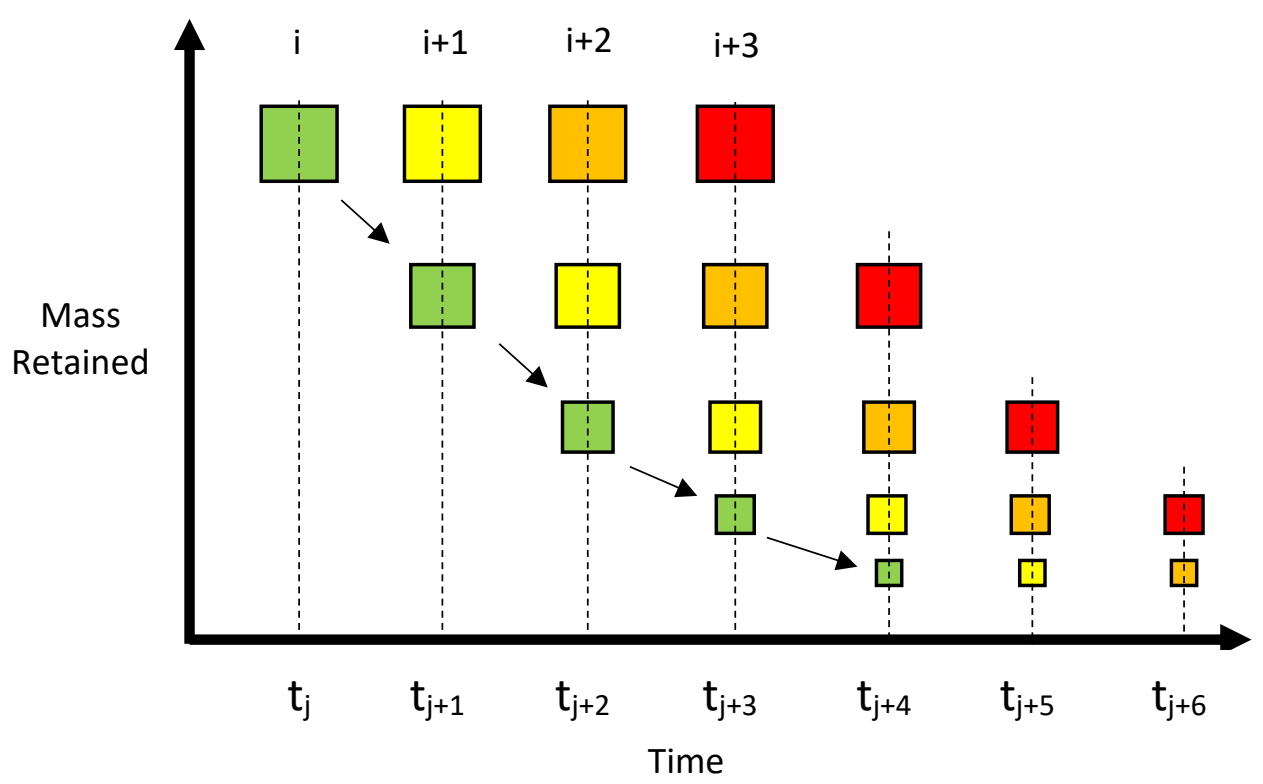

Figure 4.2: Schematic Representation of the Variation of Mass Retained in the SCRF ${ }^{\circledR}$ With Time

Once the value of $m_{\text {retained }}^{i}\left(t_{j+1}\right)$ is calculated using Equation 35, the percentage of PM oxidized $(\xi)$ is calculated at time $t_{j+1}$ for lumped mass (i) using Equation 36 and 37.

$$
\begin{gathered}
\xi^{i}\left(t_{j+1}\right)=1-\frac{m_{\text {retained }}^{i}\left(t_{j+1}\right)}{\eta_{f} m_{\text {in }}^{i}} \\
\text { where, } m_{\text {in }}^{i}=c_{\text {in }} * \frac{\dot{m}_{\text {exhaust }}}{\rho_{\text {std }}} *\left(t_{j+1}-t_{j}\right)
\end{gathered}
$$

The value of $\xi^{i}\left(t_{j+1}\right)$ calculated at time $t_{j+1}$ using Equation 36 is then used to determine the value of oxidation factor $(\mathrm{k})$ to be used in calculating the reaction rate for the next time step. The value of oxidation factor $(\mathrm{k})$ for a particular value of percentage of PM oxidized $(\xi)$ is determined by interpolating in between the specific points extracted from the trend of PM oxidized $(\xi)$ vs oxidation factor $(\mathrm{k})$ shown in Figure 4.3. This trend is obtained from the data for the reactor studies for PM oxidation in reference [23] shown in Figure 2.4. The trend is also similar in nature to that obtained by reference [31] shown in Figure 2.5. The trend shown in Figure 4.3 was used for the initial computation in the model. 


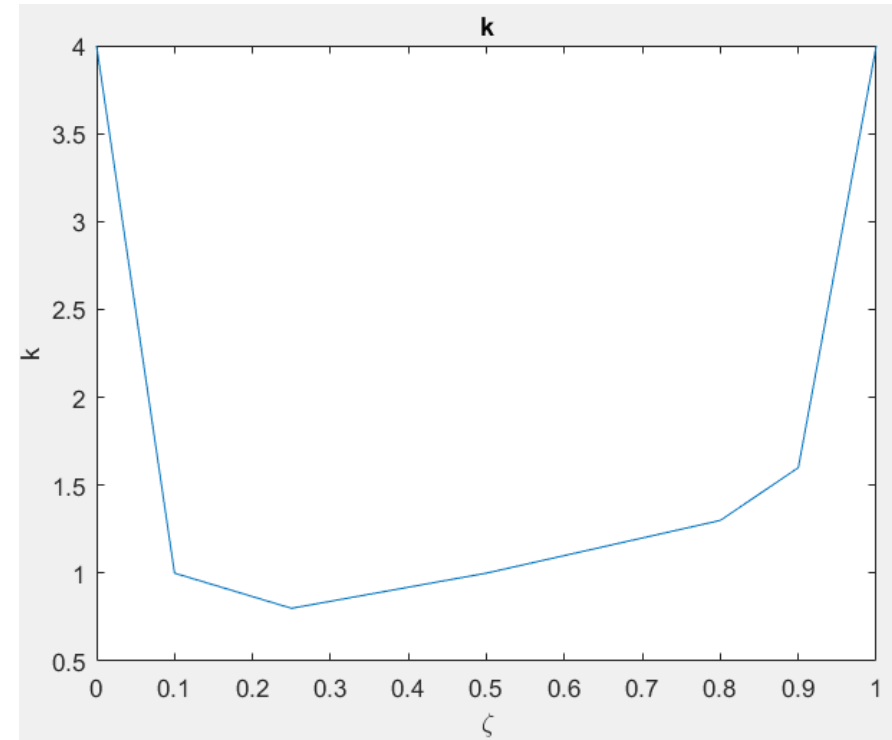

Figure 4.3: Variation of the Oxidation Factor (k) With Percentage of PM Oxidized ( $\xi$ ) [23]

The reaction rate $R R^{i}\left(t_{j+1}\right)$ for the lumped mass (i) at time $\left(t_{j+1}\right)$ is calculated using Equations 38 and 39 by multiplying the reaction rate term $\left(R R_{o}\right)$ with the oxidation factor $(\mathrm{k})$. It is important to note that the standard Arrhenius rate constant has been used in this model.

$$
\begin{aligned}
& R R^{i}\left(t_{j+1}\right)=R R_{o} * k\left(\xi^{i}\left(t_{j+1}\right)\right) \\
& \text { where, } R R_{o}=A * e^{\left(\frac{-E_{a}}{R u^{* T}}\right)} *\left[N O_{2}\right]
\end{aligned}
$$

where, $R_{0}$ is the reaction rate $[1 / \mathrm{s}], A$ is the frequency factor or pre-exponential factor $[1 / \mathrm{K}-\mathrm{ppm}$ s], $E_{a}$ is the activation energy of the reaction $[\mathrm{kJ} / \mathrm{gmol}], \mathrm{R}_{u}$ is the universal gas constant $=8314$ $[\mathrm{kJ} / \mathrm{gmol}-\mathrm{K}], \mathrm{T}$ is temperature of the reaction $[\mathrm{K}]$ and $\left[\mathrm{NO}_{2}\right]$ is the concentration of $\mathrm{NO}_{2}$ in $\mathrm{ppm}$.

After calculating the reaction rate at time $t_{j+1}$, the value of mass retained $m_{\text {retained }}^{i}\left(t_{j+2}\right)$ at time $t_{j+2}$ is calculated using Equation 35 and the same process is repeated using Equations 36-39 for the consequent time steps for the lumped mass (i) till the end of experimental data available. The same process is followed for the lumped masses $(i+1, i+2, \ldots)$ entering the SCRF ${ }^{\oplus}$ at time $\left(t_{j+1}, t_{j+2}, \ldots\right)$ till the end of experimental data available. The process of the model development and the equations used is illustrated graphically in Figure 4.4 for a better understanding. 


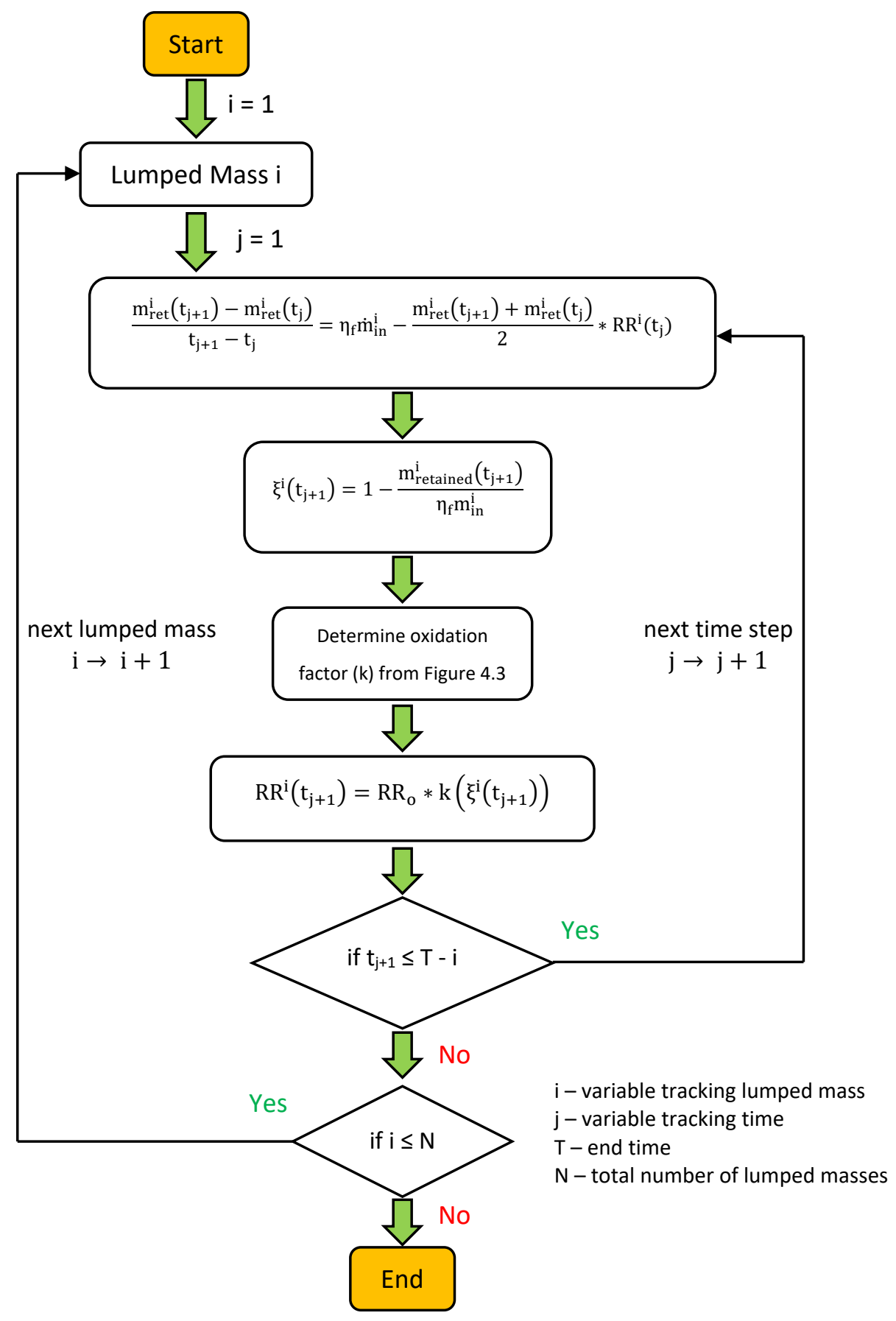

Figure 4.4: Schematic of the Model Developed for PM Oxidation 


\subsection{Application of the PM Oxidation Model's Reaction Rate Results in the SCR-F Model}

This section focuses on the application of the reaction rate results from the PM oxidation model to the SCR-F model [12]. Further, the calibration of the SCR-F model with the experimental data from Loading Tests w/o Urea is discussed in the next section.

The PM oxidation model developed as discussed in Section 4.1 can simulate the PM retained in the $\mathrm{SCRF}^{\circledR}$ with time. However, to estimate the amount of PM retained in the cake and wall, and the contribution of the cake, wall and channel to the total pressure drop across the $\mathrm{SCRF}^{\circledR}$ as well as the evolution of filtration efficiency with time and PM loading, there is a need to integrate the calibrated PM oxidation model to the SCR-F model. This is performed by applying the reaction rate results from the PM oxidation model to the SCR-F model, specifically to simulate the pressure drop and estimate the Stage 1 filtration efficiency (Appendix A) for the Loading Tests, which is discussed in the following paragraphs.

In the PM Oxidation model, each lumped mass has an oxidation factor $(\mathrm{k})$ associated to it at each time step which is used in calculating the reaction rate for that lumped mass for the next time step. At each time step, a new term defined as the average oxidation factor $\left(k_{\text {avg }}\right)$ is calculated by taking the weighted average of oxidation factor $(k)$ of all lumped masses based on the quantity of PM in each lumped mass. The formula used to calculate the average oxidation factor $\left(k_{\text {avg }}\right)$ is shown in Equation 40.

$$
k_{\text {avg }, t}=\frac{\sum_{i=1}^{t}\left(k_{i, t} * m_{\text {retained }, t}^{i}\right)}{\sum_{i=1}^{t} m_{\text {retained }, t}^{i}}
$$

The average oxidation factor $\left(\mathrm{k}_{\text {avg }}\right)$ calculated at each time-step from the PM Oxidation model is then applied to the reaction rate for the $\mathrm{NO}_{2}$ assisted oxidation of $\mathrm{PM}$ in the cake and the substrate wall in the SCR-F model by modifying Equations 14 and 15 given in Section 2.5 as shown in Equation 41 and 42 . The average oxidation factor $\left(\mathrm{k}_{\mathrm{avg}}\right)$ is interpolated based on the time step in the SCR-F model from the values calculated from the PM oxidation model and multiplied to the reaction rate for $\mathrm{NO}_{2}$ assisted oxidation of $\mathrm{PM}$ in the cake and substrate wall. 


$$
\begin{aligned}
& R R_{N O_{2, \text { cake }}}=k_{\text {avg }} * \frac{s_{p} * \rho_{i, j} * Y_{i, j, N O_{2}} * A_{c a k e} * T_{i, j} * e^{\left(-\frac{E_{a, N O_{2}}}{R_{u} * T_{i, j}}\right)} * W_{C}}{\alpha_{N O_{2}} W_{N O_{2}} \rho_{s}} \\
& R R_{N O_{2, \text { wall }}}=k_{\text {avg }} * \frac{s_{p} * \rho_{i, j} * Y_{i, j, N O_{2}} * A_{w a l l} * T_{i, j} * e^{\left(-\frac{E_{a, N O_{2}}}{R_{u} * T_{i, j}}\right)} * W_{C}}{\alpha_{\mathrm{NO}_{2}} W_{N O_{2}} \rho_{s}}
\end{aligned}
$$

where, $s_{p}$ is the specific surface area of PM $[1 / \mathrm{m}], \rho_{i, j}$ is the density of gas in each zone $\left[\mathrm{kg} / \mathrm{m}^{3}\right]$, $Y_{i, j, \mathrm{NO}_{2}}$ is the mass fraction of inlet $\mathrm{NO}_{2}$ in each zone, $A_{\text {cake }}$ is the pre-exponential for PM cake [m/K-s], $A_{\text {wall }}$ is the pre-exponential for PM in the substrate wall $[\mathrm{m} / \mathrm{K}-\mathrm{s}], T_{i, j}$ is temperature of the filter in each zone $[\mathrm{K}], E_{a, \mathrm{NO}_{2}}$ is the activation energy for $\mathrm{NO}_{2}$ assisted PM oxidation [kJ/gmol], $R_{u}$ is the universal gas constant $[8.314 \mathrm{~J} / \mathrm{gmol}-\mathrm{K}], W_{C}$ is the molecular weight of carbon $[\mathrm{kg} / \mathrm{kmol}]$, $\alpha_{\mathrm{NO}_{2}}$ is the $\mathrm{NO}_{2}$ oxidation partial factor, $W_{\mathrm{NO} 2}$ is the molecular weight of $\mathrm{NO}_{2}[\mathrm{~kg} / \mathrm{kmol}]$ and $\rho_{s}$ is the PM density $\left[\mathrm{kg} / \mathrm{m}^{3}\right]$.

\subsection{Calibration of the SCR-F Model With Loading Tests w/o Urea Data}

This section focuses on the calibration of the SCR-F model using experimental data from the eight Loading Tests w/o Urea performed in this study, after applying the reaction rate results from the PM Oxidation model to the SCR-F model as discussed in Section 4.2.

The objective of the calibration process is to determine the kinetics of PM oxidation in the cake and the wall to simulate the $\mathrm{PM}$ mass retained in the $\mathrm{SCRF}^{\circledast}$ for the two loading stages within \pm 2 $\mathrm{g}$ of the experimental values as well as to simulate the pressure drop across the $\mathrm{SCRF}^{\circledR}$ within \pm 0.5 $\mathrm{kPa}$ of the experimental values. The input parameters and the calibration parameters for the SCRF model are as follows.

\section{Input Parameters:}

1. Exhaust mass flow rate $(\mathrm{kg} / \mathrm{s})$

2. $\mathrm{SCRF}^{\oplus}$ inlet temperature $\left({ }^{\circ} \mathrm{C}\right)$ 
3. $\mathrm{SCRF}^{\circledR}$ inlet concentrations - $\mathrm{NO}$ (ppm), $\mathrm{NO}_{2}$ (ppm), $\mathrm{O}_{2}(\%), \mathrm{CO}(\mathrm{ppm}), \mathrm{CO}_{2}(\%), \mathrm{N}_{2}(\mathrm{ppm})$, $\mathrm{HC}\left(\mathrm{C}_{12} \mathrm{H}_{24}\right)(\mathrm{ppm})$ and PM concentration $(\mathrm{mg} / \mathrm{scm})$

4. Ambient temperature $\left({ }^{\circ} \mathrm{C}\right)$ and pressure $(\mathrm{kPa})$

\section{Calibration Parameters:}

1. PM oxidation kinetics ( $\mathrm{NO}_{2}$ assisted and thermal oxidation)

2. Pressure drop parameters

3. Filtration parameters

4. Cake permeability parameters

5. Thermal parameters

6. Gaseous species kinetics

The SCR-F model was already calibrated using experimental data from passive oxidation tests without urea from reference [8] as discussed in Section 2.5. The value of oxidation factor ( $k$ ) w.r.t. percentage of PM oxidized $(\xi)$ in the PM oxidation model was also calibrated using experimental data from passive oxidation tests without urea from reference [8] which will be discussed in Section 4.4. Hence, for the calibration of the SCR-F model with the Loading Tests w/o Urea data, only the parameters related to PM oxidation kinetics had to be re-calibrated to take into account the changes due to varying reaction rates with time as a result of application of the PM oxidation model results to the SCR-F model.

The procedure followed for calibration and optimizing the output of the SCR-F model is explained in the following steps:

1. Initially, the value of activation energy $\left(E_{a}\right)$ and pre-exponential $(A)$ obtained from the calibration of PM oxidation model with the passive oxidation data [8] which will be discussed in Section 4.4 were used for the $\mathrm{NO}_{2}$ assisted oxidation kinetics of PM in the cake $\left(\mathrm{E}_{\mathrm{a}, \mathrm{NO2} \text {,cake , }}\right.$ $\left.A_{N O 2, \text { cake }}\right)$ and the wall $\left(E_{a, N O 2, \text { wall }}, A_{\mathrm{NO} \text {, wall }}\right)$ in the SCR-F model. The pre-exponential for the PM oxidation in the cake and the wall are then calibrated by comparing the simulated total PM retained with the experimental data and adding the cost function shown in Equation 43 for each of the eight Loading tests w/o Urea and minimizing the total cost.

$$
\text { Cost }=\sum_{i=1}^{2}\left(m_{\text {retained }, \text { expt }, i}-m_{\text {retained }, \text { model }, i}\right)^{2}
$$

where, $i$ stands for end of Stage 1 and Stage 2. 
2. The pre-exponential for the PM oxidation in the wall ( $\left.A_{\mathrm{NO} \text {, wall }}\right)$ is then calibrated by comparing the simulated total pressure drop across the $\mathrm{SCRF}^{\circledR}$ and minimizing the total cost for all the eight Loading Tests w/o Urea. The cost functions for a single experiment is shown in Equation 44.

$$
\text { Cost }=\operatorname{delP}_{\text {expt }, i}-\operatorname{delP}_{\text {model }, i}
$$

where, i stands for end of Stage 2.

3. The pre-exponential for the PM oxidation in the cake $\left(A_{N O 2, \text { cake }}\right)$ is re-calibrated, to account for changes in the wall PM oxidation in step 2 , by comparing the simulated total PM retained with the experimental data and minimizing the total cost for all the eight experiments as explained in Step 1.

The flow chart illustrating the process of calibration of the SCR-F model is shown in Figure 4.5.
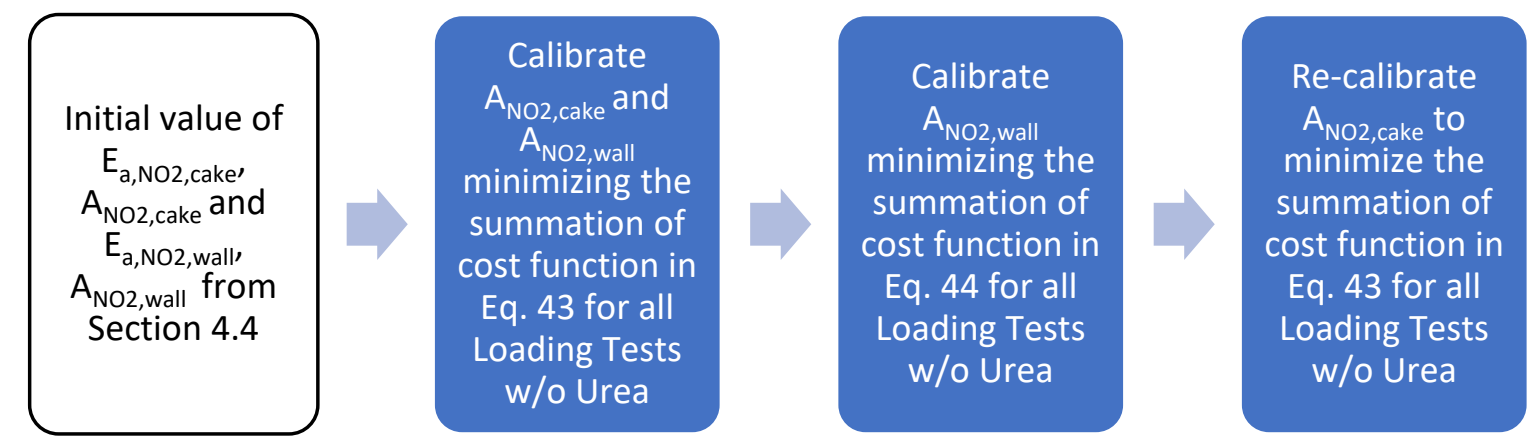

Figure 4.5: Flow Chart for the Calibration of SCR-F Model with Loading Tests w/o Urea Data

The kinetics of $\mathrm{NO}_{2}$ assisted PM oxidation obtained after calibrating the SCR-F model using reaction rate results from the PM oxidation model, is given in Section 5.4. Also, the performance of the calibrated model and the analysis of the model data for the Loading Tests w/o Urea is discussed in detail in Section 5.4. 


\subsection{Calibration of the PM Oxidation Model With Passive Oxidation w/o Urea Data}

The PM oxidation model developed as discussed in Section 4.1 requires the parameters to be calibrated to simulate the kinetics of oxidation of diesel PM retained in the SCRF ${ }^{\circledR}$. The calibration of the PM oxidation model using experimental data from the passive oxidation tests from reference [8] is discussed in detail in this section.

The passive oxidation tests [8] were designed to determine the $\mathrm{NO}_{2}$ assisted oxidation kinetics of $\mathrm{PM}$ retained in the $\mathrm{SCRF}^{\circledR}$. Each passive oxidation test consists of a loading Stage 1 (30 mins), Stage 2 (300 mins) and Ramp up (15 mins) followed by a passive oxidation stage and post-oxidation loading Stage 3 (30 mins) and Stage 4 (60 mins). Detailed description for each of these stages can be found in reference [8]. A plot of the loading profile of a passive oxidation test in terms of the pressure drop across the substrate is shown in Figure 4.6. The PM retained in the $\mathrm{SCRF}^{\oplus}$ at the end of each loading stage (represented by red dots in Figure 4.6) was calculated by measuring the weight of the $\mathrm{SCRF}^{\circledR}$ at the end of each loading stage and subtracting the clean weigh of the $\mathrm{SCRF}^{\circledR}$ without any PM loading which is discussed in detail in reference [8].

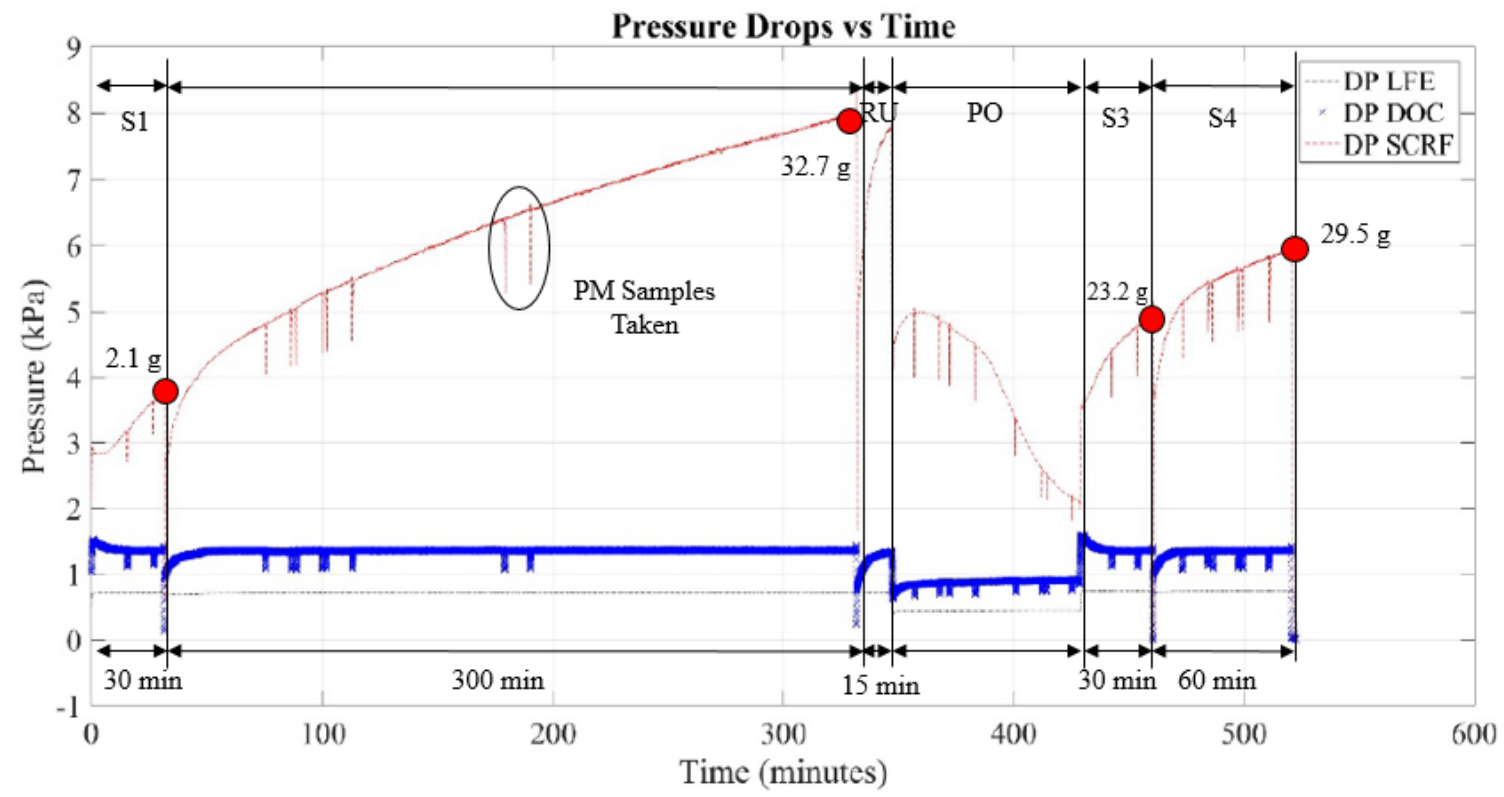

Figure 4.6: Pressure Drop vs Time for a Passive Oxidation Test PO-C [8] 
The objective of this calibration process is to determine a single set of kinetics of PM oxidation to simulate the $\mathrm{PM}$ mass retained in the $\mathrm{SCRF}^{\circledR}$ for all the stages in the passive oxidation test within $\pm 2 \mathrm{~g}$ of the experimental values of PM retained at the end of the stages. The parameters used as inputs for the model and the parameters calibrated using experimental data are as follows.

\section{Input Parameters:}

1. Exhaust mass flow rate $(\mathrm{kg} / \mathrm{s})$

2. $\mathrm{SCRF}^{\circledR}$ Inlet $\mathrm{NO}_{2}$ concentration (ppm)

3. $\mathrm{SCRF}^{\circledR}$ Inlet temperature (K)

4. $\mathrm{SCRF}^{\circledR}$ Inlet $\mathrm{PM}$ concentration $(\mathrm{g} / \mathrm{scm})$

5. $\mathrm{SCRF}^{\oplus}$ Filtration efficiency (-)

6. Duration of the experiment (minutes)

\section{Calibration Parameters:}

1. $\mathrm{NO}_{2}$ Assisted PM Oxidation Kinetics (Activation Energy $\mathrm{E}_{\mathrm{a}}$ and Pre-exponential A)

2. Oxidation Factor (k)

For the calibration, initial values of activation energy $\left(E_{a}\right)$ and pre-exponential $(A)$ are obtained from the Arrhenius plot of experimental reaction rates from reference [8]. Also, the same values of oxidation factor (k) w.r.t percentage of PM oxidized from reference [23] shown in Figure 4.3 are used for the initial calibration. The procedure followed for calibrating the parameters and optimizing the output of the model is explained in the following steps.

1) The $\mathrm{NO}_{2}$ assisted $\mathrm{PM}$ oxidation kinetics are calibrated assuming different set of kinetics in the loading stages $\left(E_{a}, A_{\text {loading }}\right)$ and passive oxidation stage $\left(E_{a}, A_{p o}\right)$. This is done by maintaining the absolute difference (Equation 45) between the model PM retained and the experimental $\mathrm{PM}$ retained at the end of the Stage 1, 2 and 3 within $\pm 2 \mathrm{~g}$ for a single set of kinetics for the loading stages for all experiments and a single set of kinetics for passive oxidation stage for all experiments.

$$
\text { Difference }_{i}=\left|m_{\text {retained,expt }, i}-m_{\text {retained, } \text { model }, i}\right|
$$

where, i stands for end of stage 1, 2 or 3 
2) In this step, the values of oxidation factor (k) for the initial portion of the PM oxidized i.e. for $\xi$ $<0.25$ are calibrated manually to obtain the same kinetics $\left(E_{a}\right.$ and $\left.A\right)$ for the loading stages and the passive oxidation stage. The comparison of the calibrated value of oxidation factor (k) w.r.t percentage of PM oxidized ( $\xi$ ) and that used initially from the reference [23] is shown in Figure 4.7. The calibrated value of oxidation factor (k) w.r.t. percentage of PM oxidized ( $\xi$ ) is fitted with a sixth order polynomial shown in Equation 46 and is used in the model for further calibration in Step 3.

$k=1256.7 \xi^{6}-4518.2 \xi^{5}+6584.6 \xi^{4}-4944.9 \xi^{3}+2003.6 \xi^{2}-411.82 \xi+33.995$

3) The pre-exponential (A) is again re-calibrated, with the same value of activation energy $\left(E_{a}\right)$ from Step 1, to account for changes in the loading stages and passive oxidation stage due to calibration of the oxidation factor (k). The cost function shown in Equation 47 for a single experiment is added for all experiments and the total cost is minimized while calibrating the value of pre-exponential (A).

$$
\text { Cost }=\sum_{i=1}^{3}\left(m_{\text {retained,expt }, i}-m_{\text {retained }, \text { model }, i}\right)^{2}
$$

where, i stands for end of stage 1, 2 or 3

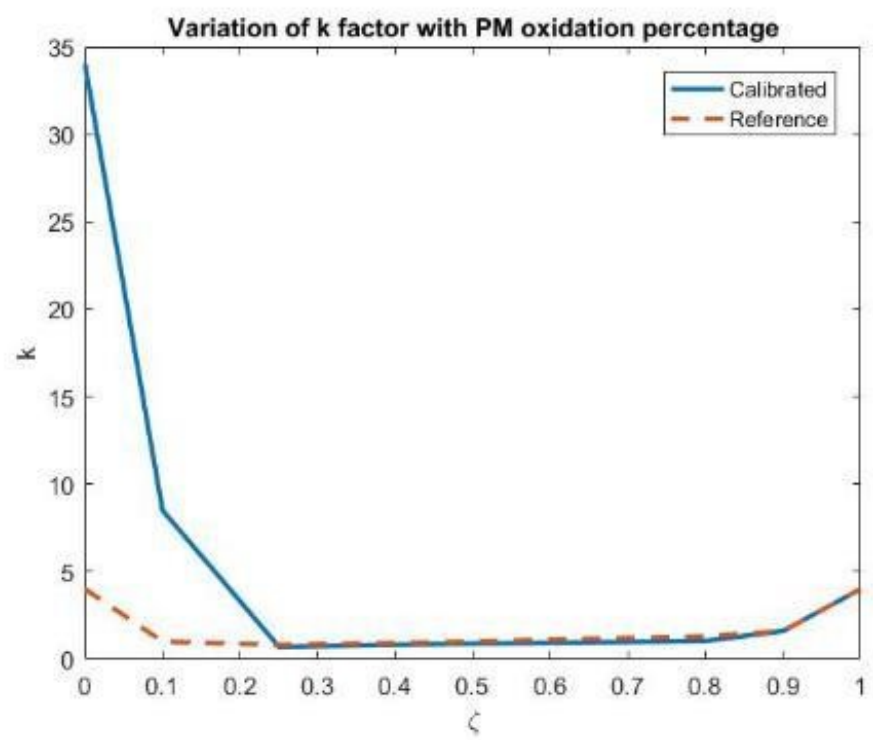

Figure 4.7: Comparison of Calibrated Oxidation Factor (k) w.r.t Percentage of PM Oxidized With That Used Initially From Reference [23] 
The flow chart illustrating the process of calibration of the PM Oxidation model is shown in Figure

4.8 .
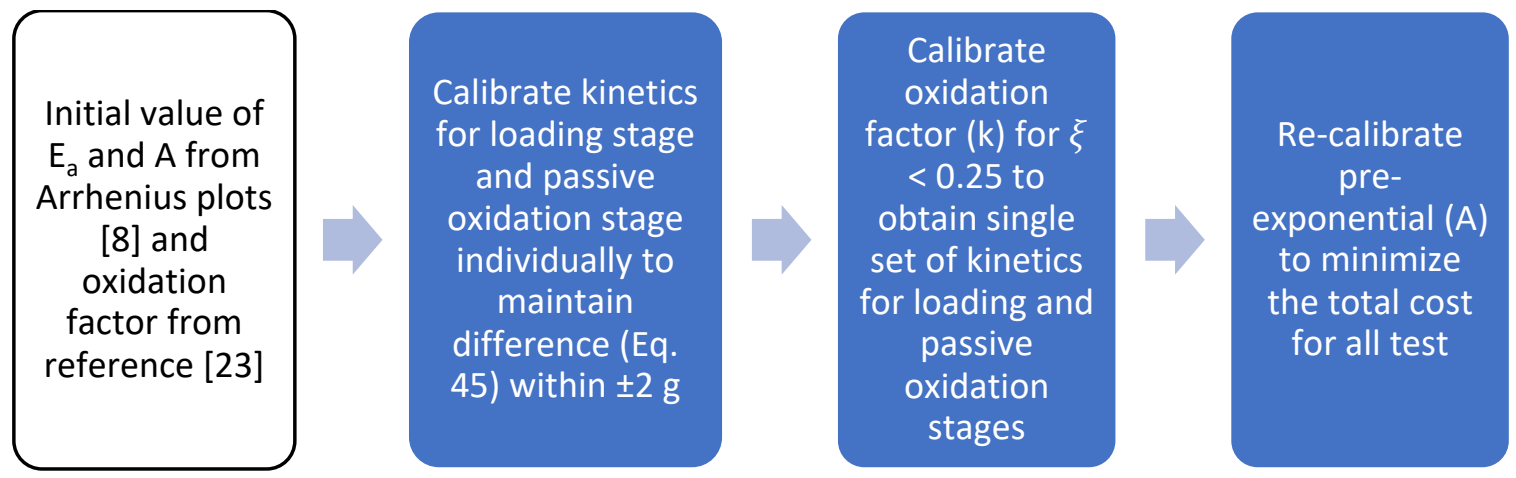

Figure 4.8: Flow Chart for the Calibration Process

The kinetics obtained after calibrating the model and the performance of the calibrated model is discussed in detail in Section 5.5. 


\section{Chapter 5. Results and Discussion}

This chapter focuses on the results and analysis of the experimental data and the modeling work carried out. Section 5.1 discusses the data and results for the Loading Tests w/o Urea in terms of the PM loading and oxidation performance of the $\mathrm{SCRF}^{\oplus}$. This is followed by Section 5.2 which focuses on the results for the Loading Tests $\mathrm{w} /$ Urea in terms of the PM loading, oxidation performance and $\mathrm{NO}_{x}$ reduction performance of the $\mathrm{SCRF}^{\oplus}$. In Section 5.3, the results for the Loading Tests $\mathrm{w} / \mathrm{o}$ and $\mathrm{w} /$ Urea are compared in terms of the kinetics of $\mathrm{NO}_{2}$ assisted oxidation of $\mathrm{PM}$ retained and the pressure drop across the $\mathrm{SCRF}^{\circledR}$. Also, there is a discussion on the comparison of the kinetics of $\mathrm{NO}_{2}$ assisted $\mathrm{PM}$ oxidation in the $\mathrm{SCRF}^{\oplus}$ under loading and passive oxidation conditions which was the primary objective for performing the Loading Tests as discussed in Section 2.4. Further, the performance of the calibrated SCR-F model with the reaction rate results from the PM oxidation model for the loading without urea data, is discussed in Section 5.4. At the end of the chapter, there is a discussion of the performance of the PM oxidation model under loading and passive oxidation conditions for a single set of kinetics.

\subsection{Loading Tests w/o Urea}

As discussed in Chapter 3, the Loading Tests were designed to determine the $\mathrm{NO}_{2}$ assisted oxidation kinetics for $\mathrm{PM}$ retained in the $\mathrm{SCRF}^{\circledR}$ for different loading conditions and to characterize the differences in the reaction kinetics of PM under loading and passive oxidation conditions. Also, the Loading Tests $\mathrm{w} /$ Urea were designed to determine the effect of urea on $\mathrm{NO}_{2}$ assisted PM oxidation kinetics as well as to understand the interaction of $\mathrm{PM}$ oxidation and $\mathrm{NO}_{\mathrm{x}}$ reduction with urea injection for the loading conditions.

Eight Loading Tests w/o Urea and four Loading Tests w/ Urea were performed with each test consisting of two stages of loading - Stage 1 and Stage 2. The data and the results for the Loading Tests w/o Urea performed are discussed in detail in this section. The variables changed when comparing one Loading Test to another are the engine speed, engine load and fuel rail pressure which results in changing the $\mathrm{SCRF}^{\circledR}$ inlet temperature and the $\mathrm{PM}$ and $\mathrm{NO}_{2}$ concentrations.

To introduce the data for the Loading Tests w/o Urea, the important engine and exhaust conditions for Stage 2 Loading for each test are given in Table 5.1. There may be slight differences between the values in Table 5.1 compared to the test matrix in Section 3.7 as these are the actual 
values obtained during the tests as contrasted to the values obtained from the point validation tests. It is important to note that the all the test conditions given in Table 5.1 lie in the region in which $90 \%$ of the PM oxidation is $\mathrm{NO}_{2}$ assisted as discussed in Section 3.7 and that there is a significant variation in the reaction rate for PM oxidation. Therefore, for the analysis of data, an assumption was made that the $\mathrm{PM}$ oxidation was completely $\mathrm{NO}_{2}$ assisted while calculating the kinetics of PM oxidation discussed later in this section.

Table 5.1: Engine and Exhaust Conditions for Stage 2 in Loading Tests w/o Urea

\begin{tabular}{|c|c|c|c|c|c|c|c|c|}
\hline Test & FRP & Speed & Load & $\begin{array}{c}\text { Exhaust } \\
\text { Flow Rate }\end{array}$ & $\begin{array}{c}\text { Std. Space } \\
\text { Velocity }\end{array}$ & PM Conc. & $\begin{array}{c}\text { DOC } \\
\text { Inlet } \\
\text { Temp. }\end{array}$ & $\begin{array}{c}\text { SCRF }{ }^{\circ} \\
\text { Inlet } \\
\text { Temp. }\end{array}$ \\
\hline [-] & {$[$ Bar] } & {$[\mathrm{RPM}]$} & {$[\mathrm{Nm}]$} & {$[\mathrm{kg} / \mathrm{min}]$} & {$[\mathrm{k} / \mathrm{hr}]$} & {$[\mathrm{mg} / \mathrm{scm}]$} & {$\left[{ }^{\circ} \mathrm{C}\right]$} & $\left.{ }^{\circ} \mathrm{C}\right]$ \\
\hline L1-Nominal & 1507 & 2401 & 203 & 10.9 & 33 & 7.1 & 273 & 264 \\
\hline L2-Nominal & 1560 & 2400 & 271 & 11.4 & 34 & 6.6 & 300 & 287 \\
\hline L2-Reduced & 1092 & 2400 & 271 & 11.5 & 34 & 11.7 & 302 & 275 \\
\hline L3-Nominal & 1575 & 2400 & 339 & 11.9 & 36 & 5.7 & 324 & 330 \\
\hline L3-Reduced & 1103 & 2400 & 339 & 12.0 & 36 & 11.0 & 337 & 332 \\
\hline L4-Nominal & 1610 & 2400 & 406 & 12.5 & 37 & 5.7 & 353 & 354 \\
\hline
\end{tabular}

\#Data obtained from Test PO-C in reference [11]

The $\mathrm{NO}, \mathrm{NO}_{2}$ and $\mathrm{NO}_{\mathrm{x}}$ values at the $\mathrm{DOC}$ inlet and $\mathrm{SCRF}^{\circledR}$ inlet for each test are given in Table 5.2. Theoretically, $\mathrm{NO}_{\mathrm{x}}$ should be conserved across the $\mathrm{DOC}$ and the $\mathrm{SCRF}^{\circledR}$ when there is no urea injection into the system. However, as observed from Table 5.2, there is slight variation in the $\mathrm{NO}_{\mathrm{x}}$ values at the $\mathrm{DOC}$ inlet and $\mathrm{SCRF}^{\circledR}$ inlet for each test. The reason for this can be attributed to the minor leakages in the aftertreatment system or the sampling system or measurement error. Also, since the UDOC, USCRF and DSCRF samples are taken at different time intervals one after the other during the tests, there may be small discrepancies in the conservation of species. To ensure 
the difference in total $\mathrm{NO}_{\mathrm{x}}$ across the DOC remained within an acceptable margin of error $(<10 \%)$, the percentage difference from the inlet concentrations is calculated using Equation 48 and the data are shown in Table 5.2. Also, the $\mathrm{NO}_{\mathrm{x}}$ values at the $\mathrm{DOC}$ inlet and $\mathrm{SCRF}^{\circledR}$ inlet for Loading Tests without Urea shown in Table 5.2 should be theoretically equal since it is assumed there are no reactions occurring in the decomposition tube between the DOC outlet and $\mathrm{SCRF}^{\circledR}$ inlet.

$$
N O_{x} \text { Difference }(\%)=\frac{N O_{x, \text { in }}-N O_{x, \text { out }}}{N O_{x, \text { in }}} * 100
$$

Table 5.2: Emission Data Across DOC for Loading Tests w/o Urea

\begin{tabular}{|c|c|c|c|c|c|c|c|c|c|}
\hline \multirow{3}{*}{ Test } & \multirow{2}{*}{$\begin{array}{c}\text { DOC Inlet } \\
\text { Temp. }\end{array}$} & \multicolumn{3}{|c|}{ DOC Inlet } & \multirow{2}{*}{$\begin{array}{c}\text { DOC NO } \\
\text { Conv. }\end{array}$} & \multicolumn{3}{|c|}{ SCRF $^{\circledR}$ Inlet } & \multirow{2}{*}{$\begin{array}{l}\mathrm{NO}_{\mathrm{x}} \\
\text { Diff. }\end{array}$} \\
\hline & & $\mathrm{NO}_{2}$ & NO & $\mathrm{NO}_{\mathrm{x}}$ & & $\mathrm{NO}_{2}$ & NO & $\mathrm{NO}_{\mathrm{x}}$ & \\
\hline & {$\left[{ }^{\circ} \mathrm{C}\right]$} & [ppm] & [ppm] & [ppm] & [\%] & [ppm] & [ppm] & [ppm] & [\%] \\
\hline L1 Nominal & 277 & 30 & 186 & 216 & 10 & 62 & 167 & 229 & -6 \\
\hline L1 Reduced" & 278 & 26 & 162 & 188 & 20 & 59 & 129 & 188 & 0 \\
\hline L2 Nominal & 300 & 29 & 261 & 290 & 22 & 88 & 203 & 291 & 0 \\
\hline L2 Reduced & 302 & 22 & 193 & 215 & 24 & 61 & 147 & 208 & 3 \\
\hline L3 Nominal & 324 & 24 & 315 & 339 & 28 & 93 & 227 & 320 & 6 \\
\hline L3 Reduced & 337 & 0 & 191 & 192 & 26 & 52 & 142 & 194 & -1 \\
\hline L4 Nominal & 353 & 15 & 333 & 348 & 31 & 120 & 230 & 350 & -1 \\
\hline L4 Reduced & 369 & 7 & 250 & 257 & 32 & 82 & 169 & 251 & 2 \\
\hline
\end{tabular}

\#Data obtained from Test PO-C in reference [11]

The percentage of NO conversion across the DOC is also calculated using Equation 49 for each test and the NO conversion percentage are given in Table 5.2. For this calculation, the NO values at the $\mathrm{DOC}$ outlet have been assumed equal to the $\mathrm{NO}$ values at the $\mathrm{SCRF}^{\circledR}$ inlet since it is assumed there are no reactions occurring in the decomposition tube between the DOC outlet and SCRF ${ }^{\circledR}$ inlet. 


$$
\text { NO Conversion }(\%)=\frac{N O_{\text {in }}-N O_{\text {out }}}{N O_{\text {in }}}
$$

where, the DOC inlet and outlet NO concentration are in ppm.

The NO conversion across the DOC is plotted against the DOC inlet temperature as shown in Figure 5.1. The trend for NO conversion across the DOC is in agreement with that observed in the literature. However, the value of NO conversion observed for test L1 Nominal and L1 Reduced is relatively low $(\leq 20 \%)$ when compared to the other Loading Tests. Hence, to check proper functioning of the $\mathrm{DOC}$ in converting $\mathrm{NO}$ to $\mathrm{NO}_{2}$, another validation test was performed which is described in detail in Appendix B.

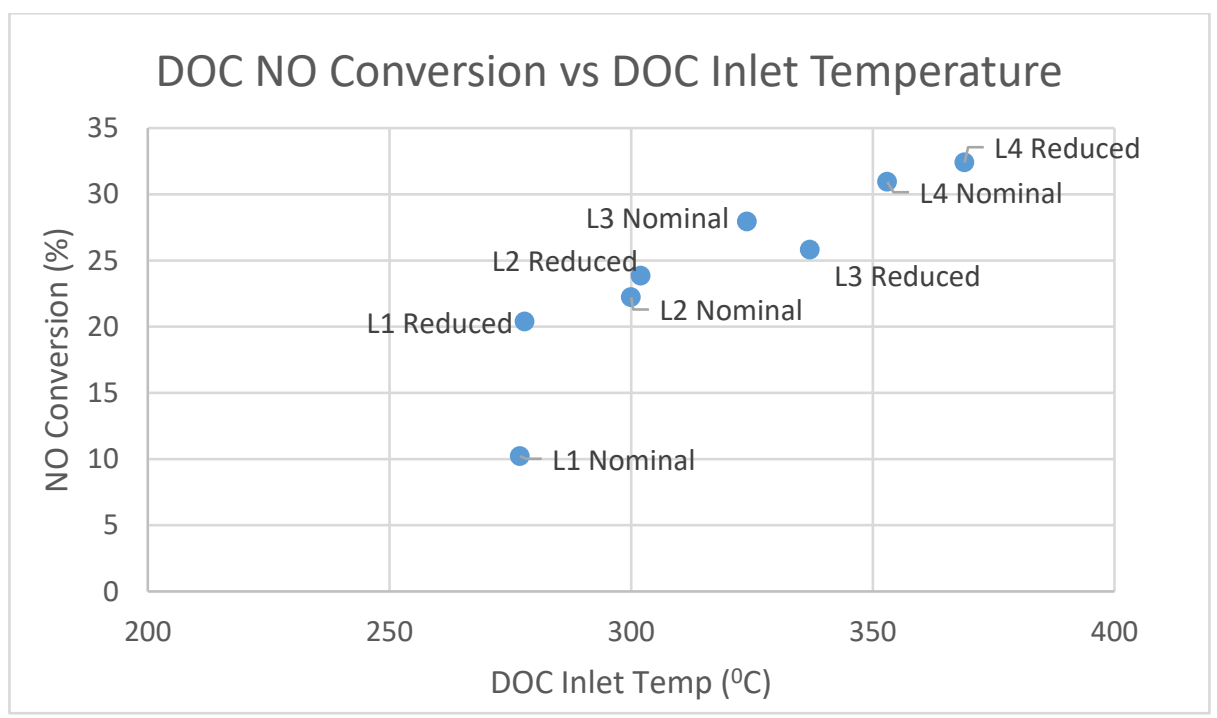

Figure 5.1: NO Conversion Across DOC vs DOC Inlet Temperature for Loading Tests w/o Urea

Next, the $\mathrm{NO}, \mathrm{NO}_{2}$ and $\mathrm{NO}_{x}$ values at the $\mathrm{SCRF}^{\circledR}$ outlet for each test are given in Table 5.3 along with the $\mathrm{NO}, \mathrm{NO}_{2}$ and $\mathrm{NO}_{x}$ values at the $\mathrm{SCRF}^{\circledR}$ inlet from Table 5.2 for comparison. As observed from Table 5.3, the $\mathrm{NO}_{2}$ value decreases across the $\mathrm{SCRF}^{\oplus}$ and the $\mathrm{NO}$ value increases across the $\mathrm{SCRF}^{\oplus}$ as $\mathrm{NO}_{2}$ is converted to $\mathrm{NO}$ while oxidizing the $\mathrm{PM}$ retained in the $\mathrm{SCRF}^{\circledR}$. The percentage difference in the $\mathrm{NO}_{\mathrm{x}}$ values at the inlet and outlet of the $\mathrm{SCRF}^{\circledR}$ was calculated using Equation 48 to ensure conservation of mass in terms of $\mathrm{NO}_{x}$ across the $\mathrm{SCRF}^{\oplus}$. The percentage difference in the $\mathrm{NO}_{\mathrm{x}}$ values at the inlet and outlet of the $\mathrm{SCRF}^{\circledR}$ for each test was within the acceptable range $(<10 \%)$ as seen in Table 5.3. 
Table 5.3: Emission Data Across SCRF ${ }^{\circledR}$ for Loading Tests w/o Urea

\begin{tabular}{|c|c|c|c|c|c|c|c|c|}
\hline \multirow{3}{*}{ Test } & \multirow{2}{*}{$\begin{array}{c}\text { SCRF }^{\circledR} \text { Inlet } \\
\text { Temp. }\end{array}$} & \multicolumn{3}{|c|}{ SCRF $^{\circledast}$ Inlet } & \multicolumn{3}{|c|}{ SCRF $^{\circledast}$ Outlet } & \multirow{2}{*}{$\mathrm{NO}_{\mathbf{x}}$ Difference } \\
\hline & & $\mathrm{NO}_{2}$ & NO & $\mathbf{N O}_{\mathbf{x}}$ & $\mathrm{NO}_{2}$ & NO & $\mathrm{NO}_{\mathrm{x}}$ & \\
\hline & {$\left[{ }^{\circ} \mathrm{C}\right]$} & [ppm] & [ppm] & [ppm] & [ppm] & [ppm] & [ppm] & [\%] \\
\hline L1 Nominal & 264 & 62 & 167 & 229 & 45 & 171 & 216 & 6 \\
\hline L1 Reduced" & 275 & 59 & 129 & 188 & 33 & 150 & 183 & 3 \\
\hline L2 Nominal & 287 & 88 & 203 & 291 & 68 & 207 & 275 & 5 \\
\hline L2 Reduced & 298 & 61 & 147 & 208 & 37 & 155 & 193 & 7 \\
\hline L3 Nominal & 330 & 93 & 227 & 320 & 72 & 256 & 329 & -3 \\
\hline L3 Reduced & 332 & 52 & 142 & 194 & 36 & 143 & 179 & 8 \\
\hline L4 Nominal & 354 & 120 & 230 & 350 & 94 & 248 & 342 & 2 \\
\hline L4 Reduced & 364 & 82 & 169 & 251 & 57 & 195 & 253 & -1 \\
\hline
\end{tabular}

\#Data obtained from Test PO-C in reference [11]

Further, to validate the $\mathrm{NO}_{x}$ values from Mass Spectrometer (MS) shown in Table 5.2 and Table 5.3 , they were compared to the $\mathrm{NO}_{x}$ values from the Calterm. The comparison of $\mathrm{NO}_{x}$ values at UDOC and USCRF ${ }^{\circledR}$ from the MS and the Calterm for all the tests is shown in Figure 5.2 and 5.3 respectively. The $\mathrm{NO}_{x}$ value at $\mathrm{UDOC}$ and $\mathrm{USCRF}^{\circledR}$ from the MS and the Calterm seem to be in agreement for all the tests except the test L3 Reduced which is the outlier point as observed from Figure 5.2 and 5.3. For test $L 3$ Reduced, the $\mathrm{NO}_{x}$ value at UDOC and USCRF ${ }^{\circledR}$ from the MS is lower compared to that from Calterm. The $\mathrm{NO}_{x}$ value at UDOC and USCRF ${ }^{\circledR}$ from MS seems incorrect as the value from Calterm agrees with the values obtained during the point validation tests (Table 3.15). The incorrect reading from the MS might be due to the filter getting plugged in the heated filter during the test and thus giving incorrect $\mathrm{NO}_{\mathrm{x}}$ values. The emission data from Calterm for test L3 Reduced was used for further analysis. 


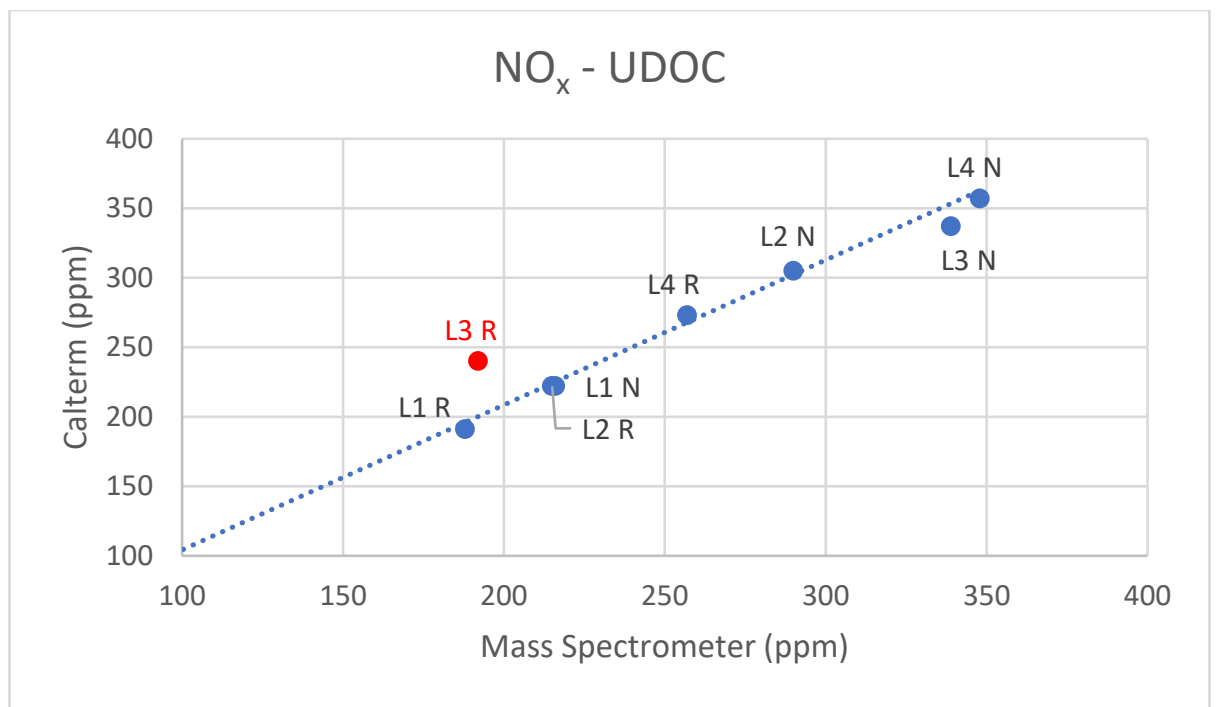

Figure 5.2: Comparison of $\mathrm{NO}_{x}$ Data From Calterm and Mass Spectrometer at UDOC

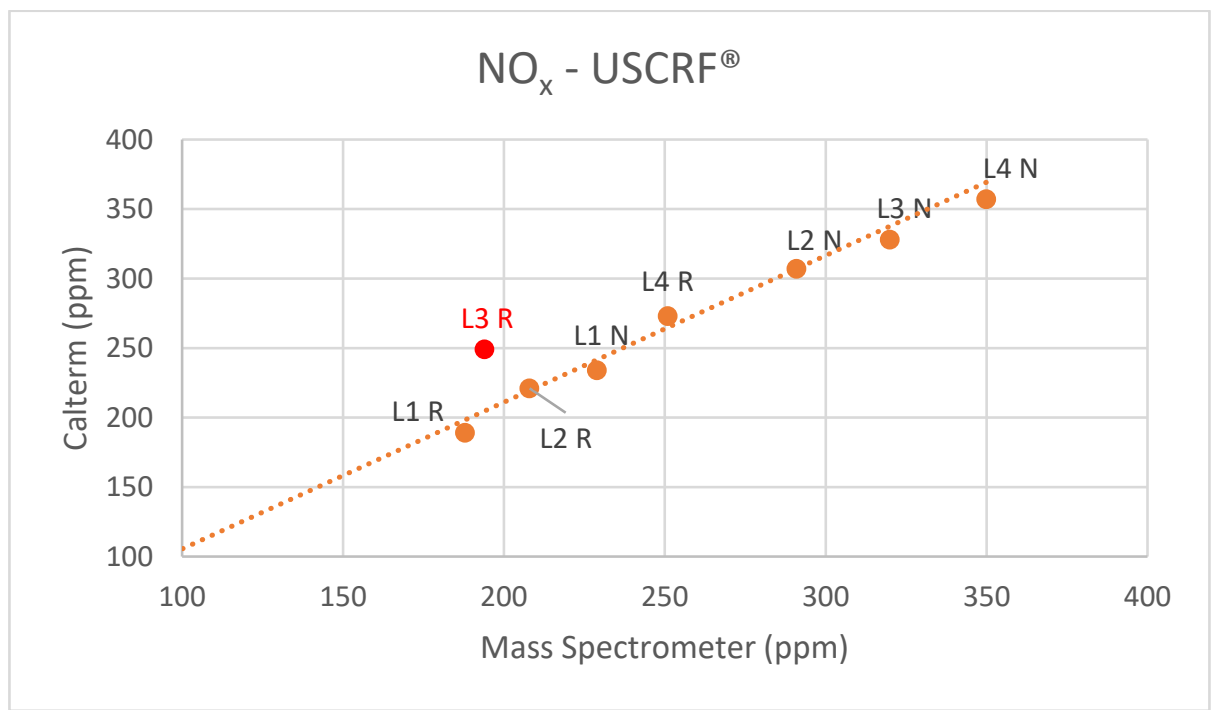

Figure 5.3: Comparison of $\mathrm{NO}_{x}$ Data From Calterm and Mass Spectrometer at USCRF ${ }^{\circledR}$

Similarly, the $\mathrm{NO}_{\mathrm{x}}$ values at $\mathrm{DSCRF}^{\circledR}$ from the $\mathrm{MS}$ is compared to that from Calterm for all the tests as shown in Figure 5.4. Tests L3 Reduced and L4 Nominal are observed to be the outlier points. For $\mathrm{L} 3$ Reduced, the $\mathrm{NO}_{\mathrm{x}}$ value at $\mathrm{DSCRF}^{\oplus}$ from Calterm agrees with the value obtained during the point validation test (Table 3.15) and so Calterm value was used for further analysis. However, for test L4 Nominal, the $\mathrm{NO}_{x}$ value from Mass Spectrometer agrees with the value obtained during the point validation test and so the Calterm value was assumed incorrect. 


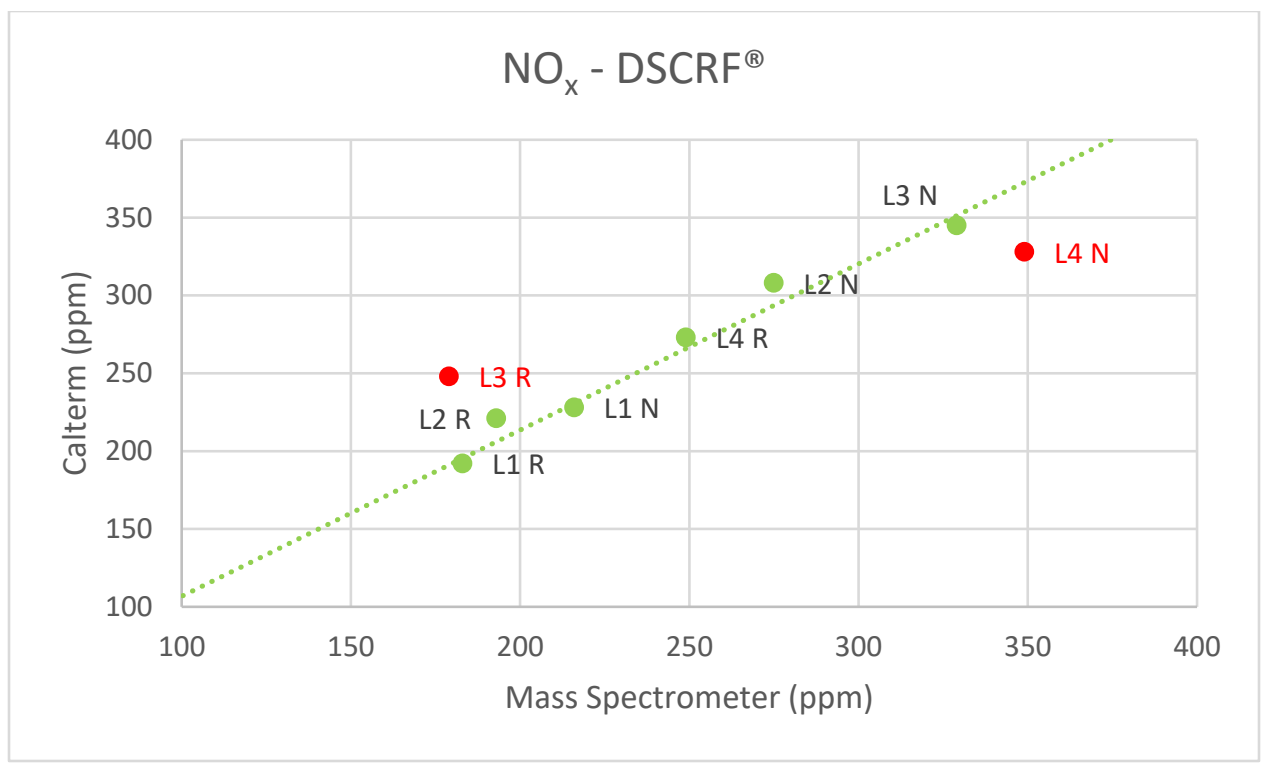

Figure 5.4: Comparison of $\mathrm{NO}_{x}$ Data From Calterm and Mass Spectrometer at DSCRF ${ }^{\circledR}$

The PM mass balance for Stage 1 and Stage 2 for these tests in shown in Table 5.4 and Table 5.5 respectively. The factors that affect $\mathrm{PM}$ loaded into the $\mathrm{SCRF}^{\circledR}$ are exhaust flowrate, fuel rail pressure, $\mathrm{SCRF}^{\oplus}$ inlet temperature and $\mathrm{NO}_{2}$ concentrations into the $\mathrm{SCRF}^{\circledR}$. An increase in $\mathrm{NO}_{2}$ and/or temperature results in a higher amount of PM oxidized and will affect the amount of PM retained in the $\mathrm{SCRF}^{\circledR}$. The parameters given in Table 5.4 and Table 5.5 are calculated using formulae discussed in Section 3.9. The calculation of the clean weight of the $\mathrm{SCRF}^{\circledR}$ is discussed in detail in Appendix A. The filtration efficiency during Stage 1 was not measured physically but was estimated based on results from the calibrated SCR-F model which is also discussed in detail in Appendix A.

During the test L3 Nominal, an active regeneration event was started by the ECU on its own during the last hour of Stage 2 as the manual control of the in-cylinder fuel dosing late into the combustion cycle was not enabled. However, the active regeneration was stopped midway, but still the values highlighted in Table 5.4 and Table 5.5 for L3 Nominal cannot be compared to other tests as the actual PM retained would be slightly higher and PM oxidized would be slightly lower than the values shown in the Table 5.4 and Table 5.5 . 
Table 5.4: PM Balance for Stage 1 for Loading Tests w/o Urea

\begin{tabular}{|c|c|c|c|c|c|c|c|c|}
\hline Test & PM Conc. & $P M_{\text {in }}$ & $\begin{array}{c}\text { Filtration } \\
\text { Efficiency** }\end{array}$ & PM $M_{\text {out }}$ & $\mathbf{P M}_{\text {start }}$ & $\mathrm{PM}_{\text {retained }}$ & PM oxidized $_{\text {on }}$ & PM $M_{\text {oxidized }}$ \\
\hline & [mg/scm] & [g] & [\%] & [g] & [g] & [g] & [g] & [\%] \\
\hline L1 Nominal & 7.2 & 1.96 & 61.6 & 0.75 & 0 & 1.14 & 0.06 & 3.3 \\
\hline L1 Reduced\# & 11.6 & 3.57 & 66.3 & 1.20 & 0 & 2.04 & 0.33 & 9.2 \\
\hline L2 Nominal & 6.4 & 1.86 & 59.8 & 0.75 & 0 & 0.76 & 0.35 & 18.8 \\
\hline L2 Reduced & 11.7 & 3.44 & 64.3 & 1.23 & 0 & 2.06 & 0.15 & 4.5 \\
\hline L3 Nominal & 5.7 & 1.77 & 57.0 & 0.76 & 0 & $0.55^{*}$ & $0.46^{*}$ & $26.1 *$ \\
\hline L3 Reduced & 11.3 & 3.61 & 61.9 & 1.38 & 0 & 1.72 & 0.52 & 14.4 \\
\hline L4 Nominal & 5.5 & 1.76 & 55.4 & 0.78 & 0 & 0.77 & 0.20 & 11.5 \\
\hline L4 Reduced & 11.0 & 3.57 & 59.6 & 1.44 & 0 & 1.47 & 0.65 & 18.3 \\
\hline
\end{tabular}

\#Data obtained from Test PO-C in reference [11]

*Cannot compare with other tests due to unexpected active regeneration in Stage 2

**Average filtration efficiency estimated using calibrated SCR-F model discussed in Appendix A

Table 5.5: PM Balance for Stage 2 for Loading Tests w/o Urea

\begin{tabular}{|c|c|c|c|c|c|c|c|c|}
\hline \multirow{2}{*}{ Test } & PM Conc. & $\mathbf{P M}_{\text {in }}$ & $\begin{array}{c}\text { Filtration } \\
\text { Efficiency }\end{array}$ & $\mathbf{P M}_{\text {out }}$ & $\mathbf{P M}_{\text {start }}$ & $\mathbf{P M}_{\text {retained }}$ & $\mathbf{P M}_{\text {oxidized }}$ & $\mathbf{P M}_{\text {oxidized }}$ \\
\cline { 2 - 8 } & {$[\mathrm{mg} / \mathrm{scm}]$} & {$[\mathrm{g}]$} & {$[\%]$} & {$[\mathrm{g}]$} & {$[\mathrm{g}]$} & {$[\mathrm{g}]$} & {$[\mathrm{g}]$} & {$[\%]$} \\
\hline L1 Nominal & 7.1 & 19.7 & 97.5 & 0.50 & 1.14 & 16.1 & 4.22 & 20.3 \\
\hline L1 Reduced & 11.7 & 33.4 & 98.4 & 0.53 & 2.04 & 25.4 & 9.47 & 26.7 \\
\hline L2 Nominal & 6.6 & 19.2 & 96.7 & 0.63 & 0.76 & 11.5 & 7.87 & 39.4 \\
\hline L2 Reduced & 11.7 & 34.3 & 97.2 & 0.95 & 2.06 & 26.8 & 8.62 & 23.7 \\
\hline L3 Nominal & 5.7 & 16.8 & 97.0 & 0.50 & $0.55 *$ & $7.7 *$ & $9.21 *$ & $53.0 *$ \\
\hline L3 Reduced & 11.0 & 33.7 & 97.1 & 0.98 & 1.72 & 20.1 & 14.3 & 40.4 \\
\hline L4 Nominal & 5.7 & 18.3 & 96.0 & 0.74 & 0.77 & 8.5 & 9.86 & 51.6 \\
\hline L4 Reduced & 10.9 & 34.8 & 97.3 & 0.94 & 1.47 & 15.0 & 20.30 & 58.4 \\
\hline
\end{tabular}

\#Data obtained from Test PO-C in reference [11]

*Cannot compare with other tests due to unexpected active regeneration in Stage 2 
The cumulative PM mass balance at the end of Stage 2 for all the tests is illustrated graphically in Figures 5.5 and 5.6. It is observed that the percentage of PM oxidized increases with increase in engine load. This is because at higher engine load, the $\mathrm{SCRF}^{\oplus}$ temperature and $\mathrm{NO}_{2}$ concentrations are higher compared to the values at lower engine load. The PM oxidized percentage increases while moving from L1 Nominal to L4 Nominal or L1 Reduced to L4 Reduced except for L3 Nominal and L1 Reduced. For L3 Nominal, the actual PM oxidized should have been lower and PM retained higher because of an unexpected active regeneration event as discussed before. For L1 Reduced, there is a possibility that the Stage 2 filtration efficiency $(98.4 \%)$ is higher than the filtration efficiency for other tests because of which the percentage of PM out is lower compared to other tests as seen in Figure 5.5. A decreasing trend in the percentage of PM mass retained is observed as we move from L1 Nominal to L4 Nominal or L1 Reduced to L4 Reduced except L3 Nominal and L1 Reduced. Difference in percentage of PM oxidized or PM retained while comparing tests at nominal and reduced fuel rail pressure is due to major difference in the PM concentrations and minor differences in the $\mathrm{SCRF}^{\circledR}$ temperature and $\mathrm{NO}_{2}$ concentrations.

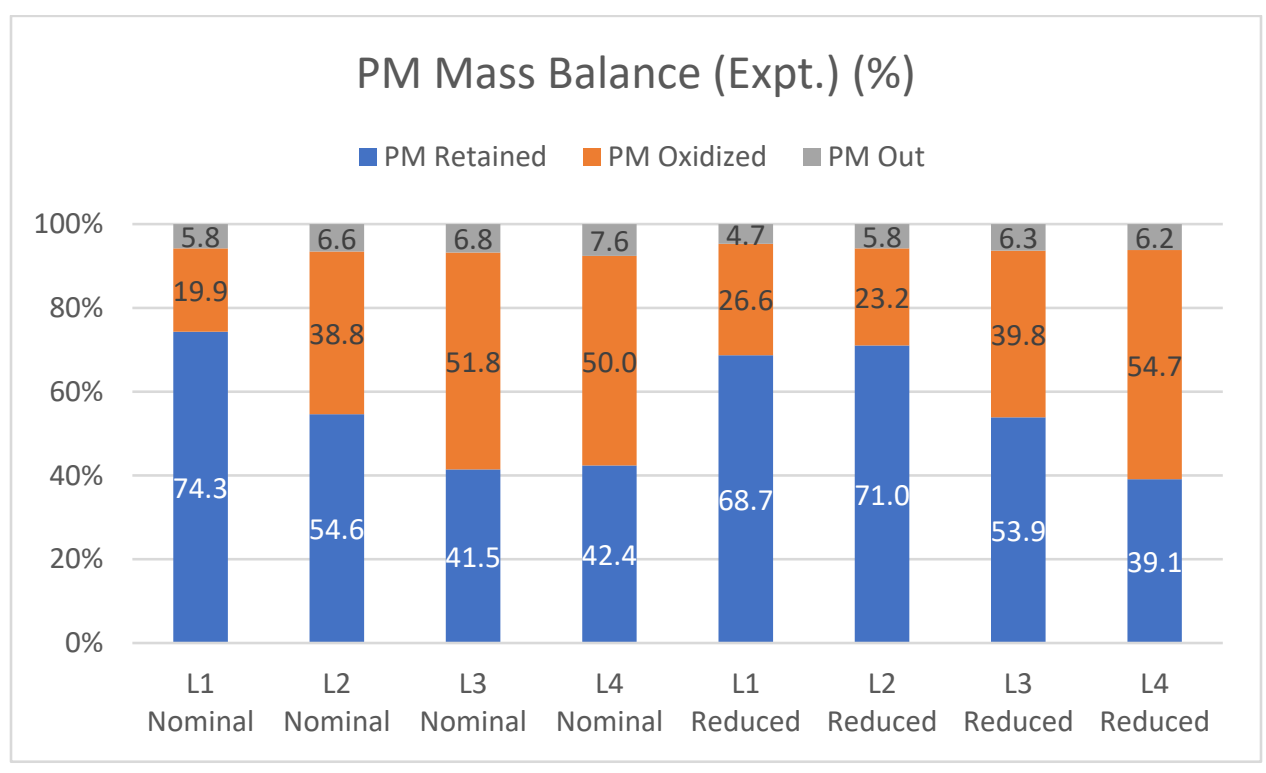

Figure 5.5: PM Mass Balance as Percentage of PM In (Expt.) for Loading Tests w/o Urea

As discussed earlier, the primary objective of the Loading Tests was to determine the $\mathrm{NO}_{2}$ assisted oxidation kinetics for $\mathrm{PM}$ retained in the $\mathrm{SCRF}^{\circledR}$ for different loading conditions and to characterize the differences in the reaction kinetics in loading and passive oxidation conditions. The average reaction rate for $\mathrm{NO}_{2}$ assisted PM oxidation during Stage 2 is calculated as explained in Section 
3.10 for all the tests and is given in Table 5.6. It is important to note that the reaction rate depends on the $\mathrm{SCRF}^{\circledR}$ temperature, $\mathrm{NO}_{2}$ concentrations and the duration and so these values are also given in Table 5.6. The reaction rate constant $(\mathrm{k})$ calculated by normalizing the average reaction rate by the $\mathrm{NO}_{2}$ concentration is also given in Table 5.6.

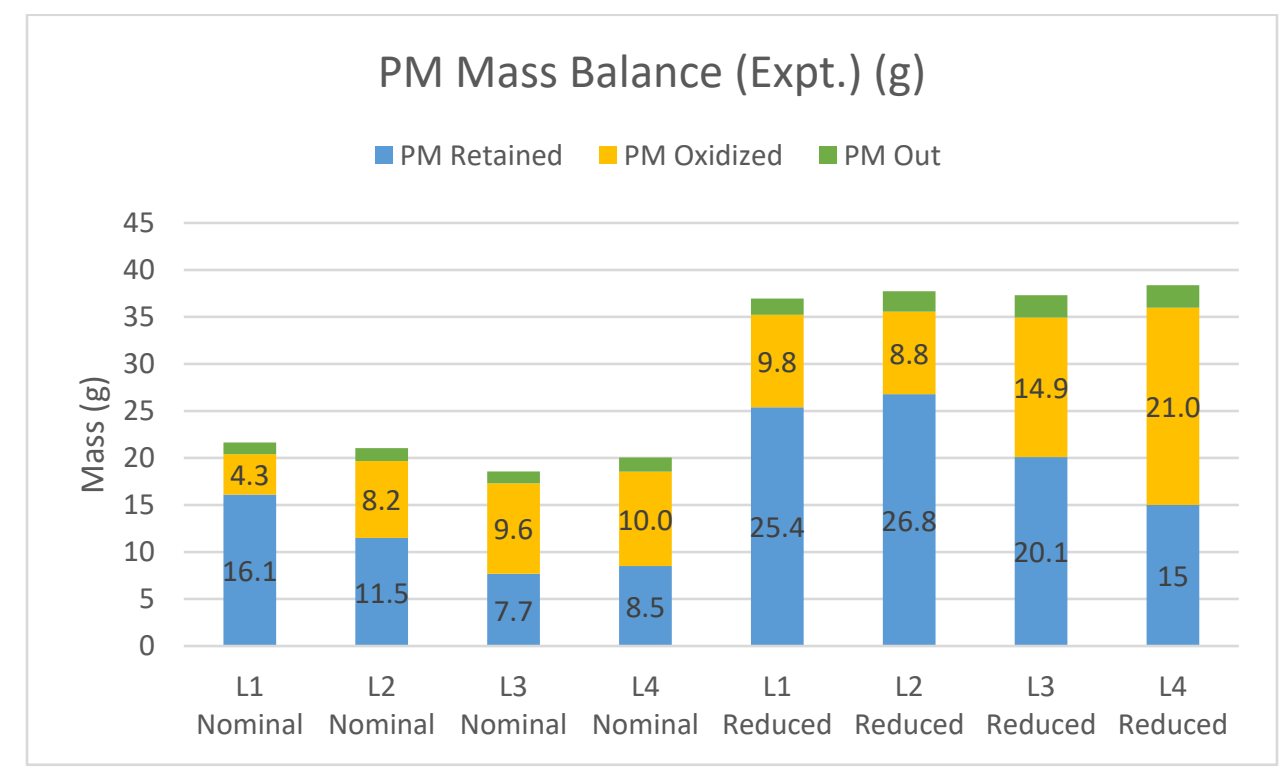

Figure 5.6: PM Mass Balance (Expt.) for Loading Tests w/o Urea

Table 5.6: Variables to Compare Kinetics of $\mathrm{NO}_{2}$ Assisted PM Oxidation Without Urea

\begin{tabular}{|c|c|c|c|c|c|c|c|}
\hline Test & $\begin{array}{c}\text { Expt. } \\
\text { Reaction } \\
\text { Rate }\left(R_{\mathrm{o}}\right)\end{array}$ & $\begin{array}{c}\text { Stage } 2 \\
\text { Duration }\end{array}$ & $\begin{array}{c}\text { SCRF }^{\circledR} \text { Inlet } \\
\text { Temp }\end{array}$ & $\begin{array}{l}\mathrm{NO}_{2} \text { into } \\
\mathrm{SCRF}^{\circledR}\end{array}$ & $\begin{array}{c}\text { PM } \\
\text { Retained }\end{array}$ & $\begin{array}{c}\text { PM } \\
\text { Oxidized }\end{array}$ & $k=R_{0} / N_{2}$ \\
\hline$[-]$ & {$[1 / s]$} & [min] & {$\left[{ }^{\circ} \mathrm{C}\right]$} & [ppm] & [g] & [\%] & {$\left[10^{6} / \mathrm{ppm} / \mathrm{s}\right]$} \\
\hline $\begin{array}{c}\text { L1 } \\
\text { Nominal }\end{array}$ & $2.53 \mathrm{E}-05$ & 299 & 264 & 62 & 16.1 & 20.3 & 0.405 \\
\hline $\begin{array}{c}\text { L1 } \\
\text { Reduced } \\
\end{array}$ & $3.50 \mathrm{E}-05$ & 300 & 275 & 59 & 25.4 & 26.7 & 0.592 \\
\hline $\begin{array}{c}\text { L2 } \\
\text { Nominal } \\
\end{array}$ & $6.11 \mathrm{E}-05$ & 300 & 287 & 88 & 11.5 & 39.4 & 0.694 \\
\hline $\begin{array}{c}\text { L2 } \\
\text { Reduced }\end{array}$ & 3.07E-05 & 299 & 298 & 61 & 26.8 & 23.7 & 0.505 \\
\hline $\begin{array}{c}\text { L3 } \\
\text { Nominal }\end{array}$ & - & 300 & 330 & 93 & $7.7^{*}$ & $53.0 *$ & - \\
\hline $\begin{array}{c}\text { L3 } \\
\text { Reduced }\end{array}$ & $6.24 \mathrm{E}-05$ & 302 & 332 & 80 & 20.1 & 40.4 & 0.780 \\
\hline $\begin{array}{c}\text { L4 } \\
\text { Nominal }\end{array}$ & $9.51 \mathrm{E}-05$ & 300 & 352 & 120 & 8.5 & 51.6 & 0.793 \\
\hline $\begin{array}{c}\text { L4 } \\
\text { Reduced }\end{array}$ & $1.08 \mathrm{E}-04$ & 302 & 364 & 82 & 15.0 & 58.4 & 1.320 \\
\hline
\end{tabular}

"Data obtained from Test PO-C in reference [11]

*Cannot compare with other tests due to unexpected active regeneration in Stage 2 
The natural log of reaction rate constant $(\mathrm{k})$ from Table 5.6 is plotted against the inverse of $\mathrm{SCRF}^{\circledR}$ inlet temperature for all the tests and is shown in Figure 5.7. The variation of $k$ with the inverse of $\mathrm{SCRF}^{\circledR}$ average temperature determined from the experimental data from passive oxidation tests w/o Urea [8] is also plotted in Figure 5.7 for comparison. As observed from Figure 5.7, the reaction rate kinetics for $\mathrm{NO}_{2}$ assisted $\mathrm{PM}$ oxidation during loading is higher compared to that during passive oxidation. A similar trend was also reported in reference [4] and reference [8] for $\mathrm{PM}$ oxidation in a $\mathrm{CPF}$ and a $\mathrm{SCRF}^{\circledR}$ respectively as discussed in Section 2.4. Also, the average reaction rate and reaction rate constant is higher for tests at higher engine load compared to tests at lower engine load. The average reaction rate for L3 Nominal was not calculated as the value of PM retained and PM oxidized computed is not consistent due to an unexpected active regeneration in Stage 2 as explained earlier.

A standard Arrhenius model is used to fit the passive oxidation data from reference [8] which results in a line with slope and y intercept which corresponds to activation energy $\left(E_{a}\right)$ and preexponential (A) respectively. The value of activation energy obtained is the minimum energy required for the oxidation of $\mathrm{PM}$ with $\mathrm{NO}_{2}$. The pre-exponential factor relates to how likely two or more molecules collide in the right orientation for the reaction to occur. The line of best fit for determining $E_{a}$ and $A$ for the passive oxidation data is plotted in Figure 5.7.

It is important to note that it is not possible to fit the data for Loading Tests w/o Urea using a standard Arrhenius model as observed from Figure 5.7. Hence, a model for PM oxidation was developed in this study to simulate the reaction kinetics during loading and passive oxidation conditions for a single set of kinetics. The development of this model is discussed in detail in Section 4.1 along with its application to the SCR-F model in Section 4.2. The performance of the SCR-F model with reaction rate results from PM oxidation model for the Loading Tests w/o Urea is discussed in detail in Section 5.4. The PM oxidation model is able to simulate the reaction kinetics during passive oxidation conditions along with the loading conditions for a single set of kinetics and the results will be discussed in Section 5.5. 


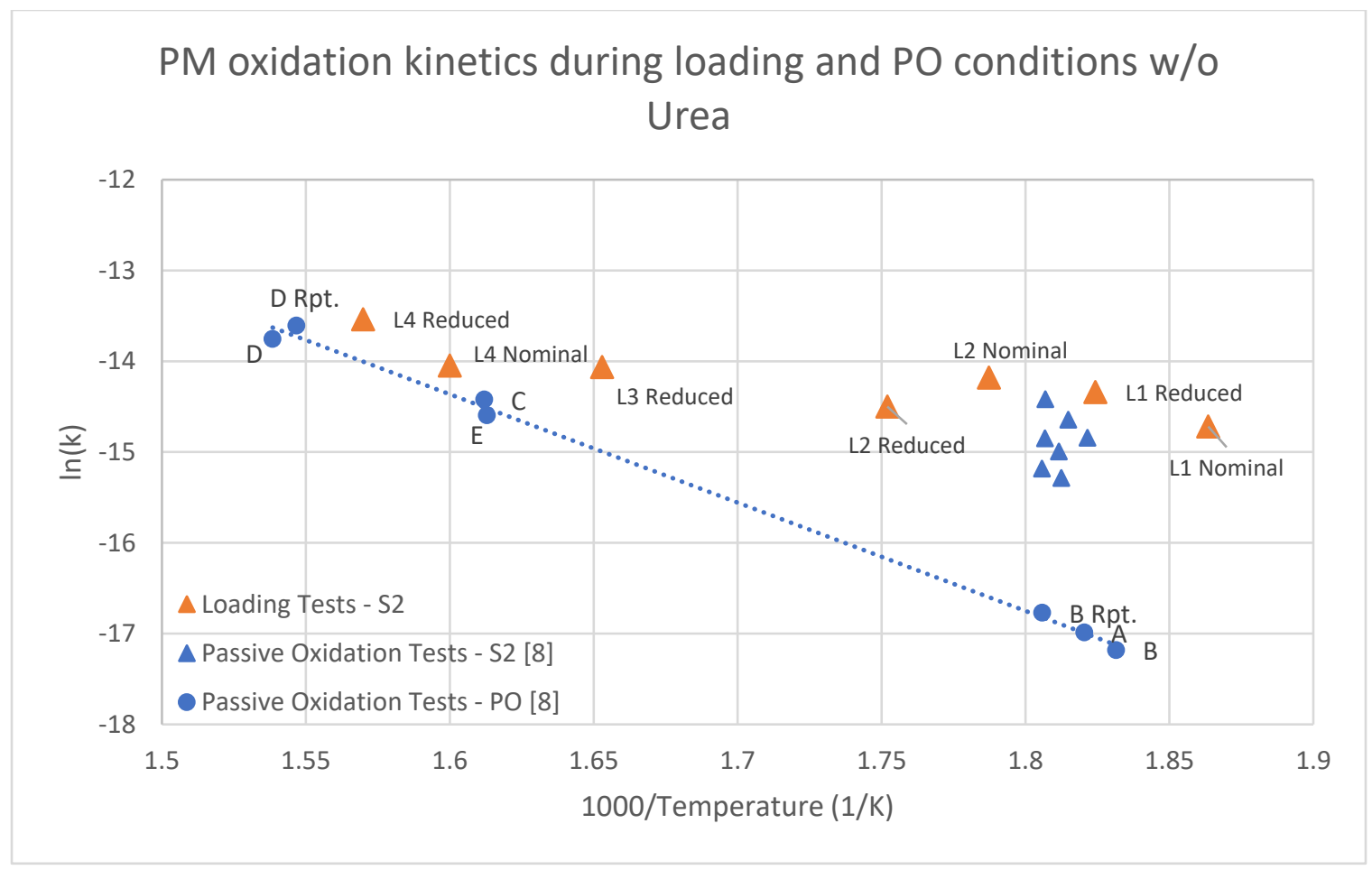

Figure 5.7: Comparison of PM Oxidation Kinetics for Passive Oxidation [8] and Loading Conditions w/o Urea in SCRF ${ }^{\circledR}$ 


\subsection{Loading Tests w/ Urea}

The results for the Loading Tests $w /$ Urea will be presented in a similar fashion to the Loading Tests w/o Urea. Since the focus of this thesis is to compare and characterize the difference in reaction kinetics under loading and passive oxidation conditions, it is important to study kinetics of PM oxidation in loading conditions with urea so that the difference in kinetics with urea injection can be quantified. As discussed earlier, all the Loading Test $w /$ Urea were performed at a target ANR of 1.0. The actual ANR will be discussed later in this section. To introduce the results for the Loading Tests w/ Urea, the engine and exhaust conditions for Stage 2 for each test are given in Table 5.7.

Table 5.7: Engine and Exhaust Conditions for Stage 2 in Loading Tests w/ Urea

\begin{tabular}{|c|c|c|c|c|c|c|c|c|c|}
\hline Test & FRP & Speed & Load & $\begin{array}{c}\text { Exhaust } \\
\text { Flow Rate }\end{array}$ & $\begin{array}{c}\text { Std. Space } \\
\text { Velocity }\end{array}$ & PM Conc. & $\begin{array}{c}\text { DOC } \\
\text { Inlet } \\
\text { Temp. }\end{array}$ & $\begin{array}{c}\text { SCRF } \\
\text { Inlet } \\
\text { Temp. }\end{array}$ & ANR \\
\hline$[-]$ & {$[$ Bar] } & {$[\mathrm{RPM}]$} & {$[\mathrm{Nm}]$} & {$[\mathrm{kg} / \mathrm{min}]$} & {$[\mathrm{k} / \mathrm{hr}]$} & {$[\mathrm{mg} / \mathrm{scm}]$} & {$\left[{ }^{\circ} \mathrm{C}\right]$} & {$\left[{ }^{\circ} \mathrm{C}\right]$} & {$[-]$} \\
\hline $\begin{array}{c}\text { L1-Nom } \\
\text { w/ Urea }\end{array}$ & 1513 & 2399 & 200 & 10.9 & 33 & 7.2 & 273 & 268 & 1.00 \\
\hline $\begin{array}{c}\text { L1-Red } \\
\text { w/ Urea }\end{array}$ & 1050 & 2404 & 203 & 11.0 & 33 & 14.1 & 287 & 283 & 0.98 \\
\hline $\begin{array}{c}\text { L3-Nom } \\
\text { w/ Urea }\end{array}$ & 1593 & 2399 & 340 & 12.1 & 36 & 6.9 & 328 & 321 & 1.09 \\
\hline $\begin{array}{c}\text { L3-Red } \\
\text { w/ Urea }\end{array}$ & 1103 & 2402 & 340 & 12.1 & 36 & 11.3 & 347 & 334 & 1.01 \\
\hline
\end{tabular}

It is important to note that the injection of urea should not have any effect on the engine and exhaust conditions given in Table 5.7. The difference between the values in Table 5.7 and 5.1 for the same test conditions are due to minor day to day variations in the performance of the engine. The major difference observed is in the PM concentrations for these tests with and without urea. The $\mathrm{NO}, \mathrm{NO}_{2}$ and $\mathrm{NO}_{x}$ values at the $\mathrm{DOC}$ inlet and $\mathrm{SCRF}^{\circledR}$ inlet for each Loading Test $\mathrm{w} /$ Urea are given in Table 5.8. Theoretically, $\mathrm{NO}_{\mathrm{x}}$ should be conserved across the $\mathrm{DOC}$ and $\mathrm{NO}_{\mathrm{x}}$ is reduced across the $\mathrm{SCRF}^{\oplus}$ when there is urea injection into the system. However, as observed from Table 5.8 , there is slight variation in the $\mathrm{NO}_{\mathrm{x}}$ values at the $\mathrm{DOC}$ inlet and $\mathrm{SCRF}^{\circledR}$ inlet for each test. The conservation of mass in terms of $\mathrm{NO}_{x}$ was checked again using Equation 48 with the maximum difference of $4 \%$ which is within an acceptable margin of error $(<10 \%)$. The reason for this difference in the $\mathrm{NO}_{x}$ values has been discussed earlier for Loading Tests w/o Urea. Also, there is 
variation in the $\mathrm{NO}_{\mathrm{x}}$ values at the $\mathrm{DOC}$ inlet and $\mathrm{SCRF}^{\oplus}$ inlet when comparing one Loading Test w/o Urea (Table 5.2) to the Loading Test w/ Urea (Table 5.8). This difference might be due to the day to day variation in calibration process of the Mass Spectrometer.

Table 5.8: Emission Data Across DOC for Loading Tests w/ Urea

\begin{tabular}{|c|c|c|c|c|c|c|c|c|c|}
\hline \multirow{3}{*}{ Test } & \multirow{2}{*}{$\begin{array}{l}\text { DOC } \\
\text { Inlet } \\
\text { Temp. }\end{array}$} & \multicolumn{3}{|c|}{ DOC Inlet } & \multirow{2}{*}{ NO Conv. } & \multicolumn{3}{|c|}{ SCRF $^{\circledR}$ Inlet } & \multirow{2}{*}{$\begin{array}{l}\mathrm{NO}_{\mathrm{x}} \\
\text { Diff. }\end{array}$} \\
\hline & & $\mathrm{NO}_{2}$ & NO & NO $_{x}$ & & $\mathrm{NO}_{2}$ & NO & $\mathrm{NO}_{\mathrm{x}}$ & \\
\hline & {$\left[{ }^{\circ} \mathrm{C}\right]$} & [ppm] & [ppm] & [ppm] & [\%] & [ppm] & [ppm] & [ppm] & [\%] \\
\hline $\begin{array}{l}\text { L1 Nominal } \\
\text { w/ Urea }\end{array}$ & 272 & 21 & 161 & 182 & 11 & 41 & 143 & 184 & -1 \\
\hline $\begin{array}{c}\text { L1 Reduced } \\
\text { w/ Urea }\end{array}$ & 287 & 23 & 142 & 165 & 15 & 45 & 121 & 166 & -1 \\
\hline $\begin{array}{l}\text { L3 Nominal } \\
\text { w/ Urea }\end{array}$ & 328 & 16 & 293 & 309 & 32 & 98 & 200 & 298 & 4 \\
\hline $\begin{array}{c}\text { L3 Reduced } \\
\text { w/ Urea }\end{array}$ & 347 & 12 & 245 & 257 & 29 & 76 & 174 & 250 & 3 \\
\hline
\end{tabular}

The percentage of NO conversion across the DOC is also calculated for these tests using Equation 49, the values of which are given in Table 5.8. Again, it is assumed that there are no reactions occurring in the decomposition tube between the DOC outlet and $\mathrm{SCRF}^{\circledR}$ inlet and so NO values at the $\mathrm{DOC}$ outlet are equal to the $\mathrm{NO}$ values at the $\mathrm{SCRF}^{\circledR}$ inlet. The $\mathrm{NO}_{x}$ reduction reactions occur only in the $\mathrm{SCRF}^{\circledR}$ and not in the decomposition tube. The NO conversion across the DOC is plotted against the DOC inlet temperature and is shown in Figure 5.8.

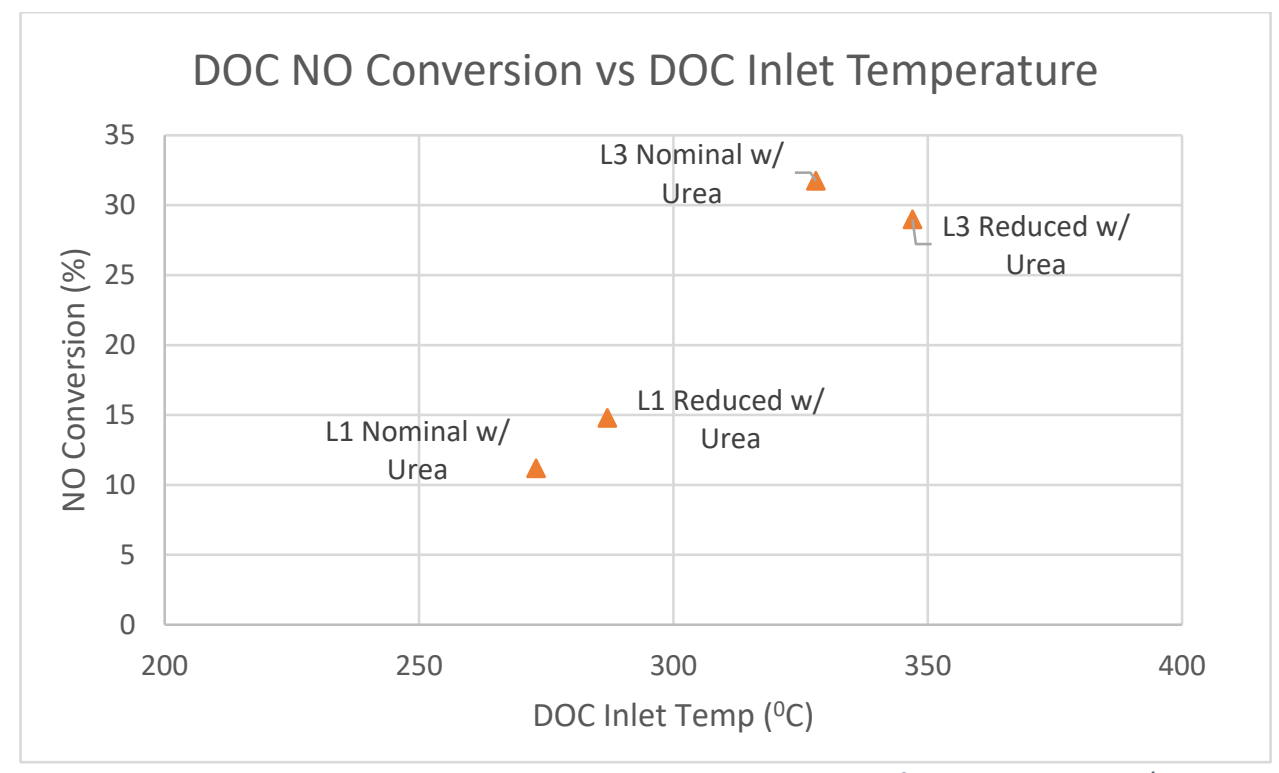

Figure 5.8: NO Conversion Across DOC vs DOC Inlet Temperature for Loading Tests w/ Urea 
Further, the $\mathrm{NO}, \mathrm{NO}_{2}$ and $\mathrm{NO}_{\mathrm{x}}$ values at the $\mathrm{SCRF}^{\circledR}$ outlet are given in Table 5.9 along with the values at the inlet for comparison. Since urea was injected into the system at ANR of 1.0, we see a significant reduction in the $\mathrm{NO}_{\mathrm{x}}$ values across the $\mathrm{SCRF}^{\oplus}$. The value of $\mathrm{NO}_{\mathrm{x}}$ reduction in percentage of inlet value is also given in Table 5.9 for each test.

Table 5.9: Emission Data Across SCRF ${ }^{\circledR}$ for Loading Tests w/ Urea

\begin{tabular}{|c|c|c|c|c|c|c|c|c|}
\hline \multirow{3}{*}{ Test } & \multirow{2}{*}{$\begin{array}{l}\text { SCRF }^{\circledR} \text { Inlet } \\
\text { Temp. }\end{array}$} & \multicolumn{3}{|c|}{ SCRF $^{\circledR}$ Inlet } & \multicolumn{3}{|c|}{ SCRF $^{\circledR}$ Outlet } & \multirow{2}{*}{$\begin{array}{l}\mathrm{NO}_{\mathrm{x}} \\
\text { Conv. }\end{array}$} \\
\hline & & $\mathrm{NO}_{2}$ & NO & $\mathrm{NO}_{\mathrm{x}}$ & $\mathrm{NO}_{2}$ & NO & $\mathrm{NO}_{\mathrm{x}}$ & \\
\hline & {$\left[{ }^{\circ} \mathrm{C}\right]$} & [ppm] & [ppm] & [ppm] & [ppm] & [ppm] & [ppm] & [\%] \\
\hline $\begin{array}{c}\text { L1 Nominal w/ } \\
\text { Urea }\end{array}$ & 268 & 41 & 143 & 184 & 0 & 36 & 36 & 80 \\
\hline $\begin{array}{c}\text { L1 Reduced w/ } \\
\text { Urea }\end{array}$ & 283 & 45 & 121 & 166 & 0 & 34 & 34 & 80 \\
\hline $\begin{array}{c}\text { L3 Nominal w/ } \\
\text { Urea }\end{array}$ & 321 & 98 & 200 & 298 & 1 & 18 & 19 & 94 \\
\hline $\begin{array}{c}\text { L3 Reduced w/ } \\
\text { Urea }\end{array}$ & 340 & 76 & 174 & 250 & 1 & 14 & 15 & 94 \\
\hline
\end{tabular}

Similar to the Loading Tests w/o Urea, the $\mathrm{NO}_{x}$ values from Mass Spectrometer (MS) shown in Tables 5.8 and 5.9 were compared to the $\mathrm{NO}_{\mathrm{x}}$ values from the Calterm for Loading Tests $\mathrm{w} /$ Urea. The comparison of $\mathrm{NO}_{x}$ values at $\mathrm{UDOC}$ and $\mathrm{USCRF}^{\circledR}$ and $\mathrm{DSCRF}^{\circledR}$ from the $\mathrm{MS}$ and the Calterm for all the tests is shown in Figures 5.9, 5.10 and 5.11 respectively. The $\mathrm{NO}_{\mathrm{x}}$ value at UDOC and USCRF ${ }^{\circledR}$ and $\mathrm{DSCRF}^{\circledR}$ from the MS and the Calterm seem to be in agreement for all the tests as they are within the acceptable margin of error at all the three locations.

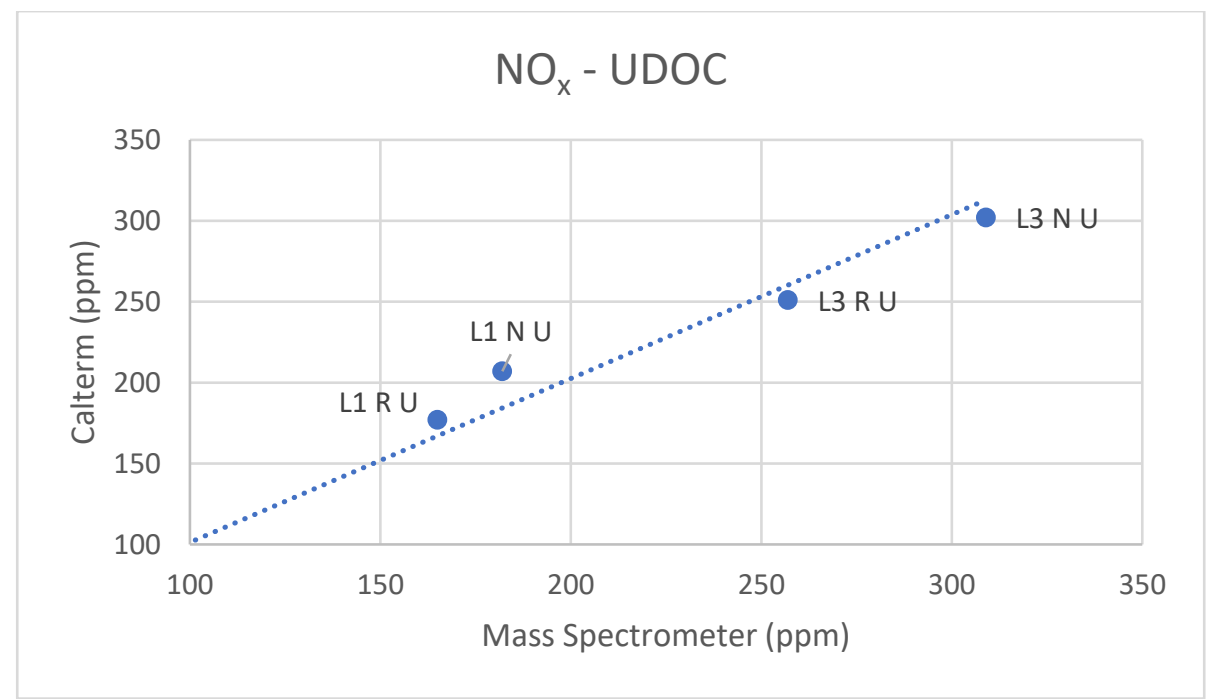

Figure 5.9: Comparison of $\mathrm{NO}_{x}$ Data From Calterm and Mass Spectrometer at UDOC 


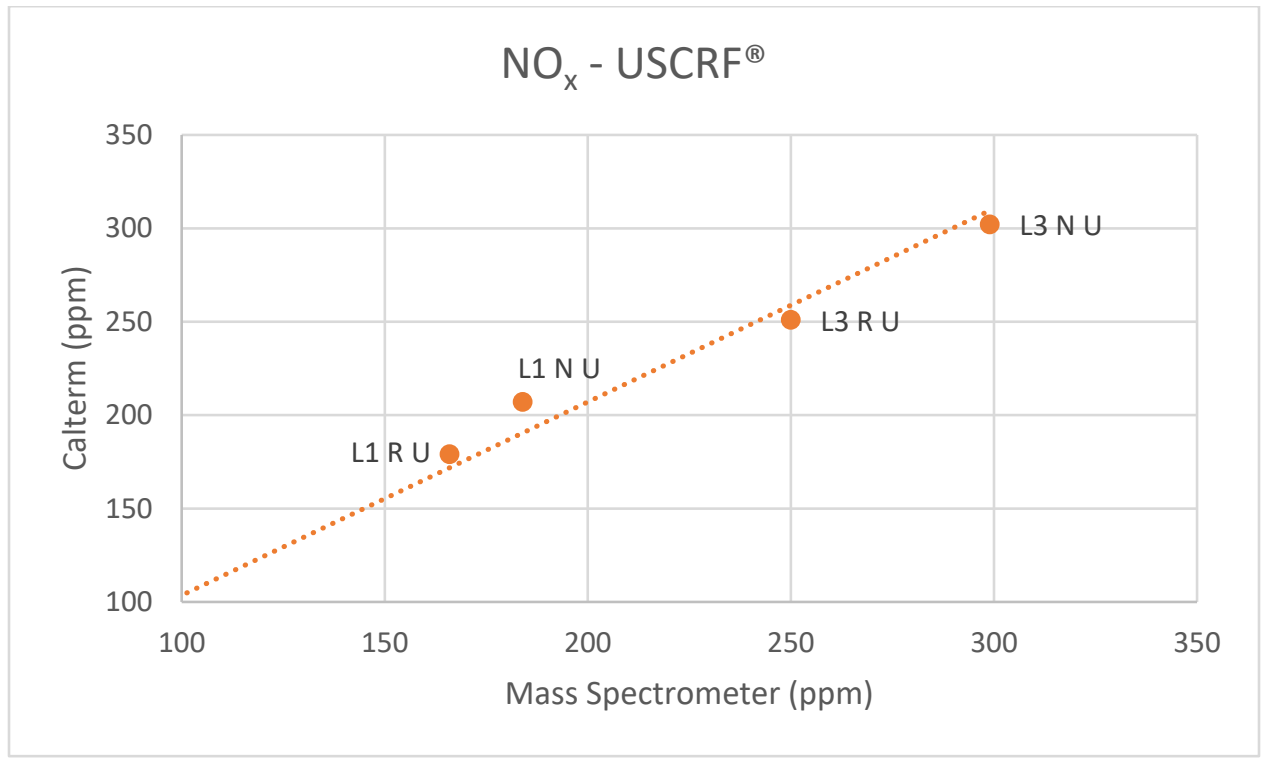

Figure 5.10: Comparison of $\mathrm{NO}_{x}$ Data From Calterm and Mass Spectrometer at USCRF ${ }^{\circledR}$

Figure 5.11 also shows the $\mathrm{NO}_{x}$ values from the Loading Tests w/o Urea at $\mathrm{DSCRF}^{\circledR}$ as compared to the $\mathrm{NO}_{\mathrm{x}}$ values from the Loading Tests $\mathrm{w} /$ Urea. As there is $\mathrm{NO}_{x}$ reduction across the $\mathrm{SCRF}^{\circledR}$ due to the $\mathrm{NH}_{3}, \mathrm{NO}$ and $\mathrm{NO}_{2}$ reactions, the $\mathrm{NO}_{x}$ values at $\mathrm{DSCRF}^{\oplus}$ are significantly lower in concentrations which is clearly seen in Figure 5.11.

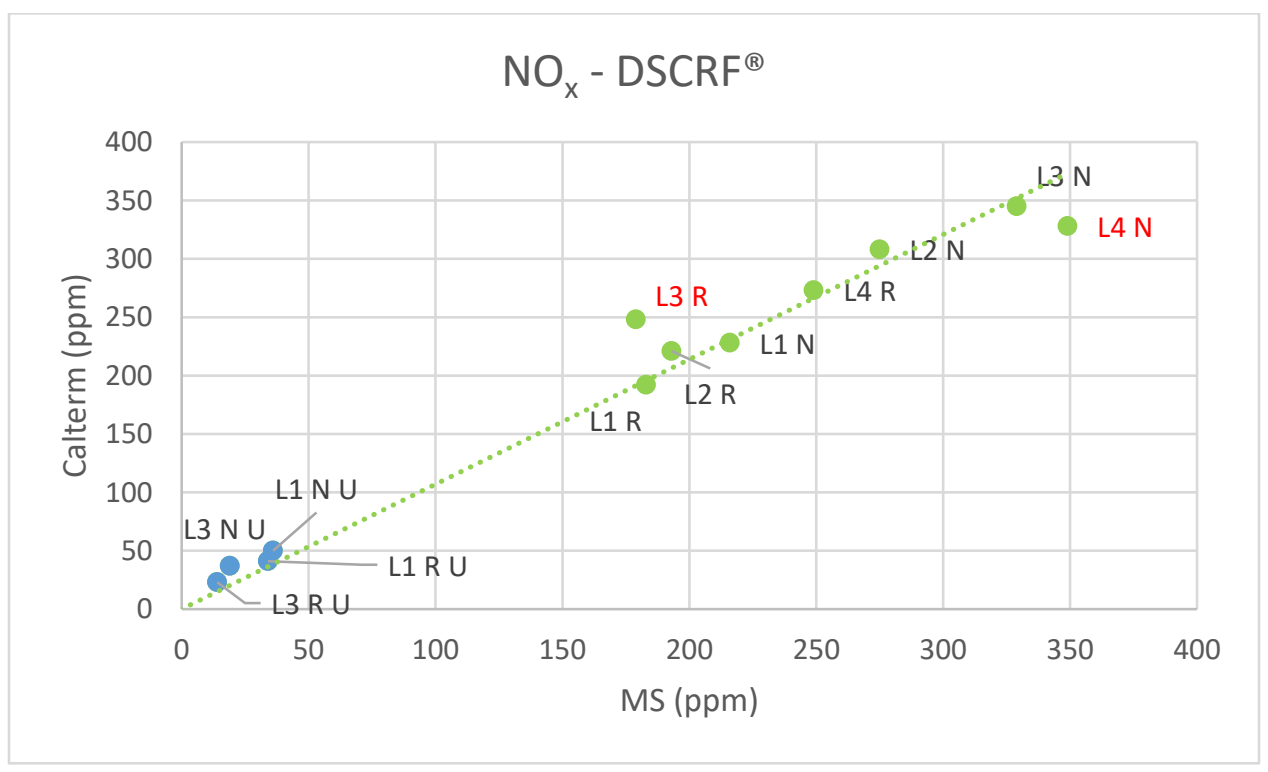

Figure 5.11: Comparison of $N_{x}$ Data From Calterm and Mass Spectrometer at DSCRF ${ }^{\circledR}$ 
The $\mathrm{NO}_{\mathrm{x}}$ reduction performance of the $\mathrm{SCRF}^{\circledR}$ for Loading Tests $\mathrm{w} /$ Urea is shown in Table 5.10. For these tests, the target ANR was 1.0. However, the values of ANR shown in Table 5.10 are the actual values used in the tests.

Table 5.10: $\mathrm{NO}_{x}$ Reduction Performance of $\mathrm{SCRF}^{\circledR}$ at ANR 1.0 During Stage 2 for Loading Tests w/ Urea

\begin{tabular}{|c|c|c|c|c|c|c|}
\hline Test & ANR & $\begin{array}{c}\mathbf{N H}_{\mathbf{3}} \\
\text { Injected }\end{array}$ & $\mathbf{N H}_{3}$ Slip & $\begin{array}{c}\mathbf{N O}_{\mathbf{x}} \text { Into } \\
\mathbf{S C R F}^{\circledR}\end{array}$ & $\begin{array}{c}\mathbf{N O}_{\mathbf{x}} \text { Out } \\
\text { of SCRF }^{\circledR}\end{array}$ & $\begin{array}{c}\mathbf{N O}_{\mathbf{x}} \\
\text { Conversion }\end{array}$ \\
\hline $\begin{array}{c}{[-]} \\
{\left[\begin{array}{c}\text { L1 Nominal } \\
\text { w/ Urea }\end{array}\right.}\end{array}$ & 1.00 & 184 & 1 & 184 & 36 & 80 \\
\hline $\begin{array}{c}\text { L1 Reduced } \\
\text { w/ Urea }\end{array}$ & 0.98 & 163 & 16 & 166 & 34 & 80 \\
\hline $\begin{array}{c}\text { L3 Nominal } \\
\text { w/ Urea }\end{array}$ & 1.09 & 325 & 23 & 298 & 19 & 94 \\
\hline $\begin{array}{c}\text { L3 Reduced } \\
\text { w/ Urea }\end{array}$ & 1.01 & 253 & 15 & 250 & 15 & 94 \\
\hline
\end{tabular}

Further, the PM mass balance for Stage 1 and Stage 2 for these tests in shown in Tables 5.11 and 5.12 respectively. It is important to note that the percentage of PM oxidized in Stage 1 and Stage 2 is low compared to the percentage of PM oxidized in Loading Test w/o Urea with similar conditions as the duration for both the tests with and without urea was the same. This difference in the percentage of PM oxidized due to urea injection has been discussed in detail in Section 5.3. The calculation of the clean weight of the $\mathrm{SCRF}^{\circledR}$ is discussed in detail in Appendix $\mathrm{A}$. The filtration efficiency during Stage 1 was not measured physically but was estimated based on results from the calibrated SCR-F model which is also discussed in detail in Appendix A.

Table 5.11: PM Balance for Stage 1 for Loading Tests w/ Urea

\begin{tabular}{|c|c|c|c|c|c|c|c|c|}
\hline \multirow{2}{*}{ Test } & $\begin{array}{c}\text { PM } \\
\text { Conc. }\end{array}$ & PM $_{\text {in }}$ & $\begin{array}{c}\text { Filtration } \\
\text { Efficiency* }^{*}\end{array}$ & PM $_{\text {out }}$ & PM $_{\text {start }}$ & PM $_{\text {retained }}$ & PM $_{\text {oxidized }}$ & PM $_{\text {oxidized }}$ \\
\cline { 2 - 9 }$[\mathrm{mg} / \mathrm{scm}]$ & {$[\mathrm{g}]$} & {$[\%]$} & {$[\mathrm{g}]$} & {$[\mathrm{g}]$} & {$[\mathrm{g}]$} & {$[\mathrm{g}]$} & {$[\%]$} \\
\hline $\begin{array}{c}\text { L1 Nominal } \\
\text { w/ Urea }\end{array}$ & 6.7 & 1.83 & 61.6 & 0.70 & 0 & 1.12 & 0.01 & 0.3 \\
\hline $\begin{array}{c}\text { L1 Reduced } \\
\text { w/ Urea }\end{array}$ & 14.1 & 3.84 & 65.0 & 1.34 & 0 & 2.29 & 0.20 & 5.3 \\
\hline $\begin{array}{c}\text { L3 Nominal } \\
\text { w/ Urea }\end{array}$ & 7.4 & 2.29 & 57.0 & 0.98 & 0 & 0.95 & 0.35 & 15.4 \\
\hline $\begin{array}{c}\text { L3 Reduced } \\
\text { w/ Urea }\end{array}$ & 12.0 & 3.73 & 61.9 & 1.42 & 0 & 2.12 & 0.19 & 5.2 \\
\hline
\end{tabular}

${ }^{*}$ Average filtration efficiency estimated using calibrated SCR-F model discussed in Appendix A 
Table 5.12: PM Balance for Stage 2 for Loading Tests w/ Urea

\begin{tabular}{|c|c|c|c|c|c|c|c|c|}
\hline \multirow{2}{*}{ Test } & $\begin{array}{c}\text { PM } \\
\text { Conc. }\end{array}$ & $\mathbf{P M}_{\text {in }}$ & $\begin{array}{c}\text { Filtration } \\
\text { Efficiency }\end{array}$ & $\mathbf{P M}_{\text {out }}$ & $\mathbf{P M}_{\text {start }}$ & $\mathbf{P M}_{\text {retained }}$ & $\mathbf{P M}_{\text {oxidized }}$ & PM $_{\text {oxidized }}$ \\
\cline { 2 - 9 }$[\mathrm{mg} / \mathrm{scm}]$ & {$[\mathrm{g}]$} & {$[\%]$} & {$[\mathrm{g}]$} & {$[\mathrm{g}]$} & {$[\mathrm{g}]$} & {$[\mathrm{g}]$} & {$[\%]$} \\
\hline $\begin{array}{c}\text { L1 Nominal } \\
\text { w/ Urea }\end{array}$ & 7.2 & 20.1 & 98.2 & 0.36 & 1.12 & 17.6 & 3.27 & 15.4 \\
\hline $\begin{array}{c}\text { L1 Reduced } \\
\text { w/ Urea }\end{array}$ & 14.1 & 39.8 & 99.4 & 0.23 & 2.29 & 31.8 & 10.1 & 23.9 \\
\hline $\begin{array}{c}\text { L3 Nominal } \\
\text { w/ Urea }\end{array}$ & 6.9 & 21.2 & 98.0 & 0.43 & 0.95 & 12.4 & 9.34 & 42.1 \\
\hline $\begin{array}{c}\text { L3 Reduced } \\
\text { w/ Urea }\end{array}$ & 11.3 & 34.8 & 97.9 & 0.74 & 2.12 & 24.6 & 11.6 & 31.3 \\
\hline
\end{tabular}

The cumulative PM mass balance at the end of Stage 2 for all the tests is illustrated graphically in Figures 5.12 and 5.13. It is observed that the percentage of PM oxidized is higher for L3 compared to $\mathrm{L} 1$. This is because at higher engine load, the $\mathrm{SCRF}^{\circledR}$ temperature and $\mathrm{NO}_{2}$ concentrations are higher compared to lower engine load. A decreasing trend in the percentage of PM mass retained is observed as we move from L1 to L3. The difference in percentage of PM oxidized or PM retained while comparing tests at nominal and reduced fuel rail pressure is due to major difference in PM concentration and minor difference in the $\mathrm{SCRF}^{\circledR}$ temperature and $\mathrm{NO}_{2}$ concentrations.

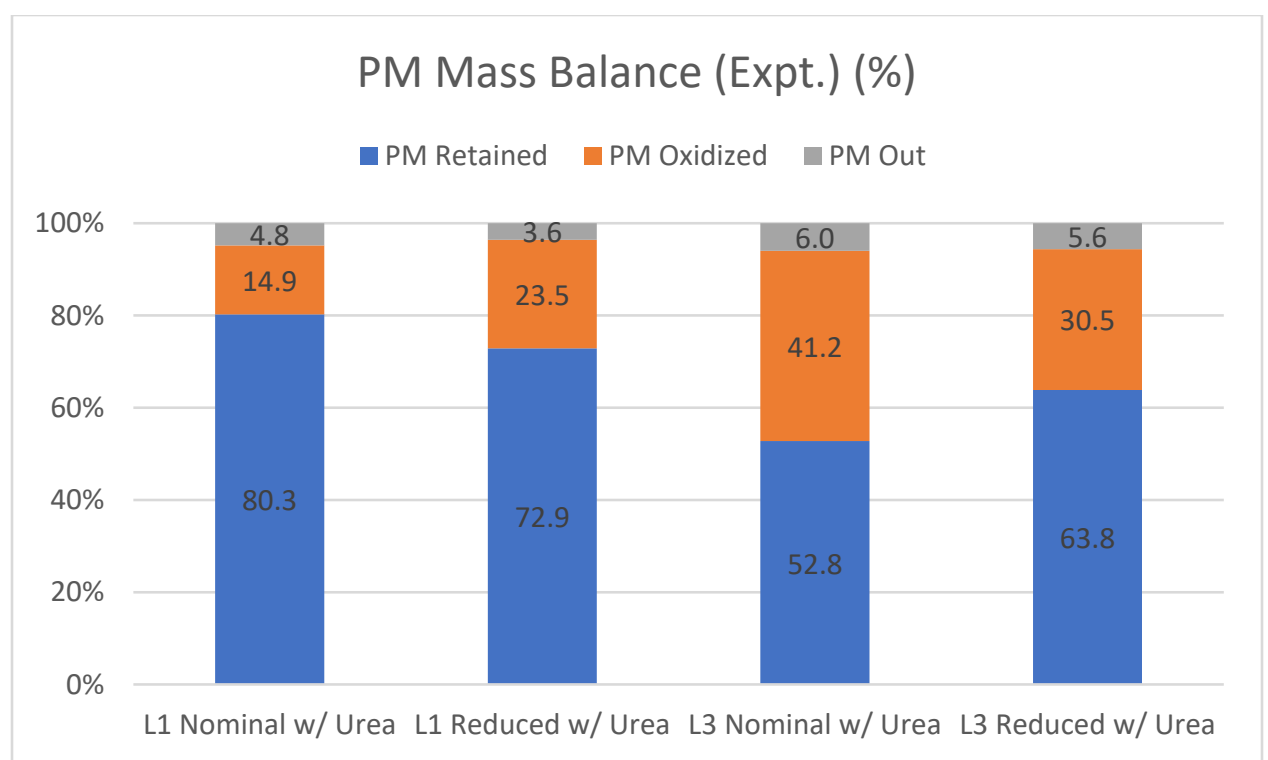

Figure 5.12: PM Mass Balance (Expt.) as \% of PM In for Loading Tests w/ Urea 


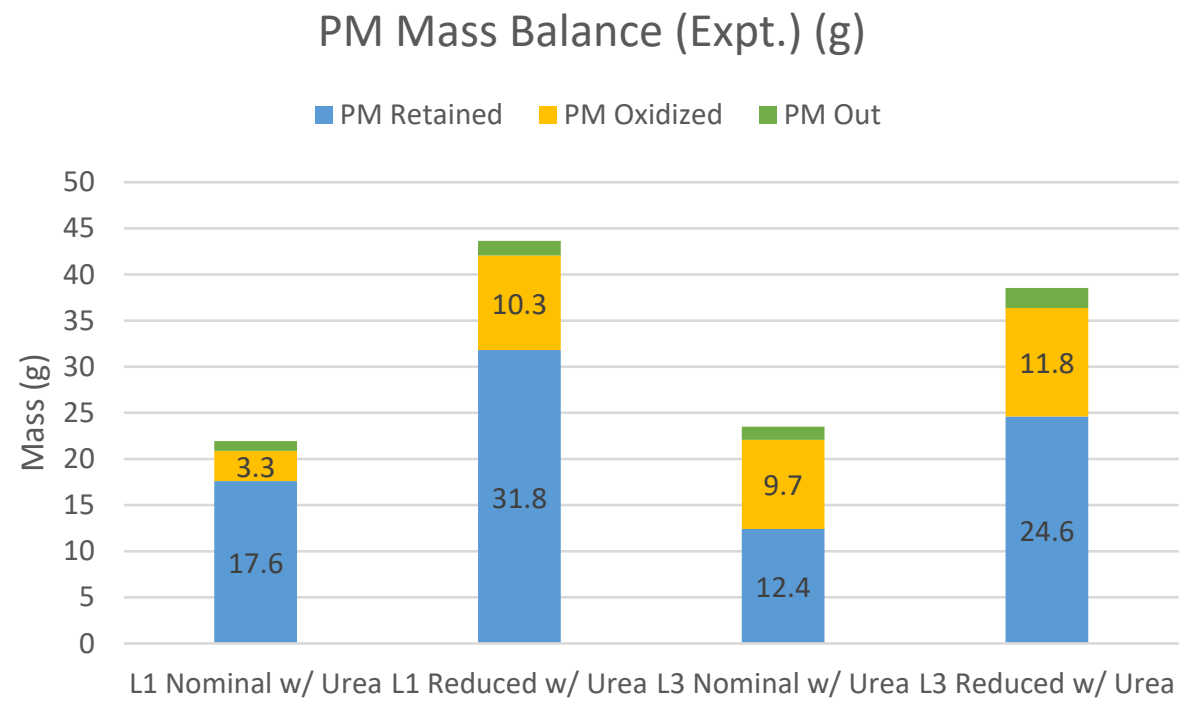

Figure 5.13: PM Mass Balance (Expt.) for Loading Tests w/ Urea

Next, the average reaction rate for $\mathrm{NO}_{2}$ assisted PM oxidation during Stage 2 is calculated as explained in Section 3.10 for all the tests and is given in Table 5.13. The SCRF ${ }^{\circledR}$ temperature, $\mathrm{NO}_{2}$ concentrations, duration and the reaction rate constant $(k)$ are also given in Table 5.13. The average reaction rate and reaction rate constant is higher for tests L3 Nominal and Reduced w/ Urea compared to L1 Nominal and Reduced w/ Urea due to higher SCRF ${ }^{\oplus}$ temperature and $\mathrm{NO}_{2}$ concentrations.

Table 5.13: Variables to Compare Kinetics of $\mathrm{NO}_{2}$ Assisted PM Oxidation With Urea

\begin{tabular}{|c|c|c|c|c|c|c|c|}
\hline Test & $\begin{array}{c}\text { Expt. } \\
\text { Reaction } \\
\text { Rate }\left(\mathbf{R R}_{\mathrm{o}}\right)\end{array}$ & $\begin{array}{c}\text { Stage } 2 \\
\text { Duration }\end{array}$ & $\begin{array}{c}\text { SCRF }^{\circledR} \\
\text { Inlet } \\
\text { Temp } \\
\end{array}$ & $\begin{array}{l}\mathrm{NO}_{2} \text { into } \\
\mathrm{SCRF}^{\circledR}\end{array}$ & $\begin{array}{c}\text { PM } \\
\text { Retained }\end{array}$ & $\begin{array}{c}\text { PM } \\
\text { Oxidized }\end{array}$ & $k=R R_{0} / N_{2}$ \\
\hline$[-]$ & {$[1 / \mathrm{s}]$} & [min] & {$\left[{ }^{\circ} \mathrm{C}\right]$} & [ppm] & [g] & [\%] & {$\left[10^{6} / \mathrm{ppm} / \mathrm{s}\right]$} \\
\hline $\begin{array}{l}\text { L1 Nominal } \\
\text { w/ Urea }\end{array}$ & $1.81 \mathrm{E}-05$ & 302 & 268 & 41 & 17.6 & 15.4 & 0.442 \\
\hline $\begin{array}{c}\text { L1 Reduced } \\
\text { w/ Urea }\end{array}$ & $3.01 E-05$ & 301 & 283 & 45 & 31.8 & 23.9 & 0.669 \\
\hline $\begin{array}{c}\text { L3 Nominal } \\
\text { w/ Urea }\end{array}$ & $6.58 \mathrm{E}-05$ & 301 & 321 & 98 & 12.4 & 42.1 & 0.672 \\
\hline $\begin{array}{c}\text { L3 Reduced } \\
\text { w/Urea }\end{array}$ & 4.32E-05 & 300 & 340 & 76 & 24.6 & 31.3 & 0.569 \\
\hline
\end{tabular}


Again, the natural log of reaction rate constant $(\mathrm{k})$ from Table 5.13 is plotted against the inverse of $\mathrm{SCRF}^{\circledR}$ inlet temperature for all the tests and is shown in Figure 5.14. A similar plot from the experimental data from passive oxidation tests with urea [8] is shown in Figure 5.14 for comparing the kinetics during loading and passive oxidation conditions with urea injection. Similar to the trend observed in Loading Tests $\mathrm{w} / \mathrm{o}$ Urea, the reaction rate kinetics for $\mathrm{NO}_{2}$ assisted PM oxidation during loading with urea injection is higher compared to that during passive oxidation with urea injection. Also, it is not possible to fit the loading with urea data (with a $\mathrm{R}^{2}$ value greater than 0.95 ) from Figure 5.14 with a single set of kinetics unlike the data for passive oxidation for which a single set of kinetics exists which is calculated using a standard Arrhenius model.

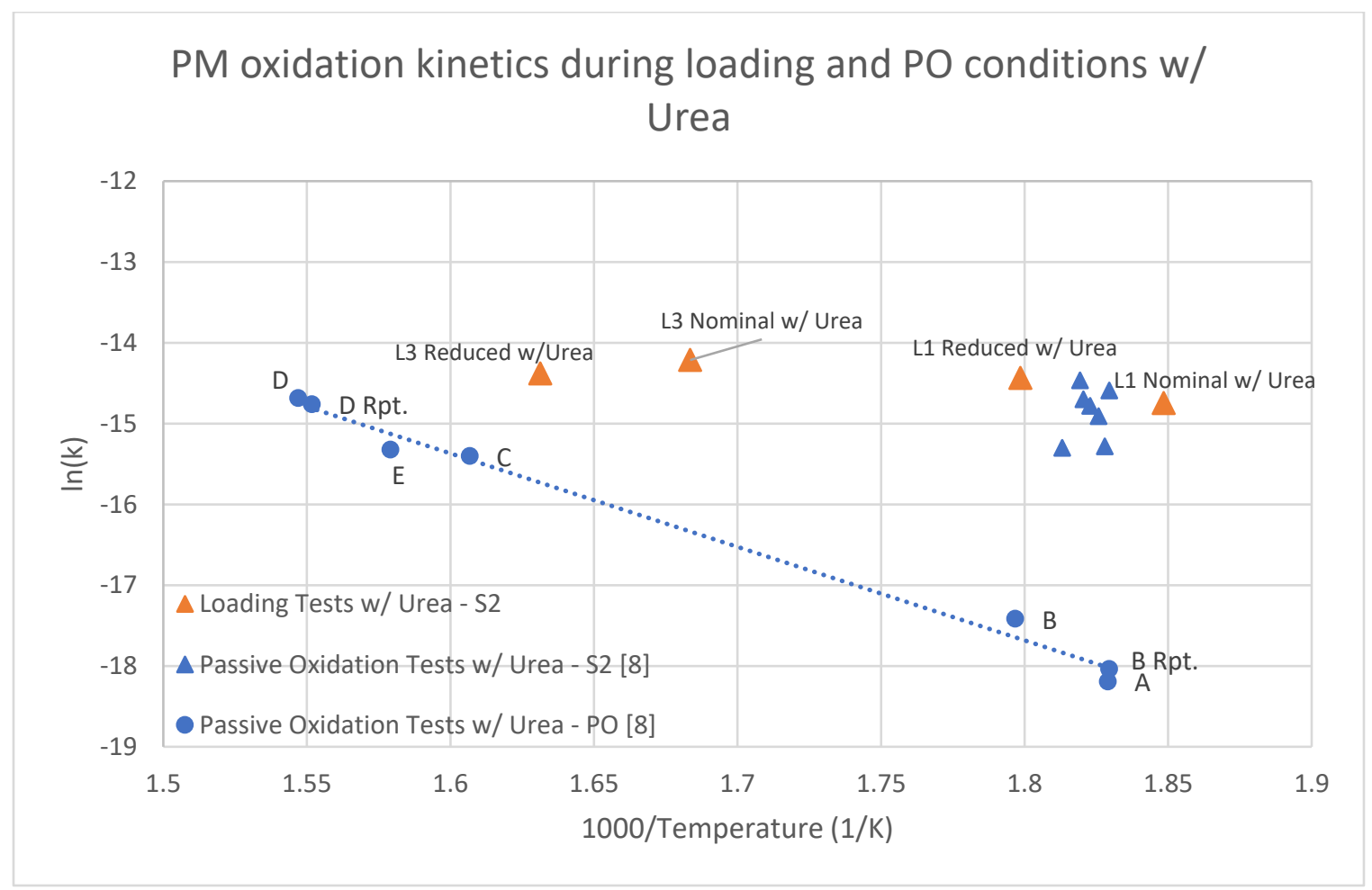

Figure 5.14: Comparison of SCRF ${ }^{\circledR}$ PM Oxidation Kinetics for Passive Oxidation [8] and Loading Conditions With Urea 


\subsection{Comparison of Results for Loading Tests w/o and w/ Urea}

The data and results for the Loading Tests w/o Urea and w/ Urea have been presented in Section 5.1 and Section 5.2 respectively. However, it is important to compare the experimental data from both these sets of tests which is focus of this section. A comparison of the $\mathrm{NO}_{2}$ assisted $\mathrm{PM}$ oxidation kinetics, $\mathrm{PM}$ oxidized, $\mathrm{PM}$ retained and $\mathrm{SCRF}^{\circledast}$ pressure drop for loading with and without urea injection will be presented and discussed.

\section{Kinetics Comparison}

The variables necessary to compare the $\mathrm{NO}_{2}$ assisted $\mathrm{PM}$ oxidation kinetics with and without urea are given in Table 5.14. The average reaction rate, PM retained and PM oxidized are compared for each of the Loading tests w/o and w/ Urea.

Table 5.14: Variables to Compare $\mathrm{NO}_{2}$ Assisted PM Oxidation With and Without Urea Injection

\begin{tabular}{|c|c|c|c|c|c|c|}
\hline Test & $\begin{array}{c}\text { Expt. } \\
\text { Reaction } \\
\text { Rate }\left(\mathbf{R R}_{\mathbf{0}}\right)\end{array}$ & $\begin{array}{c}\text { SCRF }^{\circledR} \text { Inlet } \\
\text { Temp }^{-1}\end{array}$ & $\begin{array}{c}\mathrm{NO}_{2} \text { into } \\
\mathrm{SCRF}^{\circledR}\end{array}$ & $\begin{array}{c}\text { PM } \\
\text { Retained }\end{array}$ & $\begin{array}{c}\text { PM } \\
\text { Oxidized }\end{array}$ & $k=R R_{0} / N^{2}$ \\
\hline$[-]$ & {$[1 / \mathrm{s}]$} & {$\left[{ }^{\circ} \mathrm{C}\right]$} & [ppm] & [g] & [\%] & {$\left[10^{6} / \mathrm{ppm} / \mathrm{s}\right]$} \\
\hline L1 Nominal & $2.53 \mathrm{E}-05$ & 264 & 62 & 16.1 & 20.3 & 0.405 \\
\hline $\begin{array}{c}\text { L1 Nominal } \\
\text { w/ Urea }\end{array}$ & $1.81 \mathrm{E}-05$ & 268 & $46^{1}$ & 17.6 & 15.4 & 0.394 \\
\hline L1 Reduced" & $3.50 \mathrm{E}-05$ & 275 & 59 & 25.4 & 26.7 & 0.592 \\
\hline $\begin{array}{l}\text { L1 Reduced } \\
\text { w/ Urea }\end{array}$ & 3.01E-05 & 283 & $56^{1}$ & 31.8 & 23.9 & 0.538 \\
\hline L3 Nominal & - & 330 & 93 & $7.7^{*}$ & $53.0^{*}$ & - \\
\hline $\begin{array}{l}\text { L3 Nominal } \\
\text { w/ Urea }\end{array}$ & $6.58 \mathrm{E}-05$ & 321 & 98 & 12.4 & 42.1 & 0.672 \\
\hline L3 Reduced & $6.24 \mathrm{E}-05$ & 332 & 80 & 20.1 & 40.4 & 0.780 \\
\hline $\begin{array}{l}\text { L3 Reduced } \\
\text { w/Urea }\end{array}$ & $4.32 \mathrm{E}-05$ & 340 & 76 & 24.6 & 31.3 & 0.569 \\
\hline
\end{tabular}

"Data obtained from Test PO-C in reference [11]

*Cannot compare with other tests due to unexpected active regeneration in Stage 2

${ }^{1} \mathrm{NO}_{2}$ values estimated from Calterm

The average reaction rate for PM oxidation for each Loading Test $\mathrm{w} / \mathrm{o}$ and $\mathrm{w} /$ Urea from Table 5.14 has been compared in Figure 5.15. As observed from Figure 5.15, the average reaction rate for tests with urea injection is lower compared to tests without urea injection for the same engine conditions. This is due to decrease in available $\mathrm{NO}_{2}$ in the PM cake caused by forward diffusion of $\mathrm{NO}_{2}$ as a result of the concentration gradient caused by the consumption of $\mathrm{NO}$ and $\mathrm{NO}_{2}$ by the SCR reactions in the substrate wall [12]. The reaction rate constant for tests with urea is also lower 
compared to tests without urea as observed from Figure 5.15. The average reaction rate for L3 Nominal was not calculated as the value of PM retained and PM oxidized computed is incorrect due to an unexpected active regeneration in Stage 2 as explained earlier.

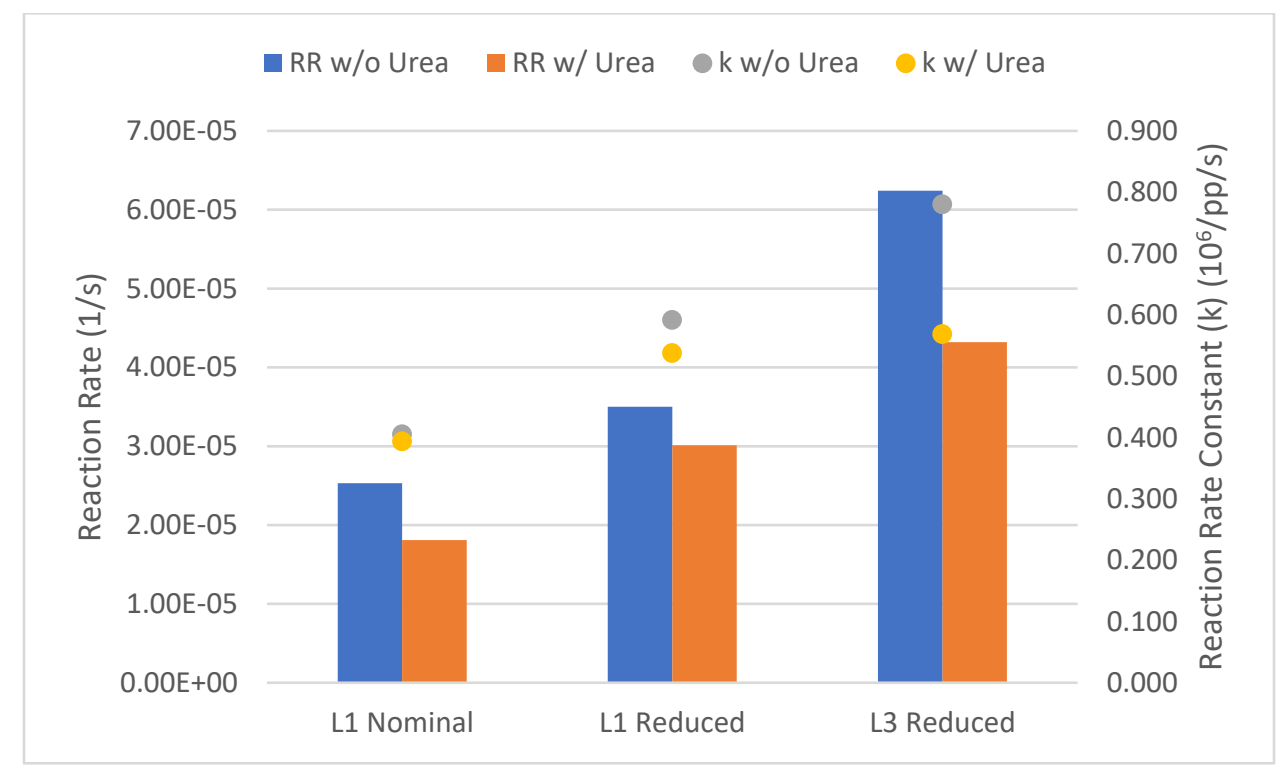

Figure 5.15: Reaction Rate Comparison for Loading Tests w/o and w/ Urea

When comparing one test without urea injection to another test with urea injection, the test with urea injection is expected to have higher value of PM retained in the $\mathrm{SCRF}^{\circledR}$. This is because of the competition between PM oxidation and the SCR reactions and hence less oxidation of the PM retained by $\mathrm{NO}_{2}$ which results in a higher $\mathrm{PM}$ retained. The same trend is observed for percentage of cumulative PM retained w.r.t. to cumulative PM entering when comparing a Loading Test w/o Urea to a Loading Test w/ Urea as shown in Figure 5.16. Figure 5.16 shows the comparison of cumulative PM oxidized for Loading Tests w/o and w/ Urea. As expected, the cumulative percentage of PM oxidized is higher for tests without urea compared to tests with urea. Similarly, Figure 5.17 shows the comparison of cumulative PM retained and PM oxidized in grams for the Loading Tests w/o and w/ Urea. 


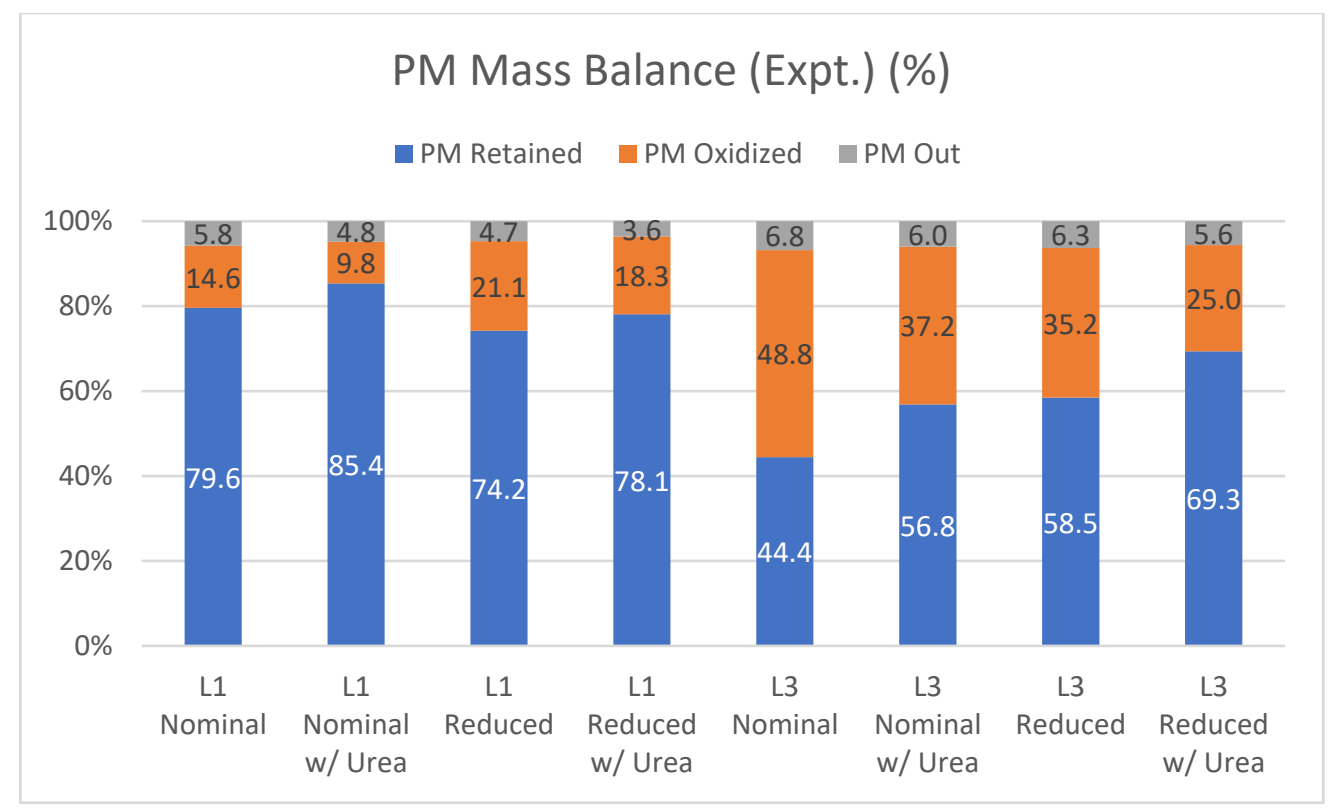

Figure 5.16: Comparison of Cumulative PM Retained and PM Oxidized as Percentage of PM In for Loading Tests w/o and $w /$ Urea

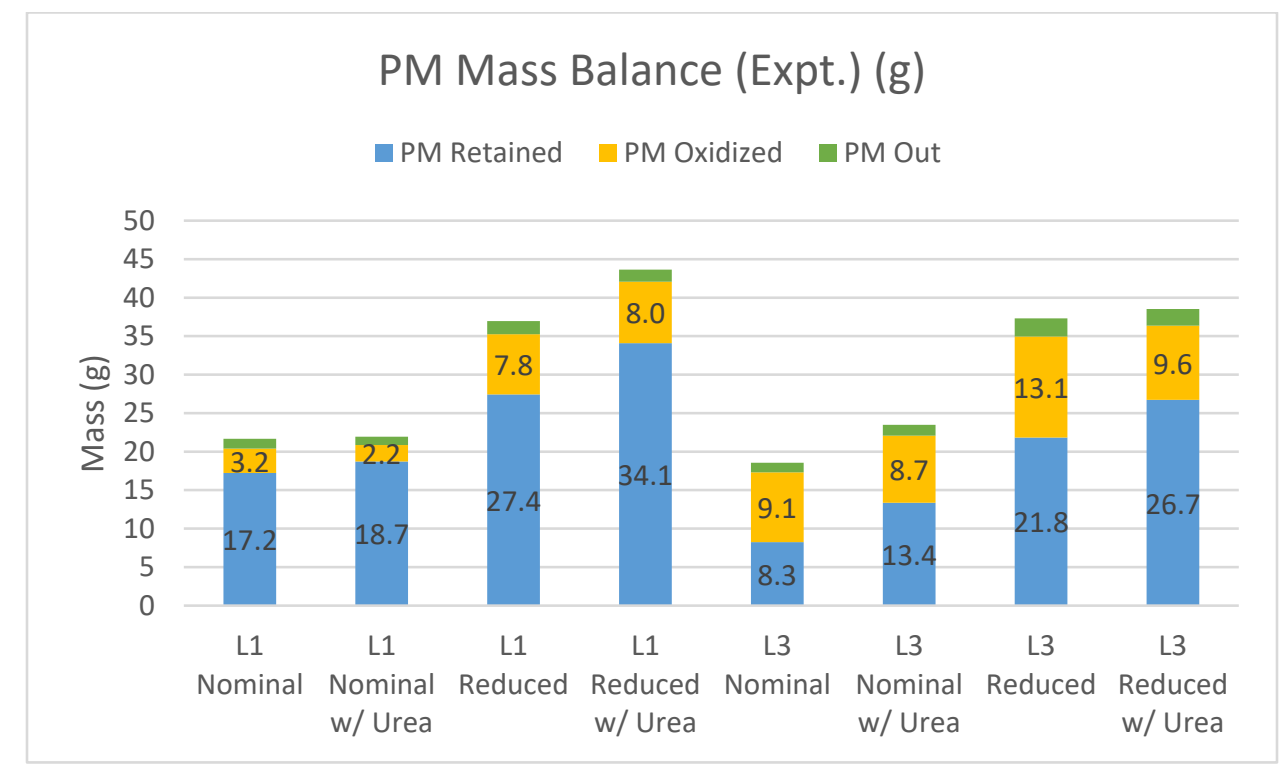

Figure 5.17: Comparison of Cumulative PM Retained and PM Oxidized for Loading Tests w/o and w/ Urea

Further, to compare the kinetics of PM oxidation during loading and passive oxidation conditions which is the primary objective of this study, the natural log of the reaction rate constant $(k)$ was plotted against the inverse of $\mathrm{SCRF}^{\circledR}$ inlet temperature for all the Loading Tests $\mathrm{w} / \mathrm{o}$ and $\mathrm{w} /$ Urea and all the Passive Oxidation Tests from reference [8] which is shown in Figure 5.18. The kinetics 
of PM oxidation during loading conditions are higher than that during passive oxidation conditions as observed from Figure 5.18. A kinetic model is needed to explain the PM oxidation under passive oxidation and loading conditions. Hence, a PM oxidation model was developed based on the shrinking core model which is able to simulate the reaction kinetics using a single set of kinetics for PM oxidation under loading and passive oxidation conditions.

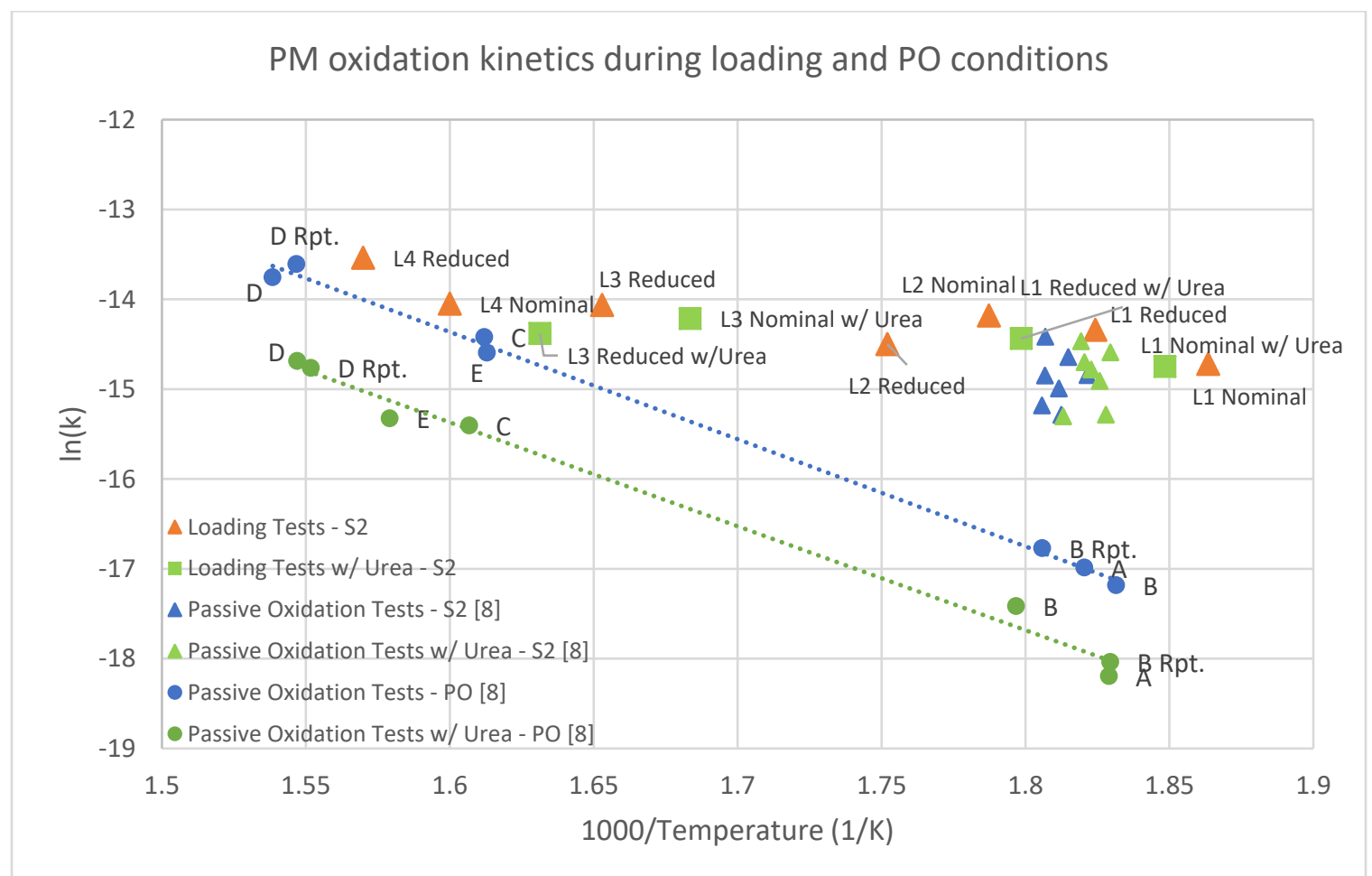

Figure 5.18: Comparison of PM Oxidation Kinetics for Passive Oxidation [8] and Loading Conditions With and Without Urea in $\mathrm{SCRF}^{\circledR}$

\section{SCRF $^{\oplus}$ Pressure Drop Comparison}

To further understand the difference in the kinetics of PM oxidation with and without urea under loading conditions, the pressure drop across the $\mathrm{SCRF}^{\circledR}$ was studied for the Loading Tests w/o Urea and the Loading Tests w/ Urea. Figure 5.19 shows the pressure drop across SCRF ${ }^{\circledR}$ vs time for test L3 Reduced without Urea and L3 Reduced with Urea. The pressure drop for all other tests are given in Appendix C. 
As discussed earlier, the PM retained in tests with urea injection is higher compared to that for the same test conditions without urea injection. The pressure drop across the SCRF ${ }^{\circledR}$ depends on the $\mathrm{PM}$ retained in the $\mathrm{SCRF}^{\circledR}$ cake and wall, the exhaust flow rate and the cake permeability. For the tests L3 Reduced and L3 Reduced with Urea, the exhaust flow rate is similar as shown in Table 5.16. However, the PM retained for L3 Reduced is $20.1 \mathrm{~g}$ compared to $24.6 \mathrm{~g}$ for L3 Reduced w/ Urea. Since the PM retained for L3 Reduced w/ Urea is higher, the pressure for this test should be higher compared to the test L3 Reduced. This trend is observed clearly in Figure 5.19 where the pressure drop for L3 Reduced with Urea is higher compared to L3 Reduced due to higher PM retained in the $\mathrm{SCRF}^{\oplus}$ and lower $\mathrm{PM}$ oxidized. The $\mathrm{SCRF}^{\oplus}$ inlet temperature, $\mathrm{NO}_{2}$ concentration into the $\mathrm{SCRF}^{\oplus}, \mathrm{PM}$ retained and PM oxidized are also given in Table 5.15 for better comparison between the two tests.

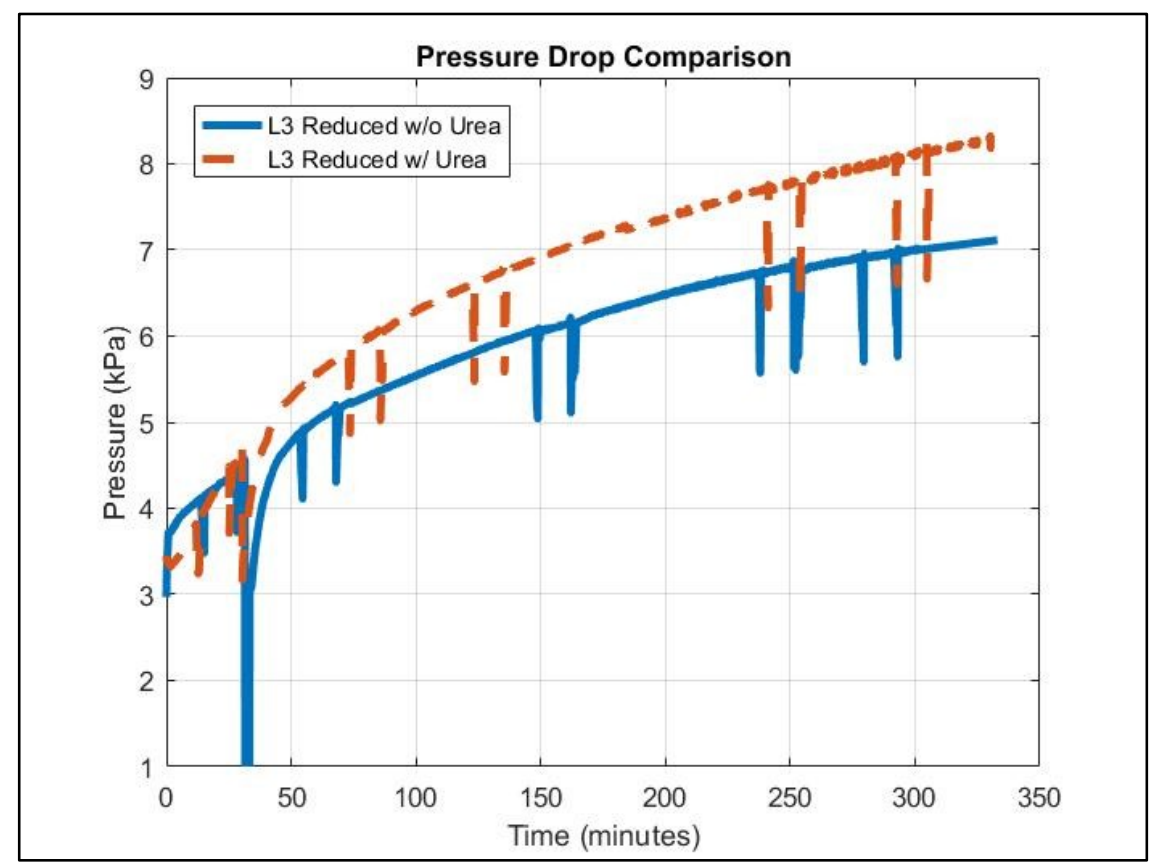

Figure 5.19: Comparison of Pressure Drop Across $S C R F^{\circledR}$ vs Time Plots for L3 Reduced w/o and w/ Urea

Table 5.15: Variables Important for Comparing Pressure Drop Across SCRF ${ }^{\circledR}$ for $L 3$ Reduced w/o and w/ Urea

\begin{tabular}{|c|c|c|c|c|c|c|}
\hline Test & Duration & $\begin{array}{c}\text { Exhaust } \\
\text { Flow Rate }\end{array}$ & $\begin{array}{c}\text { SCRF }^{\circledR} \text { Inlet } \\
\text { Temp }\end{array}$ & $\begin{array}{c}\text { NO }_{2} \text { into } \\
\text { SCRF }^{\circledR}\end{array}$ & $\begin{array}{c}\text { PM } \\
\text { Retained }\end{array}$ & $\begin{array}{c}\text { Cumulative } \\
\text { PM Oxidized }^{\circ}\end{array}$ \\
\hline$[-]$ & {$[\mathrm{min}]$} & {$[\mathrm{kg} / \mathrm{min}]$} & {$\left[{ }^{\circ} \mathrm{C}\right]$} & {$[\mathrm{ppm}]$} & {$[\mathrm{g}]$} & {$[\%]$} \\
\hline L3 Reduced & 334 & 12.0 & 332 & 80 & 20.1 & 35.2 \\
\hline $\begin{array}{c}\text { L3 Reduced } \\
\text { w/Urea }\end{array}$ & 330 & 12.1 & 340 & 76 & 24.6 & 25.0 \\
\hline
\end{tabular}


Next, the test L3 Nominal and L3 Nominal w/ Urea will be compared in a similar way. Figure 5.20 shows the pressure drop across SCRF ${ }^{\oplus}$ vs time for test L3 Nominal and L3 Nominal w/ Urea. For L3 Nominal, there was an unexpected active regeneration at the end of Stage 2 as discussed earlier which is clearly seen in Figure 5.20 as a spike in the pressure drop between 250-300 minutes.

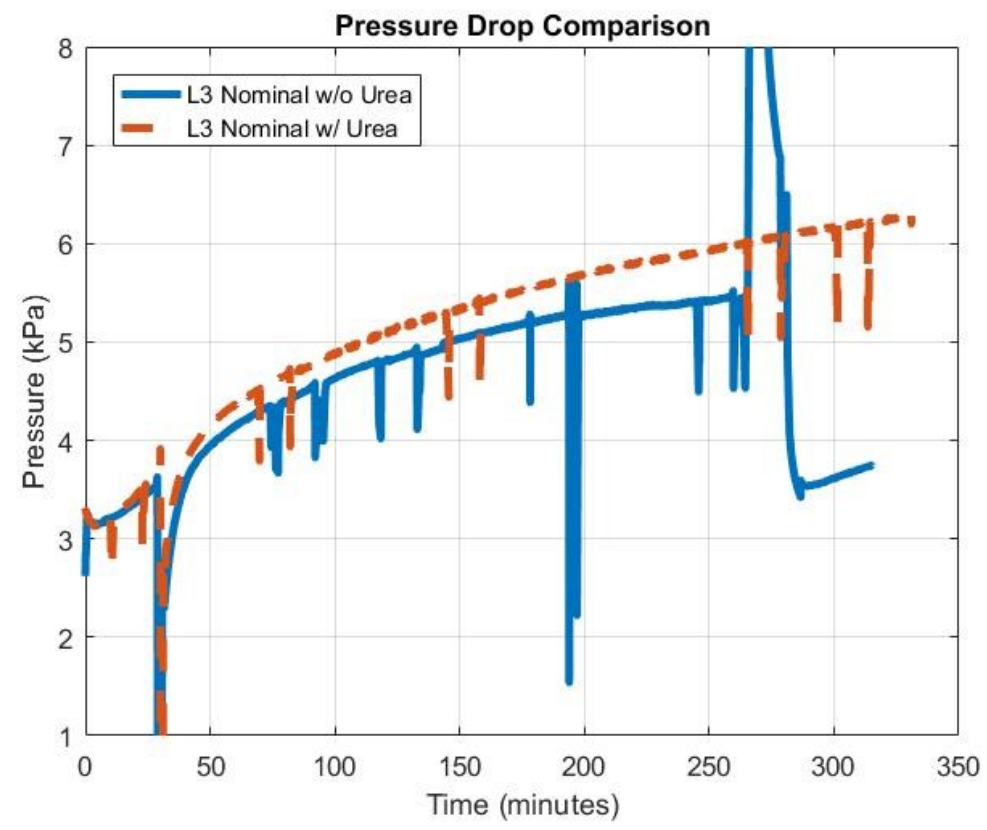

Figure 5.20: Comparison of Pressure Drop Across SCRF ${ }^{\circledR}$ vs Time plots for L3 Nominal w/o and w/ Urea

The pressure drop for L3 Nominal w/ Urea is higher than the pressure drop for L3 Nominal at all time as seen in Figure 5.20. This is because the cumulative PM oxidized is lower for L3 Nominal w/ Urea compared to L3 Nominal and so the PM retained for L3 Nominal w/ Urea is higher compared to L3 Nominal as seen in Table 5.16. Other parameters which affect the pressure drop such as the exhaust flow rate and the cake permeability are the same for the tests compared as shown in Table 5.16. The $\mathrm{SCRF}^{\circledR}$ inlet temperature, $\mathrm{NO}_{2}$ concentrations into the $\mathrm{SCRF}^{\circledR}$ and duration of the tests are also given in Table 5.16 for better comparison between the two tests.

Table 5.16: Variables Important for Comparing Pressure Drop Across SCRF ${ }^{\circledR}$ for L3 Nominal w/o and w/ Urea

\begin{tabular}{|c|c|c|c|c|c|c|}
\hline Test & Duration & $\begin{array}{c}\text { Exhaust } \\
\text { Flow Rate }\end{array}$ & $\begin{array}{c}\text { SCRF }^{\circledR} \text { Inlet } \\
\text { Temp }\end{array}$ & $\begin{array}{c}\text { NO }_{2} \text { into } \\
\text { SCRF }^{\circledR}\end{array}$ & $\begin{array}{c}\text { PM } \\
\text { Retained }\end{array}$ & $\begin{array}{c}\text { Cumulative } \\
\text { PM Oxidized }^{\circ}\end{array}$ \\
\hline$[-]$ & {$[\mathrm{min}]$} & {$[\mathrm{kg} / \mathrm{min}]$} & {$\left[{ }^{\circ} \mathrm{C}\right]$} & {$[\mathrm{ppm}]$} & {$[\mathrm{g}]$} & {$[\%]$} \\
\hline L3 Nominal & 331 & 12.1 & 330 & 93 & $10.0^{*}$ & 48.8 \\
\hline $\begin{array}{c}\text { L3 Nominal } \\
\text { w/Urea }\end{array}$ & 331 & 12.1 & 321 & 98 & 12.4 & 37.2 \\
\hline
\end{tabular}

*Estimated from SCR-F model [Section 5.4] 


\subsection{Calibration of SCR-F Model With Reaction Rate Data From the PM Oxidation Model for the Loading Tests w/o Urea}

This section focuses on the results of the calibration of the SCR-F model using experimental data from the eight Loading Tests w/o Urea, after applying the reaction rate data from the PM oxidation model to the SCR-F model as discussed in Section 4.2.

The kinetics of $\mathrm{NO}_{2}$ assisted PM oxidation in the cake and the wall and the pressure drop parameters obtained after calibrating the SCR-F model using the reaction rate data from the PM oxidation model for the Loading Tests w/o Urea is shown in Tables 5.17 and 5.18 respectively.

Table 5.17: Cake and Wall PM Oxidation Kinetics From Calibration of Loading Test w/o Urea Data

\begin{tabular}{|c|c|c|c|}
\hline & Symbol & Value & Units \\
\hline Pre Exponential of $\mathbf{N O}_{2}$ assisted PM oxidation & $A_{\mathrm{NO} 2, \text { cake }}$ & 2.6 & $\mathrm{~m} / \mathrm{K}-\mathrm{s}$ \\
\hline Activation energy of $\mathbf{N O}_{2}$ assisted PM oxidation & $\mathrm{E}_{\mathrm{a}, \mathrm{NO} 2, \mathrm{cake}}$ & 96 & $\mathrm{~kJ} / \mathrm{gmol}$ \\
\hline Pre Exponential of $\mathrm{NO}_{2}$ assisted PM oxidation & $\mathrm{A}_{\mathrm{NO} 2, \text { wall }}$ & 1.8 & $\mathrm{~m} / \mathrm{K}-\mathrm{s}$ \\
\hline Activation energy of $\mathrm{NO}_{2}$ assisted PM oxidation & $\mathrm{E}_{\mathrm{a}, \mathrm{NO} 2 \text {,wall }}$ & 96 & $\mathrm{~kJ} / \mathrm{gmol}$ \\
\hline
\end{tabular}

Table 5.18: SCR-F Model Pressure Drop Parameters From Calibration of Loading Test w/o Urea Data

\begin{tabular}{|c|c|c|c|}
\hline Parameter & Description & SCR-F & Units \\
\hline \multicolumn{4}{|c|}{ Substrate Wall } \\
\hline $\mathbf{k}_{\mathrm{o}, \mathrm{w}}$ & Initial permeability of substrate wall & $1.04 \mathrm{E}-13$ & $\left(m^{2}\right)$ \\
\hline $\mathbf{k}_{\text {o,trans }}$ & Transition permeability of substrate wall & 8.00E-13 & $\left(m^{2}\right)$ \\
\hline \multicolumn{4}{|c|}{ Wall PM } \\
\hline$C_{1 w p m}$ & First constant for wall packing density calculation & 2.35 & $\left(1 / m^{3}\right)$ \\
\hline$C_{2 w p m}$ & Second constant for wall packing density & 0.723 & $\left(\mathrm{~kg} / \mathrm{m}^{3}\right)$ \\
\hline $\mathbf{C}_{3}$ & Ref. pressure for wall permeability correction & 103.2 & $(\mathrm{kPa})$ \\
\hline $\mathrm{C}_{4}$ & Wall permeability correction factor & 110 & $(-)$ \\
\hline \multicolumn{4}{|c|}{ PM cake layer } \\
\hline$\alpha_{0, \text { cake }}$ & Initial solidosity of PM cake layer & 0.05 & $(-)$ \\
\hline $\mathbf{k}_{\text {o,cake }}$ & Initial / ref. permeability of PM cake layer & 7.01E-15 & $\left(m^{2}\right)$ \\
\hline$A_{\text {eff,cake }}$ & PM cake maximum filtration efficiency parameter & 0.95 & $(-)$ \\
\hline $\mathrm{C}_{5}$ & Cake permeability correction factor & $1.43 \mathrm{E}-13$ & $\left(\mathrm{~kg} \mathrm{~m}^{-1}\right)$ \\
\hline $\mathrm{C}_{6}$ & Ref. pressure for lambda correction & 100 & (kPa) \\
\hline $\mathrm{C}_{7}$ & Ref. temperature for lambda correction & 300 & $(\mathrm{~K})$ \\
\hline$C_{10}$ & Slope for post loading cake permeability & 0 & $(-)$ \\
\hline$C_{11}$ & Constant for post loading cake permeability & 1.485 & $(-)$ \\
\hline$C_{13}$ & Constant for oxidation cake permeability & 0.664 & $(-)$ \\
\hline
\end{tabular}


The performance of the SCR-F model for the Loading Tests w/o Urea is given in Tables 5.19 and 5.20. Table 5.19 shows the comparison of the model PM retained values to the experimental values at the end of Stage 1 and Stage 2. Table 5.19 data shows that the model PM retained data are within $\pm 2 \mathrm{~g}$ of the experimental values at the end of Stage 1 and Stage 2 for all the tests except L2 Nominal as the experimental value of PM retained is inconsistent with the trend followed by other tests (Figure 5.21). The experimental PM retained values for L3 Nominal shown in Table 5.19 should be higher as there was more PM oxidized due to an unexpected active regeneration in Stage 2 which is already discussed in Section 5.1. The plots showing the simulated PM retained in the $\mathrm{SCRF}^{\circledR}$ versus time for all the Loading Test w/o Urea are given in Appendix E.

Table 5.19: Comparison of Experimental and Model PM Retained at the End of Stage 1 and Stage 2

\begin{tabular}{|c|c|c|c|c|c|c|}
\hline \multirow{4}{*}{ Test } & \multicolumn{6}{|c|}{ PM Retained } \\
\hline & \multicolumn{3}{|c|}{ Stage 1} & \multicolumn{3}{|c|}{ Stage 2} \\
\hline & Expt. & Model & Diff. & Expt. & Model & Diff. \\
\hline & [g] & [g] & [g] & [g] & [g] & [g] \\
\hline L1 Nom & 1.1 & 1.1 & 0.0 & 16.1 & 15.7 & 0.4 \\
\hline L1 Red" & 2.0 & 2.1 & -0.1 & 25.4 & 26.9 & -1.5 \\
\hline L2 Nom & $0.8^{[1]}$ & 1.0 & -0.2 & $11.5^{1}$ & 13.9 & -2.4 \\
\hline L2 Red & 2.1 & 1.9 & 0.2 & 26.8 & 25.8 & 1.0 \\
\hline L3 Nom & $0.6^{*}$ & 0.8 & -0.2 & $7.8^{*}$ & 10.0 & - \\
\hline L3 Red & 1.7 & 1.6 & 0.1 & 20.0 & 20.2 & -0.2 \\
\hline L4 Nom & 0.8 & 0.7 & 0.1 & 8.5 & 6.9 & 1.6 \\
\hline L4 Red & 1.5 & 1.4 & 0.1 & 15.0 & 14.6 & 0.4 \\
\hline
\end{tabular}

\#Data obtained from Test PO-C in reference [11]

* The experimental value is lower than the expected PM retained due to unexpected active regeneration in Stage 2

${ }^{1}$ The experimental value is lower than the expected PM retained for the pressure drop value (Figure 5.21)

Table 5.20 shows the comparison between the model $\mathrm{SCRF}^{\circledast}$ pressure drop values and the experimental values at the end of Stage 2 . The model pressure drop across the $\mathrm{SCRF}^{\circledR}$ is within $\pm 0.5 \mathrm{kPa}$ of the experimental value at the end of Stage 2 for all the tests except L4 Reduced as the experimental pressure drop value is inconsistent with the trend followed by other tests (Figure 
5.21). For the test $L 3$ Nominal, the pressure drop value just before the start of the unexpected active regeneration in Stage 2 was compared to the model pressure drop value. The plots showing the simulated pressure drop across $\mathrm{SCRF}^{\circledR}$ versus time for all the Loading Test w/o Urea are given in Appendix F.

Table 5.20: Comparison of Experimental and Model Pressure Drop at the End of Stage 2

\begin{tabular}{|c|c|c|c|}
\hline \multirow{2}{*}{ Test } & \multicolumn{3}{|c|}{ Stage 2 Pressure Drop } \\
\cline { 2 - 4 } & Expt. & Model & Diff. \\
\cline { 2 - 4 } & {$[\mathrm{kPa}]$} & {$[\mathrm{kPa}]$} & {$[\mathrm{kPa}]$} \\
\hline L1 Nom & 6.1 & 5.8 & 0.3 \\
\hline L1 Red & 7.9 & 7.8 & 0.1 \\
\hline L2 Nom & 6.1 & 5.9 & 0.2 \\
\hline L2 Red & 7.8 & 8.0 & -0.2 \\
\hline L3 Nom & $5.5^{*}$ & $5.7\left(5.5^{*}\right)$ & $0.0^{*}$ \\
\hline L3 Red & 7.1 & 7.5 & -0.4 \\
\hline L4 Nom & 5.1 & 5.3 & -0.2 \\
\hline L4 Red & $6.0^{1}$ & 6.9 & -0.9 \\
\hline
\end{tabular}

\#Data obtained from Test PO-C in reference [3]

*Pressure drop before the unexpected active regeneration in Stage 2

${ }^{1}$ The experimental value is lower than expected pressure drop for the amount of PM retained

Further, the experimental pressure drop across the $\mathrm{SCRF}^{\circledR}$ normalized by the exhaust mass flow rate is plotted against the experimental PM retained at the end of Stage 2 for all the tests as shown in Figure 5.21 to ensure the integrity of the experimental data collected. A line has been plotted to fit the data as seen in Figure 5.21. All the tests follow a similar trend along the line except the tests L2 Nominal and L4 Reduced which are identified as the outlier points. This means that the experimental pressure drop value should be higher or lower for the amount of PM retained or vice versa for these two test points. 


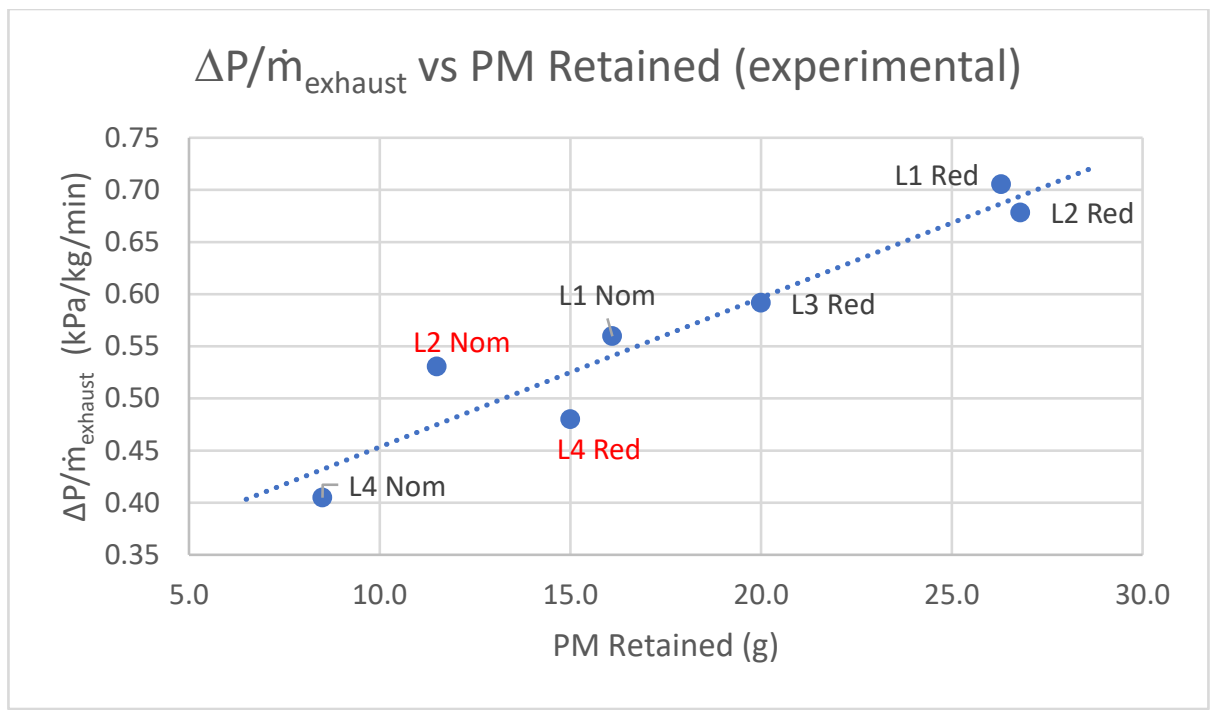

Figure 5.21: Expt. Pressure Drop Normalized by Exhaust Flow Rate vs Expt. PM Retained for Loading Tests w/o Urea

The model pressure drop across $\mathrm{SCRF}^{\circledR}$ normalized by the exhaust mass flow rate is plotted against the model PM retained at the end of Stage 2 for all the tests as shown in Figure 5.22. The cake permeability is assumed constant in the SCR-F model shown in Table 5.18 has been used in the calibrated SCR-F model. Again, a line is plotted to fit the data. All the tests follow a similar trend along the line as compared to two outlier points based on the experimental plot in Figure 5.21. Hence, either the pressure drop or PM retained data for tests L2 Nominal and L4 Reduced could be incorrect due to measurement inaccuracy. The value of pressure drop and PM retained from the model for test L3 Nominal is also consistent with the model data from other tests as it was simulated without the active regeneration that occurred with the experimental data.

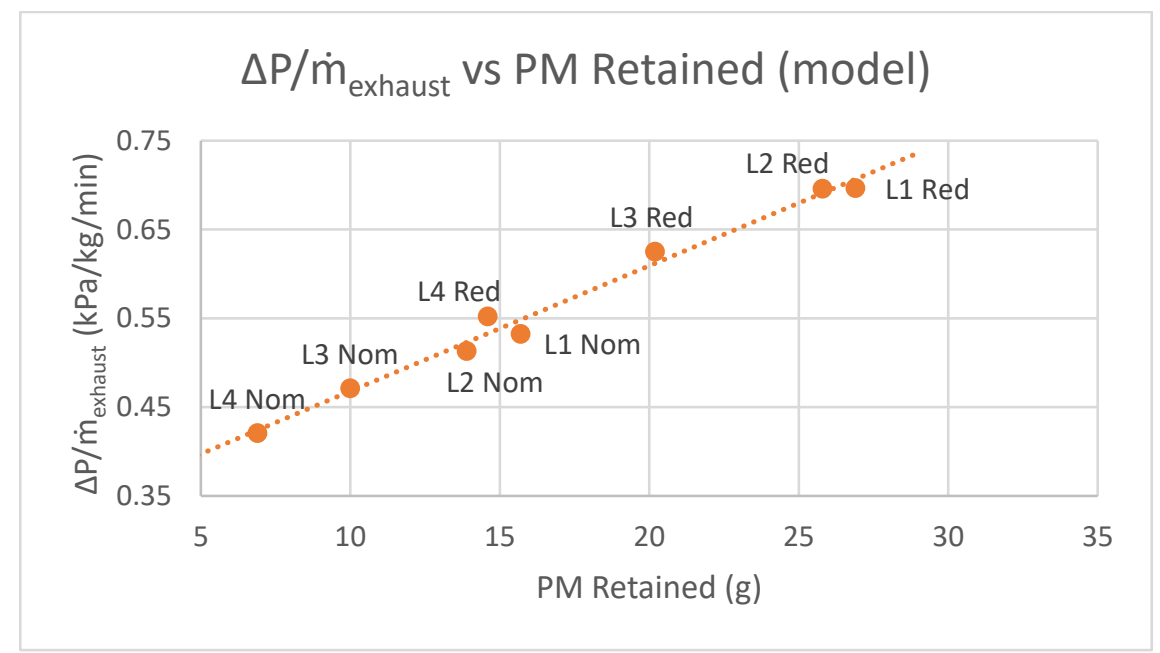

Figure 5.22: Model Pressure Drop Normalized by Exhaust Flow Rate vs Model PM Retained for Loading Tests w/o Urea 
The total model pressure drop across the $\mathrm{SCRF}^{\circledR}$ is the sum of the pressure drop across the cake, wall and channel. This is clearly observed in the model pressure drop plots in Appendix F. Similarly, the SCR-F model predicts the amount of PM retained in the cake and the wall as observed from the plots in Appendix E. The cake pressure drop normalized by the exhaust mass flow rate is plotted versus the PM retained in the cake at the end of Stage 2 for all the tests as shown in Figure 5.23. As observed from Figure 5.23, all the tests follow a similar trend along the line which implies that the amount of PM retained in the cake predicted by the model is in agreement with the cake pressure drop. Also, the wall pressure drop normalized by the exhaust mass flow rate is plotted versus the PM retained in the wall at the end of Stage 2 for all the tests as shown in Figure 5.24 to check the consistency of the SCR-F model.

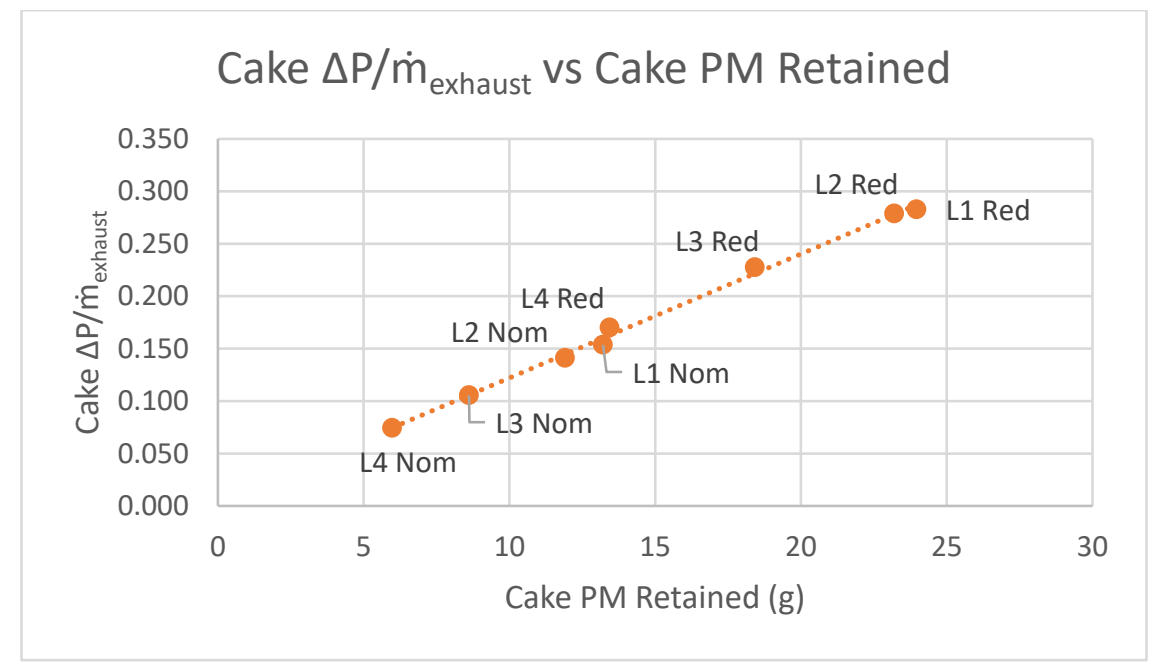

Figure 5.23: Cake Pressure Drop Normalized by Exhaust Flow Rate vs Cake PM Retained for Loading Tests w/o Urea

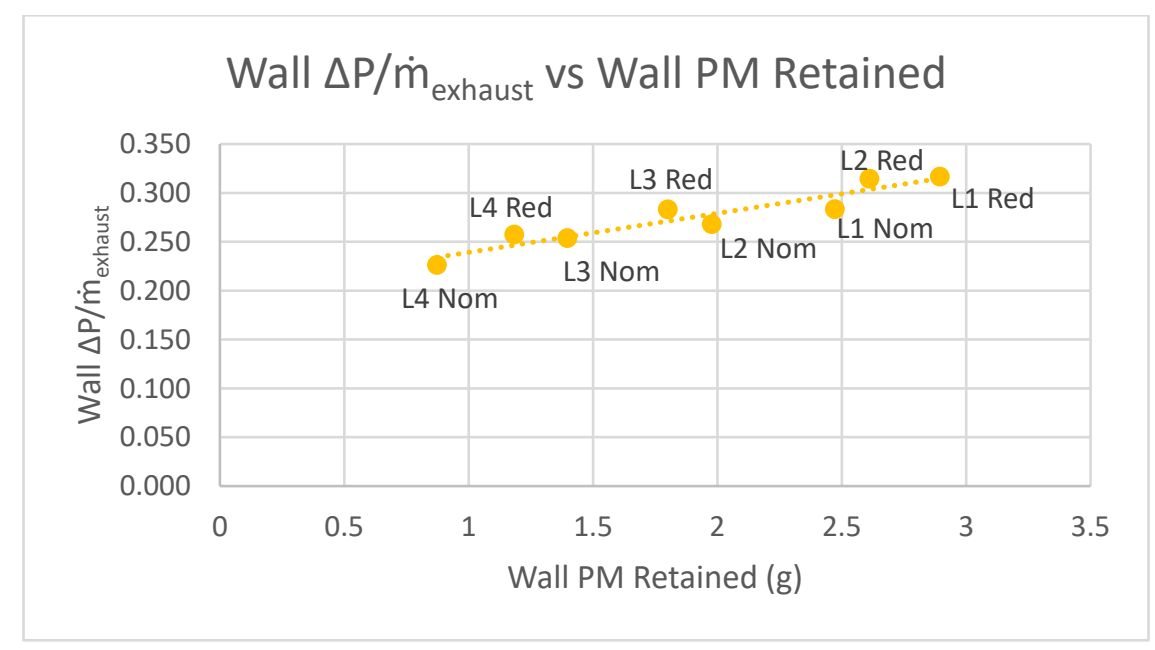

Figure 5.24: Wall Pressure Drop Normalized by Exhaust Flow Rate vs Wall PM Retained for Loading Tests w/o Urea 
The PM mass balance is analyzed for the values obtained from the model for all the tests. Figure 5.25 shows the cumulative mass balance in terms of percentage of cumulative PM entering the $\mathrm{SCRF}^{\circledR}$ using the SCR-F model for all the tests. As observed from Figure 5.25, the percentage of PM oxidized increases and the percentage of PM retained decreases with increase in engine load which is as expected. L3 Nominal and L1 Reduced also follow the expected trend which was not observed with the experimental data shown in Figures 5.5 and 5.6. The difference in the \% PM oxidized and PM retained while comparing tests at nominal and reduced fuel rail pressure is due to major differences in $\mathrm{PM}$ concentrations and minor differences in the $\mathrm{SCRF}^{\circledR}$ temperature and $\mathrm{NO}_{2}$ concentrations.

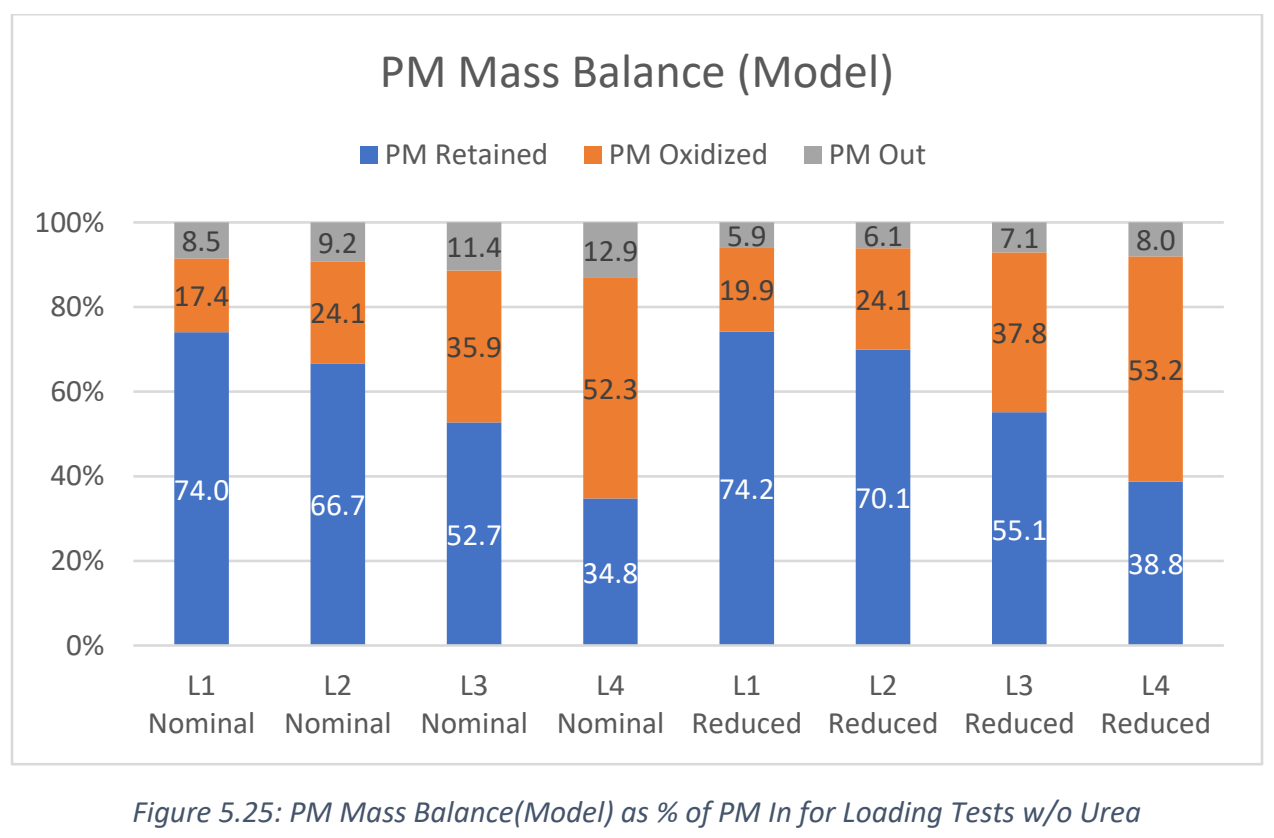

Further, the calibrated SCR-F model was used to estimate the cumulative amount of PM retained in the cake and the wall at the end of Stage 2 for all the tests. The comparison of the PM retained in the cake and wall is illustrated graphically as shown in Figure 5.26. The PM retained in the cake and the wall decreases in going from L1 to L4 for nominal or reduced rail pressure as observed from Figure 5.26. This is due to higher PM oxidation at higher engine loads due to higher SCRF ${ }^{\circledR}$ temperature and $\mathrm{NO}_{2}$ concentrations leading to lower PM retained. Also, the PM retained for tests at reduced rail pressure is higher compared to tests at nominal rail pressure because of higher $\mathrm{PM}$ entering the $\mathrm{SCRF}^{\circledR}$ due to relatively high $\mathrm{PM}$ concentrations at reduced rail pressure. 


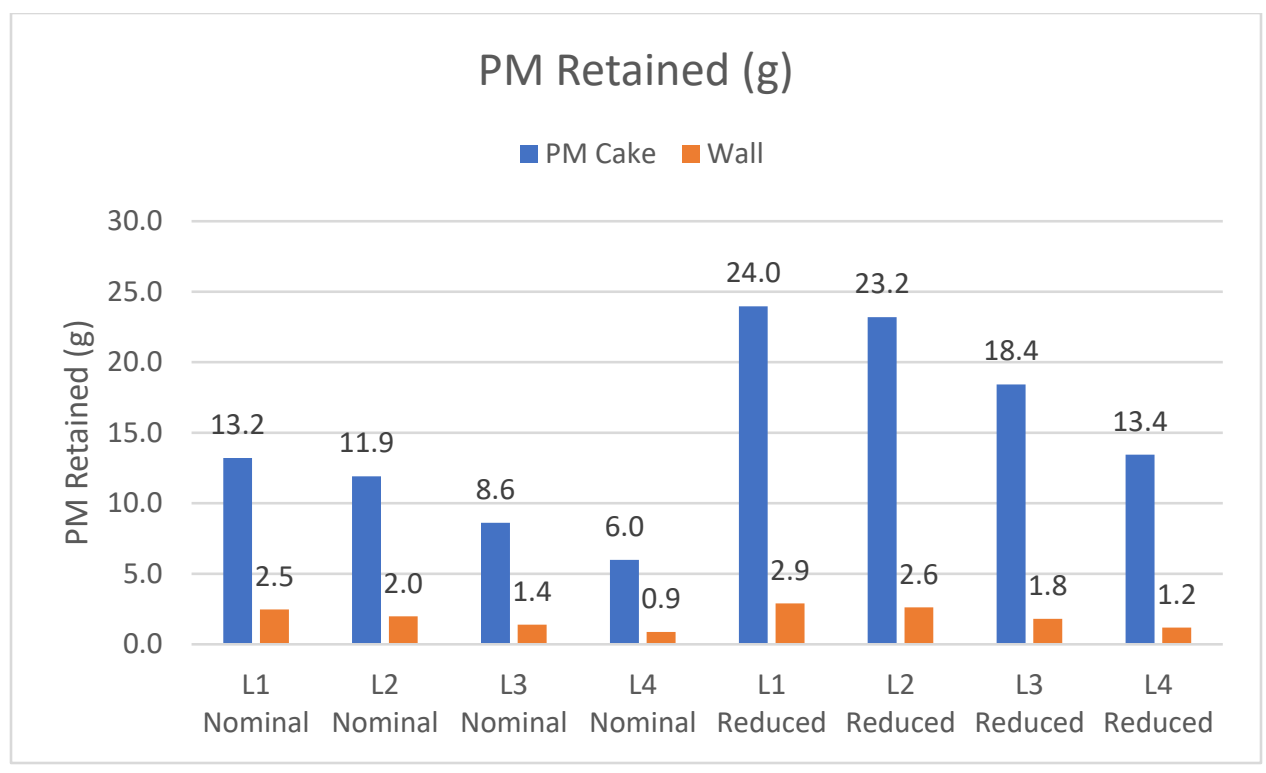

Figure 5.26: PM Retained in the Cake and the Wall

Figure 5.27 shows the distribution of PM retained in the cake and the wall in terms of percentage of the total PM retained for all the tests. It is observed that the majority of PM is retained in the cake as seen in Figure 5.27. Also, the percentage of PM retained in the cake increases with increase in engine load (L1 to L4).

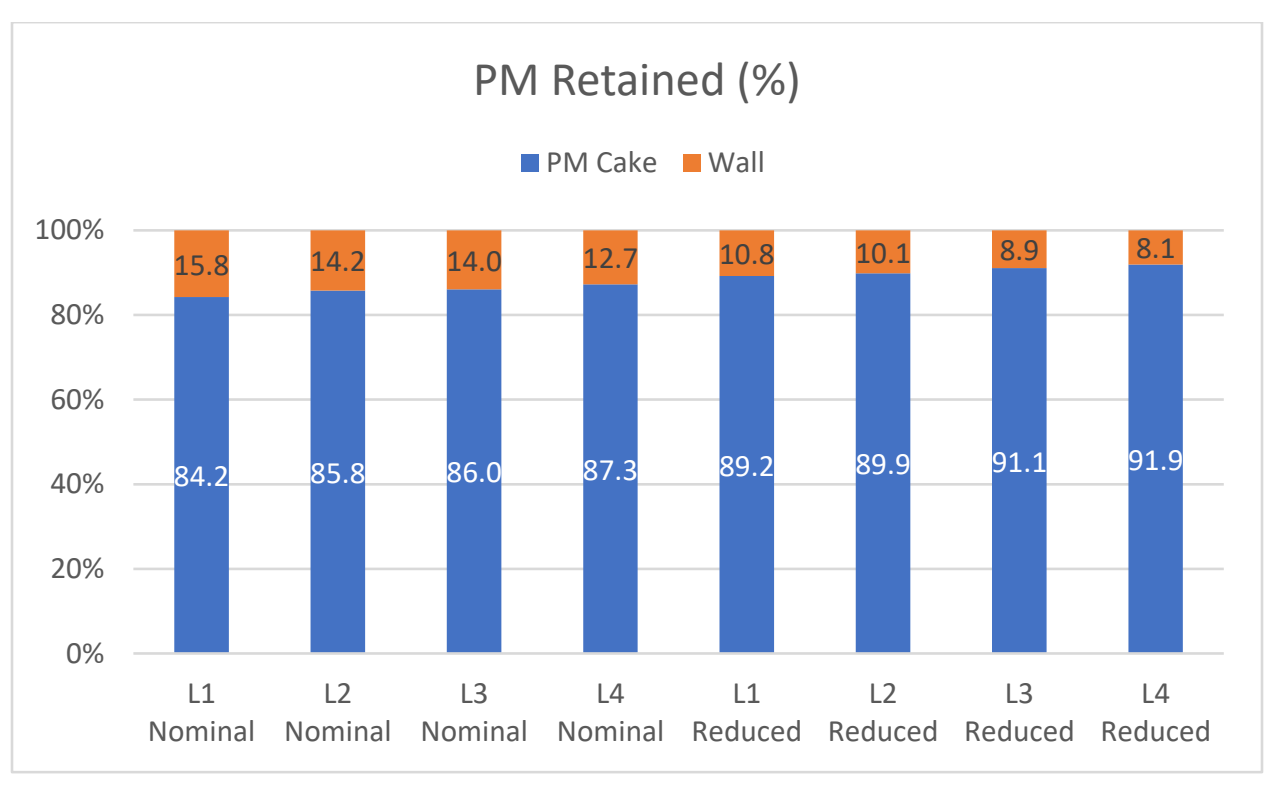

Figure 5.27: PM Retained in the Cake and the Wall as \% of Total PM Retained 
Figure 5.28 shows the PM oxidized in the cake and the wall for all the tests. It is observed that the PM oxidized in the cake and the wall increases with the increase in engine load (L1 to L4) due to increased temperature and $\mathrm{NO}_{2}$ concentrations.

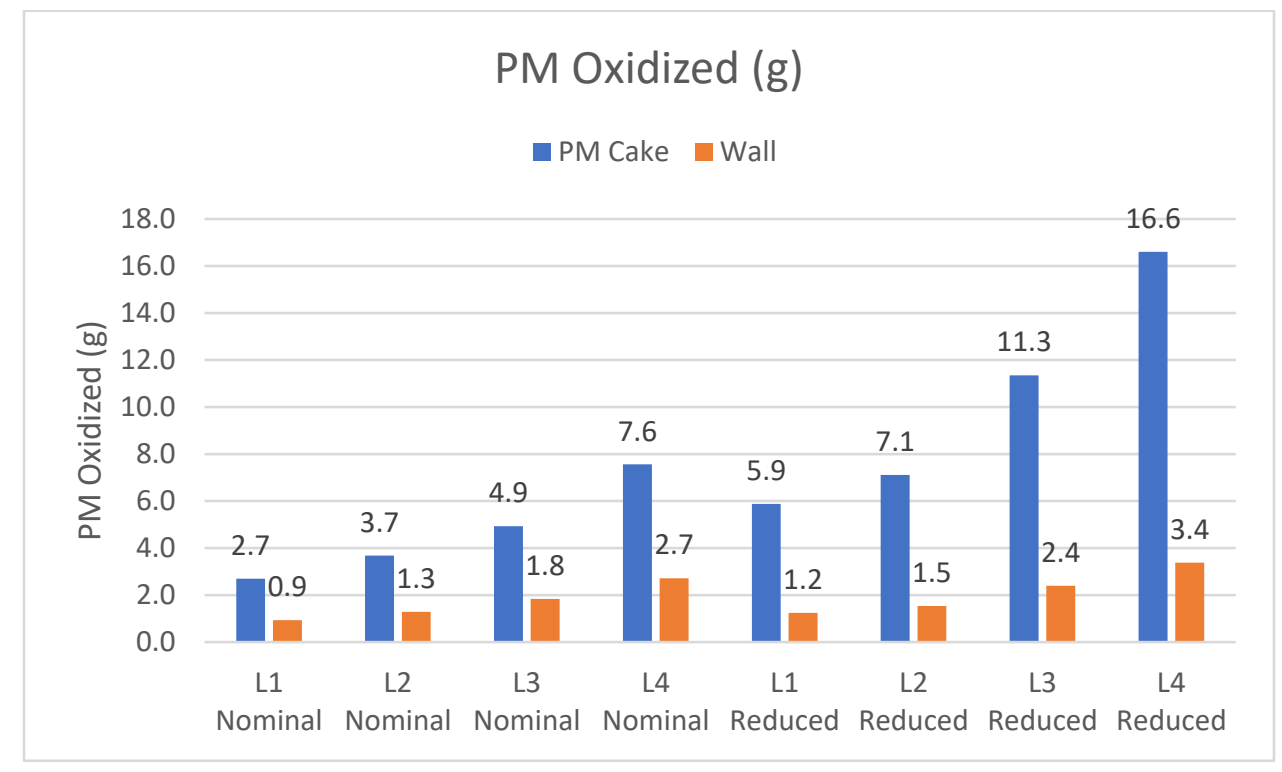

Figure 5.28: PM Oxidized in the Cake and the Wall

The distribution of PM oxidized in the cake and the wall in terms of percentage of the total PM oxidized for all the tests is given in Figure 5.29. Although no trend is observed in the percentage of PM oxidized in the cake and the wall, it is observed that the majority of PM oxidized in the cake for all the tests.

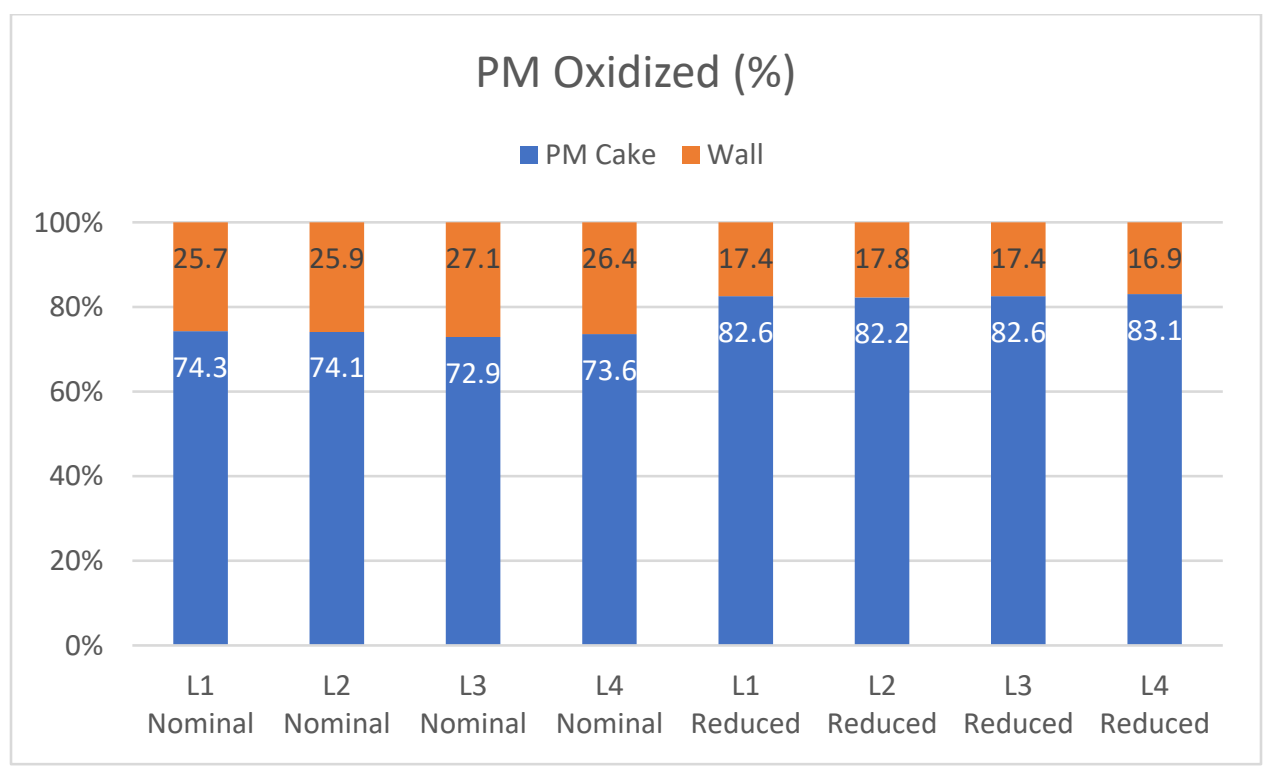

Figure 5.29: PM Oxidized in the Cake and the Wall as \% of Total PM Oxidized 


\subsection{Calibration of the PM Oxidation Model with Passive Oxidation w/o Urea Data}

The reaction rate results from the PM oxidation model were used in the SCR-F model to simulate the kinetics of PM oxidation in the cake and wall for all the Loading Tests w/o Urea. The performance of SCR-F model along with the PM oxidation model is evaluated only on the kinetics of PM oxidation in loading conditions. However, there is need to ensure that the PM oxidation model can simulate the PM oxidation using a single set of kinetics under a wide range of conditions including loading and passive oxidation conditions. This is done by calibrating the PM oxidation model with experimental data from reference [8] which is already discussed in Section 4.4. The performance of the PM oxidation model on the passive oxidation data from reference [8] is the focus of this section.

As discussed in Section 4.4, each passive oxidation test from reference [8] consists of two loading stages (Stage 1 and Stage 2) followed by a 15 min Ramp up stage, passive oxidation stage and post oxidation loading stages (Stage 3 and Stage 4). The experimental data for loading Stage 2 and passive oxidation stage is shown in Table 5.21 and 5.22. The experimental data obtained from each stage of the passive oxidation test i.e. Stage 1, Stage 2, Ramp up, Passive Oxidation Stage and Stage 3 of the test are used as input parameters for the model.

Table 5.21: Loading Conditions for Stage 2 in Configuration 1 Tests w/o Urea [8]

\begin{tabular}{|c|c|c|c|c|c|c|}
\hline \multirow{2}{*}{ Test } & $\begin{array}{c}\text { Engine } \\
\text { Speed }\end{array}$ & $\begin{array}{c}\text { Engine } \\
\text { Load }\end{array}$ & $\begin{array}{c}\text { Exhaust } \\
\text { Flow Rate }\end{array}$ & $\begin{array}{c}\text { SCRF }^{\circledR} \\
\text { In Temp }\end{array}$ & $\begin{array}{c}\text { NO }_{2} \text { into } \\
\text { SCRF }^{\circledR}\end{array}$ & PM Conc. \\
\cline { 2 - 7 } & RPM & $\mathrm{Nm}$ & $\mathrm{kg} / \mathrm{min}$ & ${ }^{0} \mathrm{C}$ & $\mathrm{ppm}$ & $\mathrm{mg} / \mathrm{scm}$ \\
\hline PO-A & 2403 & 202 & 11.2 & 279 & 61 & 13.5 \\
\hline PO-C & 2401 & 201 & 11.2 & 278 & 64 & 12.7 \\
\hline PO-E & 2401 & 201 & 11.2 & 274 & 66 & 12.2 \\
\hline PO-B & 2406 & 198 & 11.0 & 276 & 39 & 13.3 \\
\hline PO-B Rpt & 2401 & 201 & 11.3 & 279 & 77 & 13.6 \\
\hline PO-D Rpt & 2402 & 202 & 11.3 & 279 & 68 & 13.1 \\
\hline
\end{tabular}


Table 5.22: Passive Oxidation Conditions for Configuration 1 Tests w/o Urea [8]

\begin{tabular}{|c|c|c|c|c|c|c|c|}
\hline Test & $\begin{array}{c}\text { Engine } \\
\text { Speed }\end{array}$ & $\begin{array}{c}\text { Engine } \\
\text { Load }\end{array}$ & Duration & $\begin{array}{c}\text { Exhaust } \\
\text { Flow } \\
\text { Rate }\end{array}$ & $\begin{array}{c}\text { SCRF }^{\circledR} \\
\text { Inlet } \\
\text { Temp. }\end{array}$ & $\begin{array}{c}\text { NO }_{2} \text { into } \\
\text { SCRF }\end{array}$ & PM Conc. \\
\hline PPM & $\mathrm{Nm}$ & Minutes & $\mathrm{kg} / \mathrm{min}$ & ${ }^{\circ} \mathrm{C}$ & $\mathrm{ppm}$ & $\mathrm{mg} / \mathrm{scm}$ \\
\hline PO-C & 1300 & 300 & 421 & 5.6 & 276 & 263 & 2.5 \\
\hline PO-E & 1400 & 550 & 81 & 7.0 & 347 & 228 & 3.7 \\
\hline PO-B & 900 & 450 & 240 & 3.8 & 273 & 674 & 1.7 \\
\hline PO-B Rpt & 900 & 450 & 220 & 3.4 & 281 & 792 & 1.7 \\
\hline PO-D & 2100 & 600 & 153 & 13.0 & 377 & 117 & 4.2 \\
\hline PO-D Rpt & 2100 & 600 & 122 & 12.8 & 374 & 147 & 5.0 \\
\hline
\end{tabular}

The kinetics of PM oxidation obtained after calibrating the PM oxidation model as discussed in Section 4.4 is shown in Table 5.23. It is important to note that the same set of kinetics was used for all stages in the test i.e. Stage 1, Stage 2, Ramp up, passive oxidation stage and Stage 3.

Table 5.23: Calibrated $\mathrm{NO}_{2}$ Assisted $P M$ Oxidation Kinetics From the $P M$
\begin{tabular}{|c|c|c|}
\hline $\mathrm{NO}_{2}$ assisted kinetics & Value & Units \\
\hline Activation Energy ( $\left.\mathbf{E}_{\mathrm{a}}\right)$ & 96 & $\mathrm{~kJ} / \mathrm{gmol}$ \\
\hline Pre-exponential (A) & 77 & $1 / \mathrm{K}-\mathrm{ppm}-\mathrm{s}$ \\
\hline
\end{tabular}

The performance of the PM oxidation model with the same set of kinetics is given in Table 5.24. Table 5.24 shows the comparison of the model PM retained values to the experimental values at the end of Stage 1, Stage 2 and Stage 3. As observed from Table 5.24, the model PM retained values are within $\pm 2 \mathrm{~g}$ of the experimental values at the end of Stage 1 and Stage 2 for all the tests. 
Table 5.24: Comparison of Experimental and Model PM Retained at the End of Stage 1, Stage 2 and Stage 3

\begin{tabular}{|c|c|c|c|c|c|c|c|c|c|}
\hline \multirow{3}{*}{ Test } & \multicolumn{3}{|c|}{ Stage 1} & \multicolumn{3}{|c|}{ Stage 2} & \multicolumn{3}{|c|}{ Stage 3} \\
\hline & Expt. & Model & Diff. & Expt. & Model & Diff & Expt. & Model & Diff \\
\hline & [g] & [g] & [g] & [g] & [g] & [g] & [g] & [g] & [g] \\
\hline PO-A & 3.1 & 3.3 & -0.2 & 35.1 & 33.9 & 1.2 & 35.1 & 33.9 & 1.2 \\
\hline PO-C & 2.1 & 2.4 & -0.3 & 32.7 & 31.9 & 0.8 & 23.2 & 23.9 & -0.7 \\
\hline PO-E & 3.6 & 3.4 & 0.2 & 33.5 & 31.6 & 1.9 & 22.9 & 22.2 & 0.7 \\
\hline PO-B & 1.9 & 2.1 & -0.2 & 32.7 & 33.2 & -0.5 & 28.9 & 28.1 & 0.8 \\
\hline PO-B Rpt & 2.2 & 2.9 & -0.7 & 31.7 & 33.7 & -2.0 & 23 & 24.5 & -1.5 \\
\hline PO-D & 2 & 2.4 & -0.4 & 32.5 & 32.8 & -0.3 & 18 & 16.2 & 1.8 \\
\hline PO-D Rpt & 1.8 & 2.6 & -0.8 & $\begin{array}{c}29.2 \\
\left(32.5^{*}\right)\end{array}$ & 34.1 & $(-1.6)$ & $\begin{array}{c}14.5 \\
\left(15.5^{*}\right)\end{array}$ & 17.5 & $(-2.0)$ \\
\hline
\end{tabular}

The shrinking core model used in the development of PM oxidation model is capable of simulating the $\mathrm{NO}_{2}$ assisted oxidation of PM with a single set of kinetics under a wide range of conditions including loading and passive oxidation conditions as discussed in this section for data from passive oxidation tests from reference [8]. 


\section{Chapter 6. Summary and Conclusions}

This chapter summarizes the findings and accomplishments from this study. It also provides conclusions from the results for the experimental and modeling work.

\subsection{Summary}

The primary objective of this study was to carry out Loading Tests w/o and w/ Urea and measure species concentrations, PM mass retained, flowrates, substrate temperature distributions, pressure drop across the filter, and to determine the kinetics of $\mathrm{NO}_{2}$ assisted $\mathrm{PM}$ oxidation under loading conditions and compare it with kinetics under passive oxidation conditions from reference [8]. A total of 12 tests were performed in this study: eight tests without urea injection, and four tests with urea injection. The summary of the findings in this study is divided into Loading Test w/o Urea, Loading Test w/ Urea, and the modeling work.

\section{Loading Test w/o Urea}

Eight tests were performed to study the characteristics of PM oxidation in the $\mathrm{SCRF}^{\circledR}$ under loading conditions without urea injection. The exhaust flow rates and standard space velocities ranged from $10.9-12.5 \mathrm{~kg} / \mathrm{min}$ and $33-37 \mathrm{k} / \mathrm{hr}$ respectively. The $\mathrm{NO}_{2}$ concentrations at the $\mathrm{SCRF}^{\circledR}$ inlet varied from $52-120 \mathrm{ppm}$ and $\mathrm{SCRF}^{\circledast}$ inlet temperature varied from $264-374^{\circ} \mathrm{C}$. The cumulative percentage of PM oxidized varied from $19.9 \%$ to $54.5 \%$ during the 5.5-hour Loading Tests w/o Urea. The average reaction rate for Stage 2 varied from $2.53 \mathrm{E}-05$ to $1.08 \mathrm{E}-04 \mathrm{~s}^{-1}$ while the reaction rate constant ranged from $0.405-1.320 * 10^{6} / \mathrm{ppm} / \mathrm{s}$. It is not possible to fit the experimental data using an Arrhenius model to determine the kinetics of $\mathrm{NO}_{2}$ assisted passive oxidation because the reactivity of PM under loading without urea was compared to the reactivity of PM under passive oxidation conditions without urea.

\section{Loading Test w/ Urea}

Four tests were performed to study the characteristics of $\mathrm{PM}$ oxidation in the $\mathrm{SCRF}^{\circledR}$ under loading conditions with urea injection. The average ANR for tests was 1.02 with one test having an ANR of 1.09 (L3 Nominal w/ Urea). The $\mathrm{NO}_{x}$ conversion varied from $80-94 \%$. The average $\mathrm{NH}_{3}$ slip ranged from 1-12 ppm. The exhaust flow rates and standard space velocities ranged from 10.9$12.1 \mathrm{~kg} / \mathrm{min}$ and $33-36 \mathrm{k} / \mathrm{hr}$ respectively. The $\mathrm{NO}_{2}$ concentrations at the $\mathrm{SCRF}^{\circledast}$ inlet varied from 
41-98 ppm and the $\mathrm{SCRF}^{\circledR}$ inlet temperature varied from $268-334^{\circ} \mathrm{C}$. The average filtration efficiency for Stage 2 was $98.4 \%$. The cumulative percentage of PM oxidized varied from 14.9 to $41.2 \%$. The average reaction rate for Stage 2 varied from $1.81 \mathrm{E}-05$ to $6.58 \mathrm{E}-05 \mathrm{~s}^{-1}$ while the reaction rate constant ranged from $0.442-0.672 * 10^{6} / \mathrm{ppm} / \mathrm{s}$. It is not possible to fit the experimental data using an Arrhenius model to determine the kinetics of $\mathrm{NO}_{2}$ assisted passive oxidation with urea injection because the reactivity of PM under loading with urea was compared to the reactivity of PM under passive oxidation conditions with urea. A comparison of the results for these tests was done with the results for the corresponding tests without urea injection in terms of average reaction rate, reaction rate constant, cumulative PM oxidized, cumulative PM retained and $\mathrm{SCRF}^{\circledR}$ pressure drop.

\section{PM Oxidation Model and SCR-F Model}

A PM oxidation model was developed based on the shrinking core model which maintains the identity of the incoming PM masses retained in the $\mathrm{SCRF}^{\circledR}$ as compared to the SCR-F model which assumes a lumped model for the incoming PM without keeping the identity of the PM masses retained in the $\mathrm{SCRF}^{\circledR}$. The $\mathrm{PM}$ oxidation model was calibrated to simulate PM oxidation with a single set of kinetics under a wide range of conditions including loading and passive oxidation conditions. The reaction rate results from the PM oxidation model were applied to the SCR-F model to simulate the pressure drop across the $\mathrm{SCRF}^{\circledR}$ and the $\mathrm{PM}$ retained in the $\mathrm{SCRF}^{\circledR}$. $\mathrm{The} \mathrm{SCR}^{-}$ F model was calibrated using experimental data from Loading Tests w/o Urea to simulate the PM retained within $\pm 2 \mathrm{~g}$ and pressure drop across $\mathrm{SCRF}^{\circledast}$ within $\pm 0.5 \mathrm{kPa}$ of the experimental values at the end of Stage 2. The SCR-F model was also used to estimate the cake, wall and channel pressure drop and the PM retained in the cake and wall for the Loading Tests w/o Urea to check the integrity of experimental data and the consistency of the model and the experimental data.

\subsection{Conclusions}

The conclusions with respect to the goals and objectives of this study are given below.

- The reactivity of PM under loading conditions with and without urea injection is higher compared to the reactivity under passive oxidation with and without urea injection. As a 
result, a different set of kinetics for $\mathrm{NO}_{2}$ assisted oxidation is needed for loading and passive oxidation conditions using a lumped PM retained model.

- Based on the experimental data, the percentage of PM oxidized in the $\mathrm{SCRF}^{\circledast}$ increases with increasing engine load due to higher $\mathrm{SCRF}^{\circledR}$ temperatures and higher $\mathrm{NO}_{2}$ concentrations. The percentage of $\mathrm{PM}$ retained in the $\mathrm{SCRF}^{\circledR}$ follows a decreasing trend with increasing engine load. Tests L3 Nominal and L1 Reduced do not follow this trend due to measurement errors.

- The higher PM oxidation rate without urea injection compared to with urea injection during loading conditions is attributed to the competition for $\mathrm{NO}_{2}$ between the SCR reduction reactions and the $\mathrm{PM}$ oxidation reactions.

- On average, the reaction rate with urea injection during loading conditions in the SCRF ${ }^{\circledR}$ are $25 \%$ lower than the reaction rates without urea injection.

- The $\mathrm{NO}_{2}$ assisted kinetics for $\mathrm{PM}$ oxidation in the $\mathrm{SCRF}^{\circledR}$ without urea injection are obtained from the SCR-F model with an activation energy of $96 \mathrm{~kJ} / \mathrm{gmol}$ and preexponential factor of $2.6 \mathrm{~m} / \mathrm{K}-\mathrm{s}$ for the cake and $1.8 \mathrm{~m} / \mathrm{K}$-s for the wall.

- The shrinking core model used in the development of the PM oxidation model is capable of simulating PM oxidation under loading and passive oxidation conditions using a single set of kinetics. This is not possible with the standard Arrhenius model used for PM oxidation in the SCR-F model since a higher pre-exponential (A) is needed for loading conditions as compared to passive oxidation conditions.

- The SCR-F model along with the reaction rate results from the PM oxidation model is able to simulate the $\mathrm{PM}$ retained and $\mathrm{SCRF}^{\circledR}$ pressure drop within $\pm 2 \mathrm{~g}$ and $\pm 0.5 \mathrm{kPa}$ respectively of the experimental values at the end of Stage 2 for the loading conditions without urea injection. 
- Based on the modeling work performed, the percentage of PM oxidized in the SCRF ${ }^{\circledR}$ increases with increasing engine load due to higher $\mathrm{SCRF}^{\oplus}$ temperatures and higher $\mathrm{NO}_{2}$ concentrations. The percentage of $\mathrm{PM}$ retained in the $\mathrm{SCRF}^{\circledR}$ follows a decreasing trend with increasing engine load. All the tests follow this trend for modeling while there are two tests that do not follow this trend for the experimental data.

- The percentage of PM oxidized in the cake and the wall also increases with the increase in engine load (increasing temperature and $\mathrm{NO}_{2}$ concentrations) while PM retained in the cake and the wall follow a decreasing a trend with increasing engine load. The majority of PM oxidation occurs in the PM cake and the majority of the PM is retained in the PM cake. 


\section{References}

[1] "Dieselnet," [Online]. Available: https://www.dieselnet.com.

[2] Chilumukuru, K., Gupta, A., Ruth, M., Cunningham, M. et al., "Aftertreatment Architecture and Control Methodologies for Future Light Duty Diesel Emission Regulations," SAE Int. J. Engines 10(4):2017, doi:10.4271/2017-01-0911.

[3] X. Song, J. Johnson and J. Naber, "A review of the literature of selective catalytic reduction catalysts integrated into diesel particulate filters," International Journal of Engine Research, doi:10.1177/1468087414545094, 2014.

[4] K. Raghavan, "An Experimental Investigation into the Effect of $\mathrm{NO}_{2}$ and Temperature on the Passive Oxidation and Active Regeneration of Particulate Matter in a Diesel Particulate Filter," MS Thesis, Michigan Technological University, 2015.

[5] M. Jeguirim, V. Tschamber and J. F. Brilhac, "Kinetics of Catalyzed and Non- Catalyzed Oxidation with Nitrogen Dioxide Under Regeneration Particle Trap Conditions," Journal of Chemical Technology and Biotechnology, vol. 84, DOI 10.1002/jctb.2110, pp. 770-776, 2008.

[6] H. Surenahali, "Dynamic Model Based State Estimation In a Heavy Duty Diesel Aftertreatment System For Onboard Diagnostics And Controls", PhD Dissertation, Michigan Technological University, 2013.

[7] Raghavan, K., Johnson, J., and Naber, J., "An Experimental Investigation into the Effect of $\mathrm{NO}_{2}$ and Temperature on the Passive Oxidation and Active Regeneration of Particulate Matter in a Diesel Particulate Filter", Emission Control Science and Technology, doi:10.1007/s40825017-0074-2, 2017

[8] E. Gustafson, "An Experimental Investigation into $\mathrm{NO}_{2}$ Assisted Passive Oxidation with and without Urea Dosing and Active Regeneration of Particulate Matter for a SCR Catalyst on a DPF," MS Thesis, Michigan Technological University, 2016.

[9] V. Kadam, "An Experimental Investigation of the Effect of Temperature and Space Velocity on the Performance of a Cu-Zeolite Flow-Through SCR and SCR Catalyst on a DPF with and without PM Loading," MS Thesis, Michigan Technological University, 2016. 
[10] S. Gupta, "An Experimental Investigation into the Effect of Particulate Matter on $\mathrm{NO}_{\mathrm{x}}$ Reduction in a SCR Catalyst on a DPF," MS Report, Michigan Technological University, 2016.

[11] S. Sharma, "The Emission and Particulate Matter Oxidation Performance of the SCR Integrated with a Diesel Particulate Filter (the SCRF ${ }^{\circledR}$ ) with a Downstream SCR," MS Report, Michigan Technological University, 2017.

[12] V. Chundru, "Development of a High-Fidelity Model and Kalman Filter Based State Estimator for Simulation and Control of NOx Reduction Performance of a SCR Catalyst on a DPF", PhD Dissertation Proposal, Michigan Technological University, 2017.

[13] M. Colombo, G. Koltsakis and I. Koutouforis, "A Modeling Study of Soot and De-NOx Reaction Phemomena in SCRF Systems," SAE Technical Paper 2011-37-0031, DOI: 10.4271/2011-370031, 2011.

[14] E. Tronconi, I. Nova, F. Marchitti, D. Karamitros, B. Maletic, N. Markert, D. Chatterjee and M. Hehle, "Interaction of NOx Reduction and Soot Oxidation in a DPF with Cu Coating," Emissions Control Science and Technology, vol. 1, DOI: 10/1007/s40825-015-0014-y, pp. 135-151, 2015.

[15] J. Czerwinnski, Y. Zimmerli, A. Mayer, J. Lamaire, D. Zurcher and G. D'Urbano, "Investigations of SDPF -Diesel Particle Filter with SCR Coating for HD Applications," SAE Technical Paper 2015-01-1023, DOI:10.4271/2015-01-1023, 2015.

[16] M. Naseri, S. Chatterjee, M. Castagnola and H. Chen, "Development of SCR on Diesel Particulate Filter System for Heavy Duty Applications," SAE Int. J. Engines 4(1):1798-1809, doi:10.4271/2011-01-1312, 2011.

[17] Yezerets, A., N. W. C., Eadler, H.," Experimental Determination of the Kinetics of Diesel Soot Oxidation by $\mathrm{O}_{2}$ - Modeling Consequences", SAE Paper Number 2003-01-0833, doi:10.4271/2003-01-083, 2003.

[18] Chilumukuru, K., Arasappa, R., Johnson, J., and Naber, J., "An Experimental Study of Particulate Thermal Oxidation in a Catalyzed Filter During Active Regeneration," SAE Technical Paper 2009-01-1474, doi:10.4271/2009-01-1474, 2009. 
[19] Konstandopoulos, A., Kostoglou, M., Lorentzou, S., Pagkoura, C. et al., "Soot Oxidation Kinetics in Diesel Particulate Filters," SAE Technical Paper 2007-01-1129, doi:10.4271/200701-1129, 2007.

[20] K. Premchand, "Development of a 1-D Catalyzed Diesel Particulate Filter Model for Simulation of the Performance and the Oxidation of Particulate Matter and Nitrogen Oxides using Passive Oxidation and Active Regeneration Engine Experimental Data", PhD Dissertation, Michigan Technological University, 2013.

[21] B. S. Mahadevan, "Development of a Multi-zone Catalyzed Particulate Filter Model and Kalman Filter Estimator for Simulation and Control of Particulate Matter Distribution of a CPF for Engine ECU Applications", PhD Dissertation, Michigan Technological University, 2017.

[22] C., Hutton, "An Experimental Investigation Into The Passive Oxidation Of Particulate Matter In A Catalyzed Particulate Filter", MS Thesis, Michigan Technological University, 2010.

[23] Messerer, A., Niessner, R., and Poschl, U.,"Comprehensive kinetic characterization of the oxidation and gasification of model and real diesel soot by nitrogen oxides and oxygen under engine exhaust conditions: Measurement, Langmuir-Hinshelwood, and Arrhenius parameters", Carbon 44 2006, doi:10.1016/j.carbon.2005.07.017, 2005.

[24] Kandylas, I. P., Haralampous, O. A., and Koltsakis, G. C.," Diesel Soot Oxidation with $\mathrm{NO}_{2}$ : Engine Experiments and Simulations", Industrial \& Engineering Chemistry Research 22, doi:10.1021/ie020379t, 2002.

[25] Neeft, P. A., Nijhuis, T. X., Smakman, E., Makkee, M., and Moulijn, A. J.," Kinetics of the oxidation of diesel soot", Elsevier Science 12, 1997.

[26] Lee, J., Lee, H., Song, S., and Chun, K., "Experimental Investigation of Soot Oxidation Characteristic with NO2 and O2 using a Flow Reactor Simulating DPF," SAE Technical Paper 2007-01-1270, 2007, https://doi.org/10.4271/2007-01-1270, 2007.

[27] Triana, A. P., Johnson, J. H., Yang, S. L., and Baumgard, K. J.," An Experimental and Computational Study of the Pressure Drop and Regeneration Characteristics of a Diesel Oxidation Catalyst and a Particulate Filter", SAE Paper Number 2006-01-0266, doi:10.4271/2006-01-0266, 2006 
[28] Dabhoiwala, R. H., Johnson, J. H., Naber, J., and Bagley, S. T.," Experimental and Modeling Results Comparing Two Diesel Oxidation Catalyst - Catalyzed Particulate Filter Systems", SAE Paper Number 2008-01-0484, 2008, doi:10.4271/2008-01-0484, 2008.

[29] Stanmore, B.R., Brilhac, J.F., Gilot, P., "The oxidation of soot: a review of experiments, mechanisms and models" Carbon, 39, 2247-2268, 2001.

[30] van Setten B.A.A.L., Makkee M., Moulijn J.A., Science and Technology of Catalytic Diesel Particulate Filters, Catalysis Reviews, 43(4), 489-564, 2001.

[31] Konstandopoulos, A., Kostoglou, M., "The Micromechanics of Catalytic Soot Oxidation in Diesel Particulate Filters," SAE Technical Paper 2012-01-1288, doi:10.4271/2012-01-1288, 2012.

[32] Bhatia, S. K. and Perlmutter, D. D. (1980), A random pore model for fluid-solid reactions: I. Isothermal, kinetic control. AIChE J., 26: 379-386. doi:10.1002/aic.690260308

[33] Dimopoulos Eggenschwiler, P. and Schreiber, D., "Investigation of the Oxidation Behavior of Soot in Diesel Particle Filter structures," SAE Technical Paper 2015-24-2516, 2015, doi:10.4271/2015-24-2516.

[34] Hurt, R.H., Sarofim, A.F., Longwell, J.P., "Gasification induced densification of carbons: from soot to form coke", Combustion and Flame, 95, 430-432, 1993.

[35] Ishiguro, T., Takatori, Y., Akihama, K., "Microstructure of Diesel Soot Particles Probed by Electron Microscopy: First Observation of Inner Core and Outer Shell", Combustion and Flame, 108, 231-234, 1997.

[36] H. Mohammed, "Filtration and oxidation characteristics of a diesel oxidation catalyst and a catalyzed particulate filter: development of a 1-D 2-layer model", MS Thesis, Michigan Technological University, 2005.

[37] R. Dabhoiwala, "An Experimental and Modeling Study of Two Diesel Oxidation Catalyst Catalyzed Particulate Filter Systems and the Effects of a Cracked Filter on its Performance", MS Thesis, Michigan Technological University, 2007. 
[38] K. Premchand, "Experimental and Modeling Study of the Filtration and Oxidation Characteristics of a Diesel Oxidation Catalyst and a Catalyzed Particulate Filter", MS Thesis, Michigan Technological University, 2006.

[39] Lur'e, B., Mikhno, A.: Interaction of NO2 with soot. Kinet. Catal. 38(4), 490-497 (1997)

[40] V. Chundru, Unpublished PhD Dissertation, Michigan Technological University, 2018.

[41] Depcik, C., Langness, C., and Mattson, J., Development of a simplified diesel particulate filter model intended for an engine control unit, SAE Technical Paper No. 2014-01-1559, 2014.

[42] R. Foley, "Experimental Investigation into Particulate Matter Distribution in Catalyzed Particulate Filters using a 3D Terahertz Wave Scanner," MS Thesis, Michigan Technological University, 2013.

[43] J. Pidgeon, "An Experimental Investigation into the Effects of Biodiesel Blends on Particulate Matter Oxidation in a Catalyzed Particulate Filter During Active Regeneration," MS Thesis, Michigan Technological University, 2013.

[44] X. Song, "A SCR Model based on Reactor and Engine Experimental Studies for a Cu-zeolite Catalyst," PhD Dissertation, Michigan Technological University, 2013.

[45] Gregory Austin, J.D.Naber, J.H. Johnson, Chris Hutton: "Effects of biodiesel blends on particulate matter oxidation in a catalyzed particulate filter during active regeneration," SAE Paper No. 2010-51-0557. doi: 10.4271/2010-01-0557, 2010

[46] Awara A.E. "A Theoretical and Experimental Study of the Regeneration Process in a Silicon Carbide Particulate Trap Using a Copper Fuel Additive". MS Thesis, Michigan Technological University, Houghton, MI, 1996.

[47] K. L. Shiel, "A Study of the Effect of Biodiesel Fuel on Passive Oxidation in a Catalyzed Particulate Filter," MS Thesis, Michigan Technological University, 2012.

[48] Mahadevan, B., Johnson, J., Shahbakhti, M., "Predicting pressure drop, temperature and particulate matter distribution of a catalyzed diesel particulate filter using a multi-zone model including cake permeability", Journal of Emiss. Control Sci. Technol., doi: 10.1007/s40825-017-0062-6, 2017. 


\section{Appendix A: Mass Balance Equations and Data Analysis}

This appendix discusses the equations used for the analysis of experimental data from the Loading Tests $\mathrm{w} / \mathrm{o}$ and $\mathrm{w} /$ Urea. The first part of this appendix focuses on the equations and assumptions used for the calculation of the clean weight of the $\mathrm{SCRF}^{\circledR}$ i.e. without any PM loading. Further, there is a discussion on the estimation of filtration efficiency during Stage 1 from the calibrated SCR-F model. The appendix ends with a detailed description of the equations used for the mass balance for the analysis of the experimental data during Stage 1 and Stage 2 of the Loading Tests.

\section{Clean Weight of the SCRF ${ }^{\circledR}$}

The equations used for the estimation of clean weight of the $\mathrm{SCRF}^{\circledR}$ from reference [47] for all the tests are given in the following paragraphs. The $\mathrm{PM}$ retained in the $\mathrm{SCRF}^{\circledR}$ at the end of Stage 1 $\left(m_{\text {retained, }, 1}\right)$ and Stage $2\left(m_{\text {retained,s2 }}\right)$ is calculated by subtracting the clean weight of the SCRF ${ }^{\circledR}$ $\left(\mathrm{M}_{\text {clean }}\right)$ from the weight measurements of the $\mathrm{SCRF}^{\circledR}$ taken at the end of Stage $1\left(\mathrm{M}_{\mathrm{s} 1}\right)$ and Stage $2\left(\mathrm{M}_{\mathrm{s} 2}\right)$ as shown in Equations 50 and 51.

$$
\begin{aligned}
& m_{\text {retained }, S 1}=M_{S 1}-M_{\text {clean }} \\
& m_{\text {retained }, S 2}=M_{S 2}-M_{\text {clean }}
\end{aligned}
$$

The cumulative mass balance for Stage 1 and Stage 2 can be mathematically expressed as shown in Equations 52 and 53 respectively.

$$
\begin{gathered}
m_{\text {in }, S 1}-m_{\text {retained }, S 1}-m_{o x, S 1}-m_{\text {out }, S 1}=0 \\
m_{\text {retained }, S 1}+m_{\text {in,S2 }}-m_{\text {retained }, S 2}-m_{\text {ox }, S 2}-m_{\text {out }, S 2}=0
\end{gathered}
$$

where, $m_{i n, S 1}$ and $m_{i n, S 2}$ is the cumulative PM entering the $\mathrm{SCRF}^{\oplus}(\mathrm{g}), \mathrm{m}_{\mathrm{ox}, \mathrm{S1}}$ and $\mathrm{m}_{\mathrm{ox}, \mathrm{S2}}$ is the cumulative PM oxidized (g), $m_{\text {retained, }, 51}$ and $m_{\text {retained, }, 52}$ is the PM retained $(g), m_{\text {out }, S 1}$ and $m_{\text {out, }, 52}$ is the cumulative $\mathrm{PM}$ exiting the $\mathrm{SCRF}^{\circledR}(\mathrm{g})$ during Stage 1 and Stage 2 respectively. 
The average filtration efficiency during Stage 1 and Stage 2 is given by Equations 54 and 55 respectively.

$$
\begin{aligned}
& \bar{\eta}_{S 1}=\frac{m_{i n, S 1}-m_{o u t, S 1}}{m_{i n, S 1}} \\
& \bar{\eta}_{S 2}=\frac{m_{i n, S 2}-m_{o u t, S 2}}{m_{i n, S 2}}
\end{aligned}
$$

Substituting Equation 50 into Equation 52 and rearranging the terms, results in the following equation.

$$
m_{\text {retained }, S 1}=m_{\text {in,S1 }}-m_{o x, S 1}-m_{\text {out }, S 1}=M_{S 1}-M_{\text {clean }}
$$

or

$$
\left(m_{\text {in }, S 1}-m_{o u t, S 1}\right)-m_{o x, S 1}=M_{S 1}-M_{\text {clean }}
$$

Substituting Equation 54 in Equation 56, results in the following equation.

$$
\bar{\eta}_{S 1} m_{i n, S 1}-m_{o x, S 1}=M_{S 1}-M_{\text {clean }}
$$

or

$$
M_{\text {clean }}=M_{S 1}-\bar{\eta}_{S 1} m_{i n, S 1}+m_{o x, S 1}
$$

or

$$
m_{o x, S 1}=\bar{\eta}_{S 1} m_{i n, S 1}-\left(M_{S 1}-M_{\text {clean }}\right)
$$

or

$$
\frac{m_{o x, S 1}}{m_{i n, S 1}}=\bar{\eta}_{S 1}-\frac{\left(M_{S 1}-M_{\text {clean }}\right)}{m_{\text {in,S1 }}}
$$

Rearranging the terms in Equation 53, results in the following equation.

$$
m_{\text {ox }, S 2}=\left(m_{\text {in }, S 2}-m_{\text {out }, S 2}\right)+m_{\text {retained }, S 1}-m_{\text {retained }, S 2}
$$


Now, substituting Equation 55 into Equation 58, results in the following equation.

$$
m_{o x, S 2}=\bar{\eta}_{S 2} m_{\text {in,S2 }}+m_{\text {retained }, S 1}-m_{\text {retained }, S 2}
$$

Again, substituting Equations 50 and 51 into Equation 59, results in the following equation.

$$
m_{o x, S 2}=\bar{\eta}_{S 2} m_{i n, S 2}-\left(M_{S 1}-M_{c l e a n}\right)-\left(M_{S 2}-M_{\text {clean }}\right)
$$

or

$$
m_{o x, S 2}=\bar{\eta}_{S 2} m_{i n, S 2}-\left(M_{S 2}-M_{S 1}\right)
$$

or

$$
\frac{m_{o x, S 2}}{m_{i n, S 2}}=\bar{\eta}_{S 2}-\frac{\left(M_{S 2}-M_{S 1}\right)}{m_{i n, S 2}}
$$

Now, subtracting Equation 57 from Equation 60, results in the following equation.

$$
\frac{m_{o x, S 2}}{m_{i n, S 2}}-\frac{m_{o x, S 1}}{m_{i n, S 1}}=\bar{\eta}_{S 2}-\frac{\left(M_{S 2}-M_{S 1}\right)}{m_{i n, S 2}}-\bar{\eta}_{S 1}+\frac{\left(M_{S 1}-M_{\text {clean }}\right)}{m_{i n, S 1}}
$$

Rearranging the terms, results in Equation 61 which is used for the calculation of clean weight of the $\mathrm{SCRF}^{\circledR}$.

$$
M_{\text {clean }}=M_{S 1}-\left(\bar{\eta}_{S 1} m_{i n, S 1}-\left(\bar{\eta}_{S 2}-\frac{M_{S 2}-M_{S 1}}{m_{i n, S 2}}\right) m_{i n, S 1}\right)-\left(\frac{m_{o x, S 2}}{m_{i n, S 2}}-\frac{m_{o x, S 1}}{m_{i n, S 1}}\right) m_{i n, S 1}
$$

In the Equations 54 to 61 , the cumulative PM mass entering the $\mathrm{SCRF}^{\oplus}$ during Stage $1\left(\mathrm{~m}_{\mathrm{in}, \mathrm{S} 1}\right)$ and Stage $2\left(\mathrm{~m}_{\mathrm{in}, \mathrm{s} 2}\right)$ is calculated using Equation 62 and 63. 


$$
\begin{aligned}
& m_{\text {in }, S 1}=\frac{c_{i n, S 1}}{1000} * \frac{\dot{m}_{\text {exhaust }, S 1}}{\rho_{S t d}} * t_{S 1} \\
& m_{\text {in,S2 }}=\frac{c_{\text {in }, S 2}}{1000} * \frac{\dot{m}_{\text {exhaust }, S 2}}{\rho_{\text {Std }}} * t_{S 2}
\end{aligned}
$$

where, $\mathrm{C}_{\mathrm{in}, \mathrm{S} 1}$ and $\mathrm{C}_{\mathrm{in}, \mathrm{S2}}$ is the PM concentration $(\mathrm{mg} / \mathrm{scm}), \dot{m}_{\text {exhaust }, S 1}$ and $\dot{m}_{\text {exhaust, } S 2}$ is the exhaust flow rate $(\mathrm{kg} / \mathrm{min}), \mathrm{t}_{\mathrm{s} 1}$ and $\mathrm{t}_{\mathrm{s} 2}$ is the duration $(\mathrm{min})$ of Stage 1 and Stage 2 and $\rho_{\text {Std }}$ is the exhaust density at standard atmospheric conditions.

For the calculation of $M_{c l e a n}$ according to Equation 61 , the average filtration efficiency for Stage 1 $\left(\bar{\eta}_{S 1}\right)$ and the ratio of PM oxidized and PM entering during Stage $1\left(\mathrm{~m}_{\mathrm{ox}, \mathrm{S} 1} / \mathrm{m}_{\mathrm{in}, \mathrm{S} 1}\right)$ and Stage 2 $\left(m_{\mathrm{ox}, \mathrm{SS}_{2}} / \mathrm{m}_{\mathrm{in}, \mathrm{S2}}\right)$ are estimated from the calibrated SCR-F model. Experimental values are used for all the other variables in Equation 61 . Equation 61 is used to calculate the clean weight of SCRF ${ }^{\circledR}$ which is then used in Equations 50 and 51 along with the $\mathrm{SCRF}^{\circledR}$ weight measurements i.e. $\mathrm{M}_{\mathrm{s} 1}$ and $\mathrm{M}_{\mathrm{s} 2}$ to calculate the PM mass retained at the end of Stage 1 and Stage 2 respectively.

\section{Stage 1 Average Filtration Efficiency and $m_{o x} / m_{\text {in }}$ Ratio for Stage 1 and Stage 2}

The value of average filtration efficiency during Stage 1 for all the Loading Tests was estimated from the calibrated SCR-F model with an iterative process explained in the following paragraph.

For the first iteration, the filtration efficiency for Stage 1 was assumed to be $58.6 \%$ based on the previous modeling data from the MTU 1-D model [48]. Also, the ratio of cumulative PM oxidized and cumulative PM entering during Stage $1\left(m_{\mathrm{ox}, \mathrm{S} 1} / \mathrm{m}_{\mathrm{in}, \mathrm{S1}}\right)$ and Stage $2\left(\mathrm{~m}_{\mathrm{ox}, \mathrm{S2}} / \mathrm{m}_{\mathrm{in}, \mathrm{S2}}\right)$ was assumed equal, to calculate the $M_{\text {clean }}$ using Equation 61. However, this ratio is not equal as observed from the modeling data which is discussed later. The values of PM retained at the end of Stage 1 and Stage 2 for all the Loading Tests were then calculated using these two assumptions.

Next, the SCR-F model was calibrated to model the PM retained at the end of Stage 1 and Stage 2 within $\pm 2 \mathrm{~g}$ of the experimental values. Once the SCR-F model was calibrated, the average filtration efficiency for Stage 1 was estimated as the average of the filtration efficiency from the 
SCR-F model for the duration of Stage 1 for each Loading Test. Also, the ratio of cumulative PM oxidized and cumulative PM entering during Stage $1\left(m_{\mathrm{ox}, \mathrm{s} 1} / \mathrm{m}_{\mathrm{in}, \mathrm{s} 1}\right)$ and Stage $2\left(\mathrm{~m}_{\mathrm{ox}, \mathrm{s} 2} / \mathrm{m}_{\mathrm{in}, \mathrm{s} 2}\right)$ was calculated using the SCR-F model for each Loading Test.

Table A.1 gives the values of average filtration efficiency for Stage 1, and the ratio of cumulative PM oxidized and cumulative PM entering for Stage 1 and Stage 2 which are not equal, for all the Loading Tests without Urea. The same values were assumed for the Loading Tests w/ Urea.

Table A.1: Estimation of Stage 1 Filtration Efficiency and Ratio of PM Oxidized and PM Entering for Stage 1 and Stage 2 Using Calibrated SCR-F Model

\begin{tabular}{|c|c|c|c|c|c|c|c|}
\hline \multirow{2}{*}{ Test } & \multirow{2}{*}{$\begin{array}{c}\text { Stage } 1 \\
\text { Filt. Eff. } \\
\left(\bar{\eta}_{S 1}\right)\end{array}$} & \multicolumn{3}{|c|}{ Stage 1} & \multicolumn{3}{|c|}{ Stage 2} \\
\hline & & $m_{o x}$ & $m_{\mathrm{in}}$ & $\mathrm{m}_{\mathrm{ox}} / \mathrm{m}_{\mathrm{in}}$ & $m_{o x}$ & $m_{\text {in }}$ & $\mathrm{m}_{\mathrm{ox}} / \mathrm{m}_{\mathrm{in}}$ \\
\hline$[-]$ & [\%] & [g] & [g] & {$[-]$} & [g] & [g] & {$[-]$} \\
\hline L1 Nom & 61.6 & 0.08 & 1.93 & 0.042 & 4.3 & 19.3 & 0.225 \\
\hline L1 Red & 66.3 & 0.21 & 3.49 & 0.060 & 8.24 & 32.7 & 0.252 \\
\hline L2 Nom & 59.8 & 0.14 & 1.89 & 0.075 & 5.6 & 18.9 & 0.296 \\
\hline L2 Red & 64.3 & 0.28 & 3.36 & 0.084 & 9.8 & 33.5 & 0.292 \\
\hline L3 Nom & 57.0 & 0.22 & 1.78 & 0.126 & 7.1 & 17.2 & 0.413 \\
\hline L3 Red & 61.9 & 0.54 & 3.51 & 0.153 & 14.4 & 33.2 & 0.434 \\
\hline L4 Nom & 55.4 & 0.29 & 1.79 & 0.159 & 10.4 & 17.9 & 0.582 \\
\hline L4 Red & 59.6 & 0.60 & 3.51 & 0.169 & 19.5 & 34.2 & 0.570 \\
\hline
\end{tabular}

In the next iteration, the value of Stage 1 filtration efficiency and $m_{o x} / m_{\text {in }}$ for Stage 1 and Stage 2 from Table A.1 are used to calculate the clean weight of the $\mathrm{SCRF}^{\circledR}$ using Equation 61 . The calculated value of $\mathrm{M}_{\text {clean, }}$, the $\mathrm{SCRF}^{\circledR}$ weight measurements and the $\mathrm{PM}$ retained at the end of Stage 1 and Stage 2 for all the tests are listed in Table A.2.

It is important to note that the value of $\mathrm{SCRF}^{\circledR}$ clean weight is different for each test as seen in Table A.2. This difference is due to breaking of thermocouple probes on the $\mathrm{SCRF}^{\circledR}$ in between the tests which affects the $\mathrm{SCRF}^{\circledR}$ weight measurements. Any $\mathrm{SCRF}^{\circledR}$ thermocouple that broke in between the stages in a particular test was noted down and placed on the scale while weighing the $\mathrm{SCRF}^{\circledR}$ to ensure correct difference in weight measurements between Stage 1 and Stage 2. 
Table A.2: SCRF ${ }^{\circledR}$ Weights and PM Retained in Stage 1 and Stage 2

\begin{tabular}{|c|c|c|c|c|c|}
\hline Test & $\mathbf{M}_{\text {clean }}$ & $\mathrm{M}_{\mathrm{s} 1}$ & $\mathrm{M}_{\mathrm{s2}}$ & $\mathbf{m}_{\text {retained, } \mathbf{S 1}}$ & $\mathbf{m}_{\text {retained, } \mathbf{S 2}}$ \\
\hline$[-]$ & [g] & [g] & [g] & [g] & [g] \\
\hline L1 Nominal & 19693.0 & 19694.1 & 19709.1 & 1.1 & 16.1 \\
\hline $\begin{array}{c}\text { L1 Nominal w/ } \\
\text { Urea }\end{array}$ & 19714.4 & 19715.5 & 19732.0 & 1.1 & 17.6 \\
\hline L1 Reduced" & 19710.2 & 19712.2 & 19735.6 & 2.0 & 25.4 \\
\hline $\begin{array}{l}\text { L1 Reduced } \\
\text { w/ Urea }\end{array}$ & 19712.1 & 19714.4 & 19743.9 & 2.3 & 31.8 \\
\hline L2 Nominal & 19718.4 & 19719.2 & 19729.9 & 0.8 & 11.5 \\
\hline L2 Reduced & 19718.3 & 19720.4 & 19745.1 & 2.1 & 26.8 \\
\hline L3 Nominal & 19704.4 & 19704.9 & 19712.1 & 0.6 & 7.8 \\
\hline $\begin{array}{c}\text { L3 Nominal w/ } \\
\text { Urea }\end{array}$ & 19706.2 & 19707.1 & 19718.6 & 0.9 & 12.4 \\
\hline L3 Reduced & 19710.5 & 19712.2 & 19730.5 & 1.7 & 20.0 \\
\hline $\begin{array}{c}\text { L3 Reduced } \\
\text { w/ Urea }\end{array}$ & 19691.8 & 19693.9 & 19716.4 & 2.1 & 24.6 \\
\hline L4 Nominal & 19690.9 & 19691.7 & 19699.4 & 0.8 & 8.5 \\
\hline L4 Reduced & 19681.1 & 19682.6 & 19696.1 & 1.5 & 15.0 \\
\hline
\end{tabular}

"Data obtained from Test PO-C in reference [11] 


\section{Appendix B: Validation Test for NO Conversion across DOC}

This appendix discusses about the validation test which was performed to ensure proper functioning of the DOC since some of the Loading Test had a relatively low NO conversion $(<20 \%)$.

The validation test was performed at fixed engine conditions - engine speed (1200 RPM), load $(120 \mathrm{Nm})$ and exhaust flow rate $(5 \mathrm{~kg} / \mathrm{min})$. The $25 \mathrm{~kW}$ Exhaust Heater was used to increase the temperature of the exhaust in steps of $20^{\circ} \mathrm{C}$ and the DOC inlet temperature was allowed to stabilize. Once stabilized, emission samples were taken using the Mass Spectrometer for a period of 15 min each at UDOC and DDOC for each of the heater temperature set points at steady state conditions.

Table B.1 shows the $\mathrm{NO}, \mathrm{NO}_{2}$, and $\mathrm{NO}_{x}$ values at the $\mathrm{DOC}$ inlet and outlet which are used to calculate the $\mathrm{NO}$ conversion across the DOC. The $\mathrm{NO}$ conversion and $\mathrm{NO}_{2} / \mathrm{NO}_{x}$ ratio is given in Table B.1 for all set points.

Table B.1: NO Conversion Across DOC - Validation Test

\begin{tabular}{|c|c|c|c|c|c|c|c|c|c|c|}
\hline \multirow{2}{*}{$\begin{array}{l}\text { Heater } \\
\text { Temp. }\end{array}$} & \multirow{2}{*}{$\begin{array}{l}\text { DOC In } \\
\text { Temp. }\end{array}$} & \multirow{2}{*}{$\begin{array}{c}\text { DOC } \\
\text { Out } \\
\text { Temp. }\end{array}$} & \multicolumn{3}{|c|}{ DOC Inlet } & \multicolumn{3}{|c|}{ DOC Outlet } & \multirow{2}{*}{$\begin{array}{l}\text { NO } \\
\text { Conv. }\end{array}$} & \multirow{2}{*}{$\begin{array}{c}\mathrm{NO}_{2} / \mathrm{NO}_{\mathrm{x}} \\
\text { Ratio }\end{array}$} \\
\hline & & & $\mathrm{NO}_{2}$ & NO & $\mathrm{NO}_{x}$ & $\mathrm{NO}_{2}$ & NO & $\mathrm{NO}_{\mathrm{x}}$ & & \\
\hline$\left[{ }^{0} \mathrm{C}\right]$ & {$\left[{ }^{0} \mathrm{C}\right]$} & {$\left[{ }^{0} \mathrm{C}\right]$} & [ppm] & [ppm] & [ppm] & [ppm] & [ppm] & [ppm] & [\%] & {$[-]$} \\
\hline 200 & 180 & 193 & 20 & 170 & 190 & 16 & 169 & 185 & 1 & 0.09 \\
\hline 220 & 199 & 213 & 21 & 173 & 194 & 40 & 145 & 185 & 16 & 0.22 \\
\hline 240 & 216 & 231 & 22 & 173 & 195 & 58 & 124 & 182 & 28 & 0.32 \\
\hline 260 & 232 & 251 & 22 & 178 & 200 & 77 & 111 & 188 & 38 & 0.41 \\
\hline 280 & 250 & 270 & 20 & 181 & 201 & 85 & 96 & 181 & 47 & 0.47 \\
\hline 300 & 267 & 289 & 20 & 183 & 203 & 92 & 94 & 186 & 49 & 0.49 \\
\hline 320 & 285 & 308 & 19 & 187 & 206 & 99 & 89 & 188 & 52 & 0.53 \\
\hline 340 & 302 & 327 & 18 & 193 & 211 & 104 & 85 & 189 & 56 & 0.55 \\
\hline 360 & 319 & 346 & 17 & 196 & 213 & 106 & 86 & 192 & 56 & 0.55 \\
\hline 380 & 337 & 366 & 15 & 196 & 211 & 102 & 88 & 190 & 55 & 0.54 \\
\hline 400 & 354 & 384 & 14 & 193 & 207 & 94 & 97 & 191 & 50 & 0.49 \\
\hline 420 & 368 & 400 & 12 & 190 & 202 & 87 & 104 & 191 & 45 & 0.46 \\
\hline
\end{tabular}


The NO conversion across DOC is plotted against the DOC inlet temperature as shown in Figure B.1. The trend of NO conversion with DOC inlet temperature shown in Figure B.1 is in agreement with references in the literature where the peak NO conversion is in the range of $300-350{ }^{\circ} \mathrm{C} \mathrm{DOC}$ inlet temperature. Hence, it was confirmed that the DOC is performing its function properly and so there was no need to change the DOC for further Loading Tests as was done by reference [8].

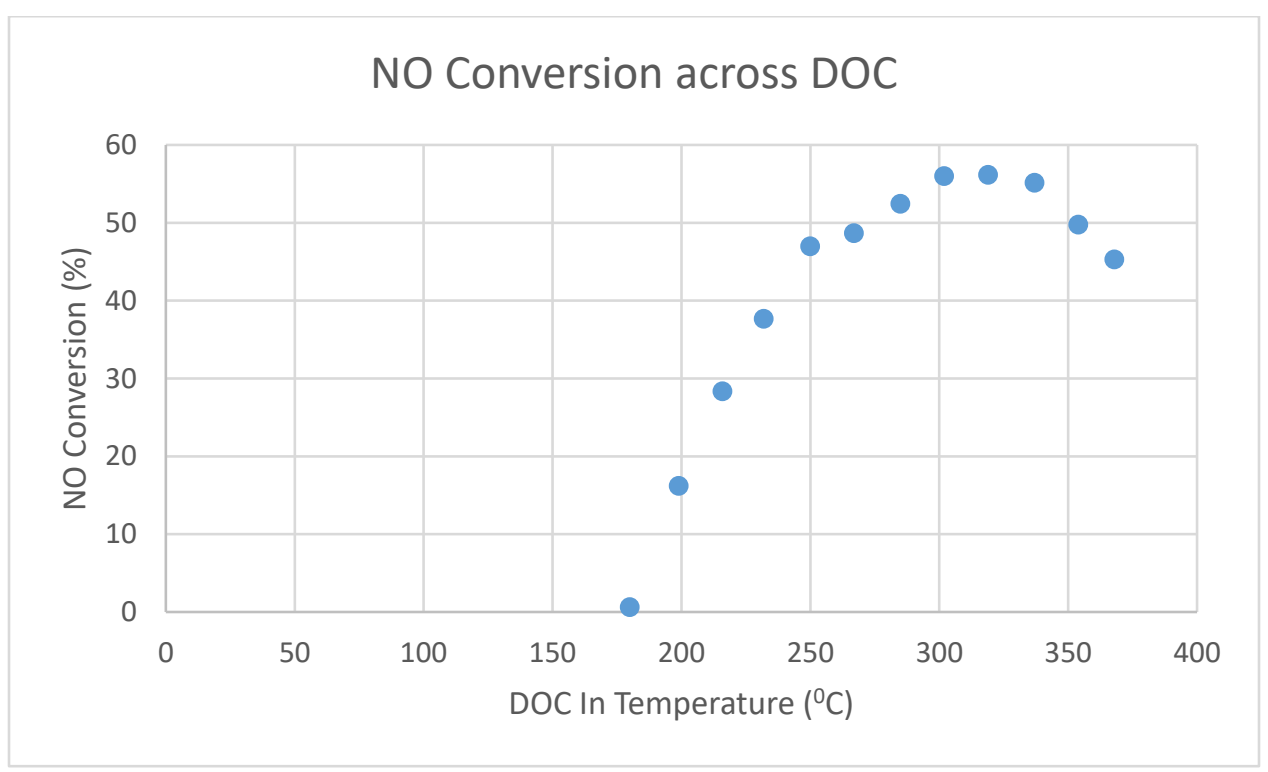

Figure B.1: NO Conversion Across DOC vs DOC Inlet Temperature 


\section{Appendix C: Experimental Pressure Drop Plots}

This appendix contains the plots for pressure drop across SCRF ${ }^{\circledR}$ vs time for each of the Loading Tests performed in this study. It also shows the comparison of pressure drop across SCRF ${ }^{\circledR}$ for Loading Tests w/o and w/ Urea in Figure C.9 to Figure C.12.

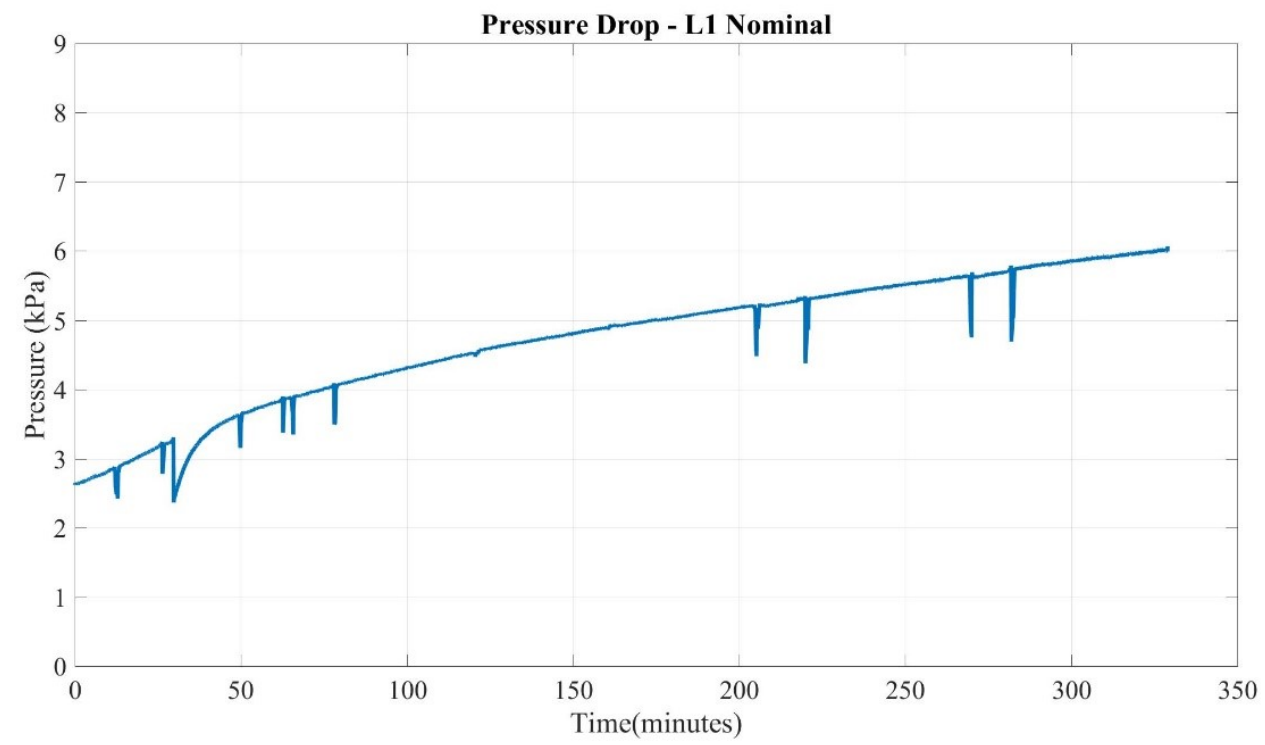

Figure C.1: SCRF ${ }^{\circledast}$ Pressure Drop vs Time for L1 Nominal

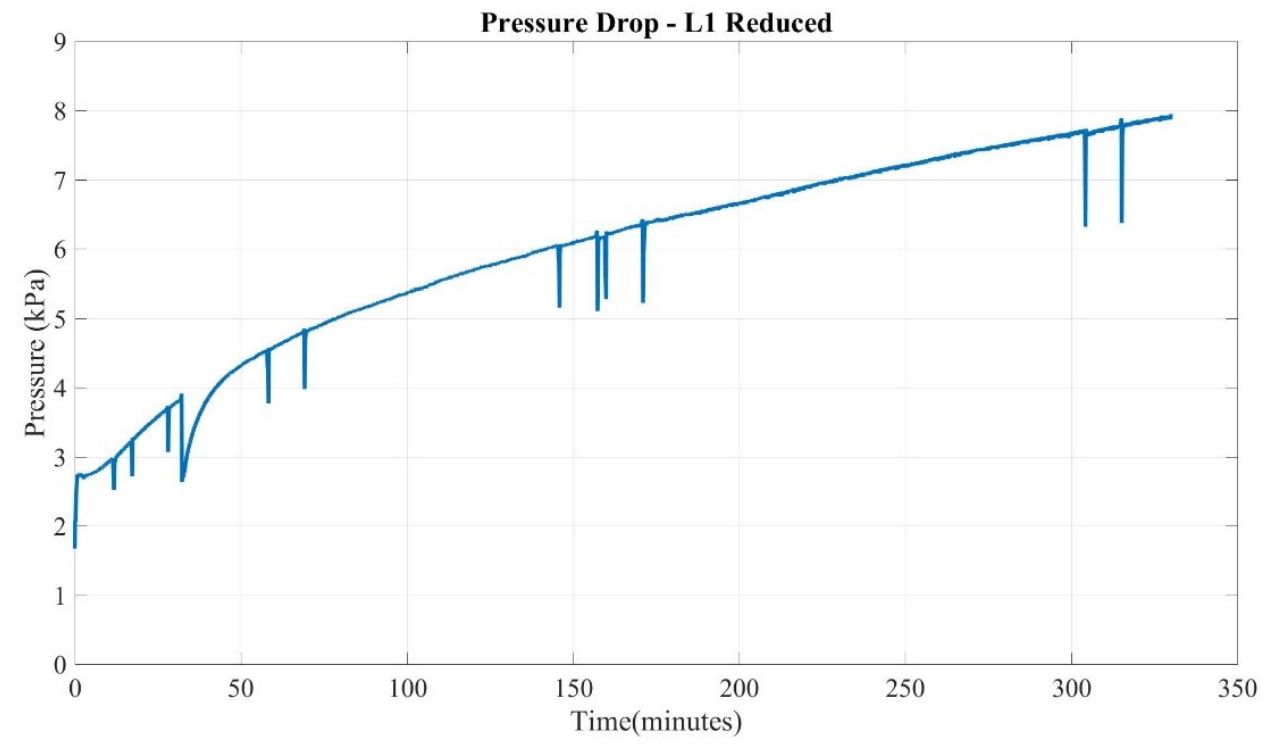

Figure C.2: SCRF ${ }^{\circledR}$ Pressure Drop vs Time for L1 Reduced [11] 


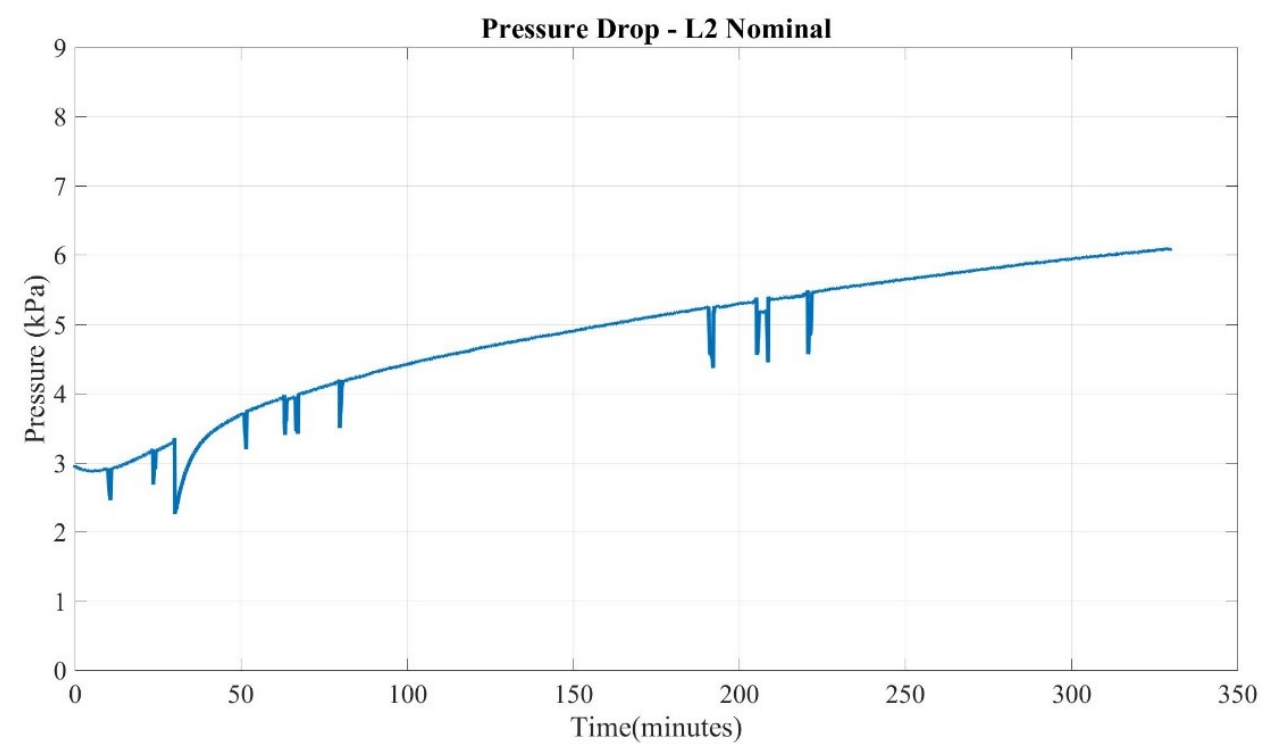

Figure C.3: SCRF ${ }^{\circledR}$ Pressure Drop vs Time for L2 Nominal

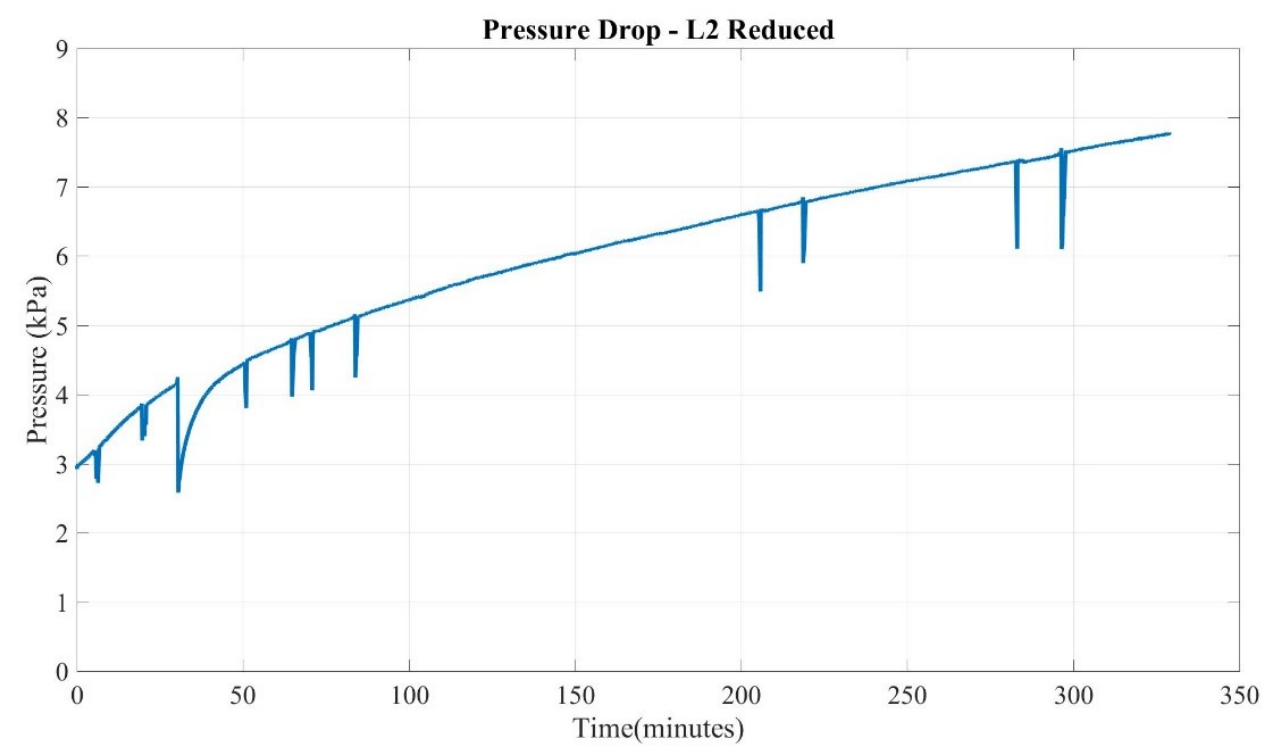

Figure C.4: SCRF ${ }^{\circledast}$ Pressure Drop vs Time for L2 Reduced 
The peak in pressure drop across SCRF ${ }^{\oplus}$ towards the end of Stage 2 in between 250-300 mins for L3 Nominal shown in Figure C.5 is because of the unexpected active regeneration event explained earlier.

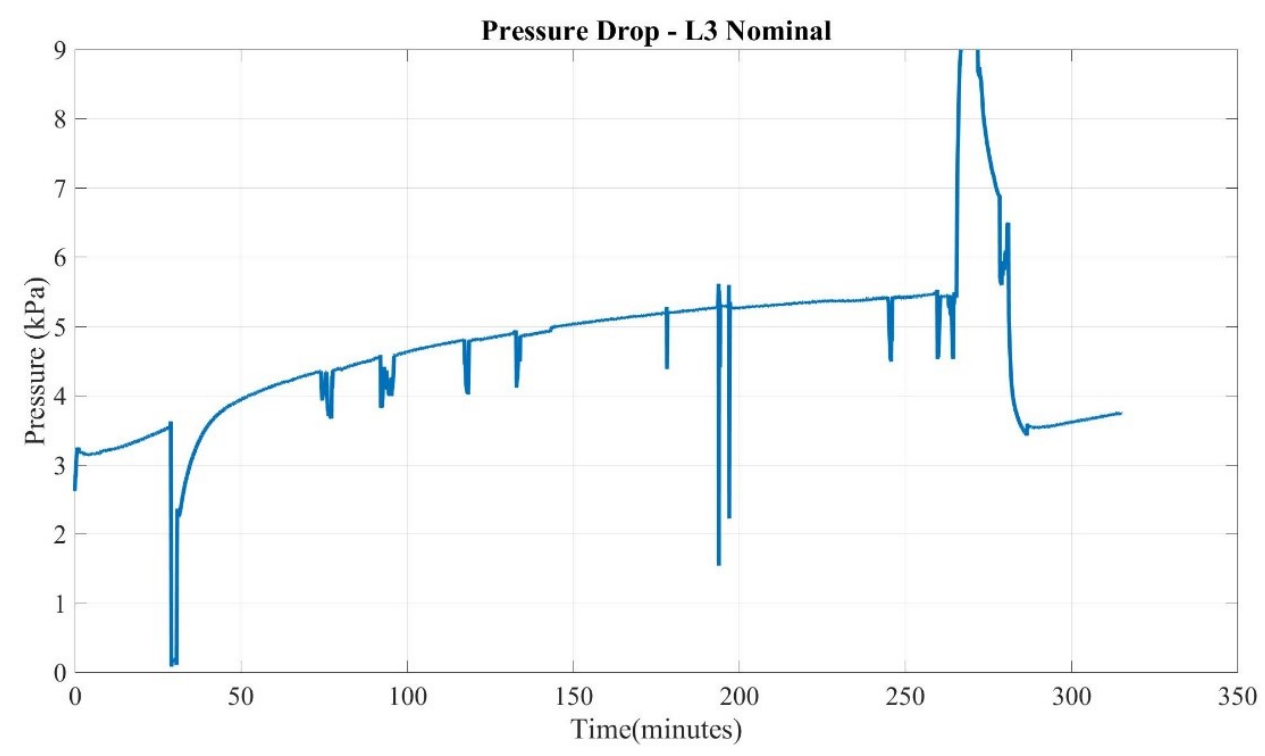

Figure C.5: SCRF ${ }^{\circledR}$ Pressure Drop vs Time for L3 Nominal

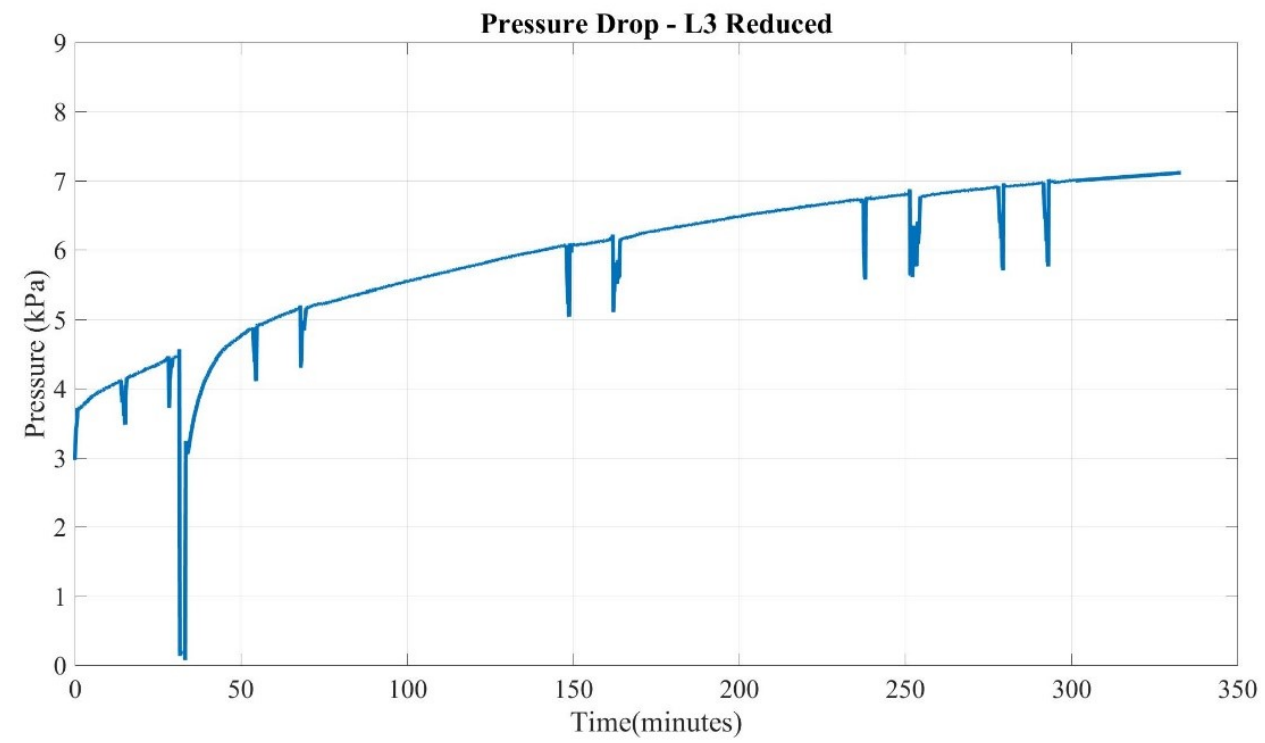

Figure C.6: SCRF ${ }^{\circledR}$ Pressure Drop vs Time for L3 Reduced 


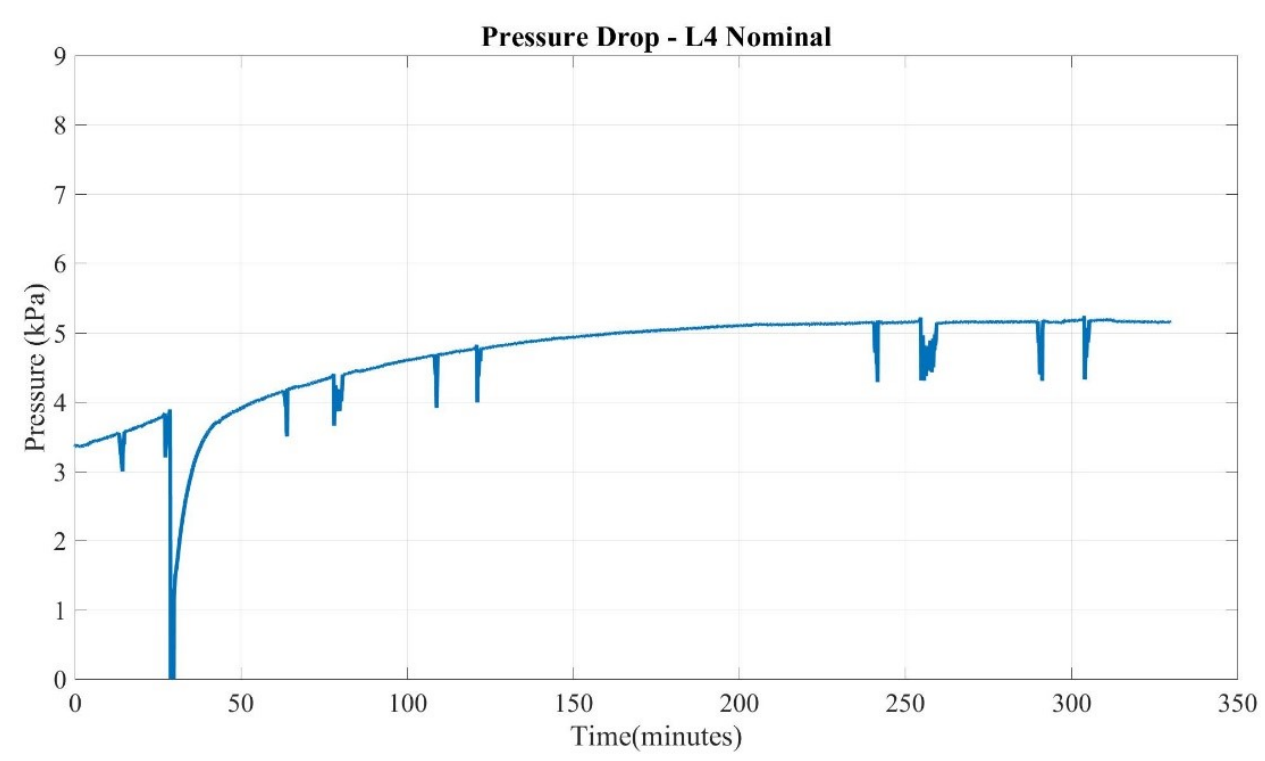

Figure C.7: SCRF ${ }^{\circledR}$ Pressure Drop vs Time for L4 Nominal

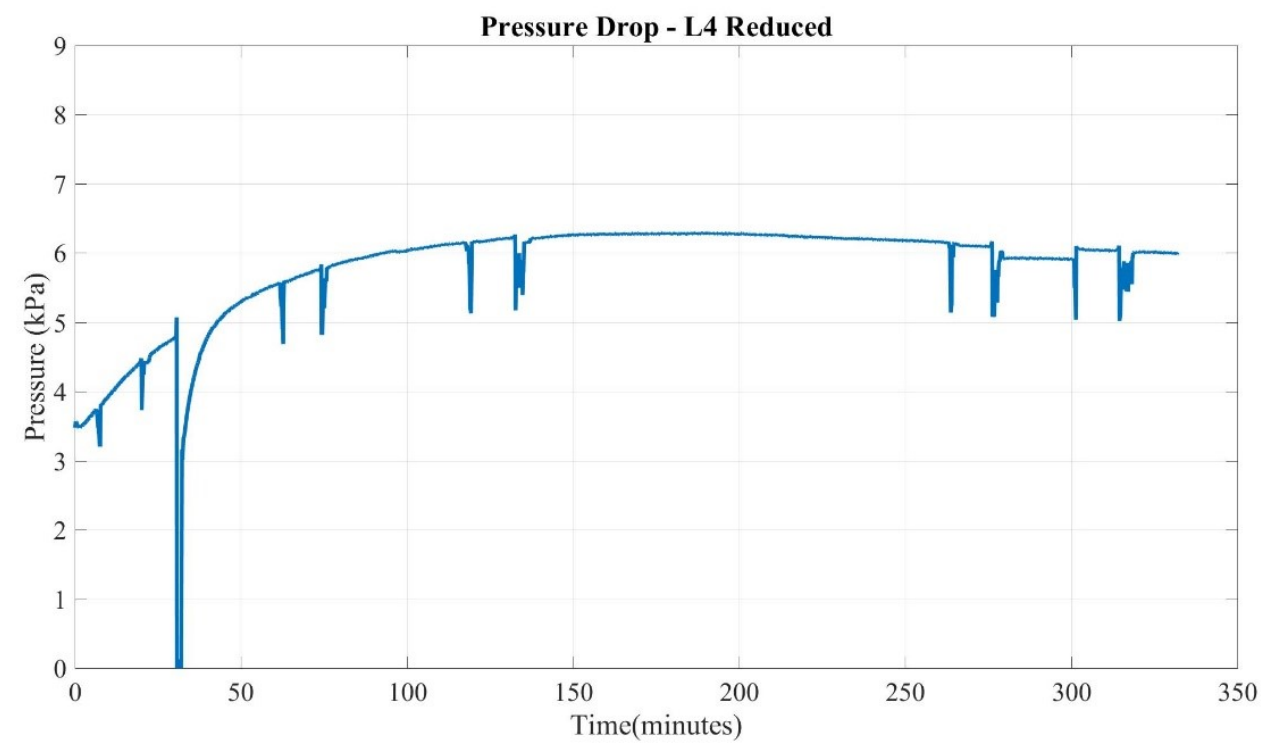

Figure C.8: SCRF ${ }^{\circledR}$ Pressure Drop vs Time for L4 Reduced 


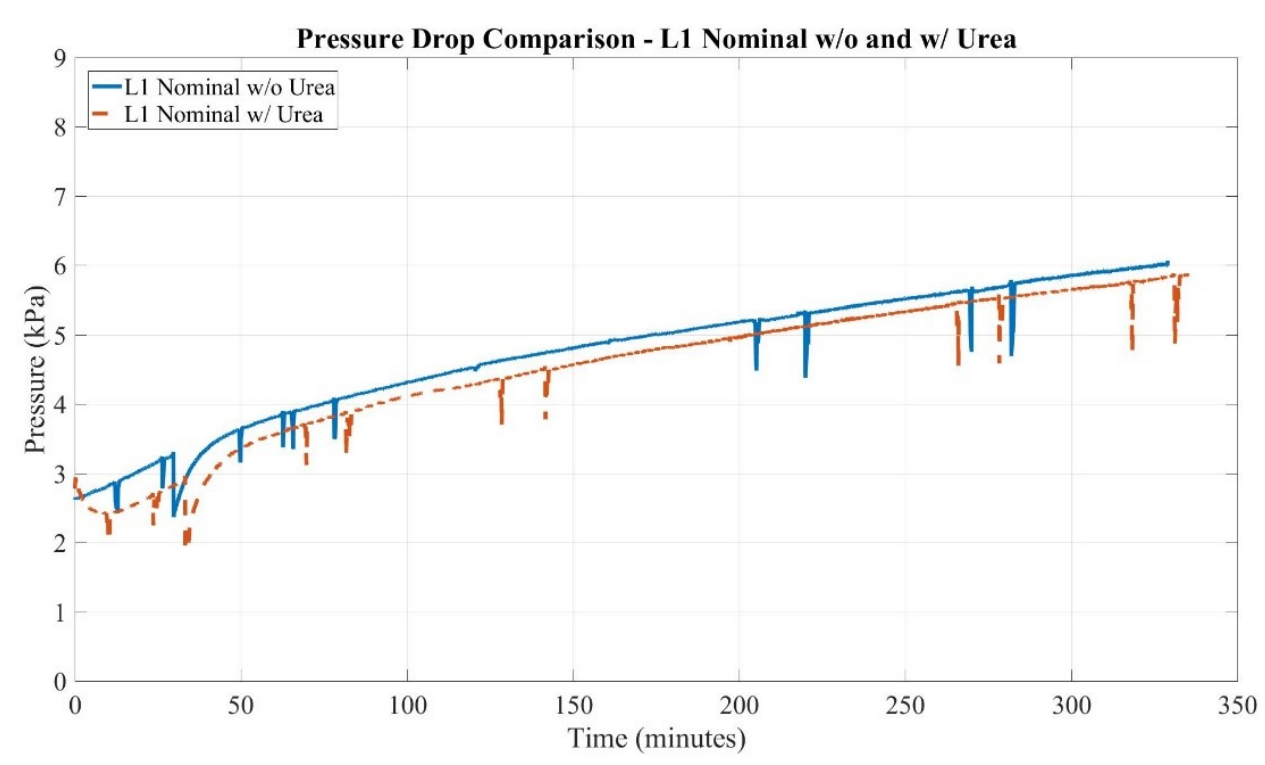

Figure C.9: SCRF ${ }^{\circledR}$ Pressure Drop Comparison for L1 Nominal w/o and w/ Urea

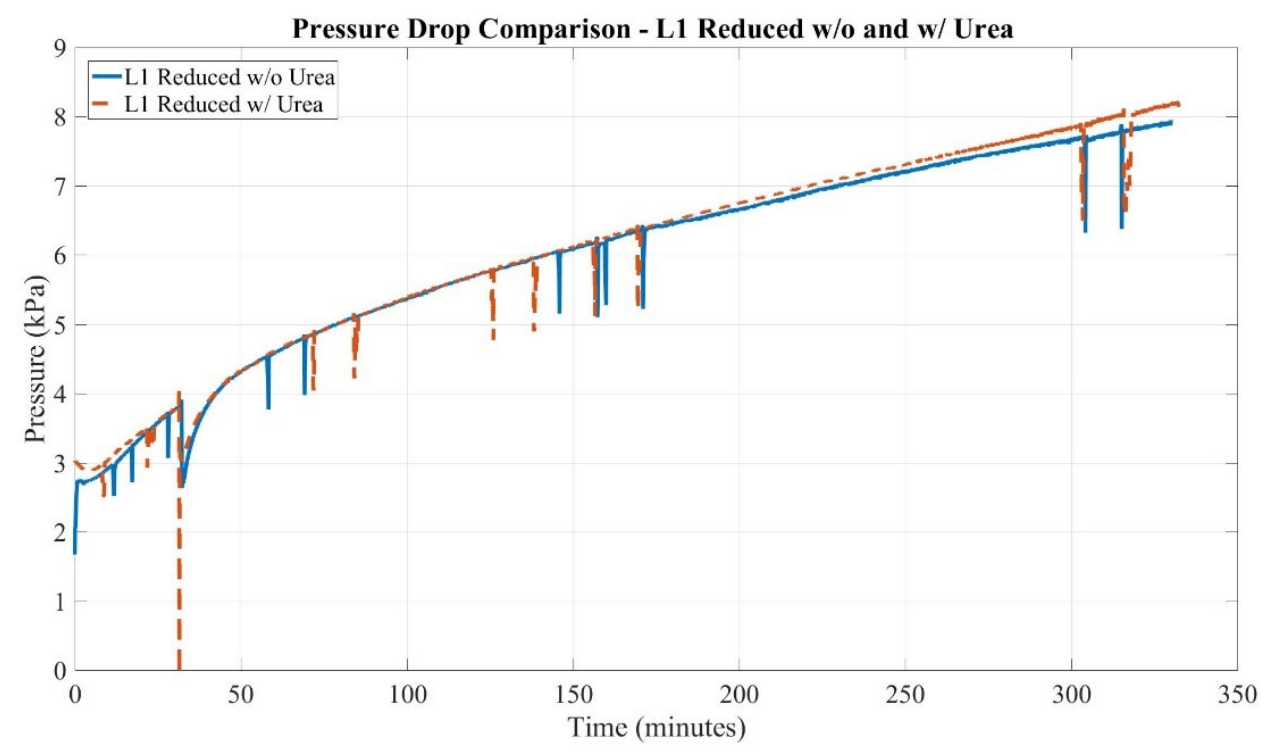

Figure C.10: SCRF ${ }^{\circledR}$ Pressure Drop Comparison for L1 Reduced w/o and w/ Urea 


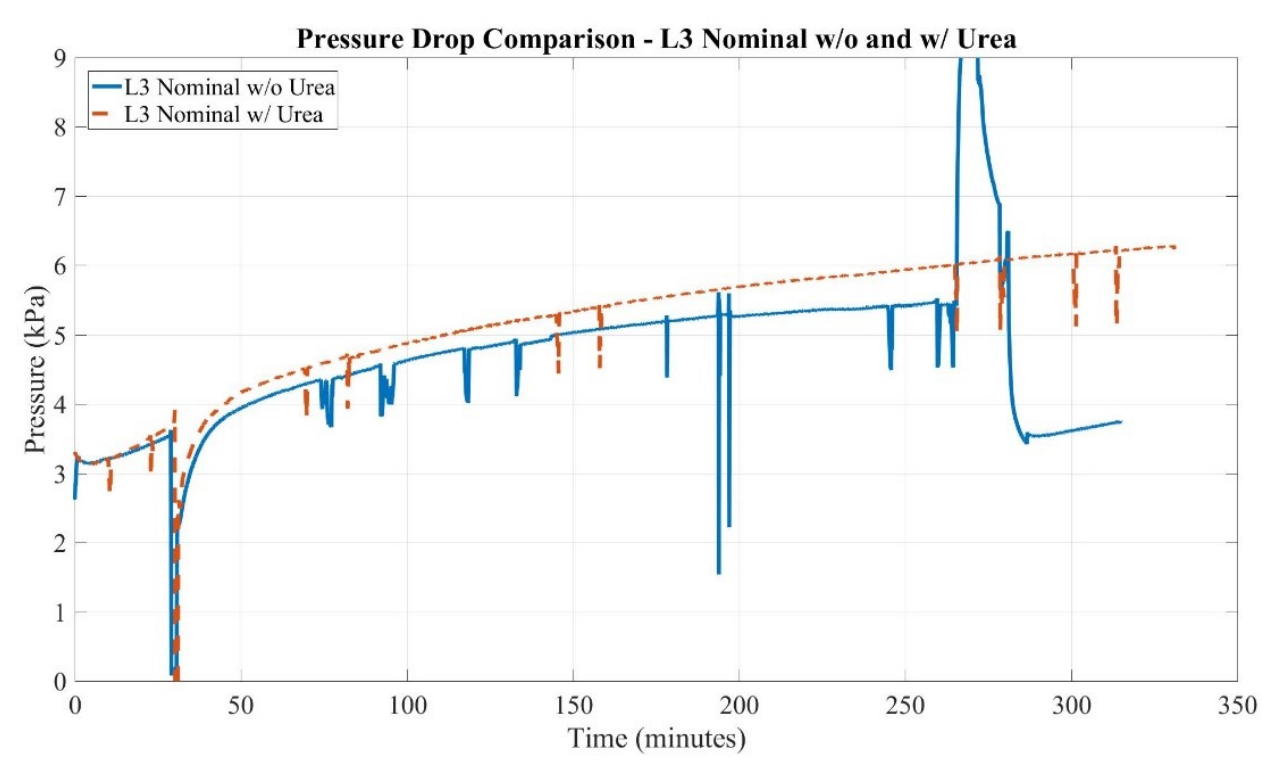

Figure C.11: SCRF ${ }^{\circledR}$ Pressure Drop Comparison for L3 Nominal w/o and w/ Urea

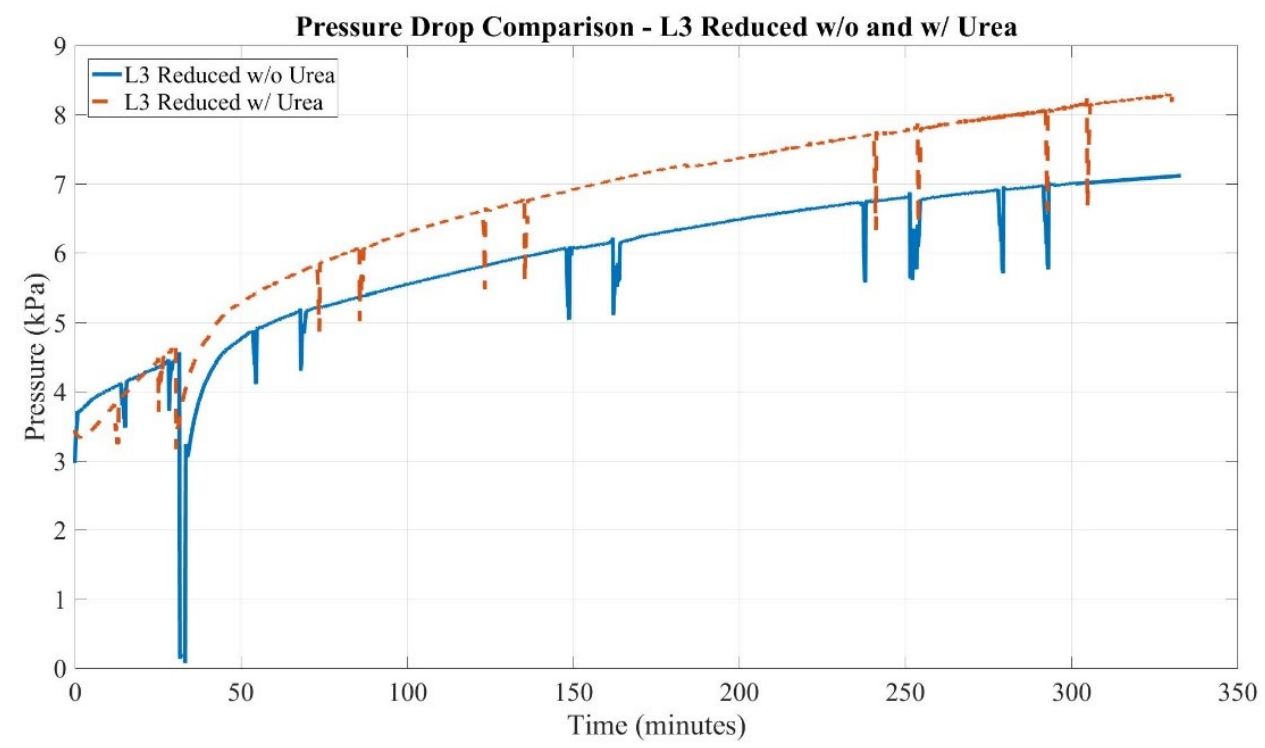

Figure C.12: SCRF ${ }^{\circledR}$ Pressure Drop Comparison for L3 Reduced w/o and w/ Urea 


\section{Appendix D: Temperature Distribution Plots}

This appendix presents plots for experimental temperature distribution in the $\mathrm{SCRF}^{\circledR}$ for all the tests for Stage 2 at a time when the temperatures have stabilized. The plots for temperature distribution in the $\mathrm{SCRF}^{\circledast}$ predicted by SCR-F model are also given for all the tests for comparison with the experimental temperature data.

As discussed earlier in subsection 3.1.3, twenty thermocouples, namely S1-S20 were instrumented in the $\mathrm{SCRF}^{\oplus}$ at different axial and radial locations according to the layout shown in Figure 3.3. Each plot shows the temperature distribution in the $\mathrm{SCRF}^{\circledast}$ generated using the temperature data collected from these twenty thermocouples. The X-axis represents the axial length $(\mathrm{mm})$ from the start of the $\mathrm{SCRF}^{\circledR}$ and the $\mathrm{Y}$-axis represents the radial distance $(\mathrm{mm})$ from the center of the $\mathrm{SCRF}^{\circledast}$. The lines on the plot represent isotherms which divide the $\mathrm{SCRF}^{\circledR}$ into different temperature zones. The thermocouples were instrumented only in one half of the SCRF ${ }^{\circledR}$ and so the temperature distribution in top half has been mirrored about the $\mathrm{X}$-axis to generate the temperature distribution for the entire volume of $\mathrm{SCRF}^{\circledR}$. The white circles on the experimental plots represent broken thermocouple at that location where the temperature data has been estimated using linear interpolation/extrapolation within the axial zone.

For Loading Tests $\mathrm{w} / \mathrm{o}$ Urea, the difference in temperature along the length of the $\mathrm{SCRF}^{\circledR}$ is negligible as observed from the experimental plots. However, there is decrease in temperature radially moving out from the center of the $\mathrm{SCRF}^{\circledR}$. The reason for this is the heat transfer to the ambient at the outer surface of the SCRF ${ }^{\circledR}$. The plots from the SCR-F model show similar trend where the temperature is decreasing radially from the center for the Loading Tests $w / o$ Urea. The differences in the value of temperature at certain locations when comparing the experimental plot to the plot from SCR-F model might be due to incorrect estimation of the temperature for the broken thermocouple. However, the overall trend between the experimental and SCR-F model plot is similar.

For Loading Tests $\mathrm{w} /$ Urea, it is observed that the temperature increases along the length of the $\mathrm{SCRF}^{\oplus}$. Similar trend was also observed by references $[8,11]$ for passive oxidation with urea injection. The increase in the temperature along the length in the second half of the $\mathrm{SCRF}^{\circledR}$ is because of the exothermic reactions taking place due to urea injection. Also, there is a decrease 
in temperature radially from the center due to heat transfer to the ambient. The experimental plots for L1 Nominal and L3 Reduced with Urea are not shown here since the temperature at some locations could not be estimated due to the fact that there were a higher number of broken thermocouples in a single axial zone in the $\mathrm{SCRF}^{\circledR}$.

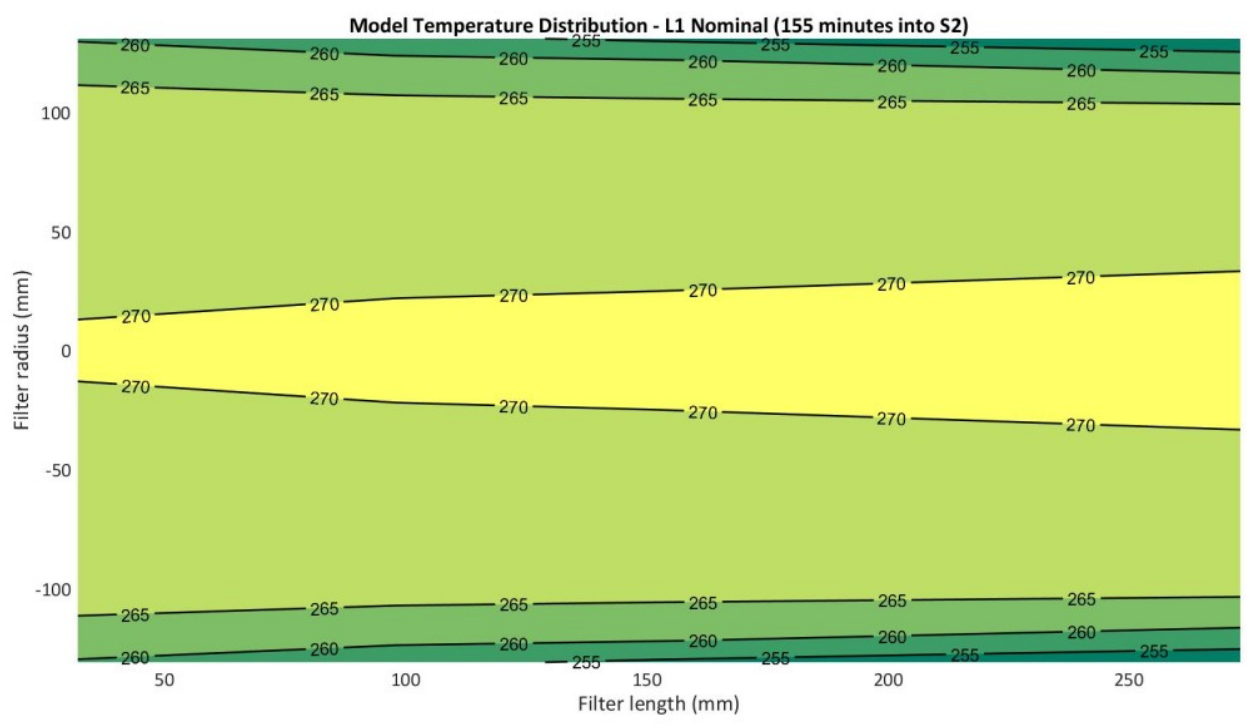

Figure D.1: SCRF ${ }^{\circledR}$ Model Temperature Distribution for L1 Nominal (155 minutes into S2) 


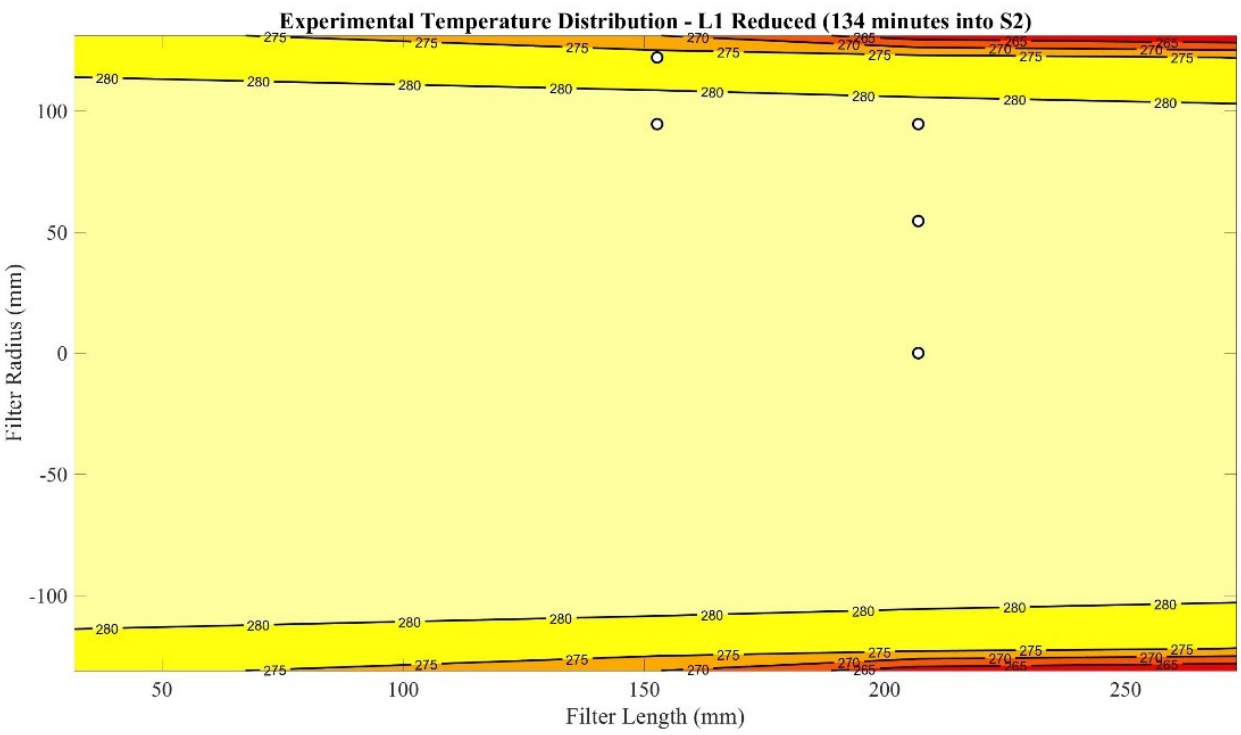

Figure D.2: SCRF ${ }^{\circledR}$ Experimental Temperature Distribution for $L 1$ Reduced (134 minutes into S2)

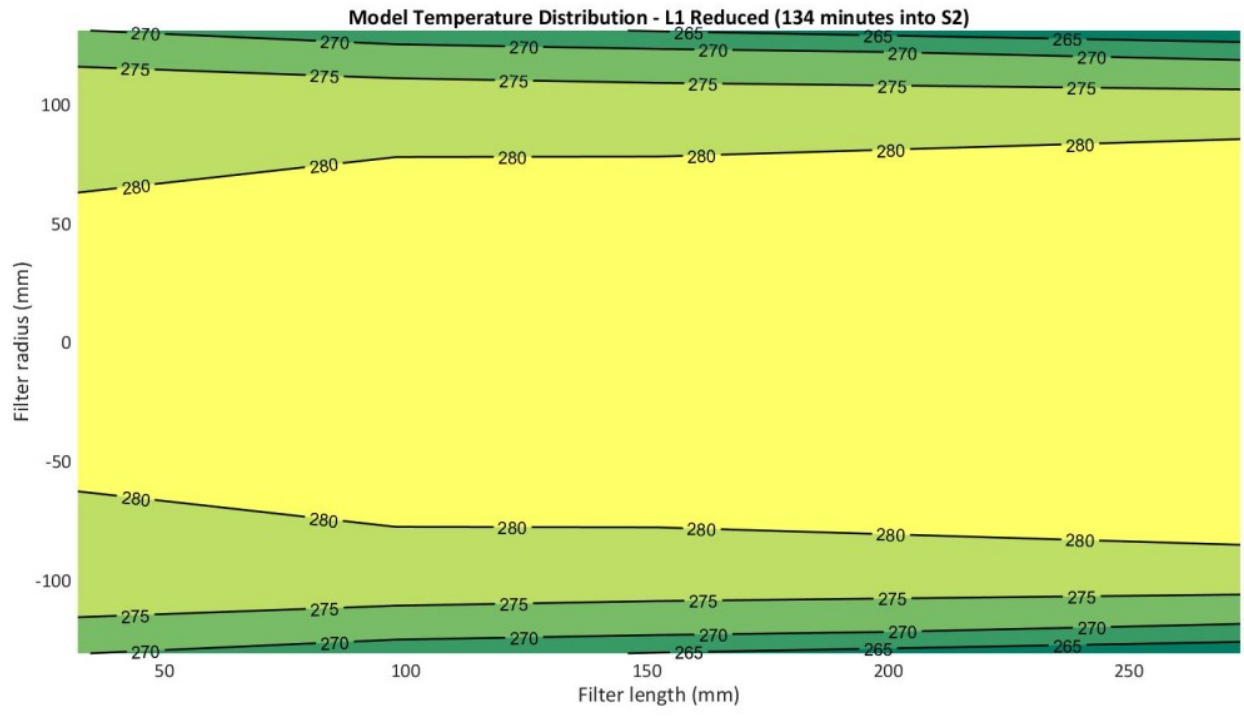

Figure D.3: SCRF ${ }^{\circledR}$ Model Temperature Distribution for L1 Reduced (134 minutes into S2) 


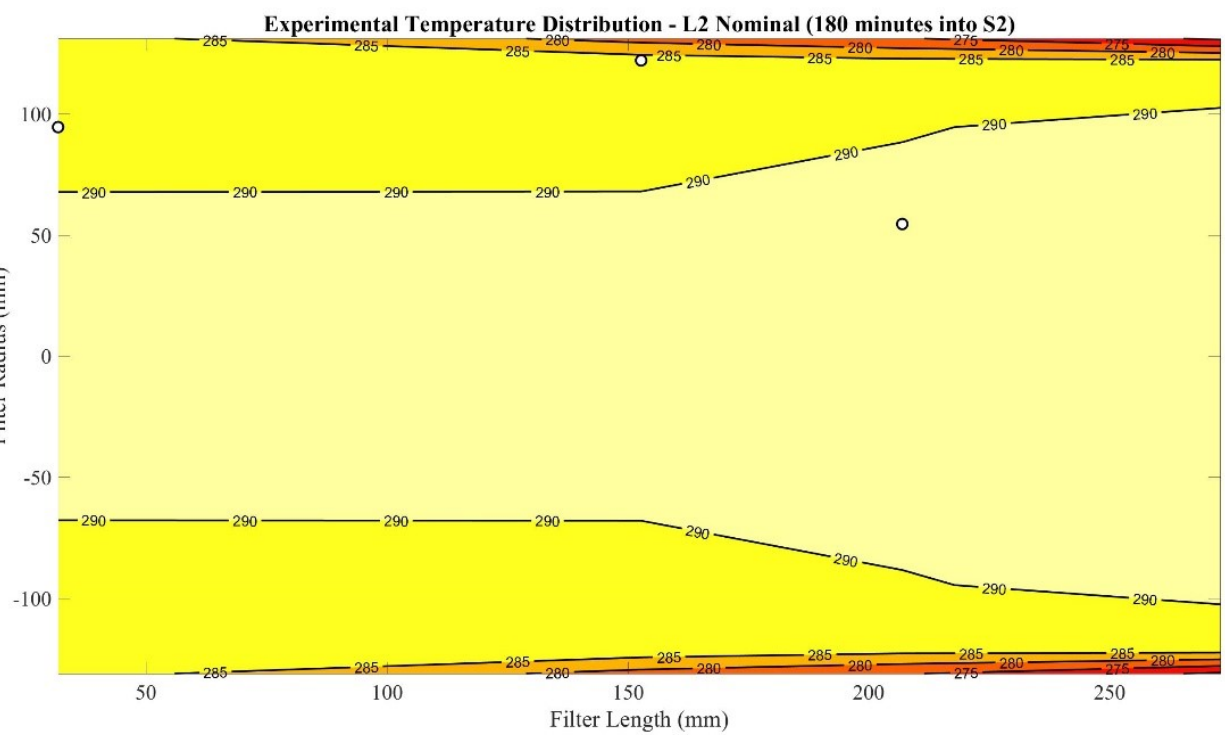

Figure D.4: SCRF ${ }^{\circledR}$ Experimental Temperature Distribution for L2 Nominal (180 minutes into S2)

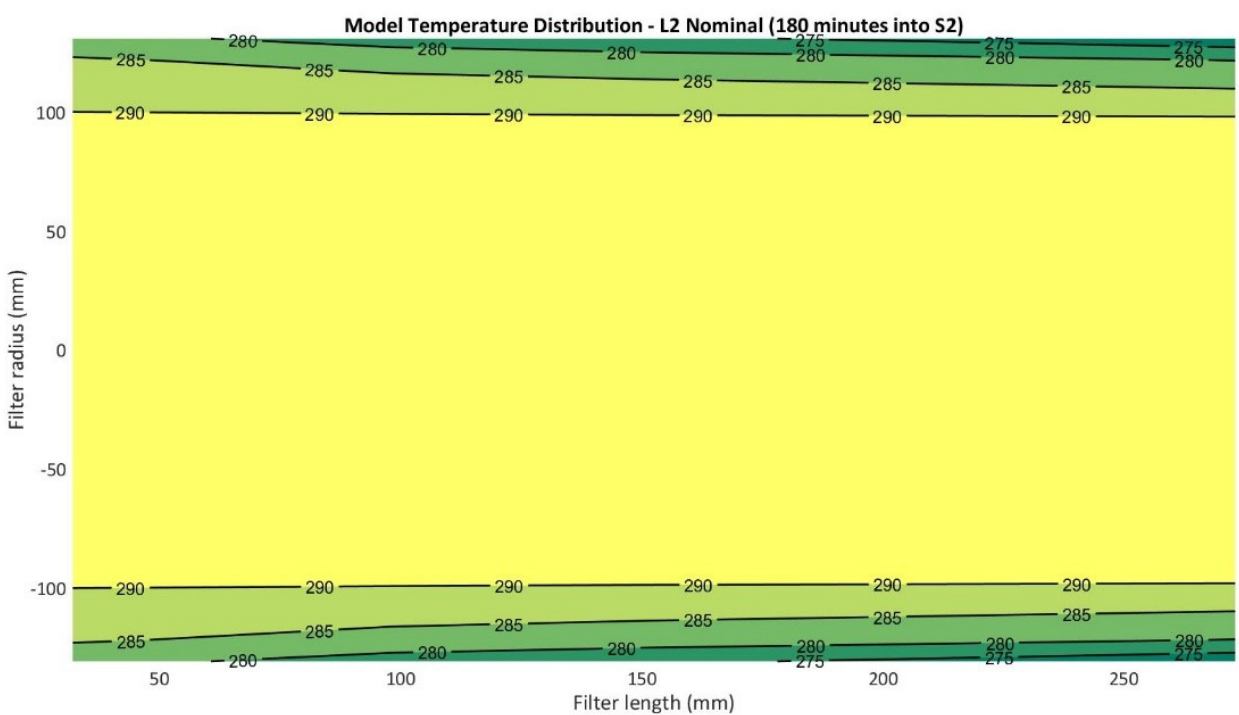

Figure D.5: SCRF ${ }^{\circledR}$ Model Temperature Distribution for L2 Nominal (180 minutes into S2) 


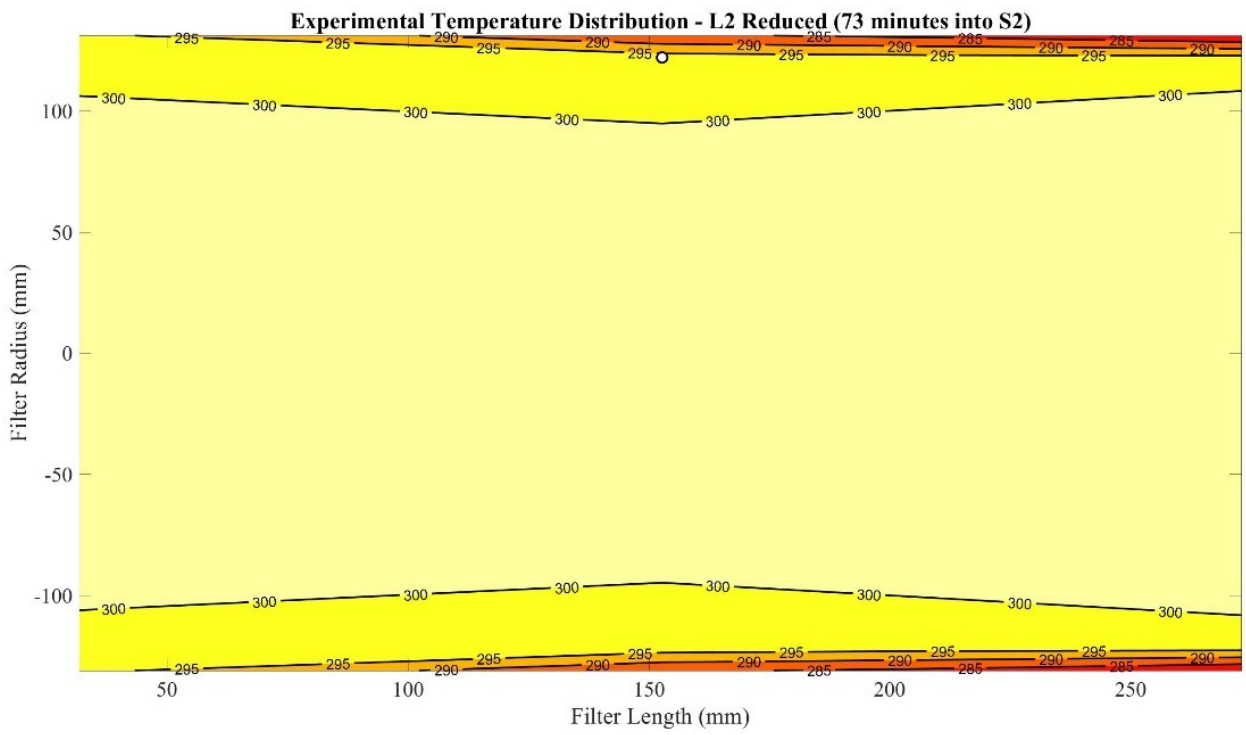

Figure D.6: $S_{C R F^{\circledR}}$ Experimental Temperature Distribution for L2 Reduced (73 minutes into S2)

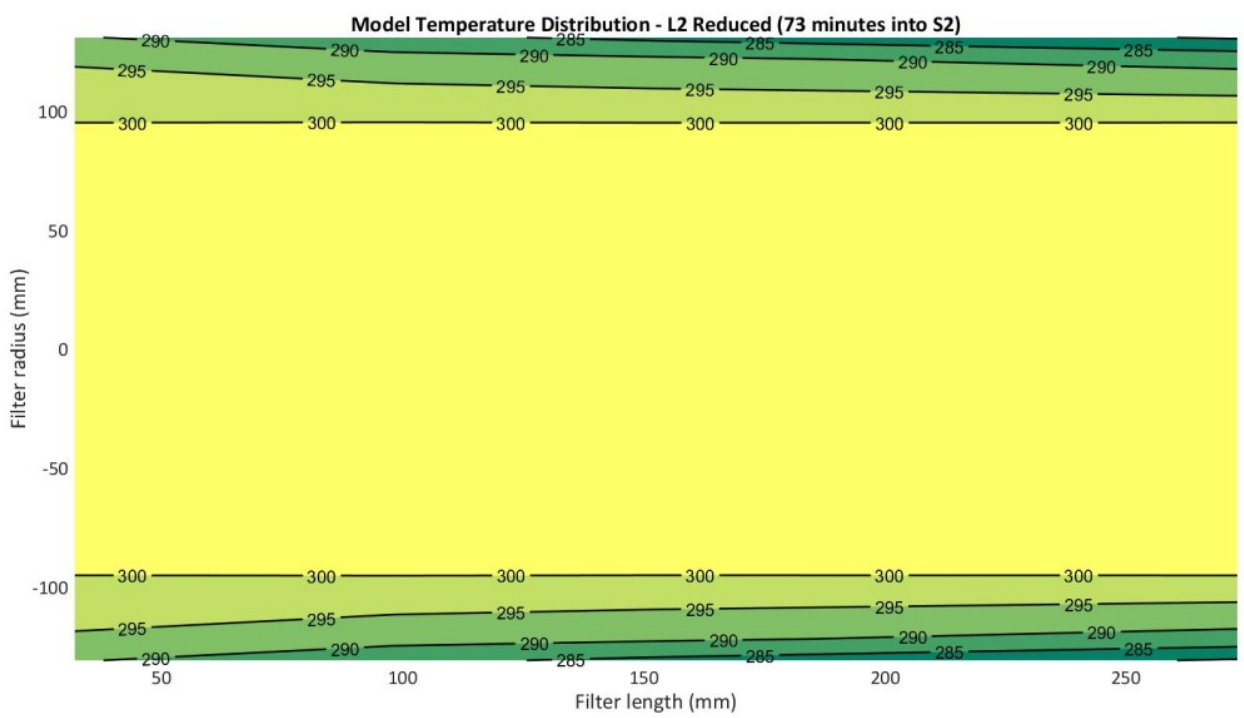

Figure D.7: SCRF ${ }^{\circledR}$ Model Temperature Distribution for L2 Reduced (73 minutes into S2) 


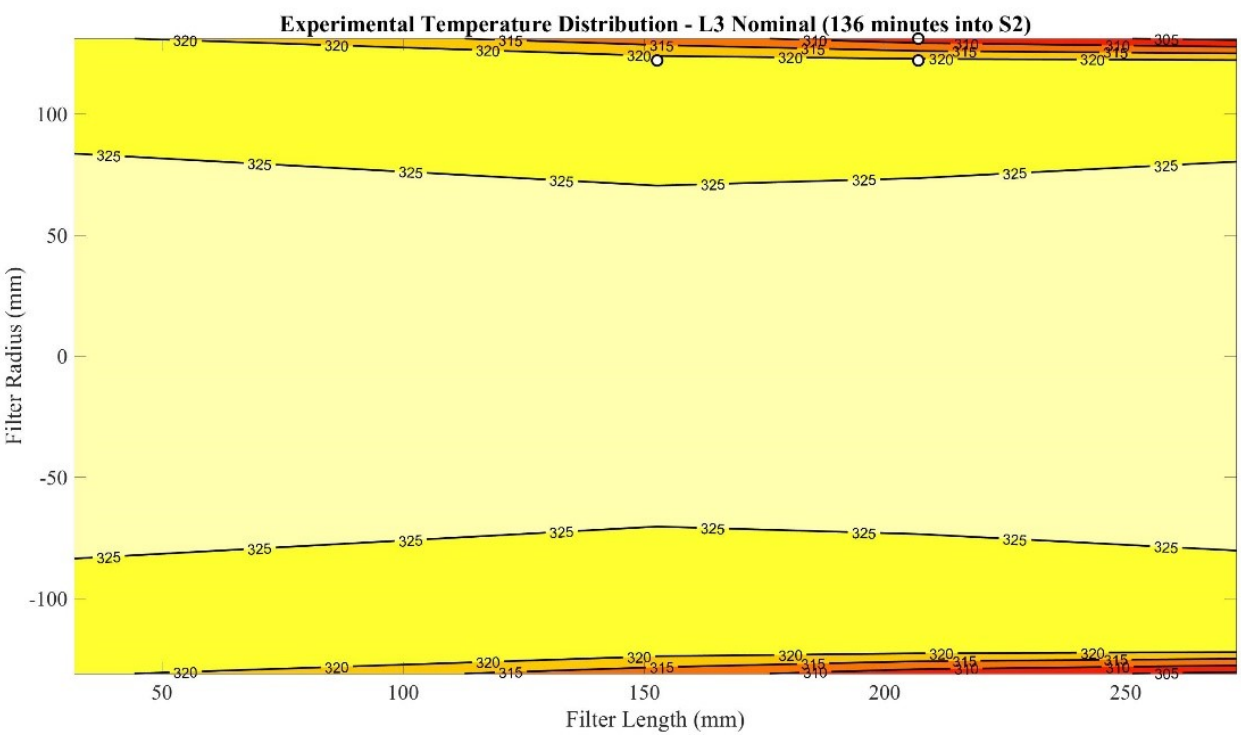

Figure D.8: SCRF ${ }^{\circledR}$ Experimental Temperature Distribution for L3 Nominal (136 minutes into S2)

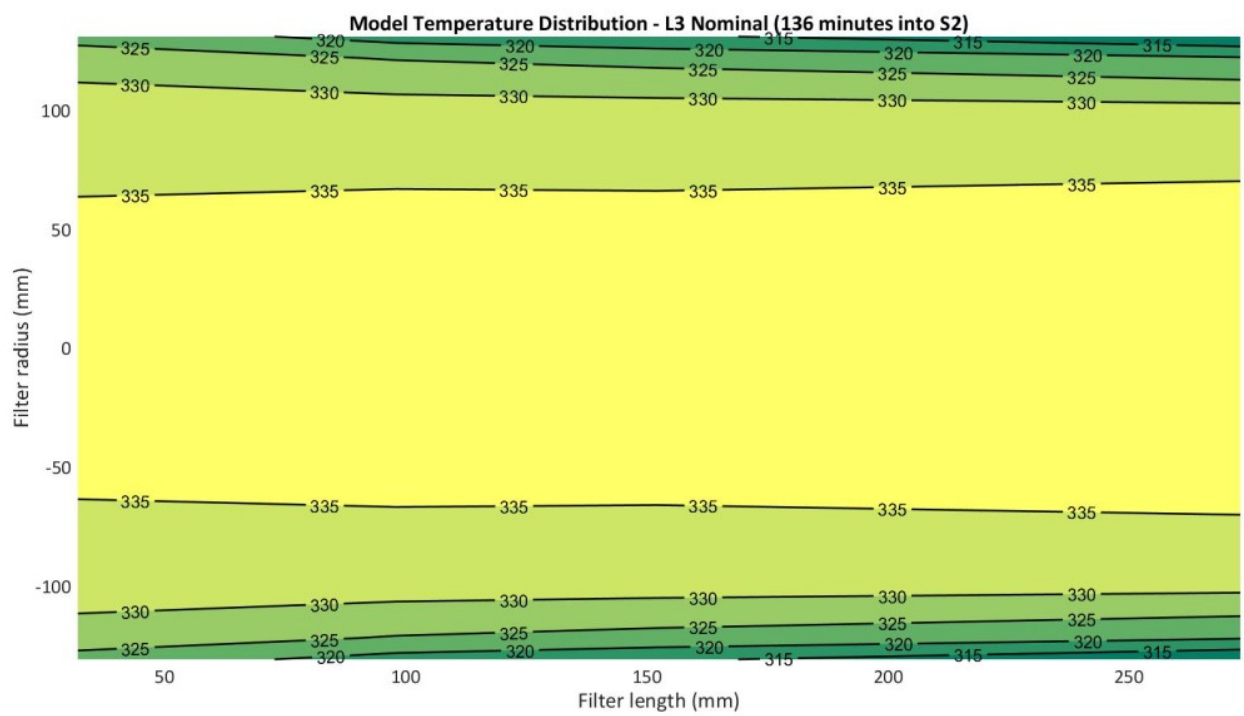

Figure D.9: SCRF ${ }^{\circledR}$ Model Temperature Distribution for L3 Nominal (136 minutes into S2) 


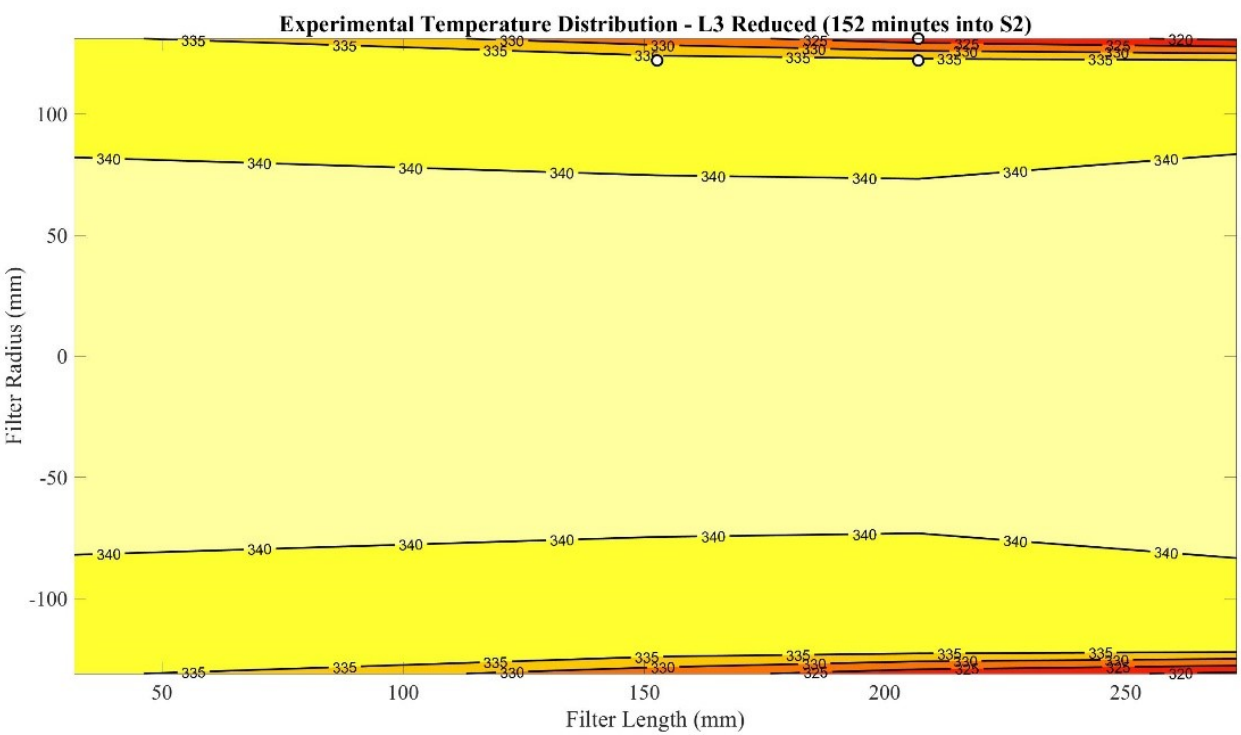

Figure D.10: SCRF ${ }^{\circledR}$ Experimental Temperature Distribution for $L 3$ Reduced (152 minutes into S2)

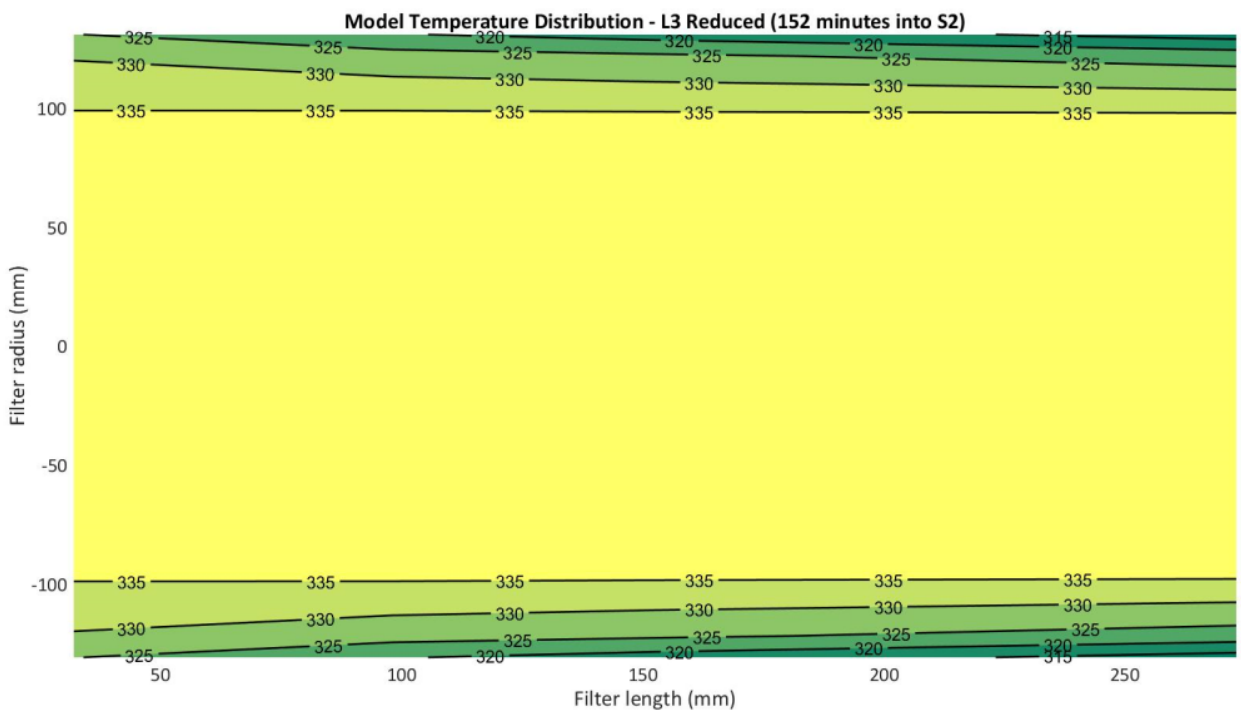

Figure D.11: SCRF ${ }^{\circledR}$ Model Temperature Distribution for L3 Reduced (152 minutes into S2) 


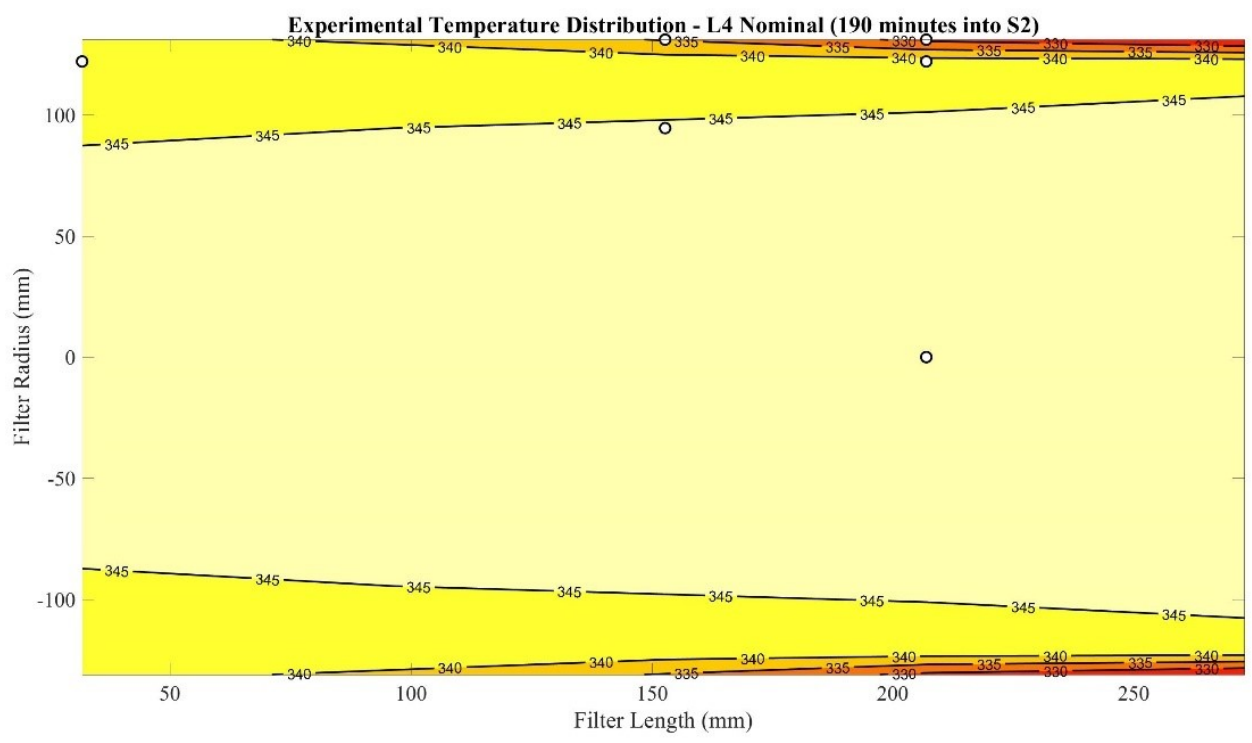

Figure D.12: SCRF ${ }^{\circledR}$ Experimental Temperature Distribution for L4 Nominal (190 minutes into S2)

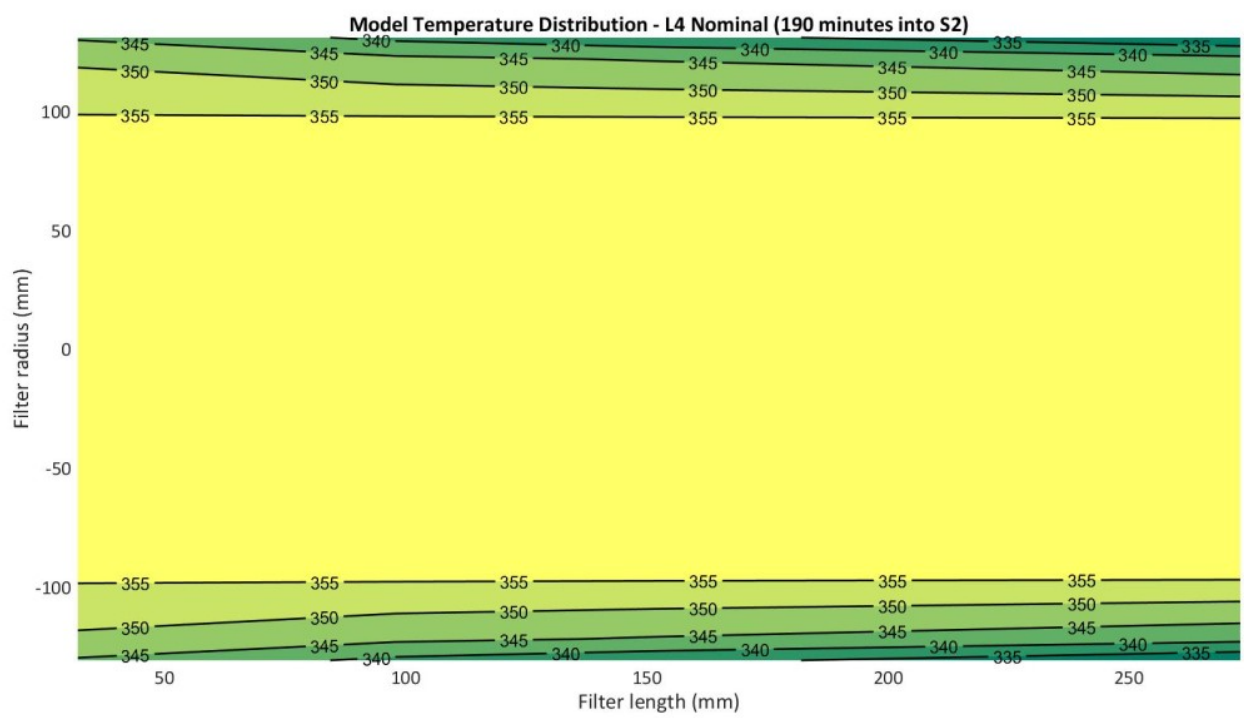

Figure D.13: $S C R F^{\circledR}$ Model Temperature Distribution for L4 Nominal (190 minutes into S2) 


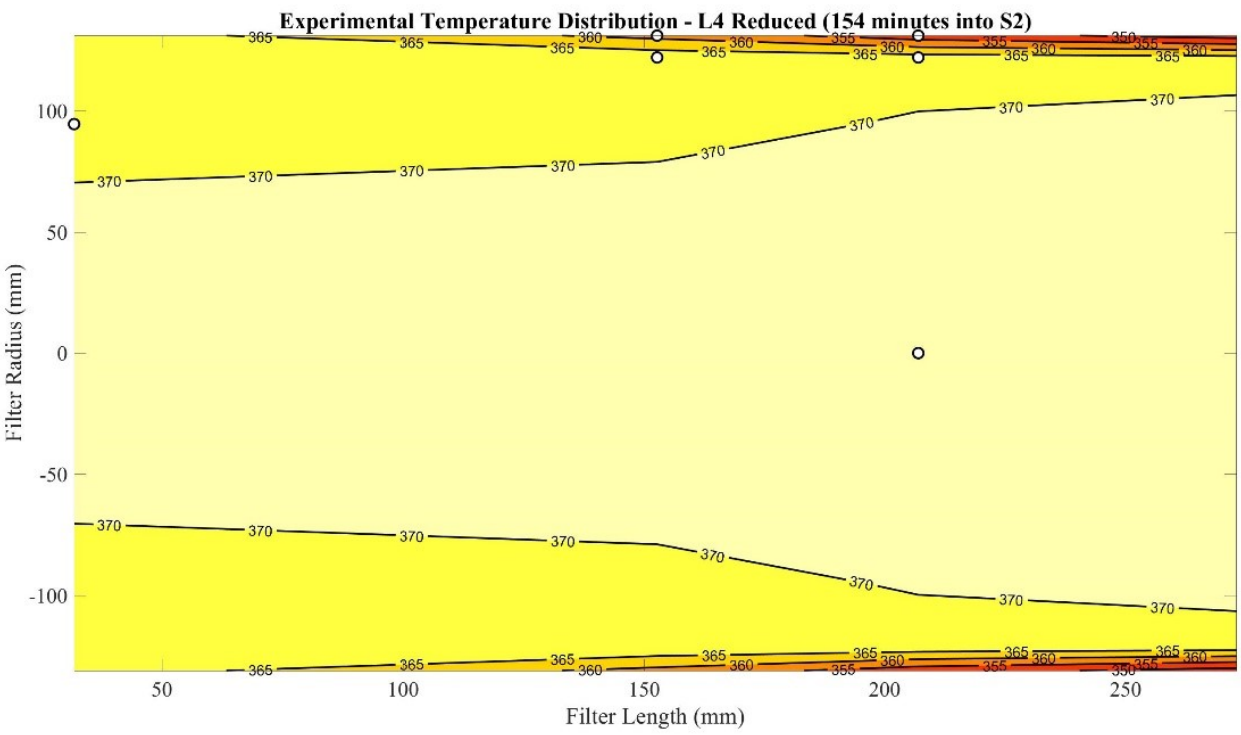

Figure D.14: SCRF ${ }^{\circledR}$ Experimental Temperature Distribution for L4 Reduced (154 minutes into S2)

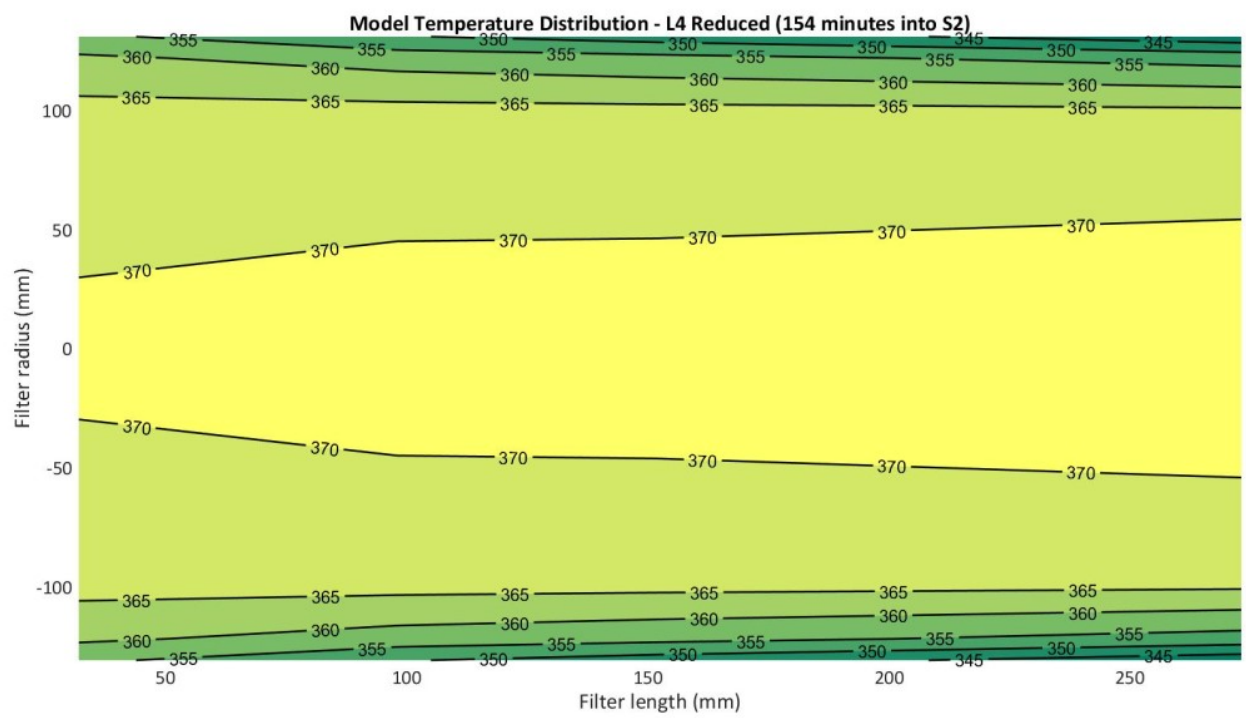

Figure D.15: SCRF ${ }^{\circledR}$ Model Temperature Distribution for L4 Reduced (154 minutes into S2) 


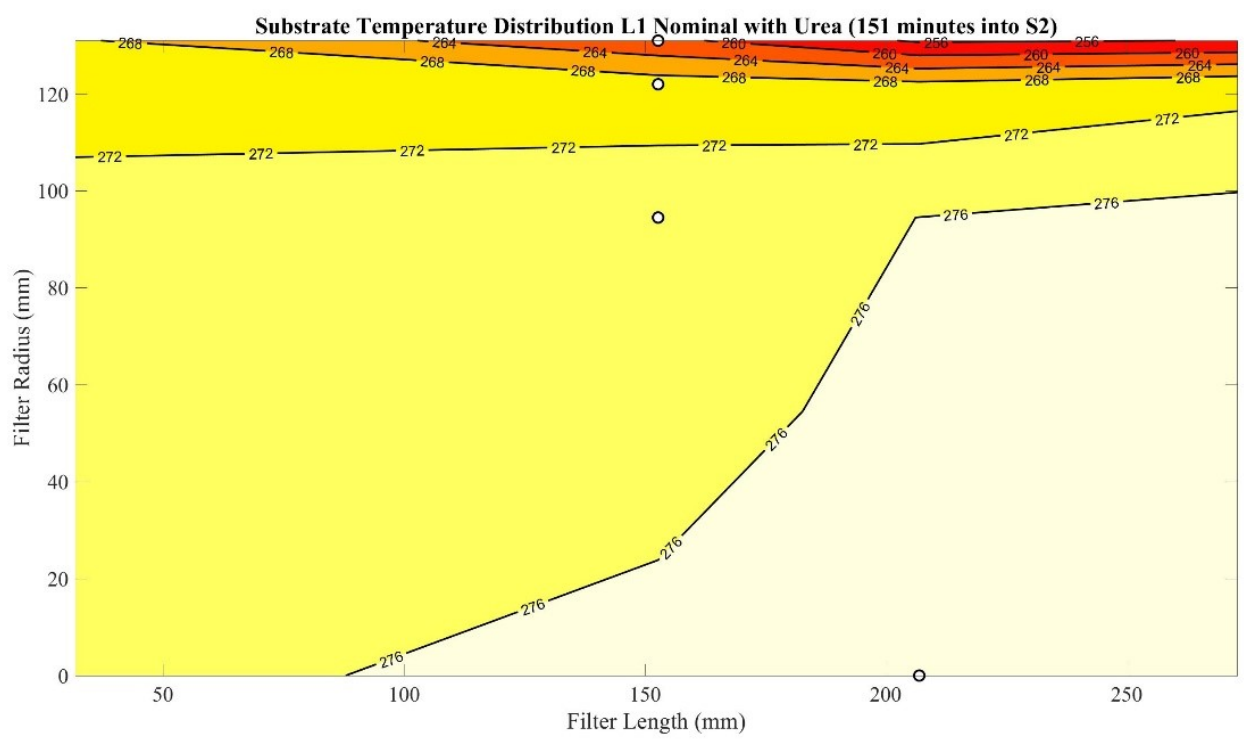

Figure D.16: SCRF ${ }^{\circledR}$ Experimental Temperature Distribution for L1 Nominal with Urea (151 minutes into S2)

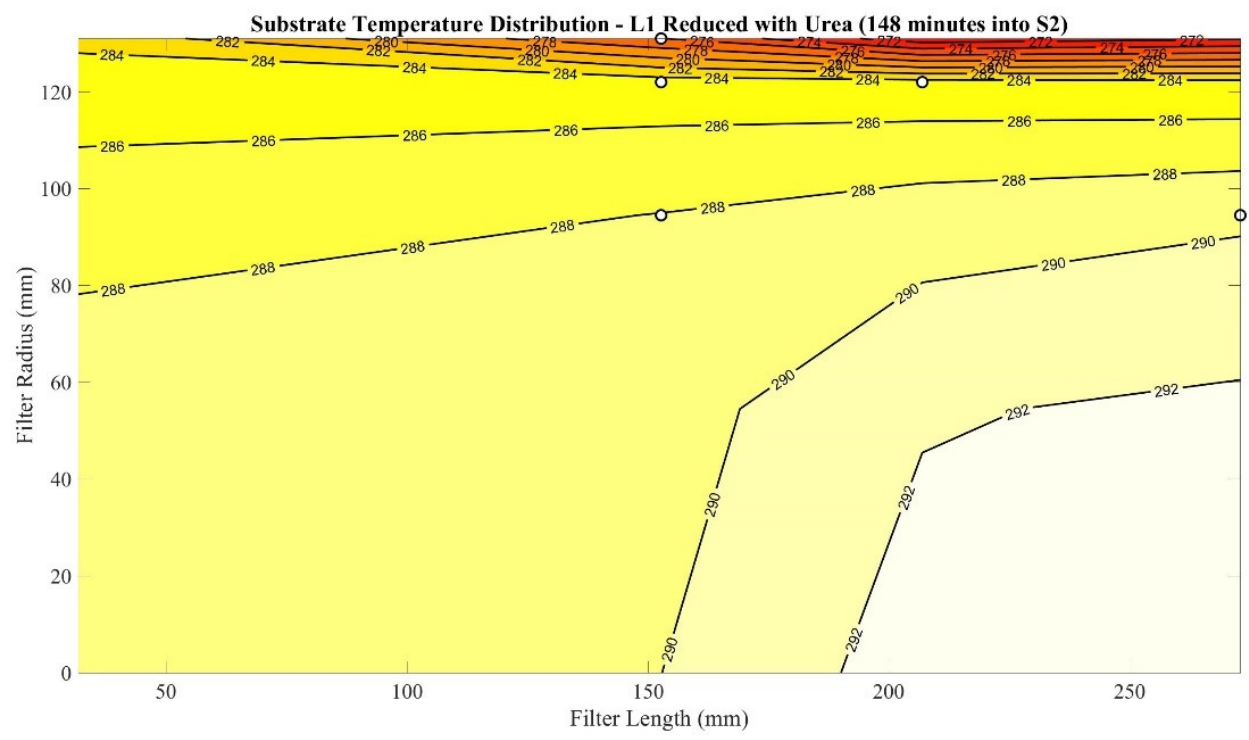

Figure D.17: SCRF ${ }^{\circledR}$ Experimental Temperature Distribution for $L 1$ Reduced with Urea (148 minutes into S2) 


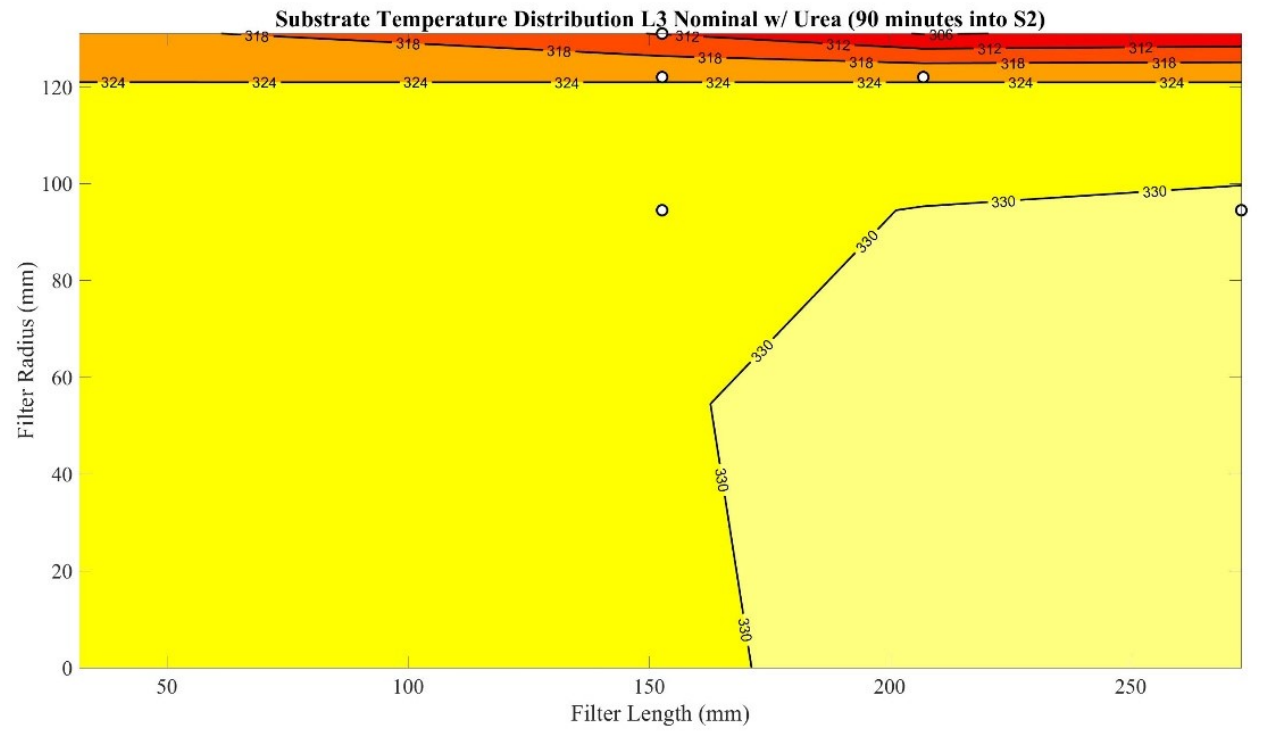

Figure D.18: SCRF ${ }^{\circledR}$ Experimental Temperature Distribution for L3 Nominal with Urea (90 minutes into S2) 


\section{Appendix E: Model PM Mass Retained Plots for Loading Tests w/o Urea Data}

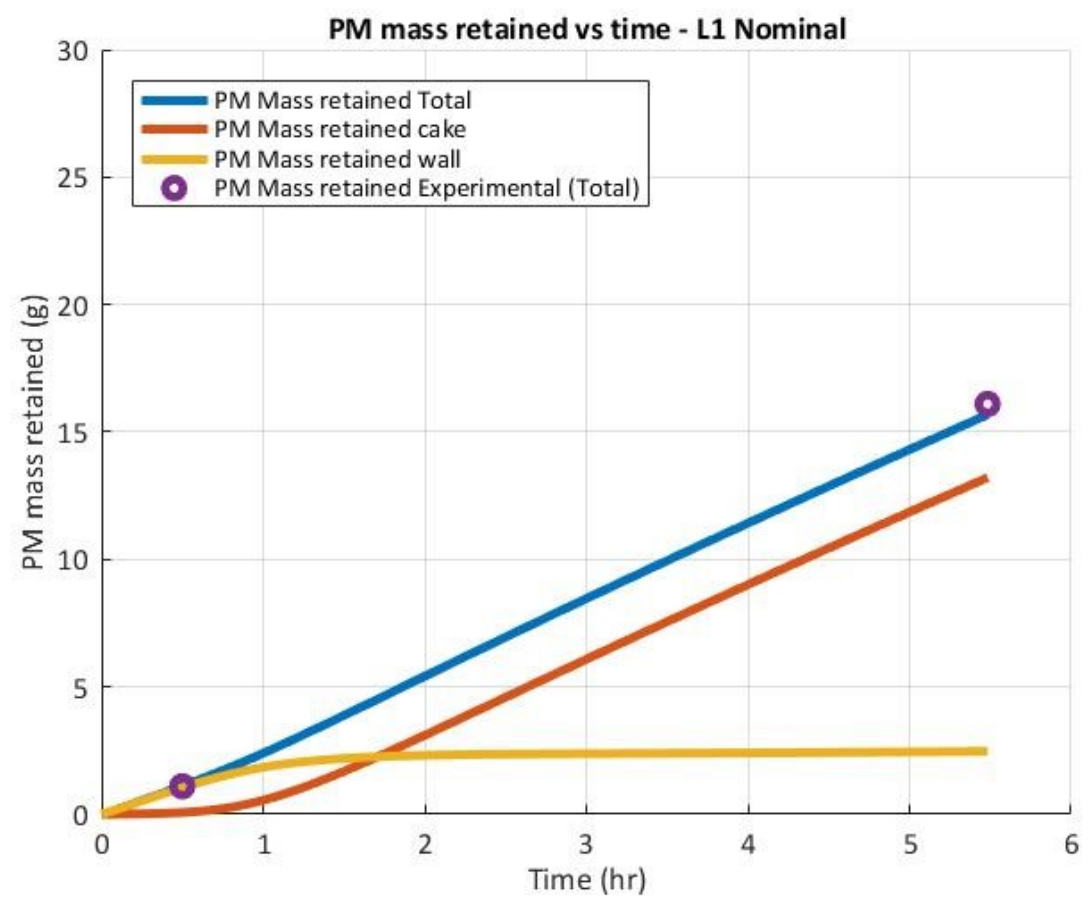

Figure E.1: PM Mass Retained vs Time for L1 Nominal

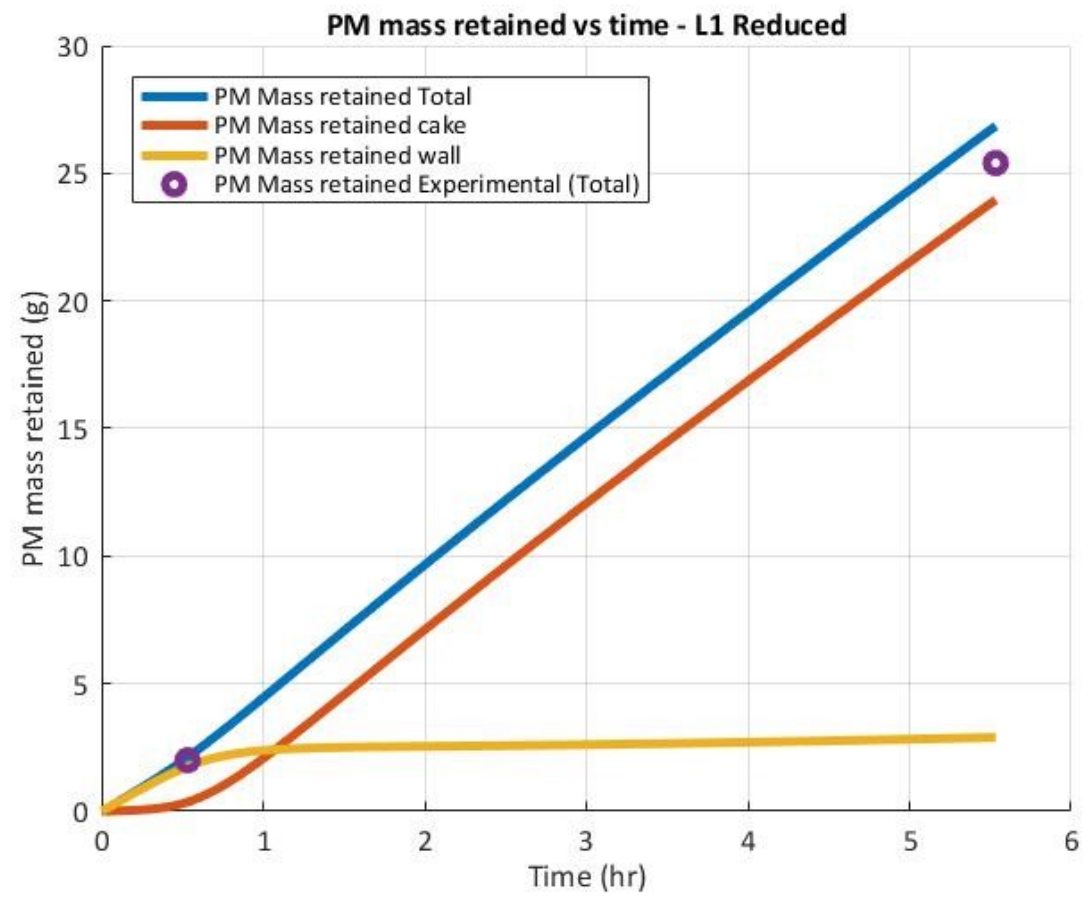

Figure E.2: PM Mass Retained vs Time for L1 Reduced 


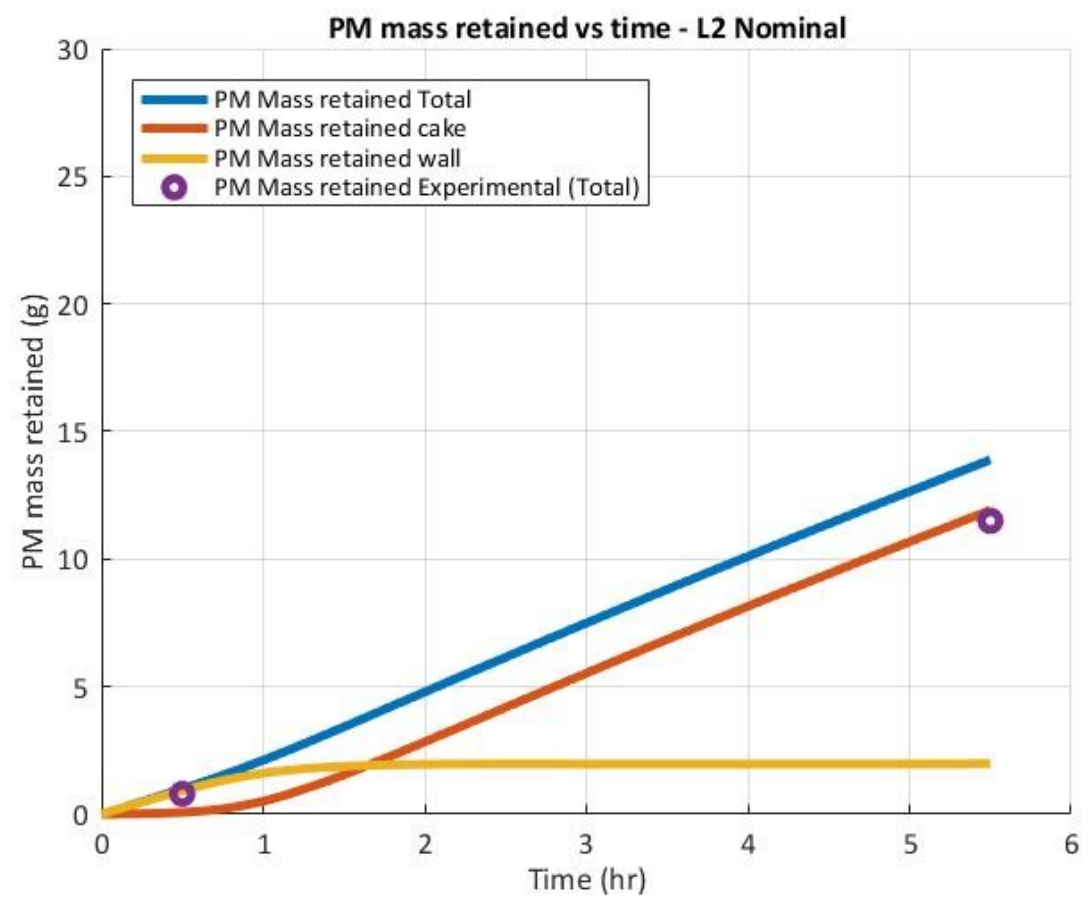

Figure E.3: PM Mass Retained vs Time for L2 Nominal

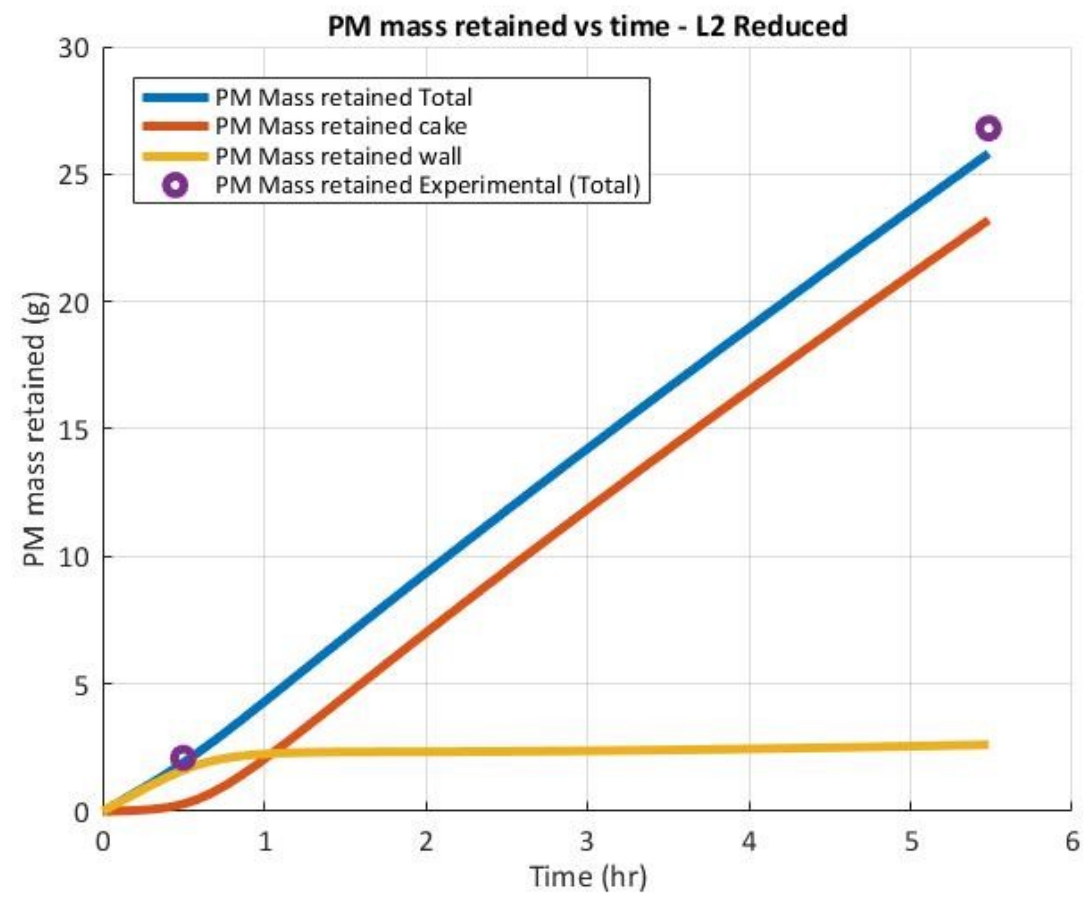

Figure E.4: PM Mass Retained vs Time for L2 Reduced 


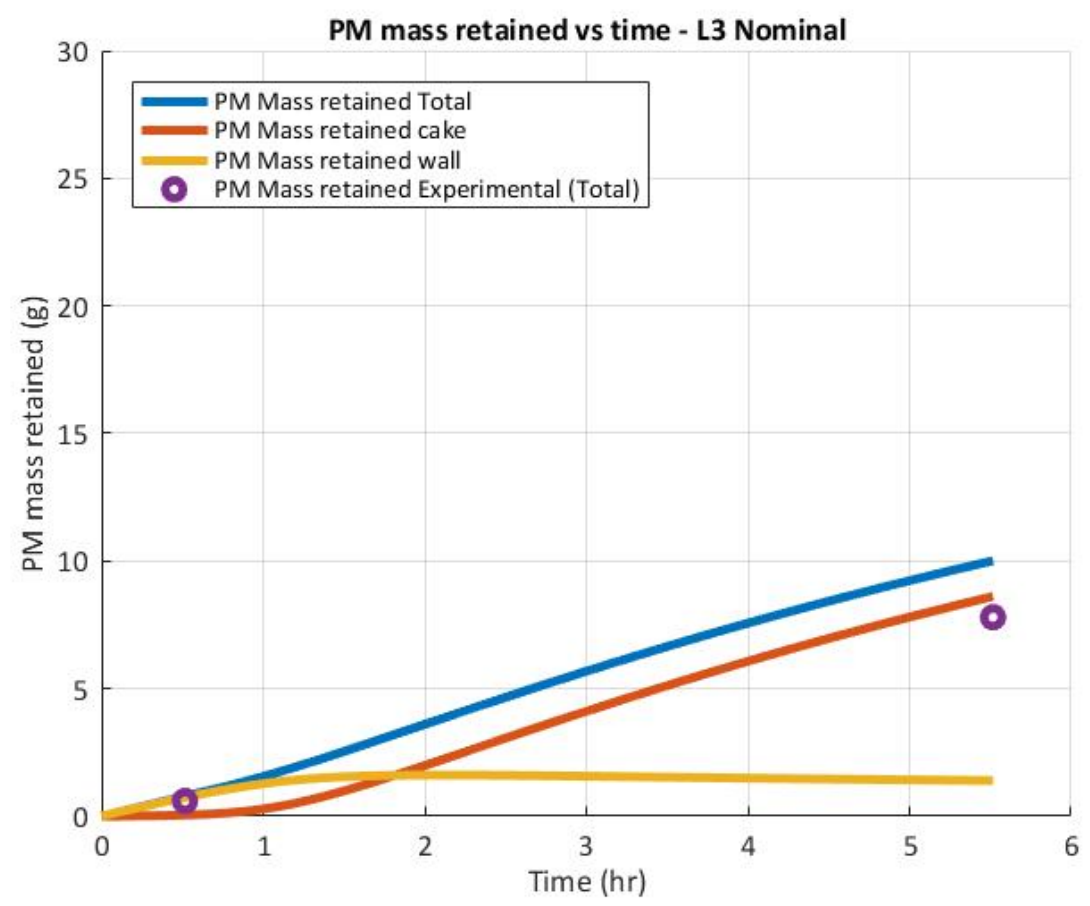

Figure E.5: PM Mass Retained vs Time for L3 Nominal

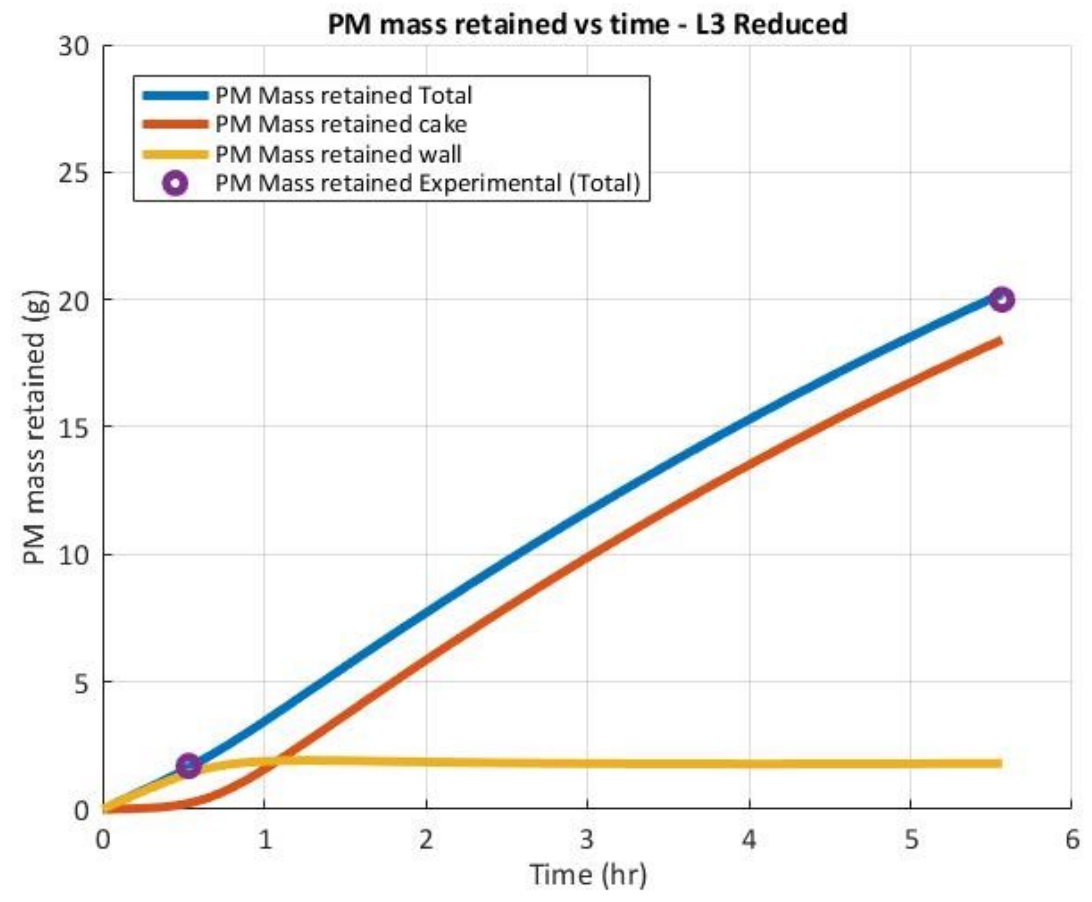

Figure E.6: PM Mass Retained vs Time for L3 Reduced 


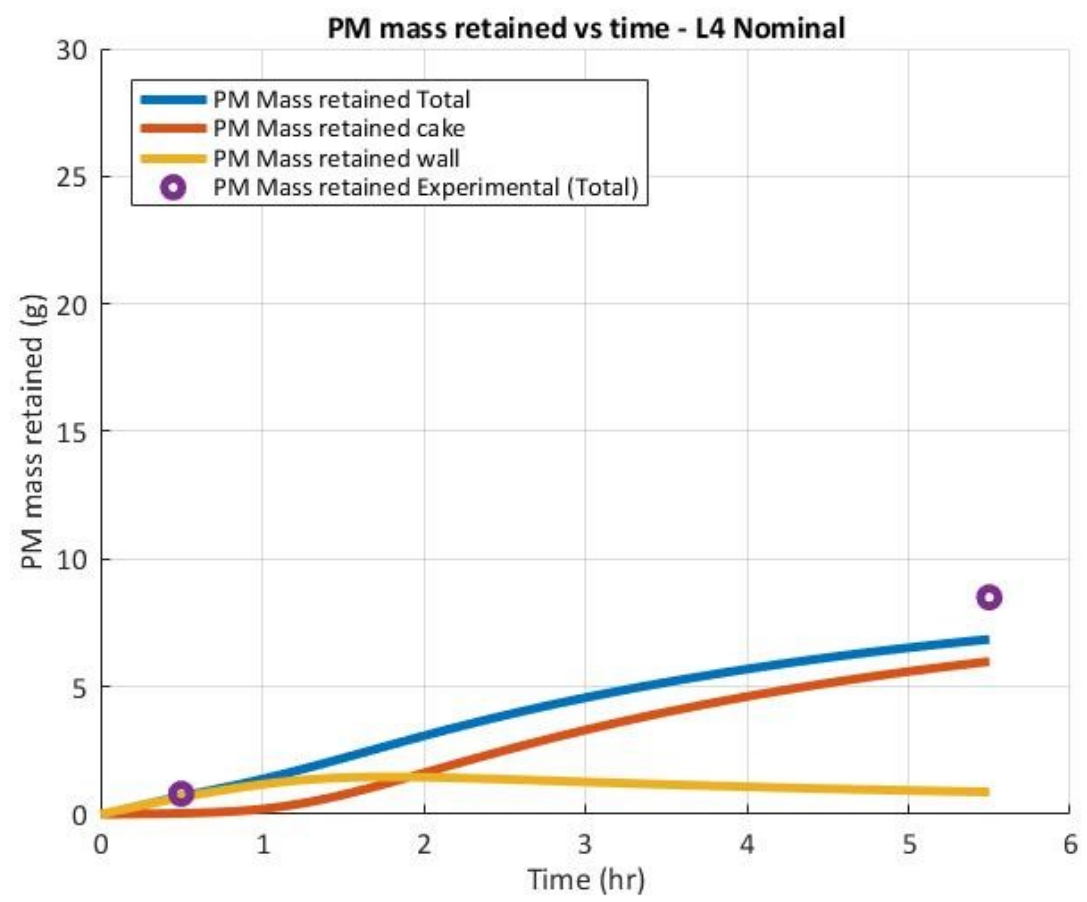

Figure E.7: PM Mass Retained vs Time for L4 Nominal

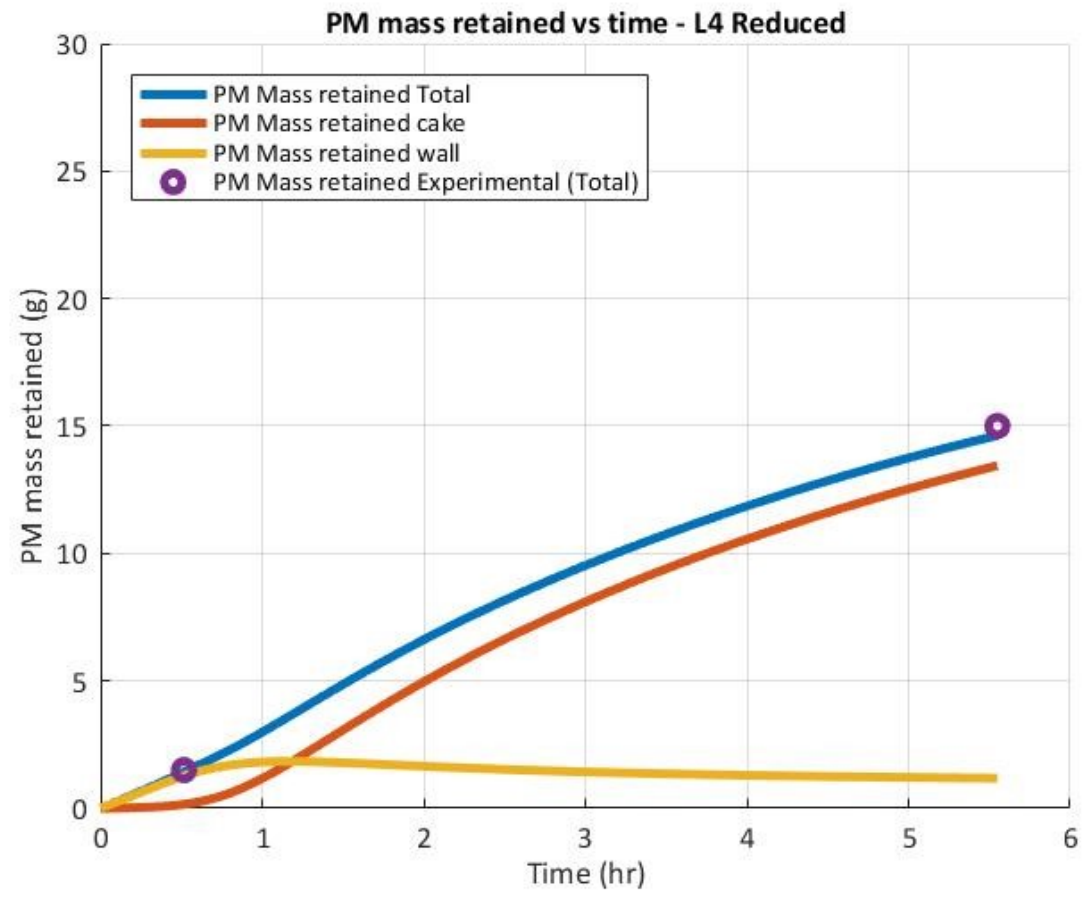

Figure E.8: PM Mass Retained vs Time for L4 Reduced 
Appendix F: Model Pressure Drop Plots for Loading Tests w/o Urea Data

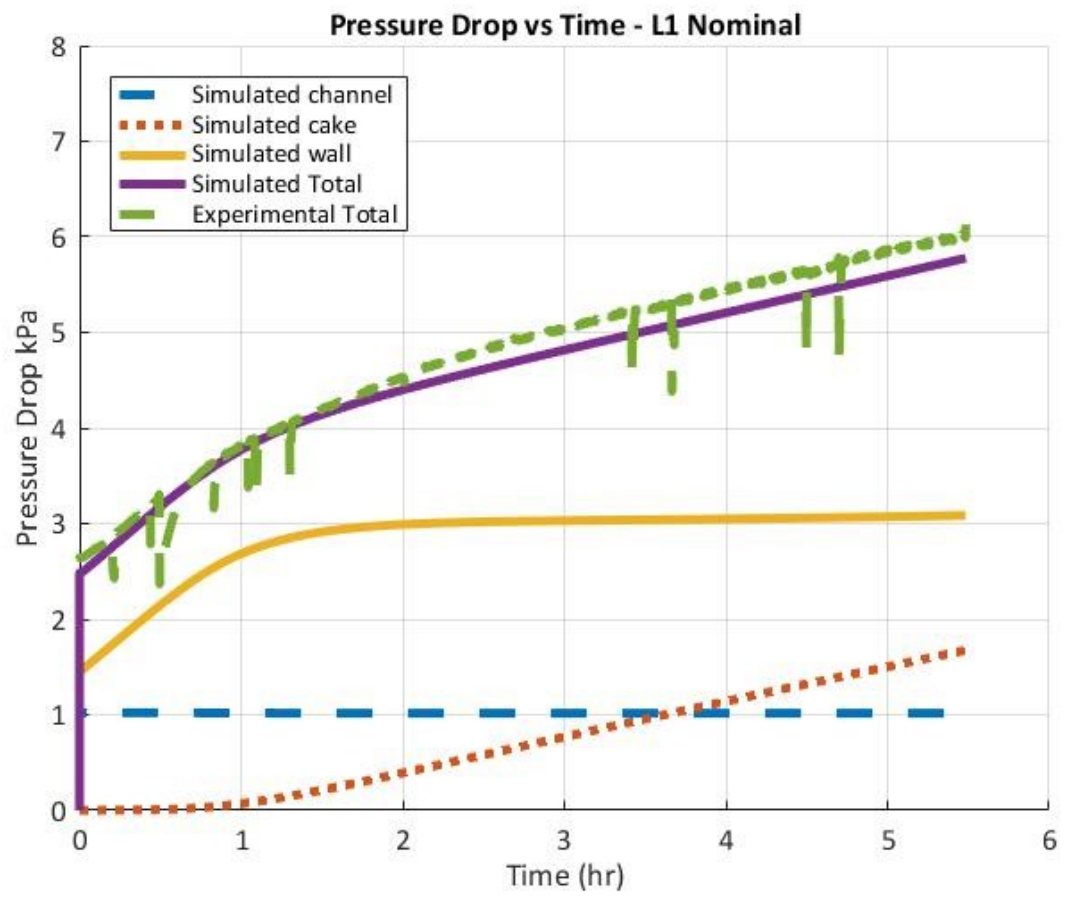

Figure F.1: Pressure Drop vs Time for L1 Nominal

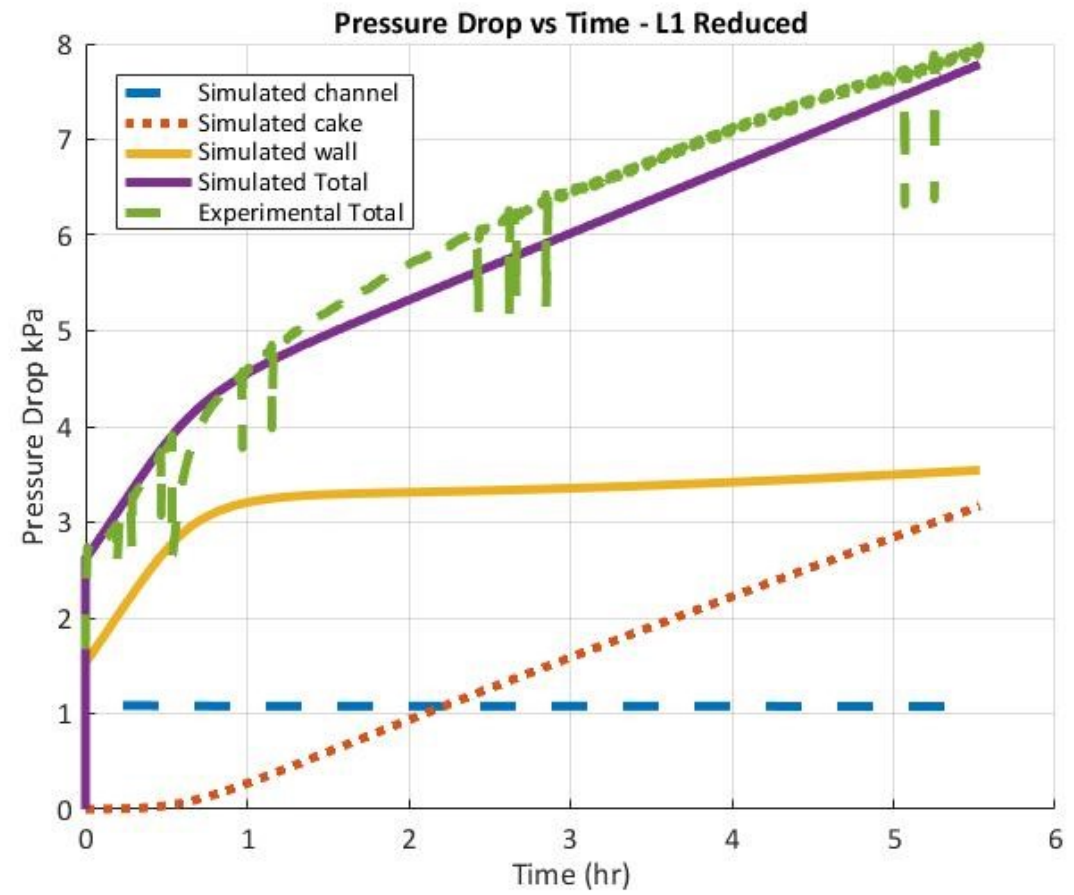

Figure F.2: Pressure Drop vs Time for L1 Reduced 


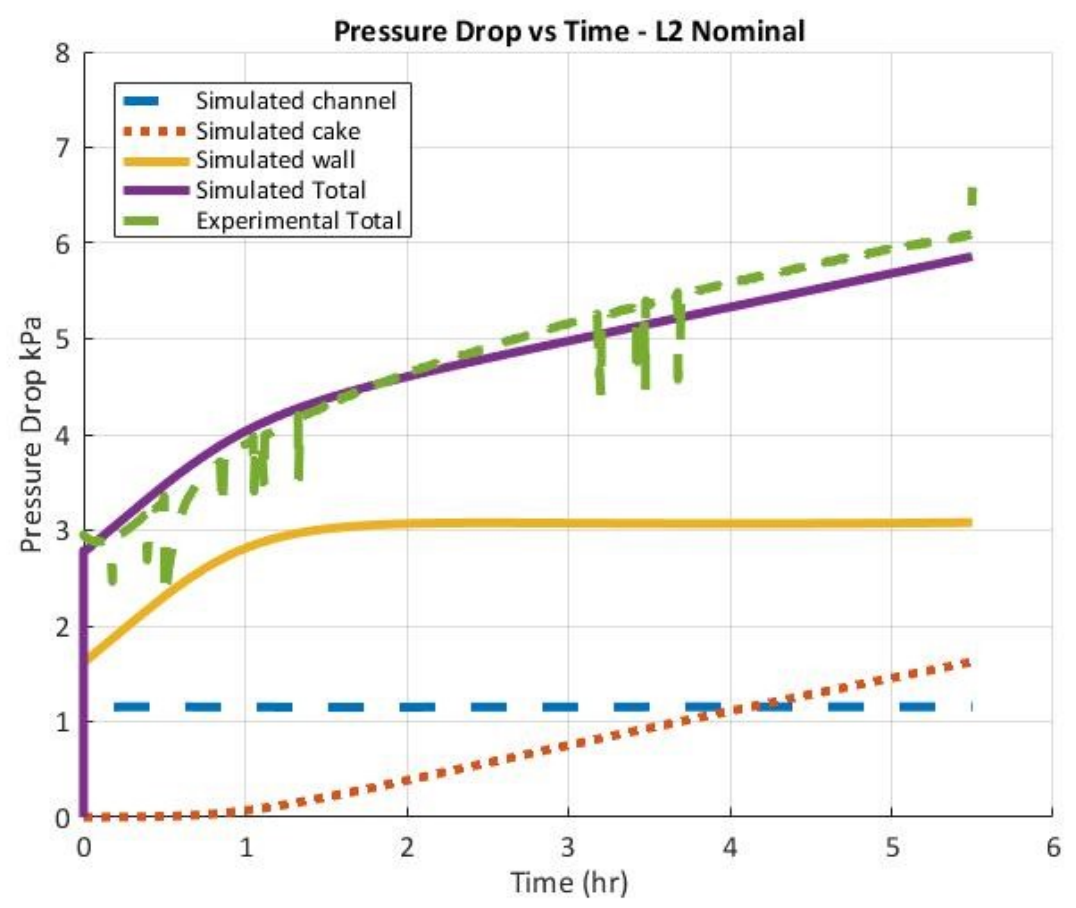

Figure F.3: Pressure Drop vs Time for L2 Nominal

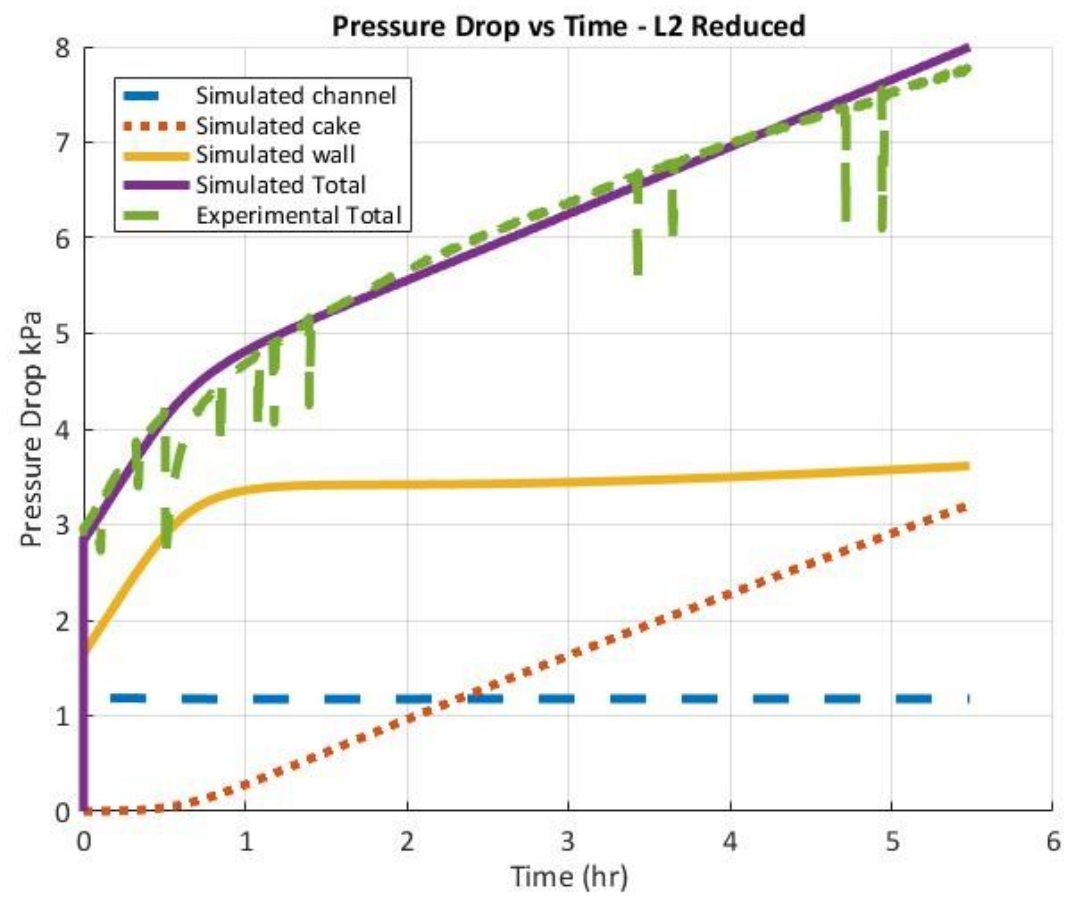

Figure F.4: Pressure Drop vs Time for L2 Reduced 


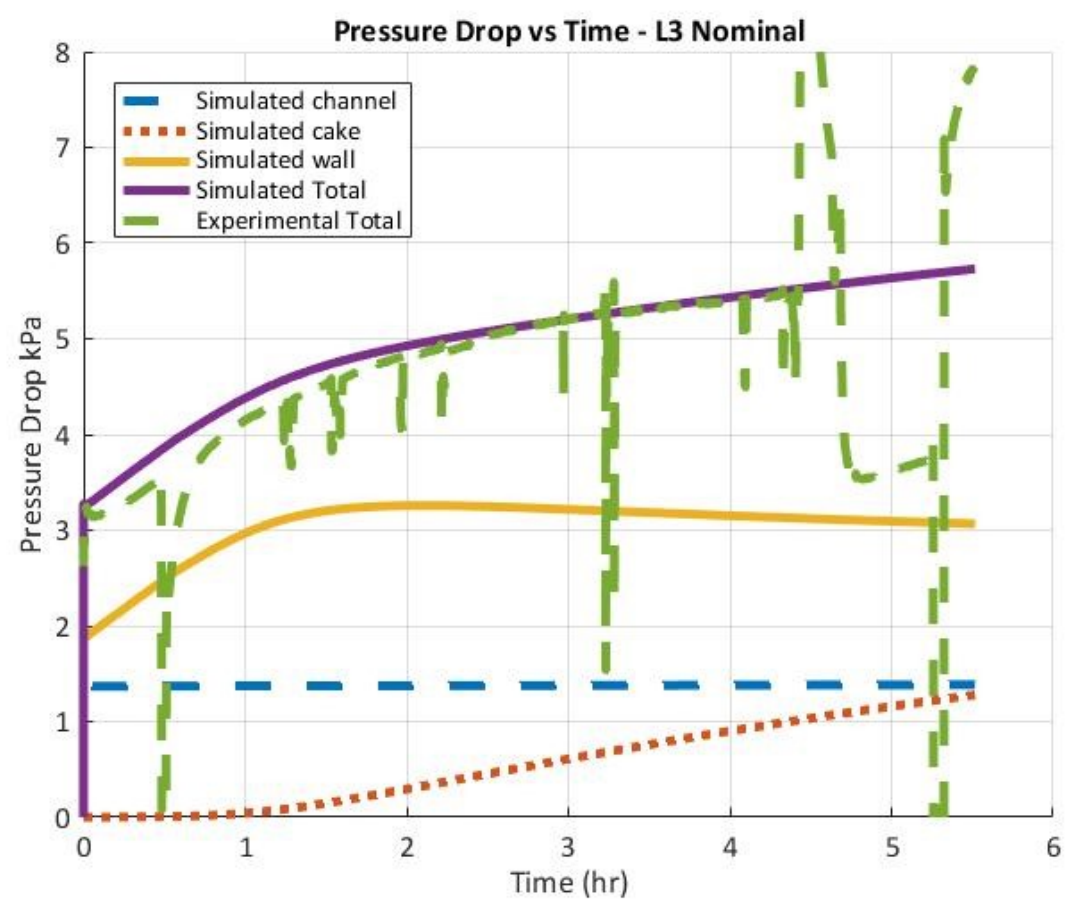

Figure F.5: Pressure Drop vs Time for L3 Nominal

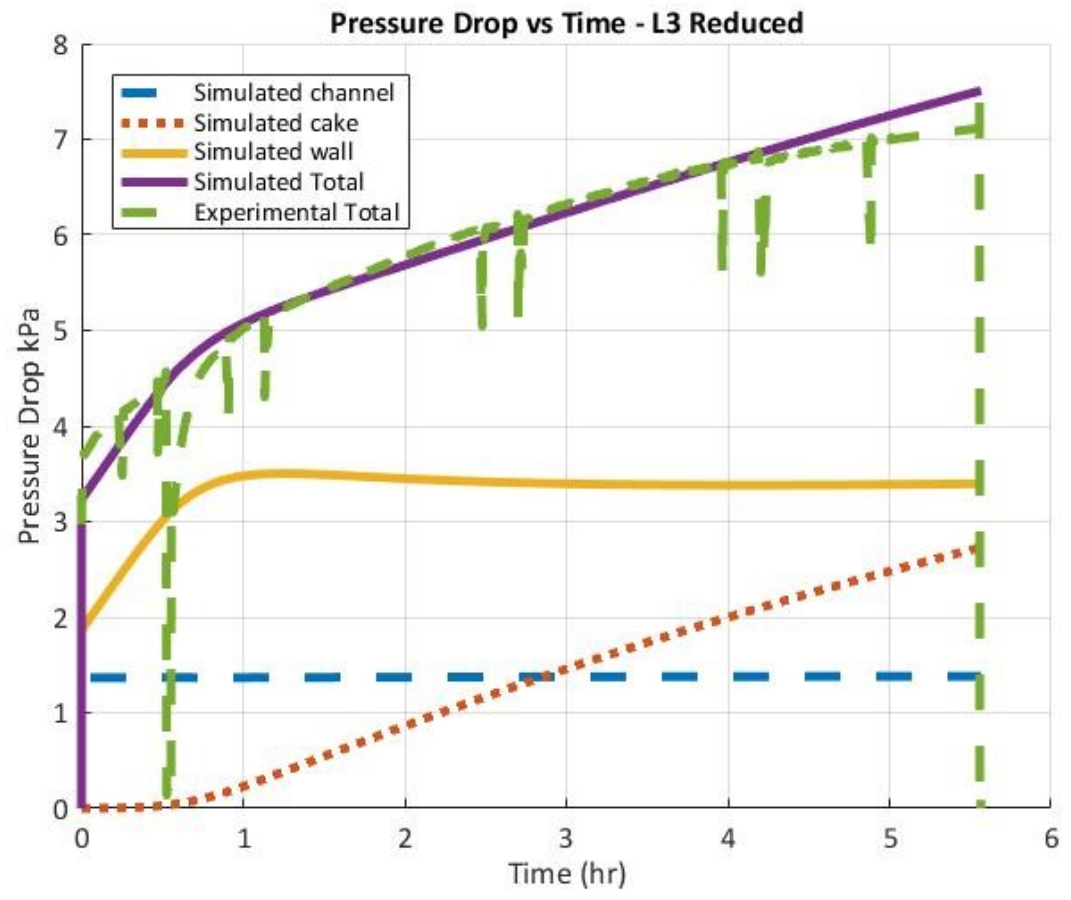

Figure F.6: Pressure Drop vs Time for L3 Reduced 


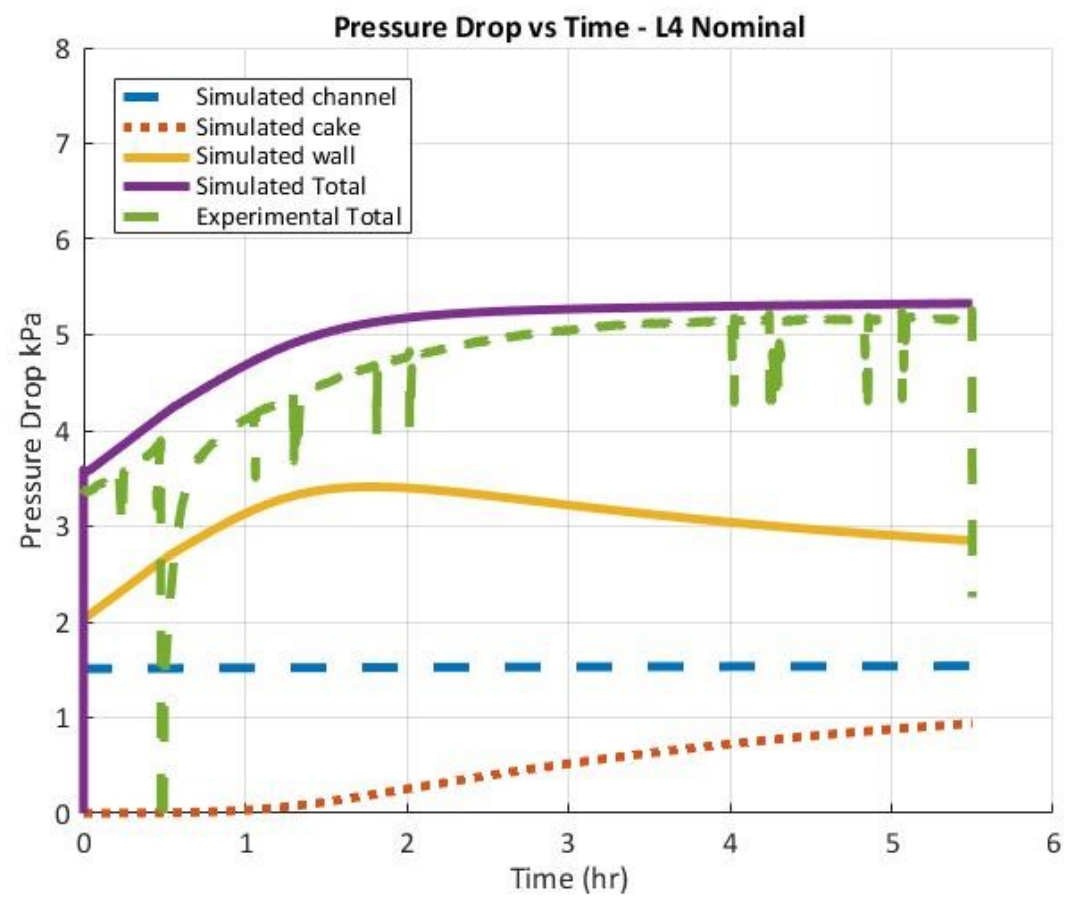

Figure F.7: Pressure Drop vs Time for L4 Nominal

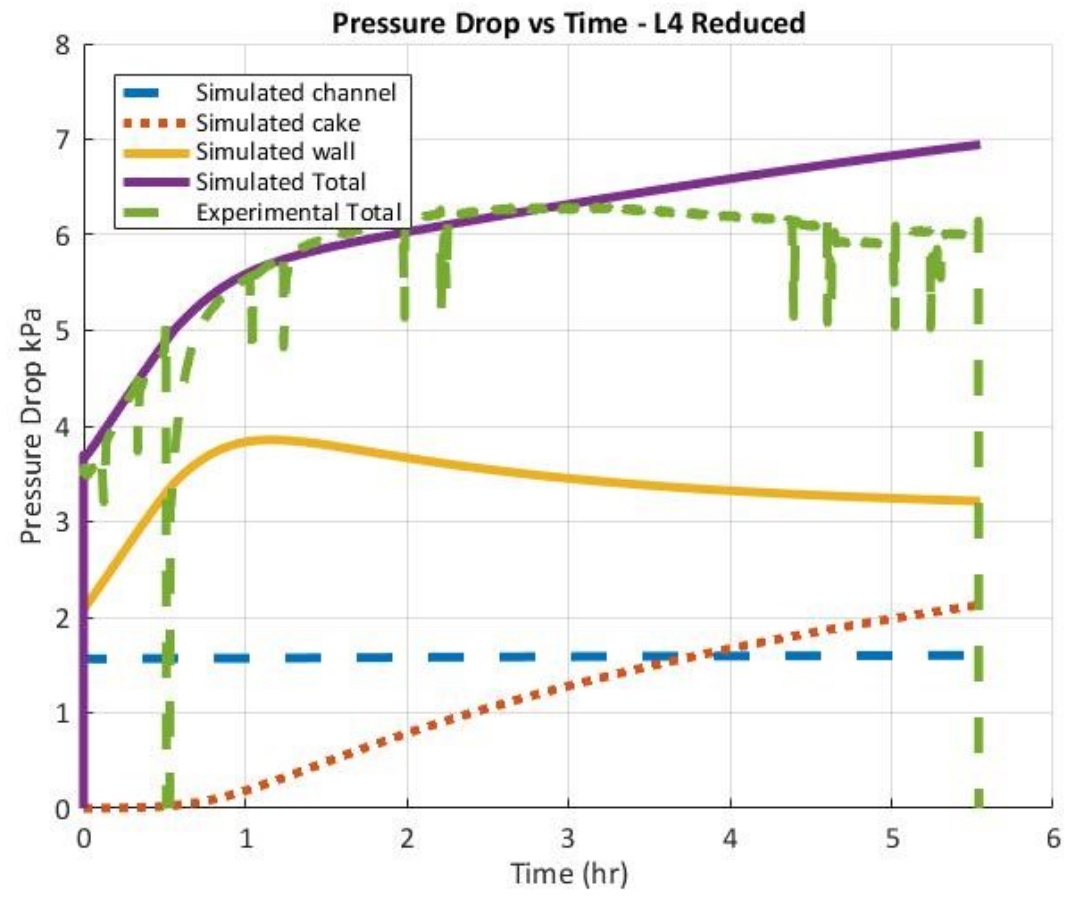

Figure F.8: Pressure Drop vs Time for L4 Reduced 
Appendix G: Model PM Mass Retained Plots for Passive Oxidation w/o Urea Data [8]

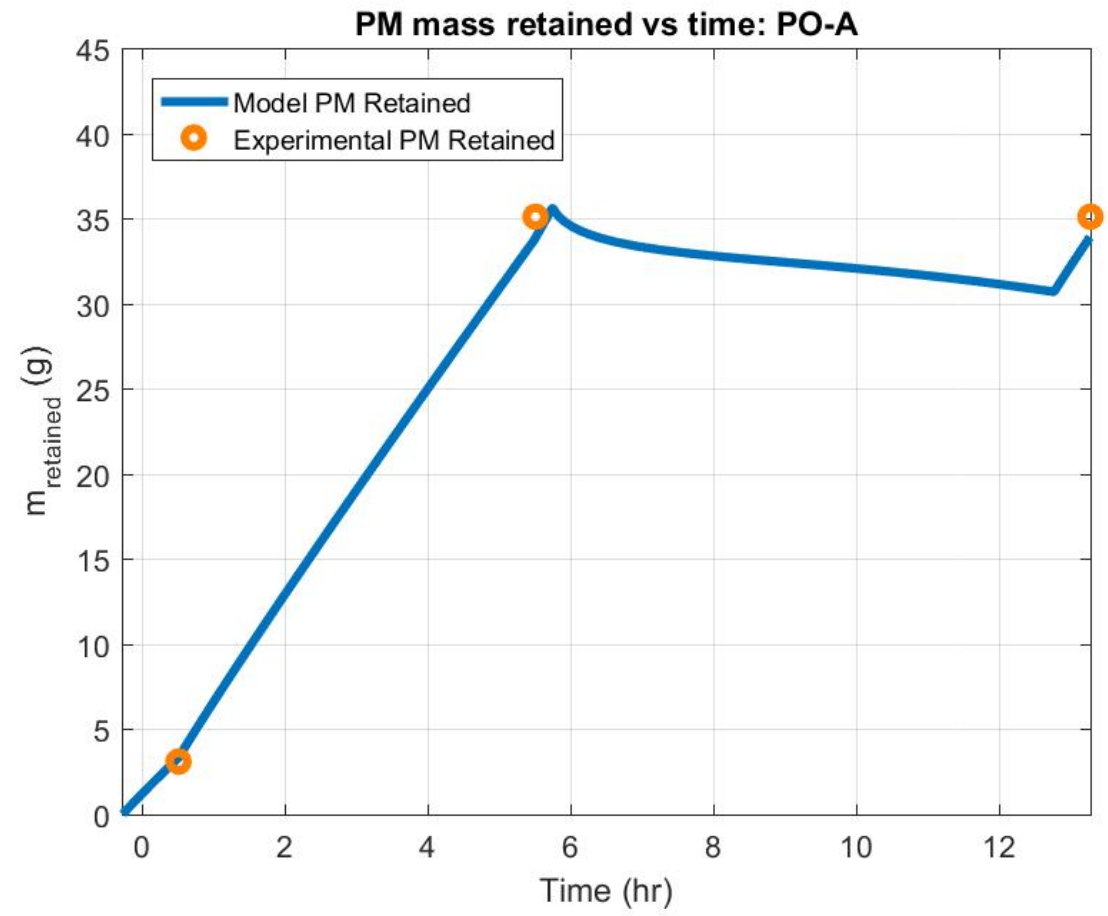

Figure G.1: PM Mass Retained vs Time for PO-A

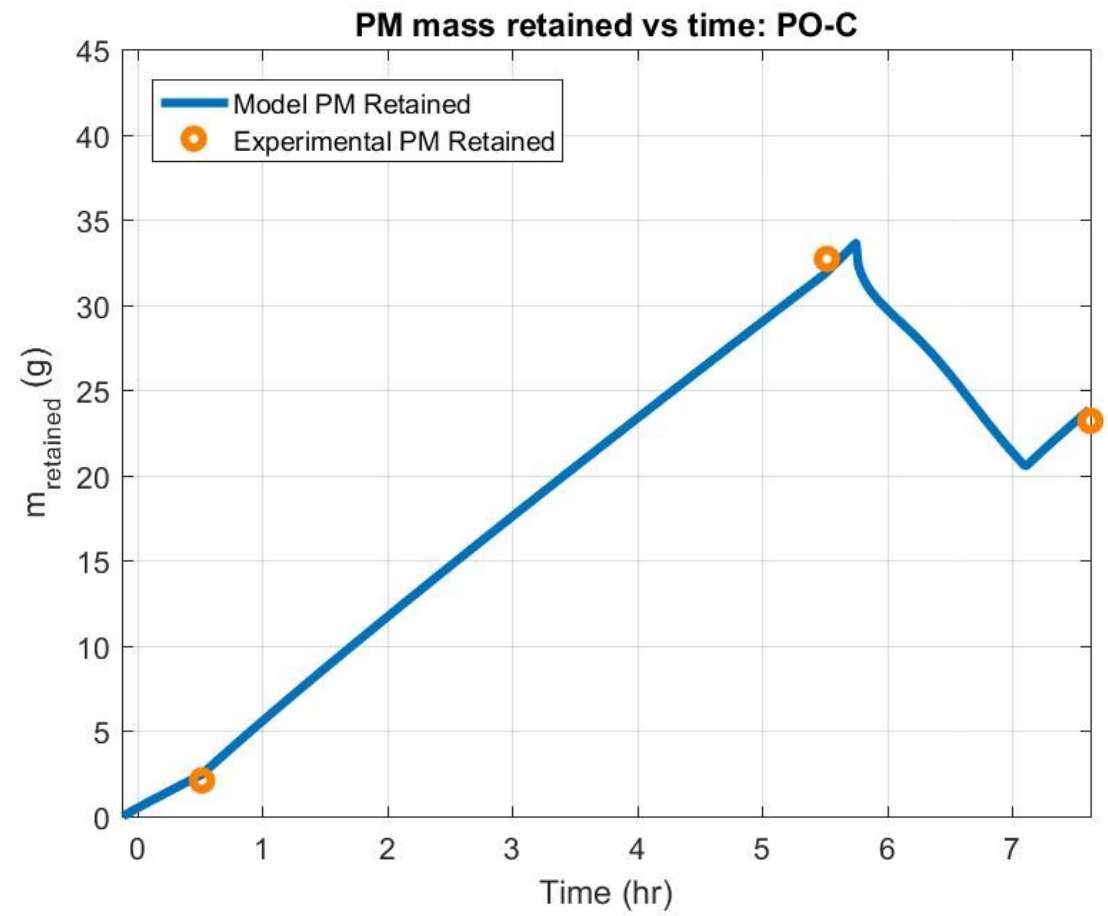

Figure G.2 PM Mass Retained vs Time for PO-C 


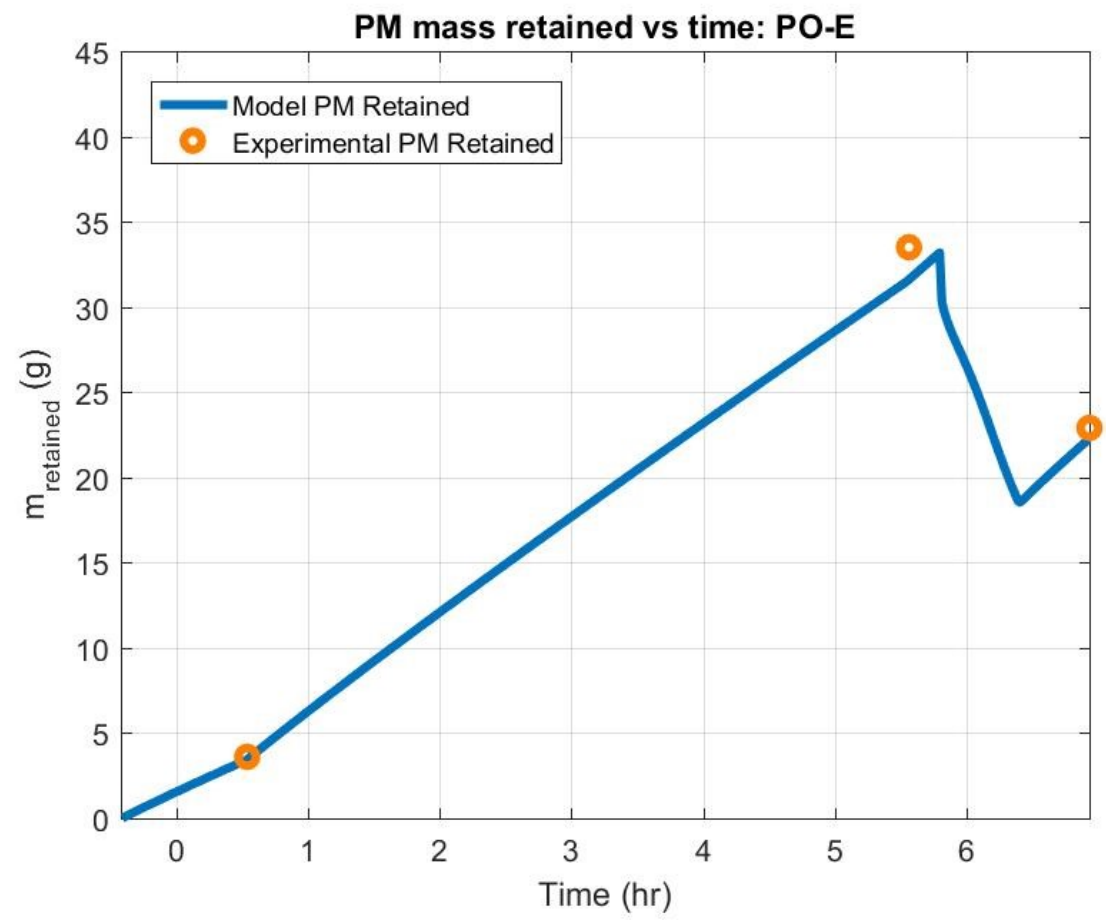

Figure G.3 PM Mass Retained vs Time for PO-E

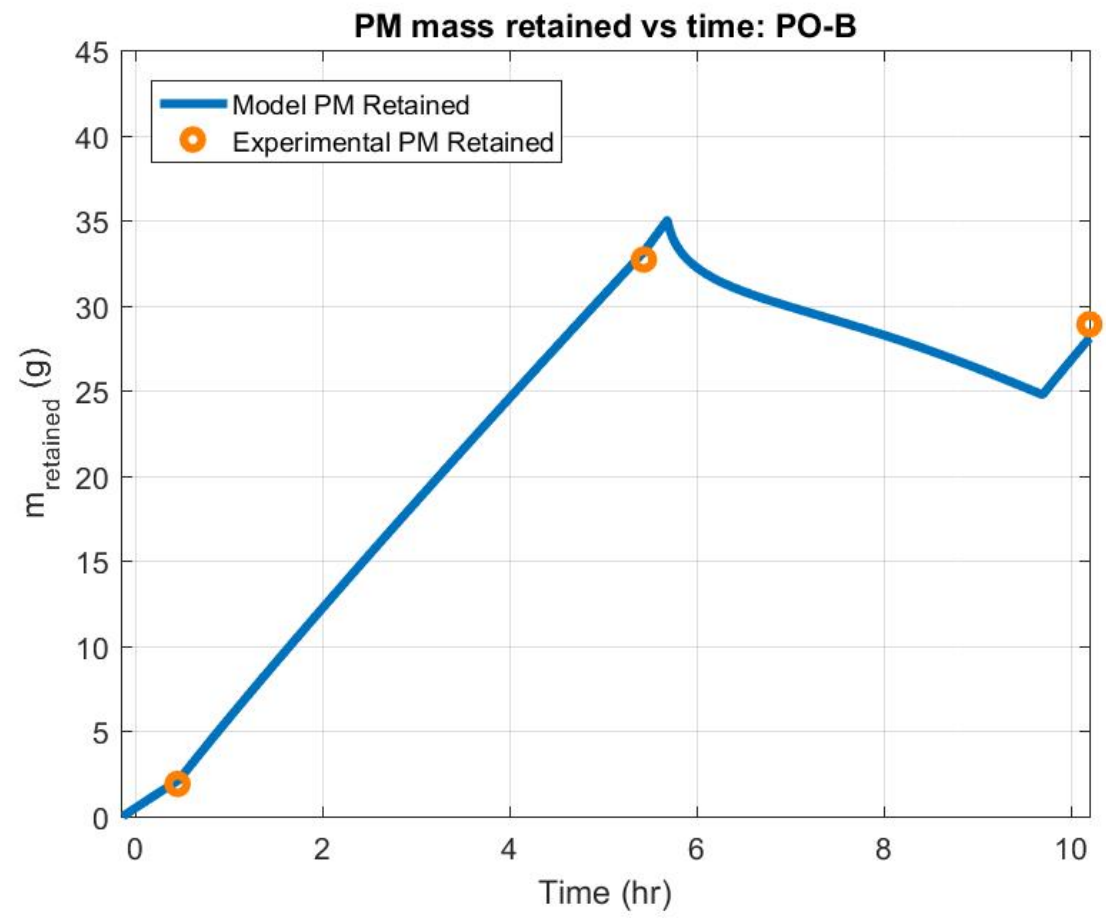

Figure G.4 PM Mass Retained vs Time for PO-B 


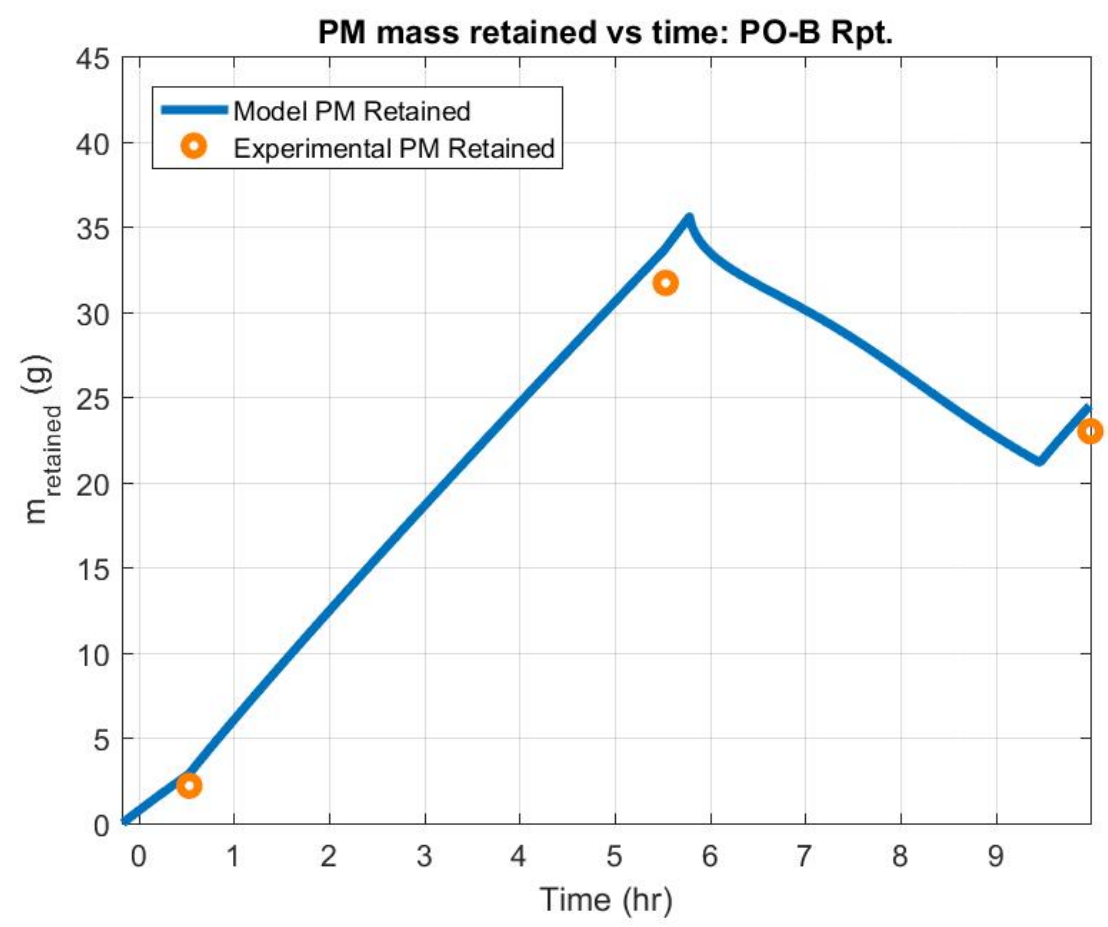

Figure G.5 PM Mass Retained vs Time for PO-B Rpt.

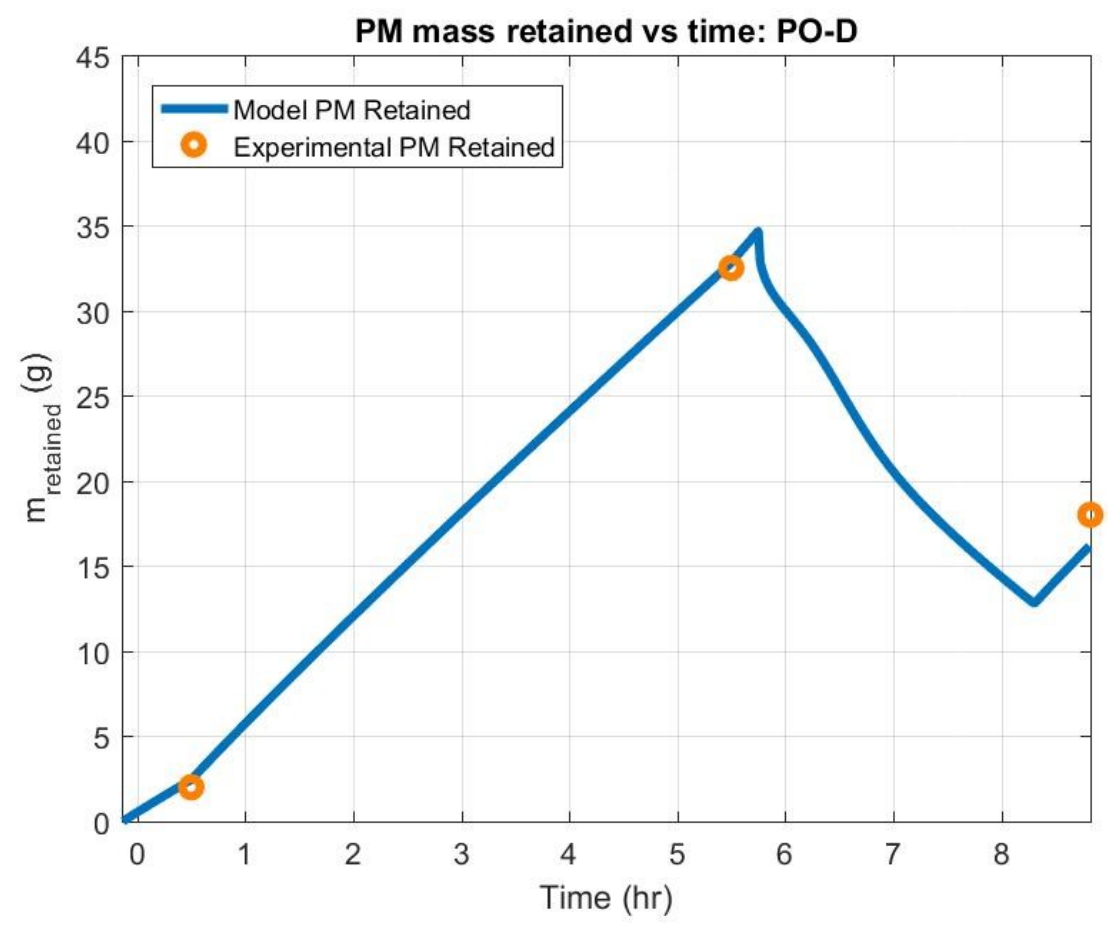

Figure G.6 PM Mass Retained vs Time for PO-D 


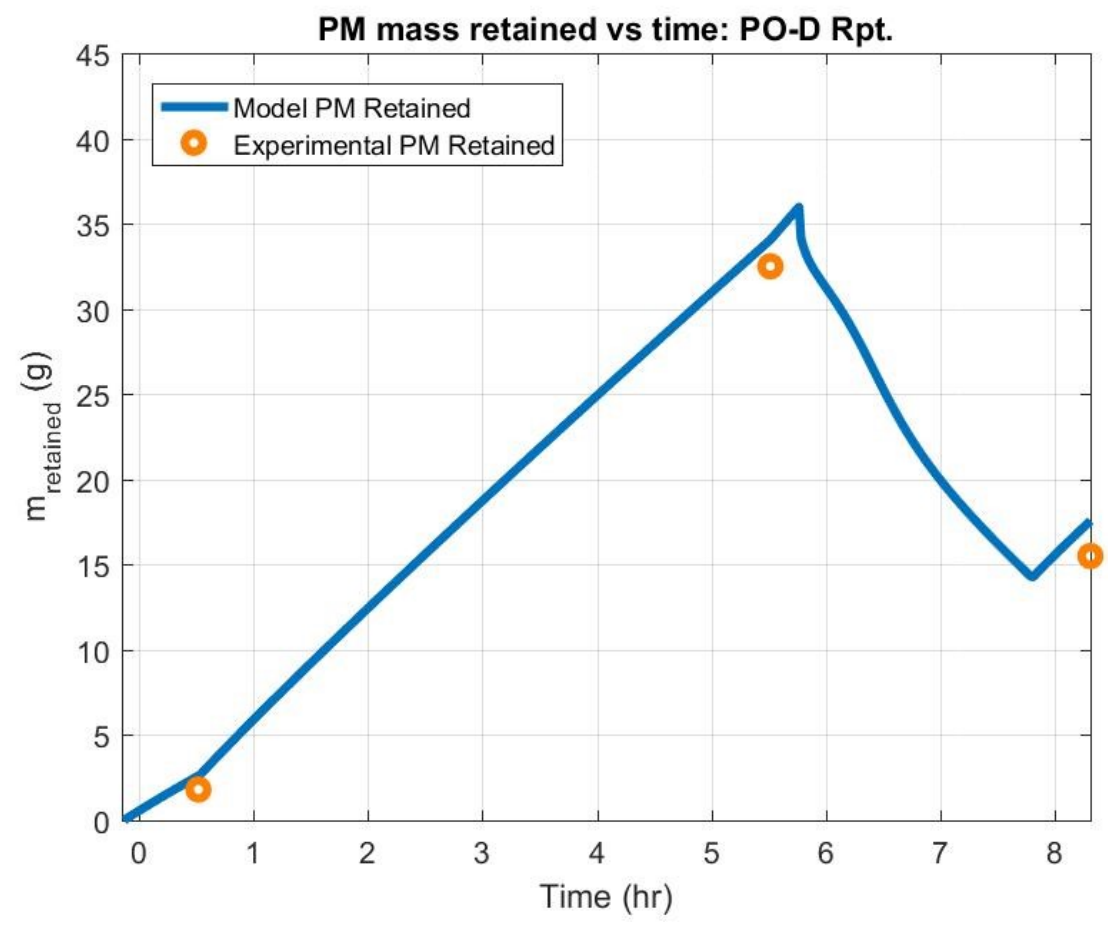

Figure G.7 PM Mass Retained vs Time for PO-D Rpt. 


\section{Permission to use copyright material from your MS thesis}

K R <kgraghav@mtu.edu>

Fri, Aug 31, 2018 at 10:58 AM

To: Abhishek Jadav<akjadav@mtu.edu>

Cc: John Johnson <jjohnson@mtu.edu>

Hi Abhishek,

Please go ahead and use any required figures or tables from my MS thesis.

Best,

Krishnan Raghavan

On Fri, Aug 31, 2018 at 4:39 AM, Abhishek Jadav <akjadav@mtu.edu> wrote:

Hi Krishnan,

I would like to request your permission for allowing me to use Figure 1.1 and Figure 3.1

from your MS thesis for my thesis titled 'Experimental and Modeling Study of

Particulate Matter Oxidation under Loading Conditions for a SCR Catalyst on a

Diesel Particulate Filter'.

Please leave this message in your reply.

Regards,

Abhishek Jadav

Graduate Student

Department of Mechanical Engineering

Michigan Tech University

Ph: +1 (906) 2758974

Linkedin: www.linkedin.com/in/jadavabhishek

Homepage: $h$ ttp://www.me.mtu.edu/ akjadav/ 


\section{Thank you for your order with RightsLink / Springer Nature}

no-reply@copyright.com <no-reply@copyright.com>

Fri, Aug 31, 2018 at 2:05 AM

To: akjadav@mtu.edu

\section{SPRINGER NATURE}

\section{Thank you for your order!}

Dear Mr. Abhishek Jadav,

Thank you for placing your order through Copyright Clearance Center's RightsLink ${ }^{\circledR}$ service.

\section{Order Summary}

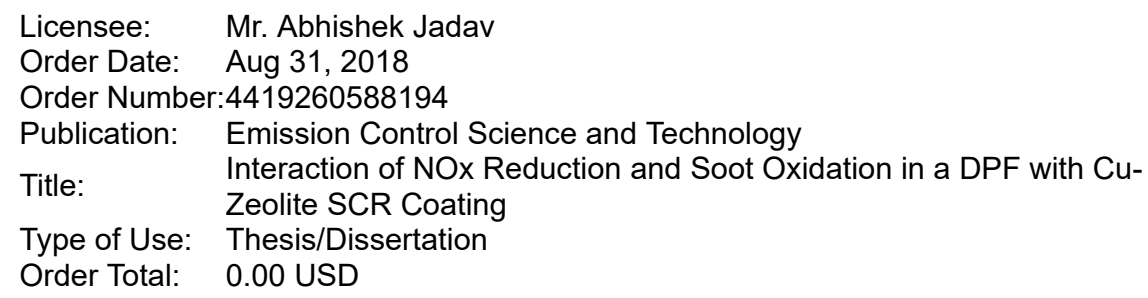

View or print complete details of your order and the publisher's terms and conditions.

Sincerely,

Copyright Clearance Center

Tel: +1-855-239-3415 / +1-978-646-2777 


\section{Thank you for your order with RightsLink / Elsevier}

no-reply@copyright.com <no-reply@copyright.com>

Fri, Aug 31, 2018 at 2:40 AM

To: akjadav@mtu.edu

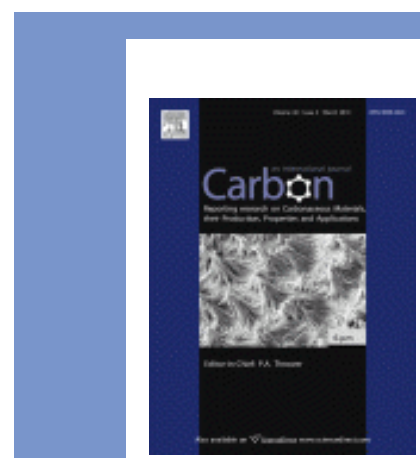

\section{Thank you for your order!}

Dear Mr. Abhishek Jadav,

Thank you for placing your order through Copyright Clearance Center's RightsLink ${ }^{\circledR}$ service.

\section{Order Summary}
Licensee: Mr. Abhishek Jadav
Order Date: $\quad$ Aug 31, 2018
Order Number:4419271189596
Publication: Carbon

Comprehensive kinetic characterization of the oxidation and gasification

Title: of model and real diesel soot by nitrogen oxides and oxygen under engine exhaust conditions: Measurement, Langmuir-Hinshelwood, and Arrhenius parameters

Type of Use: reuse in a thesis/dissertation

Order Total: $\quad 0.00$ USD

View or print complete details of your order and the publisher's terms and conditions.

Sincerely,

Copyright Clearance Center

Tel: +1-855-239-3415 / +1-978-646-2777

customercare@copyright.com 


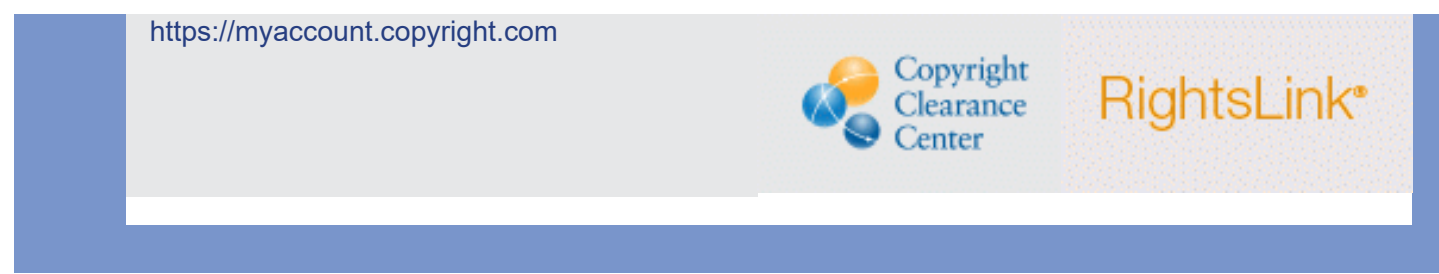

This message (including attachments) is confidential, unless marked otherwise. It is intended for the addressee(s) only. If you are not an intended recipient, please delete it without further distribution and reply to the sender that you have received the message in error. 


\section{Thank you for your order with RightsLink / Springer Nature}

no-reply@copyright.com <no-reply@copyright.com>

Sun, Sep 2, 2018 at 1:28 AM

To: akjadav@mtu.edu

\section{SPRINGER NATURE}

\section{Thank you for your order!}

Dear Mr. Abhishek Jadav,

Thank you for placing your order through Copyright Clearance Center's RightsLink ${ }^{\circledR}$ service.

\section{Order Summary}

Licensee: Abhishek K Jadav

Order Date: $\quad$ Sep 2, 2018

Order Number:4420671177252

Publication: Emission Control Science and Technology

An Experimental Investigation into the Effect of NO2 and Temperature on the Passive Oxidation and Active Regeneration of Particulate Matter in a Diesel Particulate Filter

Type of Use: Thesis/Dissertation Order Total: $\quad 0.00$ USD

View or print complete details of your order and the publisher's terms and conditions.

Sincerely,

Copyright Clearance Center 